Illinois State University

ISU ReD: Research and eData

Theses and Dissertations

$10-11-2015$

\title{
Life is Calling...How Far Will You Go...Back in the Closet? Identity Negotiation and Management Among Queer, Peace Corps Volunteers
}

Kate Elizabeth Slisz

Illinois State University, kslisz13@gmail.com

Follow this and additional works at: https://ir.library.illinoisstate.edu/etd

Part of the African Languages and Societies Commons, African Studies Commons, Social and Cultural Anthropology Commons, and the Sociology Commons

\section{Recommended Citation}

Slisz, Kate Elizabeth, "Life is Calling...How Far Will You Go...Back in the Closet? Identity Negotiation and Management Among Queer, Peace Corps Volunteers" (2015). Theses and Dissertations. 546.

https://ir.library.illinoisstate.edu/etd/546

This Thesis is brought to you for free and open access by ISU ReD: Research and eData. It has been accepted for inclusion in Theses and Dissertations by an authorized administrator of ISU ReD: Research and eData. For more information, please contact ISUReD@ilstu.edu. 


\title{
LIFE IS CALLING...HOW FAR WILL YOU GO...BACK IN THE CLOSET? IDENTITY NEGOTIATION AND MANAGEMENT AMONG QUEER, PEACE CORPS VOLUNTEERS
}

\author{
Kate E. Slisz
}

\section{Pages}

There is little to no research surrounding the experiences of queer, foreign-aid workers. To address this gap, a study was conducted to explore how compulsory heterosexuality affects the social construction of sexuality in societies where queer, foreign-aid workers serve and how this influences their identity negotiation and management processes. Participants consisted of ten self-identified queer, Returned Peace Corps Volunteers (RPCVs), as well as, the researcher herself who also identifies as queer. Data was gathered through both semi-structured interviews and autoethnographic research. Meaning structuring through narratives was used to analyze the data. Analysis revealed that strategies of silencing, counterfeiting, and lying by omission were popular identity negotiation practices among participants, as well as relying on the heteronormative assumption. Additionally, data showed that compulsory heterosexuality played a major role in the social construction of sexuality where these queer volunteers served, as heteronormativity continues to be perpetuated and reinforced by various 
institutions, including the government, religion, education, social norms, and the media. Finally, it was found that the foreign-aid organization examined in the study-The Peace Corps - played a passive role in the negotiation and management strategies of its queer volunteers. Therefore, this study recommends that three practical steps be taken to better train and support future, queer Peace Corps Volunteers: (1) Sensitivity training for Peace Corps staff, (2) infusion of LGBT issues into volunteers' training sessions, (3) and creation and distribution of resources for queer volunteers.

KEYWORDS: Compulsory Heterosexuality, Identity Negotiation and Management, Intersectionality of Identity, Queer Studies, Social Construction of Sexuality, SubSaharan African Studies 


\section{LIFE IS CALLING...HOW FAR WILL YOU GO...BACK IN THE CLOSET? IDENTITY NEGOTIATION AND MANAGEMENT AMONG QUEER, PEACE CORPS VOLUNTEERS}

KATE E. SLISZ

A Thesis Submitted in Partial Fulfillment of the Requirements for the Degree of

\section{MASTER OF SCIENCE}

Department of Sociology and Anthropology

ILLINOIS STATE UNIVERSITY 
Copyright 2016 Kate E. Slisz 
LIFE IS CALLING...HOW FAR WILL YOU GO...BACK IN THE CLOSET? IDENTITY NEGOTIATION AND MANAGEMENT AMONG QUEER, PEACE CORPS VOLUNTEERS

KATE E. SLISZ

COMMITTEE MEMBERS:

Maria Schmeeckle, Chair

Becca Chase

Marion Willetts 


\section{ACKNOWLEDGMENTS}

I wish to express my deepest gratitude to my advisor Dr. Maria Schmeeckle for her full support, guidance, understanding, and encouragement throughout the duration of this project. Without her incredible patience and faith in me, my thesis work would have been nearly impossible. I would also like to express my appreciation to Dr. Becca Chase and Dr. Marion Willets for having served on my committee.

A special thanks also goes to the fellow Peace Corps volunteers I served with from 2012-2014 in Sub-Saharan Africa. Without their unwavering support, I would not have been able to successfully complete my Peace Corps service nor this thesis. For two years, we failed together, we succeeded together, and we learned more about ourselves and the world than we ever thought possible. Forever and always, I will be grateful for knowing each and every one of you.

Additional thanks goes to the participants of my study. For their sacrifice of going back into the closet in an effort to better our world and for sharing their stories so openly with me, I am eternally grateful.

Furthermore, to all queer individuals in the foreign-aid sector that came before me, served with me, and that will come after me, I thank you and respect you deeply. In the closet or not, we are a community. We have a voice. We can make a difference. Thank you for proving that each and every day. 
Finally, I would like to thank my family and girlfriend for their unconditional love and support during this process. Without their constant reassurance and motivation, this thesis would be a perpetual work in progress.

K. E. S. 


\section{CONTENTS}

\section{Page}

ACKNOWLEDGMENTS

CONTENTS

iii

IMPORTANT NOTE

vii

\section{CHAPTER}

I. INTRODUCTION 1

Research Questions $\quad 2$

Gaps in the Literature $\quad 3$

Sociological Significance $\quad 4$

II. REVIEW OF RELATED LITERATURE 5

Compulsory Heterosexuality $\quad 5$

Origin of the Concept 5

Foundation for a Critical, Social Theory of Sexuality 8

The Status of Compulsory Heterosexuality Today 9

Compulsory Heterosexuality in a Global Perspective 14

$\begin{array}{ll}\text { Sexual Identity and Negotiation Management } & 17\end{array}$

$\begin{array}{ll}\text { Identity and Self } & 17\end{array}$

Intersectionality of Identity: Seeing People as

Multi-Faceted 20

Sexuality and Identity $\quad 21$

Queer Identity Negotiation and Management Strategies 24

Queer Identity Management in the Workplace 24

Identity Management Among Queer Migrants 29 
Identity Management Among Queer Anthropologists

Literature Search Strategies

III. DESIGN AND METHODS

Overall Approach and Rationale $\quad 42$

Data Collection Methods

The Role of Semi-Structured Interviews

The Role of Autoethnography and Reflexivity

Sample

Participants

Country of Service

History of Peace Corps in Country of Service

Peace Corps' Focus in Country of Service

Legal Status of LGBT Individuals in

Country of Service

Data Management and Data Analysis

Ethical Issues

IV. RESULTS AND ANALYSIS

The Narrative of a Peace Corps Volunteer

A Seed is Planted...

Applying for Service

To Come Out or to Not Come Out?

Being Invited to Serve and Researching the Social Climate

Desire to Serve Outweighs Concerns of

Going Back into the Closet

Preparing for Departure: Saying Good-Bye to the Familiar

And so it Begins: The Staging Process

Good-Bye America: Hello to the Toughest

Job You'll Ever Love....and/or Hate

Learning How Intersectionality of Identity Impacts Service

Leaving PST Behind and Heading to Site 
Discovering the Varying Attitudes Surrounding

Homosexuality

Don' t Ask, Don't Tell

It's All Relative: Social Climate Surrounding

Homosexuality

An LGBT Movement: Thriving and Growing

Volunteers' Identity and Negotiation Strategies

Impact of Suppressing One's Identity

110

Coming Out to Locals

112

The Struggle to Remain Authentic to One's Self

Taking Part in the Local LGBT Social Scene

Coping Strategies for Going Back in the Closet

Queer Volunteers Dating in the Peace Corps

Additional Coping Strategies

The Role of Intersectionality of Identity on One's

Peace Corps Service

Taking on a Peace Corps Persona

160

An Unauthentic and Superficial State of Being

163

Heading Home

Readjusting to Life Outside the Closet

Conclusion

170

Summary

Discussion

Limitations

Future Research Suggestions

V. IMPLICATIONS AND PRACTICAL SOLUTIONS

Need for Improvement: Queer Volunteers Voice Concerns

Improving Social Climates Where Volunteers Serve

What Changes are Necessary?

Taking Action: Practical Steps to Better Serve

Queer Volunteers

Sensitivity Training for Peace Corp Staff

Infusion of LGBT Issues into Volunteers' Training Sessions

Creation and Distribution of Resources for Queer Volunteers 
APPENDIX B: LGBT Sensitivity Training Example 


\section{IMPORTANT NOTE}

With the controversy that exists surrounding the use of the term "queer", it is important to note how this particular study views and defines the term. "In English, the word 'queer' originally meant 'strange' in the broadest sense. This word comes from the Germanic root quer, which means 'to cut across' or 'at an angle to,' so it has the connotation of being off the straight (or normal) path" (Steinberg 2009: para. 3). In the beginning of the $20^{\text {th }}$ Century, "queer" began to be used as a derogatory term against the lesbian, gay, bisexual, and transgender (LGBT) community (Steinberg 2009). More recently though, members of the LGBT community have been working to reclaim the word and eradicate the negative connotations society has attached to it. "Many people who choose to identify as queer do so because they feel it allows for a broader identity as opposed to the more perceived rigid labels of bisexual, gay, lesbian, and transgender" (UUA 2001, II 2). These individuals view the term "queer" to be "more open, fluid, and all-encompassing" (UUA 2001: II 2). This study supports the notion that sexuality is fluid and cannot and should not be confined to rigid, heterocentric categories. Therefore, this study uses "queer" as "an inclusive, unifying sociopolitical umbrella-term for persons who are gay, lesbian, bisexual, pansexual, transgender, transsexual, intersexual, etc." (Steinberg 2009: II 3) 


\section{CHAPTER I}

\section{INTRODUCTION}

Due to globalization, our world is more connected than ever. Globalization can be defined as "the compression of the world and the intensification of consciousness of the world as a whole" (Robertson 1992:8). One of the effects of globalization has been an increase in the foreign-aid sector. Many individuals may be surprised to learn that foreign-aid is a surprisingly large employment sector. Edwin Thomas (2012) sheds light on the sector's depth and breadth:

It includes employers as varied as the U.S. government, the United Nations and just maybe a large local church. The jobs encompass everything from volunteering, to driving a truck full of relief supplies, to doing a tour with Doctors Without Borders, to working on a solar water distillation project in a remote area, to teaching English with the Peace Corps. (II 1)

As one can see, work in this sector is very diverse. To mention just a few areas, foreignaid jobs can be found in governance, healthcare, education, gender equality, disaster preparedness, infrastructure, economics, livelihoods, human rights, forced migration, security, conflict, and the environment (Oxford University 2012). To put it simply, foreign-aid workers strive to meet the needs of communities in the "developing" world. These individuals and groups work with the local people to plan and implement sustainable solutions to overcome daily obstacles and long-term challenges. Due to the scope of the foreign-aid sector, employees represent all walks of life. These individuals are sent all over the globe, working in cultures radically different than their own. 
Furthermore, foreign-aid workers serve "in complex environments where problems related to prolonged civil conflicts, poverty and disaster are rife. These conditions place humanitarian staff at risk of experiencing traumatic and daily cumulative stress"

(McFarlane 2004:1). Additionally, foreign-aid workers are subject to the laws and

cultural norms of the society they serve in. All of these factors can cause the acclimation process to be very challenging for foreign-aid workers.

Although foreign-aid and international development has and continues to be a hot topic among scholars today, I was unable to locate any research that examines the experiences of a very marginalized group of employees: Queer, foreign-aid workers. All foreign-aid workers face certain challenges, such as overcoming culture shock and acclimating to their new environment., Queer, foreign-aid workers, however, are confronted with an additional challenge: In many countries where they work, homosexuality is socially unacceptable and, in some cases, punishable by death. This reality can create serious obstacles for queer, foreign-aid workers. Therefore, the question arises as to what strategies they implement to overcome such obstacles. Are queer, foreign-aid workers serving in silence?

\section{RESEARCH QUESTIONS}

In order to address the challenges that queer, foreign-aid workers face while serving abroad, I have designed a qualitative study that focuses on the following research questions:

RQ1: How do queer, foreign-aid workers negotiate and manage their queer identities while serving abroad? 
RQ2: What role, if any, does compulsory heterosexuality play in the social construction of sexuality in societies where queer, foreign-aid workers serve, and how does this affect their queer identity negotiation and management processes?

RQ3: What role, if any, does the organization (i.e. Peace Corps) itself play in the negotiation and management processes of its queer, foreign-aid workers?

These issues were examined through the use of ten, semi-structured interviews, coupled with autoethnographic research. By interviewing former queer, Peace Corps volunteers and by serving as a queer, Peace Corps volunteer myself, I was able to gain insight into the overall experience of queer, foreign-aid workers.

\section{GAPS IN THE LITERATURE}

Although a plethora of research has been done to investigate how queer individuals develop and manage their identities in developed countries, little to no research has been conducted on the negotiation and management of queer identity in other parts of the world. In addition, research exists on queer migration of individuals leaving less accepting countries to come live in more accepting countries, but there is little to no research that has studied the experiences of queer individuals who move from countries where homosexuality is legal to countries where it is illegal. Furthermore, research has examined the notion of compulsory heterosexuality, but little research has looked at this social phenomenon outside of the United States. Finally, virtually no research exists on queer volunteers' experiences in the Peace Corps nor does any research exist on queer, foreign-aid workers in general. Therefore, this study addresses these gaps in the literature and aims to provide a platform for these individuals' experiences to be shared. 


\section{SOCIOLOGICAL SIGNIFICANCE}

This study not only addresses the previously mentioned gaps in the literature, but it also contributes immensely to sociological research. More specifically, it expands upon existing research pertaining to the social construction of sexuality and the social construction of identity in general. It also provides cross-national research pertaining to compulsory heterosexuality, which is lacking in the research surrounding the sociology of sexuality. Finally, it sheds light on how queer individuals construct and manage their identities while working in societies where homosexuality is not tolerated or tolerated to a lesser extent than in the United States.

Before queer identity negotiation and management among queer, foreign-aid workers can be properly addressed, a conceptual framework must first be laid and previous research must be examined. Therefore, I will first explain the concept of compulsory heterosexuality, which paved the way for a critical, social theory of sexuality to emerge. Second, I will highlight the key literature surrounding identity, focusing mainly on identity development and management processes. Third, I will provide a discussion on the current literature related to queer identity management strategies. Lastly, I will highlight the key literature search strategies that were utilized throughout this study. 


\section{CHAPTER II}

\section{REVIEW OF RELATED LITERATURE}

\section{COMPULSORY HETEROSEXUALITY}

This study utilizes the notion of compulsory heterosexuality (Rich 1986) as a framework to examine the social regulation of sexuality in societies. This notion has been an invaluable tool in this study because compulsory heterosexuality sheds light on how social institutions are at the root of reinforcing sexual hierarchies and regulating citizens' sexual behavior.

\section{Origin of the Concept}

In 1986, feminist Adrienne Rich published her groundbreaking essay, “Compulsory Heterosexuality and Lesbian Existence.” In this essay, Rich urged heterosexual feminists to examine heterosexuality in an entirely differently light. She challenged them to move away from viewing heterosexuality as simply a type of behavior or definition of attraction but, rather, as a social institution that controls human behavior and perpetuates gender and sex roles. In her now famous essay, Rich elegantly conveyed how women had no other choice but to marry men and lead heterosexual existences:

It was necessary, in order to survive economically, in order to have children who would not suffer economic deprivation or social ostracism, in order to remain respectable, in order to do what was expected of women, because, coming out of "abnormal" childhoods, they wanted to feel "normal" and because heterosexual 
romance has been represented as the great female adventure, duty, and fulfillment. (Rich 1986:322)

Rich further explained how the institutionalization of heterosexuality leads to an assumption in society that women and men are innately attracted to each other emotionally and sexually. She emphasized that without even realizing it, young children learn what behaviors are "normal" for men and women and this leads to the misconception that heterosexuality is the only acceptable or "natural" way of living.

Other scholars have examined society's normalization of gender and sex roles and its relationship between compulsory heterosexuality. For example, Butler (1990) explains how growing up in a society that classifies feelings, behaviors, and social roles in gender terms forces individuals to learn not only what gender is supposed to be but also what it means to act in gender-appropriate ways. These behaviors are socially enforced by a system of sanctions and rewards. Girls who act more masculine than feminine and boys who act more feminine than masculine are often labeled and treated as deviant because they are defying social norms. Furthermore, Butler emphasizes how the social construction and regulation of gender norms causes individuals to believe that gender lies at the core of one's identity. In other words, males who act masculine and females who act feminine are understood as expressing a deeply rooted gender identity. However, Butler argues that there is no core gender identity that drives individuals' behavior. Instead, she explains how these behaviors are actually taught to individuals through their families and other institutions. Therefore, the social creation, regulation, and normalization of dichotomous gender identities masks the role that social and political forces play in shaping individuals into gendered and sexual beings. In addition, the illusion of natural gender identities also hides the role gender plays in the regulation and 
perpetuation of heteronormativity and heterosexual dominance. Society's notion of a gender binary has become so normalized that it is now seen as innate or as a fact of life. As a result, society has become organized around how the life of a man and woman should "properly" unfold: marriage, the nuclear family, etc. Heteronormativity leads to the belief that heterosexuality is the "normal" way of living.

It is important to the note that the social construction of the gender binary plays a substantial role in the perpetuation of inequality in society, in regards to both gender and sexuality. By viewing men and women as naturally different and complementary makes heterosexuality and, therefore, also marriage and the heterosexual family, seem like the "normal" way of living. Rich best illustrates how this institutionalization of heterosexuality leads to an institutionalized inequality of power between not only heterosexuals and non-heterosexuals but also between men and women, with far reaching consequences. She claims that under a regime of compulsory heterosexuality, men control numerous aspects of women's lives: sexuality, childbirth and rearing activities, physical movement, labor, and even access to knowledge. She also explains how compulsory heterosexuality leads to discrimination against homosexuals and to the intolerance and/or invisibility of gay men and lesbians in society. Therefore, compulsory heterosexuality is an important focus of this study because it has the potential to influence queer, foreign-aid workers' identity management practices in societies where the gender binary is still seen as a fact of life and, as a result, homosexuality is illegal or socially unacceptable. 


\section{Foundation for a Critical, Social Theory of Sexuality}

The conceptualization of compulsory heterosexuality was groundbreaking in

itself, but it also proved to be a major theoretical accomplishment because it allowed for a structural sociology of heterosexuality to develop. Furthermore, this theoretical breakthrough shed light on the social construction of gender and sexuality and how both create social divisions and hierarchies in society. This allowed heterosexuality to be examined as neither a matter of choice nor as ordained by nature but, rather, as a social institution (Jackson and Scott 2010). Simply put, the conceptualization of heterosexuality as an institution made possible a critical, social theory of sexuality to emerge:

The center of analysis shifted from the individual homosexual and from individual acts of discrimination to the institutional enforcement of normative heterosexuality and its consequences for non-heterosexuals...Politically, the focus changed from an agenda of further education and rights to contesting the social inequalities produced by the institutional enforcement of heterosexuality. (Seidman 2009:18)

In summary, scholars and researchers began to study sexuality not as a natural phenomenon but as fundamentally social.

Therefore, since the conceptualization of compulsory heterosexuality, there has been a shift in the way scholars and researchers view sexuality. Today, the most progressive scholars and researchers view sexuality and the beliefs surrounding it not as a natural or innate but, rather, as a social construction. The classification of certain sexual behaviors and desires as good versus bad or normal versus abnormal is actually the product of social creation and regulation of sexual identity. Jeffrey Weeks (1986) explains:

We can no longer set "sex" against "society" as if they were separate domains. We must learn to see that sexuality is something which society produces in complex ways. It is a result of diverse social practices that give meaning to 
human activities...to struggles between those who have power to define and regulate, and those who resist. Sexuality is not given, it is a product of negotiation, struggle. (26)

Therefore, this study views the meaning, the organization, and the social acceptability surrounding sexual behaviors and desires as products of social factors and investigates how societies use these factors to regulate sexuality in order to keep power structures in place. Again, this ties into the concept of compulsory heterosexuality that was fleshed out earlier. Overall, this study investigates how these factors play a role in the social construction of sexuality in the societies where queer, foreign-aid workers serve and how this affects their identity negotiation and management.

\section{The Status of Compulsory Heterosexuality Today}

Although researchers have shed light on the negative effects of compulsory heterosexuality, it has not been socially de-constructed in full. It is still very much embedded in our society, as well as other societies around the world. Institutions and laws continue to shape and regulate individuals' sexuality. These social forces continue to create and perpetuate sexual hierarchies. "That is, certain sexual desires and acts are respected, valued, and supported by laws, custom, and institutions while others are stigmatized, criminalized, and punished" (Seidman 2010:55). Societies still regulate sexuality in all these ways. In the United States and in various other areas of the world, heterosexuality continues to be the norm. As a result, heterosexuals are still granted privileges that are denied to homosexuals. For example, heterosexuals have full civil and political rights:

Their unions and families are recognized by the state and other social institutions. In advertisements, theater, art, literature, music, television, movies, and even in medical and scientific knowledge, being heterosexual, pursuing heterosexual 
romance, getting married, and being part of a heterosexual family are social ideals. (Seidman 2010:57)

The normalization of heterosexuality continues to be enforced through various social institutions: schools, the media, and the government. To put it simply, a very complex network of social norms and rules regulates sexuality. This complex network of various institutions works together to perpetuate the misconception that heterosexuality is the only "normal" and natural way of living. Homophobia is one result of this misconception and is used as a tool to perpetuate the norm of heterosexuality. Due to both compulsory heterosexuality and homophobia, individuals come to believe that heterosexuality is natural and superior to homosexuality. This leads to the supported denial of rights, the harassment, physical assault, shaming, and social isolation of homosexuals. Simply put, "the state is a powerful social force that constructs and controls our sexual lives" (Siedman 2010:105). Therefore, this study investigates the influence the state has on the identity negotiation and management of queer, foreign-aid workers and how social attitudes, such as homophobia, play a role in these queer workers' experiences.

With that said, it is important to note that theorists today have been working to address the status of compulsory heterosexuality in our society today. The hierarchical relationship between heterosexuality and homosexuality has come under immense opposition. Roseneil (2000) argues that society is currently witnessing a collapsing of the hetero/homosexual binary. This has resulted in a significant cultural challenge to heteronormativity. People have begun "questioning the normativity and naturalness of heterosexuality, re-configuring the hierarchical inside/outside relationship between homosexuality and heterosexuality, and destabilizing the binary opposition between the two categories" (Roseneill 2000:11). Today, people are beginning to view sexuality to be 
more on a spectrum or a continuum as opposed to a binary approach. Therefore, contemporary sociologists theorize that there has been a shift from compulsory heterosexuality to normative heterosexuality, meaning social institutions continue to shape and regulate individuals' sexuality but not to the extent it did in the past.

Heterosexuality continues to be the norm, but not all homosexual individuals feel socially pressured to lead heterosexual lives. Theorists suggest this shift from compulsory heterosexuality to normative heterosexuality can be explained though changes in sexual mores, the apparent decline of the traditional patriarchal nuclear family, and through the increasing visibility, acceptability, and rights gained by sexual minorities (Seidman 2010). In fact, Seidman argues that compulsory heterosexuality has declined in today's day and age. He claims compulsory heterosexuality describes a unique period in U.S. history, roughly from the 1950 s to the 1980 s— “an era characterized by a state-driven nationwide politic aggressively enforcing institutionalized normative heterosexuality" (Seidman 2009:27).

Theorists do not suggest abandoning the notion of compulsory heterosexuality, which they claim remains indispensable for understanding the structural factors surrounding sex and gender differences and hierarchies. Instead, they argue that the concept of compulsory heterosexuality should be used in a more reflective way, examining the consequences of organizing a society exclusively around heterosexuality. Additionally, they remind others the importance of examining compulsory heterosexuality with a lens that takes into consideration historical preconditions and parameters. This is important to remember when looking at the role compulsory heterosexuality plays in the various societies where foreign-aid workers serve. 
It should not be denied that major progress has occurred in the fight for equality between heterosexuals and homosexuals. American society has come a long way from the days when gay male sex was a criminal offense and when lesbians risked losing custody of their children. In fact, there have been many, major advances pertaining to the rights of sexual minorities. For example, on June 26, 2015, the Supreme Court ruled in favor of same-sex marriage, legalizing it in all 50 states (Vogue and Diamond 2015). New York Times Journalist Adam Liptak described the aftermath of the decision and how it aligned with the changing attitudes of American society:

The decision, which was the culmination of decades of litigation and activism, set off jubilation and tearful embraces across the country, the first same-sex marriage in several states, and resistance - or at least stalling in others. It came against the backdrop of fast-moving changes in public opinion, with polls indicating that most Americans now approve of the unions (2015: para. 4)

I remember watching this news early Friday morning, almost in disbelief, and as I looked at pictures of the White House lit up in rainbow lights later that evening, I could not believe how much progress had been made in such a short period of time. Prior to my departure for Peace Corps in 2012, just six states had legalized gay marriage. New York was the sixth and largest state to do so when they signed the bill into law in June of 2011 (Confessore \& Barbaro 2011). Fast forward just four years and same-sex marriage was now a federal law. This drastic change has been interesting to process as a recently returned, queer RPCV. While I was gone, I missed a lot of the milestones in regards to the fight for marriage equality in the United States, so this new change in both law and social climate surrounding homosexuality in the United States has been an interesting phenomenon to process but a welcome one at that. 
It is important to note that although marriage equality has been reached in the United States, it would be a mistake to think that true equality has been reached. Society has come a long way, but, the "world we have won," as Weeks (2007) points out, creates new dilemmas and obstacles to overcome. Greater public openness to sexual diversity and the granting of equal rights to sexual minorities exist alongside continued homophobic harassment, bullying, and violence in schools, workplaces, and on the streets (Hennessy 2000). In addition, some queer individuals may live lives comparable to those of their heterosexual counterparts, but many still face prejudice and discrimination. There is no universal reality for queer individuals:

For some, their lives are almost indistinguishable from heterosexuals. They have families, live in the suburbs, pursue careers, buy homes, celebrate anniversaries, and have children. Still, even for individuals whose lives are conducted beyond the closet, there are still risks in openness, which include harassment, ridicule, disapproval, violence, and discrimination. For others, their lives are built around being gay - their friends are gay, and they live, eat, and work in gay enclaves. For still others, their lives are not all that different from the closeted homosexuals of the 1960s and 1970s; they marry someone of the opposite sex, are silent in the face of homophobic expression, and live in a constant state of fear. (Seidman 2010:73)

A more comprehensive protection of rights is needed before the queer community reaches full equality. As the Human Rights Campaign (HRC) explains, "The patchwork of current LGBT legal protections leaves millions subject to uncertainty and potential discrimination that impacts their safety, their family and their way of life." (Human Rights Campaign 2015a: para. 1). Marriage equality is a step in the right direction, but it is definitely not the end of the fight for equality. HRC elaborates:

Even after a marriage victory at the Supreme Court, in most states in this country, a couple who gets married at 10 a.m. remains at risk of being fired from their jobs by noon and evicted from their home by 2 p.m. simply for posting their wedding photos on Facebook. No one should be fired, evicted from their home, or denied services because of who they are or whom they love. All LGBT Americans 
deserve a fair chance to earn a living and provide for their families and that all employees are hired, fired or promoted based on their performances. (Human Rights Campaign 2015b: para. 1)

Therefore, marriage equality is a welcome change but many more are needed. I am happy that I will be around to witness and take part in the next stage of the movement for change and equality.

Jackson and Scott (2010) argue that although the boundaries of normative heterosexuality are regulated, heterosexuality retains its hold as the normative form of human sexuality and is taken for granted as such in much of everyday life. This being the case, scholars and theorists argue that the sociological critique of heterosexuality has by no means outlived its usefulness and, therefore, will be used as theoretical lens throughout this study.

Compulsory Heterosexuality in a Global Perspective

Although compulsory heterosexuality has been almost exclusively studied in America, it is not a social phenomenon that is unique to American society. In fact, it is very important for the scope of this study to look at compulsory heterosexuality in a global perspective. "Same-sex erotic behavior is virtually universal in human societies. Few societies that have been carefully studied have been found to yield no evidence of same-sex eroticism" (Drucker 1996:75). Furthermore, Binnie (2004) argues, "National differences in regulation and control of sexualities do matter and reveal much about the specific constructions of national identity and sexual cultures" (12). To elaborate, when it comes to public opinions, laws, and behaviors surrounding homosexuality, it varies considerably around the world. Eric Rand (2005) explains, "Regimes of visibility and silencing, promulgated by the state, the media, individuals, and communities, make 
histories that affect people's lives in extremely varied ways, from defining criminality to internalizing codes of behavior" (97). Therefore, it would be a grave mistake to generalize the effect of compulsory heterosexuality around the world.

Various sources can be drawn upon to shed light on how compulsory heterosexuality operates in different societies. For example, Amy Adamczyk and Cassidy Pitt (2009) made an important observation in their study pertaining to attitudes about homosexuality. They found that marriage between same-sex couples is legal in some countries, such as Canada, Belgium, and the Netherlands, yet in nearly every African country homosexuality is illegal and gay marriage is an unspoken topic. To build upon this, Brian Whitaker (2006) provides further evidence of the varying attitudes surrounding homosexuality around the world with his description of gay and lesbian life in the Middle East:

People whose sexuality does not fit the norm have no legal rights; they are condemned to a life of secrecy, fearing exposure and sometimes blackmail; many are forced into unwanted marriages for the sake of their family's reputation; there is no redress if they are discriminated against; and agencies providing advice on sexuality and related health matters are virtually non-existent. (10)

Furthermore, according to a report created by Alok Gupta (2008) for the Human Rights Watch, there are more than eighty countries around the world that view acts of homosexuality as criminal behavior. Nearly half of those countries—-thirty-seven—are located on the continent of Africa (Rupar 2014). Legal sanctions for breaking such laws vary from country to country and range from requiring "perpetrators" of homosexual acts to pay fines to having them put to death (Gupta 2008). There are currently ten countries where homosexuality may be punishable by death-Yemen, Iran, Iraq, Mauritania, Nigeria, Qatar, Saudi Arabia, Somailia, Sudan, and The United Arab Emirates (Rupar 
2014). This reiterates the fact that compulsory heterosexuality exists in societies to varying degrees.

In his Human Rights Watch report, Gupta (2008) made the following statement on how these laws perpetuate homophobia and inequality around the world:

These laws invade privacy and create inequality. They relegate people to inferior status because of how they look or who they love. They degrade people's dignity by declaring their most intimate feelings "unnatural" or illegal. They can be used to discredit enemies and destroy careers and lives. They promote violence and give it impunity. They hand police and others the power to arrest, blackmail, and abuse. They drive people underground to live in invisibility and fear. (5)

As a result, in societies where compulsory heterosexuality exists, heterosexuals have a privileged identity status, meaning they benefit from numerous privileges. In contrast, if an individual is not heterosexual, he or she may face public disrespect, ridicule, social isolation, criminal punishment, and even violence. In a speech given to the United Nations, former Secretary of State Hillary Clinton (2011) had the following to say about how queer individuals are treated around the world, "Many are treated with contempt and violence by their fellow citizens while authorities empowered to protect them look the other way or, too often, even join in the abuse." This only works to perpetuate the institutionalized heterosexuality that exists in many societies around the globe. Overall, it is important to investigate the social norms and rules surrounding sexuality where the queer, foreign-aid workers serve. This provides insight into the diversity of ways sexuality is regulated in societies around the world and could be invaluable knowledge in the quest to understand their identity negotiations and management mechanisms.

In the previous sections, I fleshed out the concept of compulsory heterosexuality and how it is applied to this particular study. Now I will move on to a discussion of how this study conceptualizes and theorizes identity. 


\section{SEXUAL IDENTITY AND NEGOTIATION MANAGEMENT}

This study focuses on the interplay between societies' pressures to conform to norms and queer, foreign-aid workers' identity management. Therefore, it is essential that we take some time to reflect on past and current perspectives surrounding identity formation and management.

\section{Identity and Self}

Queer, foreign-aid workers who serve in societies where homosexuality is illegal or less accepted compared to where they originate from are forced to negotiate their queer identity. Rosenwald and Ochberg (1992) argue that "social ideology is individually appropriated in the construction of life histories and selves," meaning the norms and customs of a certain society, undoubtedly, influence the identity development of the individuals residing there (5). Furthermore, Espin (1997) explains:

Becoming a member of a new society stretches the boundaries of what is possible in several ways. One's life and roles change, and with them, identities change as well. In the new culture, new societal expectations lead to transformation in identity. The identities expected and permitted in the home culture may no longer be those expected or permitted in the host society. Boundaries are crossed when new identities and roles are incorporated into life. Most (individuals)...do not fully suspect how many emotional and behavioral boundaries they are about to cross. (191)

This sheds light on how situational, social structure, and cultural elements influence the identity management of individuals. This study focuses on the impact of situational and cultural features on queer, foreign-aid workers' identity development and the level of control surrounding their presentation of self.

George Herbert Mead's (1934) and Charles Horton Cooley's (1902) work form the foundation of the symbolic interactionist perspective of identity. Their work highlights "the social nature of the self and the importance of social interaction for self- 
formation, maintenance, and change" (Kaufman and Johnson 2004:811). Additionally, Goffman (1959) emphasized how influential the situational context of interaction can be on the presentation of one's self. Theories of this nature recognize that identity is not simply an individualistic characteristic or state but, rather, a fluid process of negotiation and management that is influenced by both internal and external factors. To put it simply, identity formation is not a unidirectional process. Furthermore, Blumer's (1969) work highlights that even though individuals are shaped by the meanings imposed upon them by society, they still play an active role in shaping the world around them by supplying it with meaning. More specifically, symbolic interactionists describe identity as "continually in flux, shaped and reshaped by the give-and-take in shared meaning between self and society" (Killian and Johnson 2006:63). Therefore, it is important to keep in mind that regardless of external pressures, individual agency still plays an important role in identity formation and management. This is key as it suggests that queer, foreign-aid workers play a vital role in their own identity negotiation and management processes.

With that said, the degree of agency an individual has in his or her own identity formation and management depends on a myriad of factors. According to Burke and Reizes (1991), “An identity process is a continuously operating, self-adjusting feed back loop: individuals continually adjust behavior to keep their reflected appraisals congruent with their identity standards or references" (840). Powers (1973) further explains that a society's control system plays a large role in determining the degree of choice individuals have in the presentation of self, as well as how they interpret others' presentation of self. Therefore, queer, foreign-aid workers may not want to negotiate their sexual identities 
while serving abroad, but the control systems in their respective society may leave them with no other choice. Also, if they did present themselves as queer, the control systems of the society would influence what meanings others assigned to those identities. Thus, this could affect the way locals view queer, foreign-aid workers, which, in turn, could impact the success of their work. To build upon this, Burke (1991) argues that individual actors must assess the institutional context of a situation before deciding how to present themselves to others. Because queer, foreign-aid workers are serving in cultures very different than their own, they must present themselves in a way that is in accordance with the laws and social norms of where they are serving if they wish to successfully integrate into the culture where they are working. This study focuses on structural influences on identity development, management, and enactment.

Furthermore, Tajfel and Turner $(1979 ; 1982)$ explain that individuals have multiple identities that get set in motion by different social contexts. "When a category membership becomes salient (relevant to social context), self-perception and conduct become in-group normative. Perceptions of other groups become out-group stereotypical" (Owens, Robinson, Smith-Lovin 2010). Therefore, queer, foreign-aid workers living in societies where homosexuality is illegal or frowned upon may feel obligated to negotiate their sexual identity in order to feel accepted into the wider society. Otherwise, they would be forced to face the consequences of belonging to an out-group of society. This is extremely relevant when investigating the negotiation and management processes of queer, foreign-aid workers. This is also a good segue in to a discussion of how multiple identities affect identity management processes. 
Intersectionality of Identity: Seeing People as Multi-Faceted

It is important to note that we cannot generalize the experiences of all queer individuals. Sexuality is merely one facet of an individual's identity. Therefore, this study examines not only the differences between social groups but also differences within the same social group. Cronin and King (2010) explain that queer individuals "are positioned at the intersection of multiple identifications, the effects of which will change depending on context" (887). To build upon this, Bhavnani and Phoenix (1994) elaborate, "Identity is not one thing for any individual; rather, each individual is both located in, and opts for, a number of differing and, at times, conflictual, identities, depending on the social, political, economic, and ideological aspects of their situation" (9). Furthermore, Luibheid (2005) explains that it imperative for researchers investigating issues of sexuality to treat queers "not solely as sexual subjects, but in relation to multiple identities that directly affect them" (xxvi). Therefore, this study takes into account the effects of intersectionality on the identity management strategies of queer, foreign-aid workers.

It is important to flesh out what we mean by intersectionality and how it is applied to this study. "Intersectionality theory examines the social divisions, identifications, and power relations that structure people's lives, particularly those people deemed to be marginalized" (Cronin and King 2010:879). To put it simply, intersectionality takes into consideration the multiple facets of one's identity and how these facets intersect one another. Furthermore, intersectionality theory examines what identity negotiation and management strategies individuals utilize to navigate through the obstacles caused when different facets of one's identity intersect with each other. As Cronin and King (2010) explain, "Applying intersectionality theory can be problematic because decisions about 
which categories should be included are reflexive, selective tasks" (884). Cronon and King suggest starting with a singular group, which in this case would be queer individuals, and then unraveling other intersecting identifications. As a result, this study will focus on how sexuality intersects with gender, race, age, socio-economic status, foreigner status, and foreign-aid worker status, as these are related to issues of identity management and negotiation while serving abroad. Intersectionality theory implies for example, that a young, queer woman doing foreign-aid work abroad would have a different experience than an older, queer man doing the same work.

This study also takes into consideration foreign-aid workers' sense of agency, meaning they willingly chose to serve in a place where queer individuals may face opposition. This is important to keep in mind because these queer, foreign-aid workers were neither being forced to work in these cultures nor were they being forced to remain there against their wills. In this case, intersectionality theory implies queer foreigners have a different experience than queer natives. Overall, this study seeks to discover what role intersectionality of identity plays in the negotiation and management strategies of queer, foreign-aid workers

Sexuality and Identity

Although this study looks at the role intersectionality plays on identity management, the main focus is on one particular aspect of identity: sexuality. Researchers started taking interest in sexual identity development in the beginning of the 1970s. They were interested in explaining the process in which queer individuals developed and maintained their identities. Therefore, various developmental/stage models of sexual identity development emerged between 1970 and the early 1990s (Cass 1979; 
Coleman 1982; Lee 1977; Martin 1991; Minton and McDonald 1984; Plummer 1975; Troiden 1979.) These initial models were built upon two main assumptions. First, they assumed that the process of identity development was the same for all gay and lesbian individuals. Second, they assumed that identity development was a linear process. Most of these models consisted of three broad stages: "First awareness of same-sex attractions or gay, lesbian, bisexual feelings; exploration and testing LGB feelings; and integration of LGB identity ('coming out')" (Shapiro, Rios, and Stewart 2010:492). These initial models also assumed that sexual identities were formed through sequential stages that began in early adulthood and resulted in a static, integrated identity. Although these models provided important insight, they did not account for differences in queer identity development across cultures and national contexts (Shapiro, Rios, and Stewart 2010). Therefore, this study utilizes alternative models and analyses of sexual identity development.

This study draws upon sources that have taken alternative approaches to explaining sexual identity development and management (Cox and Gallois 1996; Diamond 2007; Floyd and Stein 2002; Hansen and Evans 1985; Hollander and Haber 1992; Horowitz and Newcomb 2001; Morris 1997; Sophie 1986). These models are appropriate in the use of this study for many reasons. First of all, they recognize that sexual identity development is not universal, meaning it cannot be generalized across cultures or even within cultures. Each individual's process of sexual identity development is unique and depends on various contextual factors. These sources provide a general framework of sexual identity development, but they do not claim each individual's experience will be the same. Furthermore, these sources recognize that identity 
development is not a linear process. In contrast to previous models, these newer approaches to sexual identity emphasize "the process of identity formation is a continual, two-way interactive process between the individual and the social environment" (Horowitz and Newcomb 2001:1). These newer models also provide insight because they use a constructivist framework to contextualize sexual identity within a broader social framework. Finally, these approaches are useful because they illustrate the fluidity of sexual identity. Seeing that this study investigates the negotiation and management of queer, foreign-aid workers, it examines the role of contextual factors in the fluidity of sexual identity development and management in various cultures around the world.

This study also utilizes the notion of performativity (Austin 1962), which claims that performance is not limited to the theater but also exists in the in various spheres of life, including social. In his book The Social Construction of Sexuality, Seidman explains how the idea of gender as performance can also be applied to the idea of sexuality. Seidman puts forth the argument that heterosexuality and homosexuality should not be viewed as static, core identities that motivate individuals' behavior. Instead, through a performance approach, sexual identity should be seen as a process. Therefore, researchers should investigate the micro-dynamics underlying the formation of sexual identity. For example, they should examine which behaviors and signs come to be indicators of sexual identity and why. Seidman claims:

A performative approach to sexual identity should not be interpreted as saying that identities are freely chosen or that they are somehow not real because they are produced through a performance. They are quite real as we experience them and in terms of their personal and social consequences. In addition, although they may be performances, they are not freely chosen; a system of compulsory heterosexuality exerts enormous social pressure on each of us to "perform" the appropriate gender and sexual identity. (2010:38) 
Individuals who do not conform to society's gender or sexual norms face much adversity, ranging from being denied respect to being the target of harassment or violence. Based on Butler's (1990) performative theory approach to gender and Seidman's re-focusing of this theory to pertain specifically to sexuality, this study investigates the micro-dynamics underlying the formation of sexual identity and how this affects identity negotiation and management.

Now that we have a framework as to how identity is conceptualized and theorized throughout this study, we will move onto a discussion of queer identity negotiation and management strategies.

\section{QUEER IDENTITY NEGOTIATION AND MANAGEMENT STRATEGIES}

No research has been found on the experiences of queer, foreign-aid workers. Additionally, little to no research has been completed on queer individuals experiences in developing countries in general. Therefore, this study draws upon sources that have investigated the identity management strategies of queer workers living in developed countries, the experiences of queer migrants in developed countries, and queer anthropologists conducting fieldwork abroad. Although none of these three types of sources align perfectly with the specifics of this study, they shed light on possible negotiation and management processes that queer, foreign-aid workers implement while serving abroad.

\section{Queer Identity Management in the Workplace}

Disclosing one's sexual orientation has been one of the toughest issues that queer individuals face in the workplace. Coming out at work "involves considerable emotional turmoil and a fear of retaliation and rejection" (Griffith and Hebl 2002:1191). 
Furthermore, the process of coming out can have drastic implications for the social and economic status of queer workers (Willis 2011:959). According to the Human Rights Campaign (2012):

Qualified, hardworking Americans are denied job opportunities, fired or otherwise discriminated against just because they are lesbian, gay, bisexual or transgender (LGBT). There is no federal law that consistently protects LGBT individuals from employment discrimination; it remains legal in 29 states to discriminate based on sexual orientation, and in 34 states to do so based on gender identity or expression. As a result, LGBT people face serious discrimination in employment, including being fired, being denied a promotion, and experiencing harassment on the job. (para. 1)

This sheds light on why queer workers struggle with coming out in the workplace.

However, in a recent comprehensive analysis, Dovidio and Gaertner (2000) concluded that overt, formal displays of discrimination are becoming less frequent. For example, a field study by Hebl, Foster, Mannix, and Dovidio (2002), found no differences in hiring rates among straight and queer workers, but they did discover that employers spoke fewer words, terminated interactions, and engaged in more nonverbal discrimination with queer employees compared to heterosexual ones. Therefore, this suggests that discrimination in the workplace does still exist. However, it may manifest itself in more subtle ways (Griffith and Hebl 2002:1191). With that said, it is important to note that queer individuals' experiences vary from workplace to workplace. Therefore, in this particular study, it is important to remember that although queer, foreign-aid workers may serve in the same country, the communities they reside in have their own, unique views surrounding homosexuality. Therefore, it's important to take these differences in social climate and attitudes surrounding homosexuality of various settings when examining how queer, foreign-aid workers negotiate and manage their identities while serving abroad. 
In contrast to the negative effects of coming out at work, past research has also shown that staying in the closet can have detrimental effects as well. For example, studies have shown that queer individuals who choose not to disclose their sexual orientation at work report increased health risks (Cole et al. 1996), lower levels of both psychological well-being and life satisfaction (Garnets and Kimmel 1993; Lane and Wegner 1995; Savin-Williams and Rodriquez 1993), less positive attitudes toward work and careers (Colgan et al. 2006; Ragins, Singh, and Miller 2007), and they also exert a substantial amount of time and energy on identity negotiation and management strategies (Ellis and Riggle 1996). According to Griffith and Hebl (2002), “At present, it seems that gay/lesbian workers face a double-edged sword when managing their stigmatized sexual identity at work - they face problems if they don't disclose, and they face problems if they do" (1191). Therefore, it is easy to see why the majority of queer workers struggle with whether or not to disclose information about their sexuality at work.

It is commonly assumed that queer employees face a dichotomous choice pertaining to coming out at work: Stay in the closet or openly identify as queer. Although some individuals may chose one of these two extremes, there is actually a spectrum of strategies that queer workers utilize. Some individuals do attempt to pass as heterosexual. As Willis (2011) points out, "Strategies for 'passing' heavily depend on the presumption of heterosexuality" (960). Norms surrounding heterosexuality may vary from place to place, so strategies for passing vary as well. Woods and Lucas (1993) refer to this strategy as "counterfeiting" because the individual creates and embodies a fake, heterosexual identity.

Silence is another popular strategy among queer workers. These employees use 
strategies of concealment, such as presenting oneself as asexual or simply avoiding questions about his or her personal life (Chrobot-Mason et al 2001; Woods and Lucas 1993). Self-editing, or monitoring and modifying speech, is another concealment strategy that queer workers have reported using (Rogers and Hebl 2001; Willis 2011). An example of this is when queer individuals use neutral pronouns ('they' rather than 'she' or 'he') when talking about a significant other. Willis (2011) explains that researchers perceive strategies that perpetuate silence surrounding queer identity as both good and bad:

[Researchers] perceive the discourse of silence in the workplace as a contradictory position that is simultaneously empowering and oppressive for LGBQ-identifying workers - oppressive by cloaking lesbian and gay workers from visibility whereas empowering through having to avoid assuming a fixed subject position within a 'heteronormative agenda. (961)

This sheds light on the fact that each strategy has its own strengths and weaknesses, and there is, unfortunately, not a magic answer as to how one should manage their queer identity at work. This also reiterates why the decision to come out at work is such a difficult one for queer individuals.

In contrast to silencing strategies, some queer workers may be comfortable fully disclosing their sexual orientation at work, depending on the climate of the work place. In fact, Shallenberger (1994) found that some queer workers use the opportunity of coming out at work to advocate for their community. These workers seek people out to disclose this information to with the hope of discussing issues relevant to the queer community. Other workers may be more comfortable reaching out to just one or two employees for support. However, with this particular strategy, queer workers risk the possibility of being involuntarily "outed" by their co-workers to other co-workers (Badgett 1996; Ward 
and Wistanley 2005). In contrast, some queer employees choose a more passive strategy. They do not go out of their way to come out, but they also do no attempt to conceal their queer identity either. They simply allow others to draw their own conclusions. It should be noted that this is by no means an exhaustive list of identity management strategies, but it undoubtedly provides insight into the process of identity negotiation. Furthermore, it is good to have a foundational knowledge of possible strategies that queer, foreign-aid workers may utilize.

What we have learned in this section is that queer individuals are not limited to a dichotomous choice when it comes to revealing their queer identities. It is, in fact, a much more intricate and complex process. Choosing which strategy or strategies to employ depends a myriad of factors. Both the social climate of the workplace and how comfortable each worker is personally with his or her own queer identity must be taken into consideration. For example, individuals who are not "out" outside of work, may utilize some of the same strategies they have been using in the "real" world to manage their queer identities. However, if an individual is completely out to their family and friends, then he or she will have to decide whether or not they want to disclose such information to co-workers. In addition, duration of time that the foreign-aid workers are in a particular community and whether or not they had an accessible support system may impact the choice of strategy utilized. Overall, it is important to take all of these factors into consideration when trying to understand how queer, foreign-aid workers manage and negotiate their queer identities.

Although it is insightful to see how queer individuals manage their identities at work, it is important that we remember the scope of this study. We are not simply looking 
at identity negotiation in the workplace. The participants in this study were doing foreignaid work abroad, meaning they worked in a culture very different than their own. Therefore, they were forced to manage and negotiate their identities not only in the workplace but out of the workplace as well. To gain perspective on how queer individuals acclimate to a new culture's norms and attitudes surrounding homosexuality, we now turn to past research done on queer migration.

\section{Identity Management Among Queer Migrants}

Research has yet to be conducted on the migration of queer individuals from countries with more accepting views of homosexuality to countries with less accepting views of homosexuality. My study addresses this gap. Nevertheless, we can still gain valuable insight into how foreign-aid workers may negotiate and manage their queer identities by examining the experiences of queer migrants who have left less accepting countries to live in more accepting countries. These experiences shed light on how queer individuals' identities are influenced and transformed when they find themselves living in culture with different norms and ideals.

One source that contains a plethora of knowledge on this topic is Luibheid's and Cantu's (2005) book Queer Migration: Sexuality, U.S. Citizenship, and Border Crossing. This book includes numerous pieces from various scholars who have investigated the norms, institutions, and discourses that affect queer immigrants. The book also includes ethnographic studies of how queer immigrants have assimilated into U.S. communities, which can be helpful in the process of investigating queer volunteers' identity management strategies. The following sections touch upon important themes from this book. 
First of all, as mentioned before, the intersectionality of identities plays a key role in the lives of queer individuals. The effects of the intersectionality of identity is even more important to remember when you add the additional identity of immigrant to the mix. In his chapter on the social and legal barriers of queer migration, Timothy $\mathrm{J}$ Randazzo (2005) elaborates on the topic:

The experience of being lesbian, gay, or transgender and an immigrant is not just a matter of membership in both groups. On the contrary, the intersection of these identities - not to mention their imbrication with gender, class, race, and ethnicity — can result in profound isolation and marginalization from support and resources. (38)

This sheds light on the obstacles queer immigrants face when they come to a new country. Although they may have escaped persecution based on their queer identity, many queer immigrants find themselves discriminated against based on other attributes.

Leaving homogenous societies, many of these immigrants do no consider the role class, race, ethnicity, and their new immigrant status will now play in their everyday lives. As a result of this unforeseen discrimination, they gravitate towards immigrant communities where the people are culturally similar to those they left behind. Randazzo explains that this, unfortunately, leads queer migrants into homophobic communities where they are unlikely to reveal their sexual orientation. "Many newly arrived immigrants who depend on their immigrant communities for support are understandably hesitant to reveal their sexual orientation" (Randazzo 2005:41). Therefore, they find themselves implemented the same concealment strategies they utilized back home: hiding, lying, and silence.

The lack of support and resources that immigrants can face in a new country brings up an important point of discussion: how adjusting to every day life abroad 
influences queer identity negotiation and management. In his chapter on claiming queer cultural citizenship, Horacio N. Roque Ramirez (2005) explains that "the everyday life of transnational queers is shaped by seemingly banal practices that do in fact reveal the constant negotiation of 'home' as a matter of 'here,' 'there,' and 'in-between"' (180). To build upon this, in his chapter on migrancy, modernity, and mobility, Martin F. Manalansan (2005) further stresses why the impact of everyday activities on immigrants should not be overlooked. "The focus on the quotidian life unveils the veneer of the ordinary and the commonplace to lay bare the intricate and difficult hybrid negotiations and struggles between hegemonic forces" (148). Ramirez explains that these difficult hybrid negotiations lead to inner turmoil for immigrants because they are faced with "competing systems of desire in a transnational frame" (150). Furthermore, Shohat and Stam (1994) argue that immigrants are "confronted with the 'theatrical' challenge of moving, as it were, among diverse performative modes of sharply contrasting and ideological worlds" (42). This constant battle between the ideals of their homeland and the ideals of their new homeland can make it very difficult for immigrants to fully acclimate to their new culture.

When queer migrants find themselves in this constant negotiation between two worlds, it can affect their queer identity negotiation and management strategies. For example, if queer immigrants are focused on adapting to their new life abroad, this may postpone any plans they have surrounding their queer-self. Unless a queer person feels comfortable, welcomed, and safe in the community he or she is living, it is difficult for that individual to "come out," let alone live as an openly queer individual. Therefore, 
queer immigrants may spend years in the closet before they feel fully acclimated and comfortable with exploring their queer identity in their new culture.

With that said, it is also important to remember that these immigrants are coming from places where homosexuality was not only frowned upon, but in many cases, illegal. Therefore, they have not only been conditioned all their lives to behave in accordance with these laws surrounding homosexuality, but they have also been ingrained with certain beliefs pertaining to homosexuality. Most people know of and are familiar with the term homophobia. However, a large majority of the population has yet to become familiarized with internalized homophobia and the impact it has on queer individuals. Frost and Meyer (2009) illuminate that internalized homophobia represents "the gay person's direction of negative social attitudes toward the self" (97). The internalization of societal homophobia can be organized into three stages. In the first stage, individuals recognize society's disqualification of them from first-class citizen status, and they realize they are viewed as minorities in this culture. In the second stage, gay and lesbian individuals learn to cope with being treated as a stigmatized member of society. The third and final stage consists of individuals carefully controlling to whom they do and do not reveal their sexual identity (Demino, Appleby, and Fisk 2007). These scholars' research finds that the culmination of these three stages often result in psychological distress and, more times than not, self-hatred. Therefore, it is important to remember the role that internalized homophobia plays in the lives of queer immigrants. They must, first, overcome this psychological distress and/or self-hatred before they can even consider living their lives as openly queer individuals. 
Minority stress is another important social phenomena to take into consideration when looking at the lives of queer individuals. Minority stress results from "culturally sanctioned, categorically ascribed inferior status, social prejudice, and discrimination" (Otis, et al. 2006:83). Previous research has been done to examine the role minority stress plays in lives of gay and lesbian individuals, and results indicate a significant relationship between minority stress and adverse psychological health effects (Bos et al. 2004). Minority stress and internalized homophobia go hand-in-hand when examining queer identity negotiation and management. In this study on the identity negotiation of queer, foreign-aid workers, it is interesting to see how adjusting to everyday life, as well as minority stress, affects the identity management processes. Foreign-aid workers may often feel torn between behaving in a way they were accustomed to back home and behaving in a way that upheld the norms and ideals of the country in which they were working. After all, Espin (1999) explains:

The internalization of cultural and familial norms has deep roots in the psychology and identity of all human beings. Those who are uprooted from one society, no matter how successfully they adapt to life in another, do not fully let go of the internalized injunctions. (5)

This may be true of not only behaviors and attitudes surrounding their queer identities but all of their identities. Similar to how queer migrants learn to live in a new culture that possesses a more accepting environment of homosexuality, queer foreign-aid workers must learn to navigate through a new culture that has a less accepting environment of homosexuality. Queer migration sheds light on important dilemmas individuals face when they find themselves in a culture so radically different from their own.

There is an important difference between the queer migrants examined in this section and queer, foreign-aid workers that needs to be addressed. Ultimately, queer 
migrants have a choice as to whether or not they want to fully assimilate to their new culture's way of life nor not. Similarly, queer, foreign-aid workers have the choice of becoming foreign-aid workers or pursuing a different career path. However, while working overseas, queer, foreign-aid workers are expected to respect and abide by the laws and customs of the country in which they are working. To gain a better understanding of the obstacles these foreign-aid workers may face, we now turn to a discussion on queer anthropologists who conduct fieldwork. As there has yet to be any research conducted on the experiences of queer, foreign-aid workers, queer anthropologists might be the most comparable group we have at the moment to gain insight from for this study.

\section{Identity Management Among Queer Anthropologists Conducting Fieldwork}

The issue of sexuality in the field has rarely been researched or discussed. However, Lewin and Leap's (1996) book, Out in the Field, provides a rare window into the experiences of lesbian and gay anthropologists conducting fieldwork abroad. The book contains numerous essays about their research and personal experiences, the obstacles they face when writing about the queer population, and the impact of doing so on their careers. For the sake of this study, I will focus on the essays that provide insight into how gay and lesbian anthropologists negotiated and managed their queer identities while conducting fieldwork abroad. The following sections will highlight the information from this book that proved the most helpful in the planning and implementation of my study.

Regardless of the location or nature of anthropological fieldwork, anthropologists are trained to fit into the community of people they are studying. They are not necessarily 
expected to give up all their ideals and beliefs and fully engage in those of their host community, but they are urged to behave in a way that will gain their community's trust and respect. This ultimately means behaving in a manner that respects the local laws and customs. Lewin and Leap elaborate on how important this is to the success of fieldwork:

No matter what the specific difficulties accounts of fieldwork focus on, they are virtually unanimous in emphasizing the importance of playing a suitable role in the setting one has chosen. Both the memories of established anthropologists and various manuals that explain the mechanics of the field worker's craft place considerable emphasis on the ways in which one must self-consciously manage one's identity in order to complete the research successfully. Some recommend finding a way to fit into the local social structure. (1996:5)

This advice can also be applied to the foreign-aid work. Unless foreign-aid workers gain the trust and respect of the locals they are working with and demonstrate a certain level of respect for their way of living, they may not succeed either.

Successfully fitting into the local social structure of a society and becoming an "insider" presents special challenges for queer anthropologists compared to their heterosexual counterparts. According to Lewin and Leap (1996),"While other insiders are unlikely to have concealed their gender, ethnicity, or national origin, lesbians and gay men have a long and necessary tradition of secrecy about their identity" (11). The experiences of gay and lesbian anthropologists shed light on the urgency of identity management in the course of everyday activities:

We must consider on a daily basis how much of our personal lives to reveal, how to create a 'role' for ourselves that will lessen the likelihood of ostracism or other hostile treatment, and how to coordinate our homosexuality, however we perceive it, with other dimensions of our identities... Where we believe that sexual orientation is a biologically driven propensity or a negotiated identity, whether we wish we could change or are defiantly proud, whether we believe that our sexual orientation is 'who we are' or only a minor theme in our larger identities - the management of information about our homosexuality is still a central theme in how we move around the world. (Lewin and Leap 1996:13) 
Due to this reality, gay and lesbian anthropologists use a combination of identity negotiation and management strategies in the field. First of all, gay and lesbian anthropologists looking to conceal their queer identities are aided by heteronormativity and the "heterosexual assumption." This occurs when heterosexuality is so pervasive in a certain place that it becomes the norm, and, thus, everyone just assumes everyone is heterosexual (Lewin and Leap 1996). For example, in Liz Goodman's (1996) essay, Rites of Passing, prior to her arrival in the field, she had decided she must remain in the closet, but she struggled with whether she should present herself as asexual or pretend she had a boyfriend back home. Fortunately for Goodman, she never had to make that decision. After immediately hitting it off with one of the men in her community and spending a substantial amount of her time with him, the local people just started to assume they were dating. She neither confirmed nor denied this assumption. Instead, she just let people believe what they wanted to believe. She, of course, confided in this man the truth about her sexuality, but he was accepting and kept her secret for the duration of the stay. In fact, the two still spent a considerable amount of time together, and he became a support system for her during her time in the field.

Goodman not only found this strategy of letting others assume she was straight useful, but the whole experience of being treated as heterosexual proved to be very enlightening:

I was able to take off the costume of the queer and put on the clothes of respectability. For me as an out lesbian, the field offered me a first taste of living at the heart of a community's values, of feeling like a normal and accepted person. I entered this community without a past and with no stake in people knowing that I was a lesbian. Once I learned to cope with the practical aspects of living in the Dale, I was able to enjoy the status of normality that was such a sharp contrast to the sometimes painful ousiderness that I knew awaited me back home. (1996:57). 
Goodman's experience sheds light on the fact that the experience of identity negotiation and management for queer individuals may have positive effects. Although many queer individuals may struggle with such negotiation, others, such as Goodman, find it to be a very rewarding and eye-opening experience overall.

With that said, most queer anthropologists do not feel comfortable relying on the "heterosexual assumption" as a sole strategy and implement other identity management strategies. Other anthropologists reported using concealment strategies. For example, William Leap's (1996) strategy was to keep his professional and personal life apart while in the field. He explains, "My identity management strategies in Indian country included everything from cloaked ambiguity (as among the pueblos) to an explicit stance as an outsider with useful skills (as a Norther Ute). But in no case did research topics and personal identity need to coincide" (142). Repression was another strategy implemented. Ralph Bolton, a former Peace Corp Volunteer, actually came to terms with his sexuality during his time abroad. However, he knew he could not come out to the community members in his rural village, and, therefore, used repression to get through his service. He accomplished this by throwing himself in his work. After returning back to the states, it still took him many years to fully come to terms with his gay identity, but he emphasizes that his time abroad played a large role in his coming out process. Ralph's story is very important to reflect on. It sheds light on the fact that some foreign-aid workers may first realize their queer identity while working abroad. Also, foreign-aid workers may have experiences in the field that do not fully impact them until years down the road. All of this is important to keep in mind while discussing this study. 
Some gay and lesbian anthropologists simply avoid field locations where they would have to completely conceal their queer identity. Additionally, a lack of access to fellow queer individuals for support also dissuades many queer anthropologists from going to certain settings. Ester Newton (1996) explains:

Prospective dissertation projects in East Africa and Figi...presented unknown dangers that scared me off. Most closeted gay people - as I then was - manage information and stress in America by retreating to private or secret 'gay zones' where, alone and with other gays, we can 'be ourselves.' No African or Fijian village would offer such refuge, I figured, and what if they found me out? (220).

The element of the unknown plays an important role in identity management strategies. Furthermore, fear and rejection of one's queer identity keeps many gay and lesbian anthropologists in the closet during their fieldwork or deters them altogether from certain field assignments.

Not all queer anthropologists chose to conceal their queer identity while conducting fieldwork abroad. In fact, some believe that attempting to hide one's queer identity can be detrimental to the research at hand. Frank Proschan (1990) who conducted fieldwork in Cambodia emphasizes, "As a result of my own evasiveness and their sensitive avoidance of potentially embarrassing questions, I remained a riddle to the people with whom I worked" (59). As a result, this made it hard for his informants to trust him, and many did not feel comfortable disclosing personal information to him. Proschan elaborates, “As long as I presented myself as a riddle, leaving any sexual identity undefined and unsaid, my Cambodian friends consistently left anything with explicitly sexual content unsaid in my presence—silence begetting silence" (62-62). Therefore, Proschan and other queer anthropologists urge others to be open and to find a way to integrate their queer identities into their work. 
Overall, each queer anthropologist's experience in the field is unique, and, therefore, it is impossible to definitively say how queer anthropologists should manage their identities. For some, it may be essential for their own safety and/or the success of their research to remain in the closet and to attempt pass as straight. However, for others, concealing their queer identity may actually be harmful to their work. In addition, there are those who simply avoid the dilemma altogether and conduct fieldwork in settings where they do not have to worry about negotiating their queer identities. The truth of the matter is that no queer anthropologist will know exactly what identity management strategies they will have to implement until they arrive in the field and gain a true understanding of what is and what is not acceptable behavior in that society. The experiences of the queer anthropologists above provide valuable insight into the dilemmas queer, foreign-aid workers may face and what identity management strategies they may implement during their own time abroad.

With that said, being queer is only one issue that queer anthropologists face in the field. Similar to queer migrants, queer anthropologists have to adapt to everyday life in their new setting as well. Williams (1996) details the obstacles that arise when adjusting to a new way of life:

Being gay is only one potential issue involved in living in a fieldwork setting. In my experience doing fieldwork on numerous Indian reservations, in a Maya village in Yucatan, among Native Alaskans, in Java, and most recently among Polynesians, I have found that my gayness is much less of a problem than the common obstacles facing most fieldworkers. Sanitation, deciding what local foods and drinks I can safely consume, money transfers, diarrhea, snarling dogs, allergies, finding a suitable place to live, arranging to keep in touch with my parents...these are the kind of daily issues to which one has to adjust when arriving at an new local. They must be attended to before one can even begin to think about one's interactions with the local people. (70) 
This sheds light on the fact that queer identity management may not be the most pressing issue for queer, foreign-aid workers who are striving to overcome everyday obstacles, such as where to obtain clean, drinking water or healthy food to eat. It also sheds light on how different facets of one's identity affects working abroad in different ways and to different degrees. In this example, William's identity as a foreigner affected his life abroad more so than his identity as a gay male, especially when he was first trying to acclimate to his new culture.

To build upon this notion, Wafer (1996) states, “ Issues of identity management did, of course, confront me, but they were not related to my sexual orientation so much as to my identity as an anthropologist, a white foreigner, and a person with a source of dollars" (266). This reinforces the important role intersectionality plays in identity management processes. To further build upon this, Kennedy and Davis (1996) who actually conducted research on a small, lesbian community explains:

In the process of research and writing, Davis and I became progressively aware that the common bond of lesbianism and familiarity with the social context did not make positioning ourselves in relation to the complex and powerful forces of class, race, and gender oppression — not to mention homophobia-easy. (173)

To elaborate, it would be a mistake to assume that sexual orientation automatically binds all queer individuals together. Queer individuals themselves often make this same assumption until the reality of intersectionality sets in. According to Kate Weston (1996), "Disillusionment sets in as queers began to recognize what later seemed obvious: their different positioning within a population defined in terms of sexuality but crosscut by lines of race, gender, age, ability, and class" (282). This study as a whole pays particular attention to the role intersectionality plays on the identity management practices of queer, foreign-aid workers. 


\section{LITERATURE SEARCH STRATEGIES}

Sources were obtained through a variety of means. First of all, materials that I received from the Peace Corps' website and during my application/placement process were very useful in the development of this study. Next, the University's library's database was utilized to find relevant articles and books. Some of the search terms I used included: identity, identity development, identity formation, identity management, identity negotiation, intersectionality, gay, lesbian, bisexual, queer, LGBT, compulsory heterosexuality, institutionalized heterosexuality, social regulation of sexuality, social construction of sexuality, sociology of sexuality, globalization of sexuality, queer migration, international development, foreign-aid workers, coming out in the workplace, identity management in the workplace, disclosure, silencing, and passing. These searches led me to a variety of articles and books surrounding identity development, compulsory heterosexuality and social regulation of sexuality, as well as queer identity management and negotiation processes. I also talked to various professors and peers about my project. These individuals were able to recommend additional articles and books that I could utilize throughout this study. 


\section{CHAPTER III}

\section{DESIGN AND METHODS}

\section{OVERALL APPROACH AND RATIONALE}

To explore how queer, foreign-aid workers negotiate and manage their queer identities while serving abroad, I utilized qualitative research methods. Qualitative research is a subjective approach to research that uses words to describe meaning, to discover things, and to understand phenomena (Cottrell and McKenzie 2005). The qualitative researcher studies "things in their natural settings, attempting to make sense of, or to interpret, phenomena in terms of the meanings people bring to them" (Cottrell and McKenzie 2005:18). This study aims to make sense of how compulsory heterosexuality affects the social construction of sexuality in societies where queer, foreign-aid workers serve and how this influences the negotiation and management of their queer identities

A qualitative approach to this study was ideal for many reasons. First of all, qualitative research methods are especially useful in the exploration of new areas of research. Therefore, it proved to be a very beneficial method in this study that aimed to explore a topic that had yet to be researched: The experiences of queer, foreign-aid workers in societies where compulsory heterosexuality still exists. Additionally, the population of this study (queer, foreign-aid workers) is not easily identifiable, making the obtainment of a large sample size very difficult. Therefore, this reinforced the decision to 
take a qualitative approach. Finally, qualitative methods allowed for the examination of complex questions and obtainment of in-depth information that would have otherwise been nearly impossible with quantitative methods. Taking all of these factors into consideration leads me to believe that the use of qualitative methods was the best approach for a study of this nature.

\section{DATA COLLECTION METHODS}

Throughout out this study, I used two qualitative research methods to collect my data: semi-structured interviews and autoethnography. To assess how queer, foreign-aid workers negotiate and manage their queer identities while working abroad, semistructured interviews were conducted with ten, Returned Peace Corps Volunteers who self-identity as queer. It is important to note that all participants were assigned a pseudonym to protect their anonymity. Additionally, as a queer, Peace Corps volunteer myself, I gathered autoethnographic data during my Peace Corps service from September 2012-October 2014. The following sections will provide a more thorough explanation of semi-structured interviews and autoethnography, as well as a description of how each method was utilized in this specific study.

\section{The Role of Semi-Structured Interviews}

To put it simply, a semi-structured interview is a verbal exchange where the interviewer attempts to obtain information from another person by asking questions. "Although the interviewer prepares a list of predetermined questions, semi-structured interviews unfold in a conversational manner offering participants the chance to explore issues they feel are important” (Longhurst 2010:103). This method allowed me to gain indepth information that might not have otherwise been obtainable through other research 
methods. According to Reinard (2001), "unlike many questionnaire studies, interviews can produce interpretations for the reasons behind answers. By reporting on the results of follow-up questions and funnel question patterns, interviewers often gain insight to explain previously unknown reasons" (242). Furthermore, as Ochberg (1992) argued, "the tales we tell each other about who we are and might yet become are individual variations on the narrative templates our culture deems intelligible" (214). Therefore, semi-structured interviews not only provide insight into how queer individuals negotiate and manage their queer identities as foreign-aid workers, but they also shed light on the cultural factors forcing such negotiation to occur among these individuals.

Questions were arranged before the interview and allowed for deviation if participants choose to elaborate on a certain question. There were five main categories of questions. Interviewees were first asked several questions pertaining to their Peace Corps experience in general, focusing on the location and description of their primary assignment. Next, they were asked more specific questions in terms of what their expectations, concerns, and fears were, in regards to going into Peace Corps as a member of the queer community. Third, they were asked specific questions about the social climate and social structure of their community where they served. This helped to assess the role compulsory heterosexuality played in the social construction of sexuality in the communities where they served. Next, interviewees were asked questions related to how, if at all, they negotiated and managed their queer identities in these settings, and why they felt the need to do so. Finally, interviewees were asked to discuss how their Peace Corps experience as a whole has shaped or had any lasting effects on their queer identities. (See Appendix A for the list of interview questions). 


\section{The Role of Autoethnography and Reflexivity}

In terms of my design and methods, the advantage of conducting a study on past behavior of queer Peace Corps volunteers was that their experiences had already occurred. Therefore, my presence as a researcher did not affect how my participants' experiences unfolded. However, as a researcher, I was in a unique position. Like my participants, I had served as a queer individual in the Peace Corps myself. As a result, I did have to work to keep my personal biases in check as I carried out this study. Therefore, to ensure that my own experience of negotiating and managing my queer identity did not affect how I collected and analyzed my interview data, I used the research method of authoethnography to keep my own frame of reference and biases in check.

Autoethnography has been defined as a "qualitative research method that utilizes data about self and context to gain an understanding of the connectivity between self and others within the same context" (Ngunjiri, Hernandez, and Chang 2010). Therefore, I used autoethnography as a way to interrogate how we, as queer individuals, navigate through the Peace Corps and as foreign-aid workers. Carolyn Ellis and Arthur P. Bochner (2000) provide a more in-depth explanation of autoethnography:

Autoethnography is an autobiographical genre of writing and research that displays multiple layers of consciousness, connecting the personal to the cultural. Back and forth autoethnographers gaze, first through an ethnographic wide-angle lens, focusing outward on social and cultural aspects of their personal experience; then, they look inward, exposing a vulnerable self that is moved by and may move through, refract, and resist cultural interpretations. As they zoom backward and forward, inward and outward, distinctions between the personal and cultural become blurred, sometimes beyond recognition. Usually written in first-person voice, autoethnographic texts appear in a variety of forms - short stories, poetry, fiction, novels, photographic essays, personal essays, journals, fragmented and layered writing, and social science prose. In these texts, concrete action, dialogue, emotion, embodiment, spirituality, and self-consciousness are featured, appearing as relational and institutional stories affected by history, social structure, and 
culture, which themselves are dialectically revealed through action, feeling, thought, and language. (739)

To successfully accomplish the intricate process, I kept an autoethnographic journal throughout my Peace Corps service. In this journal, I recorded detailed notes surrounding my thoughts, feelings, and experiences as a queer individual serving in the Peace Corps. The purpose of this journal was be two-fold. First, it helped me to be aware of my biases and subjectivity surrounding the negotiation and management of queer identity in the Peace Corps. Therefore, I was able to analyze my interview data more objectively. Second, this journal provided me with supplemental data surrounding how queer individuals manage and negotiate their identities while serving abroad as foreign-aid workers.

SAMPLE

The subject population for this project was foreign-aid workers who self-identify under the umbrella term "queer." To find participants that meet these parameters, I used Peace Corps as a sampling pool. I found the Peace Corps to be an acceptable sampling pool for various reasons. Since the Peace Corps was officially founded in 1961, more than 200,000 volunteers have served in 139 countries worldwide. Throughout the years, volunteers have focused on various foreign-aid issues: education, health, business development, youth development, and the environment. Among these volunteers, there has been a wide range of diversity in regards to gender, marital status, race, age, and sexual orientation (Peace Corps 2012a). In addition, Peace Corps volunteers are subject to the laws and cultural norms of the society they serve in. Furthermore, "Homosexuality is considered socially unacceptable or even illegal in some of the countries where the Peace Corps has programs. Those realities can create special challenges for Peace Corps 
Volunteers" (Peace Corps 2012b: para. 3).Taking all of these factors into consideration, the Peace Corps served as an appropriate venue to gather participants who have both worked in the foreign-aid sector and also self identify as queer. Additional parameters should be noted. Subjects had to be at least 18 years of age. They were not excluded based upon race, ethnicity, marital status, or any other factors besides the previously stated requirements.

Originally, my plan was to gather participants by contacting the Lesbian, Gay, Bisexual, Transgender Peace Corps Alumni Network. This network is an organization made up of several hundred members throughout the country and around the world who have served in Peace Corps since its inception in 1961. It is also an active, affiliate member of the National Peace Corps Association. This proved to be unnecessary though. After serving as a Peace Corps volunteer myself, I was able to network with multiple queer volunteers who then, in return, introduced me to other queer contacts. Therefore, I was able to recruit all ten participants starting with my personal network of queer Peace Corps volunteers, and then the rest were obtained through a snowball sampling technique. In the end, I interviewed 10 queer, returned Peace Corps volunteers who all served in the same country of service that I did.

\section{Participants}

This study consisted of eleven Returned Peace Corps Volunteers (RPCVs) in total. Ten individuals were interviewed about their Peace Corps experience, and I was the eleventh participant. Serving as a Peace Corps volunteer, I conducted an autoethnography for two-plus years and used this as one form of data in my study. Age of participants ranged from twenty-five to forty-five years old at the time of being interviewed. Seven 
were Caucasian, two were multi-racial, one participant was African American, and one identified as Latina. Of the participants, eight were female and three were male. Four individuals identified as gay, four identified as queer, two identified as bisexual, and one individual identified as pansexual. Participants originated from all over the United States. Five were originally from the Midwest, three were from the West Coast, two were from the Southwest portion of the United States, and one was from the East Coast. In regards to educational background, nine participants had their Bachelor's degree at the time this study was conducted and two had their Master's. These individuals' time as Peace Corps volunteers spanned a timeframe of five years. All volunteers served between the timeframe of 2011-2015. Although they did not all serve at the same time, some volunteers' services did overlap, and they all were volunteers in the same country of service.

\section{Country of Service}

The country of service where all eleven individuals lived and worked is located Sub-Saharan Africa. It is one of Africa's least densely populated countries with approximately two million people in a land area slightly smaller than Texas. The population includes more than twenty African ethnic groups and a small portion of the population are of Indian and European descent. The country is about $70 \%$ Christian, but other religions are represented in larger towns. This country maintained one of the world's highest economic growth rates since it gained its independence in the mid 1960s. However, the HIV/AIDS epidemic halted that growth drastically. In fact, it not only has affected economic progress but continues to impact all aspects of life for residents of this country. Nearly one in five people are estimated to be HIV-positive, making it one of the 
highest infection rates in the world. The long-term impact of the epidemic is tragic. The government estimates that the population will be $18 \%$ lower than it would have been in the absence of the disease (Peace Corps 2014a).

\section{History of Peace Corps in Country of Service}

The Peace Corps began working in this country just two months after it gained independence in the mid-1960s. When the nation gained its independence, there was a great need for a skilled labor force. Peace Corps teamed up with the country to help develop its work force. From 1966-1998, more than 1,800 Peace Corps Volunteers served in this country and contributed to nearly every sector of the country's development, including education, health, environment, urban planning, and economics. Volunteers filled significant gaps in the labor force and, in many cases, made singular contributions to the country's development. There are numerous leaders in the country who have a Peace Corps connection, whether it is as a co-worker, teacher, or friend.

Since its independence in 1966, this country progressed from being one of the world's poorest countries to one of the few developing nations to reach middle-income status. The country's per capita income grew rapidly. Life expectancy at birth increased from just forty-eight years to over sixty years. Formal sector employment grew from a mere 14,000 jobs to 120,000 . Moreover, the nation's infrastructure, including roads, power generation, schools, health facilities, and housing, increased dramatically. Due to this newly developed economic stability and growth, Peace Corps decided to withdraw from the country in 1997.

Then the HIV/AIDS epidemic broke out. In 2003, the President of this country recognized that HIV/AIDS was starting to erode the country's impressive strides in 
development and requested Peace Corps return. Peace Corps volunteers did, indeed, return and continue to serve there to this day, working on assignments related to solely to HIV/AIDS education and prevention.

\section{Peace Corps' Focus in Country of Service}

When one asks a Peace Corps volunteer what type of work they did abroad, the answer they are mostly likely to initially receive is a quizzical stare. This is due to the fact that volunteers tend to wear many hats while abroad and their job description cannot be explained easily or in a succinct manner. Peace Corps is a 24/7 job. One's role as a Peace Corps Volunteer is not limited to a 9-5 job. As cultural ambassadors, volunteers' off-hours and free time still require them to always "be on" in terms of their commitment to service. Furthermore, the type of work they do at their different institutions falls under many different categories. As HIV/AIDS affects nearly all sectors of life, it is not just a health issue that they are addressing. It is an economical, a political, and a social issue as well. Therefore, volunteers plan and implement programs and trainings to address all of these areas in various ways.

For those who do not like such an ambiguous and arbitrary answer, the following will flesh out how Peace Corps as an organization and the government of the country define Peace Corps volunteers' work. The National AIDS Coordinating Agency (NACA) of this country has Peace Corps volunteers focus on capacity-building. Volunteers work in four specific programs areas: Schools, Community-based and non-governmental organizations, clinics and health management teams, and local government and capacity building. For those assigned to schools, volunteers are considered Life Skills liaisons to the school and the community. Furthermore, volunteers facilitate the implementation of 
the life skills curriculum that was developed by the government and work with teachers and school officials to develop the life skills of students and community members. This is attempted in various ways and includes, but is not limited to, after school clubs, leadership camps for students and teachers alike, health workshops at the local clinics, the building of libraries, etc. Volunteers who are assigned to community based and nongovernmental organizations (NGOs) build organizational and staff capacity in management, programming, resource use, and fundraising. Volunteers in clinics and health management team increase awareness of HIV/AIDS and prevention, develop community support groups, work with youth, build technical capacity, and increase participation in government programs, such as safe male circumcision campaigns. Volunteers in local government capacity building (LGCB) work in District AIDS Coordinating (DAC) offices and Social and Community Development (S\&CD) offices. They build capacity in program planning, implementation, monitoring and evaluation, and the mobilization of government and community responses to HIV/AIDS (Peace Corps 2014a). The participants of this particular study represent all four program areas.

\section{Legal Status of LGBT Individuals in Country of Service}

As stated earlier, Sociologist Steven Seidman describes compulsory heterosexuality as a unique period in U.S. history, roughly from the 1950s to the 1980 s"an era characterized by a state-driven nationwide politic aggressively enforcing institutionalized normative heterosexuality" (Seidman 2009:27). In America, compulsory heterosexuality has declined, but in other parts of the world it is still very much a social reality. In fact, the social climate of the country where these volunteers served is often compared to that of America in the 1950s, especially in terms of views surrounded 
gender and homosexuality. Part of this social climate stems from the instutionalized homophobia that exists in the social, political, economic, and even religious arenas. Like America in the 1950s, this country has legal sanctions in place surrounding homosexual activity. Furthermore, views on homosexuality are not limited to the legal sphere. They spill into the social world as well, where LGBT individuals face much social stigma and ostracism. Lesbian, gay, bisexual, and transgender individuals in this country are considered second-class citizens, meaning they are not entitled to the same rights and protections as their heterosexual and cisgender counterparts.

According to the country's Penal code, if an individual, male or female, is caught participating in same-sex sexual acts, that person is guilty of an offense and is liable to imprisonment for up to seven years. Additionally, same-sex couples have no legal recognition and same-sex marriage is not allowed. To clarify though, the general belief in this country is that homosexuality is NOT an identity, but, rather, a behavior. Therefore, homosexual acts are illegal and punishable by up to seven years in prison but simply identifying as homosexual is not illegal. Someone who identifies as lesbian, gay, or bisexual may face social stigma and discrimination, but to be arrested, they must be caught in a sexual act with someone of the same sex (BONELA, LeGaBiBo, and IGLHRC 2008). Due to the aforementioned sanctions surrounding homosexuality, one can see that compulsory heterosexuality is very much prevalent and pervasive in this society.

Gender identity and sexual orientation, although related and connected, are two different aspects of a person's self. In this country, it is illegal to commit homosexual acts, but there are no laws that outlaw being transgendered or the act of transitioning. 
With that said, there are also no laws in place to protect such individuals either.

Additionally, like gay, lesbian, and bisexuals, transgendered people are at risk of encountering social stigma, prejudice, and discrimination (BONELA, LeGaBiBo, and IGLHRC 2008).

\section{DATA MANAGEMENT AND DATA ANALYSIS}

Through the method of semi-structured interviews, I was able to obtain nearly fifteen hours of audio, which I then transcribed verbatim. In addition to the interviews, hundreds of pages of autoethnogrpahic notes were taken throughout my Peace Corps service. Kvale's (1996) meaning structuring through narratives was then used to analyze this qualitative data. This particular method combines two methods of analysis: meaning condensation and narrative structuring. To put it simply, meaning condensation is the process of extracting the main messages from each interview. This is accomplished by compressing longer statements into briefer statements, with the ultimate goal of rephrasing each message into just a few words. "Meaning condensation thus involves a reduction of large interview texts into briefer, more succinct formulations" (Kvale 1996:192). In comparison, the method of narrative structuring allows the researcher to compress the interview text, but, in contrast, it also allows for expansion "by developing the potentialities of meaning in a simple interview story into more elaborate narratives" (Kvale 1996:193).

Therefore, the combination of these two methods, meaning structuring through narratives, can best be defined as the "condensation or a reconstruction of the many tales told by different subjects into a richer, more condensed and coherent story than the scattered stories of the separate interviewees." Ultimately, my aim was to use the data 
collected from the stories of ten, separate queer, RPCVs' to create a more complete narrative of queer, foreign-aid workers (Kvale 1996:199). I followed the advice of Carolyn Ellis (1999) and analyzed my data in a way that:

Produces evocative stories that create the effect of reality; celebrates concrete experience and intimate detail; examines how human experience is endowed with meaning; is concerned with moral, ethical, and political consequences; encourages compassion and empathy; helps us know how to live and cope; features multiple voices and repositions readers and 'subjects' as co participants in dialogue. (669)

I believe the analysis method of meaning structuring through narratives helped me to accomplish exactly that.

Meaning structuring through narratives was also used to analyze the autoethnographic data collected in this study. Rather than viewing my journal as a documentation of one ongoing experience, I choose to view it as a compilation of various experiences I had throughout my Peace Corps service. Therefore, there were many narratives within it to analyze. It should also be noted that while analyzing my autoethnographic data, I took multivocality into consideration. Mizzi (2010) defines multivocality as "the plural and sometimes contradictory narrative voices located within the researcher" (2). Furthermore, he explains researchers use multivocality as an autoethnographic method to " (a) illustrate that there is no single and temporally-fixed voice that a researcher possesses, (b) unfix identity in a way that exposes the fluid nature of identity as it moves through particular contexts, and (c) deconstruct competing tensions within the autoethnographer as s/he connects the personal self to the social context" (1). Utilizing multivocality as an additional method of analysis not only enhanced the reflexivity of the methodology, but it also provided invaluable insight into 
how the intersectionality of my identity affected the way in which I interpreted and made meaning of my experience as a queer, Peace Corps volunteer.

\section{ETHICAL ISSUES}

Participation in this study was completely voluntary, and participants had the choice to withdraw at any time. Participants were not offered any compensation for participating. Due to the locations of each participant, interviews were conducted via skype and over the phone. This allowed participants to complete the interview in a setting of their choosing. Participants also signed an informed consent form after being briefed on the study, their rights as interviewees, and the nature of the interview questions. These forms were sent via e-mail. Participants had to sign the form, scan it, and e-mail it back to me. In some cases where this was not plausible, verbal consent was obtained and recorded with the rest of the interview. Interviews varied in length, ranging from one hour to two hours and forty-five minutes. Interviews were taped using a digital recorder and then transcribed verbatim. Confidentiality was confirmed through written and oral communication. All participants were assigned a pseudonym in the final written report, and no names or identifying characteristics were associated with any data obtained, including the name of the country in which these individuals served. Data (the audio recordings and transcripts) were kept in a safe, locked location throughout the duration of the study. Upon completion of the study, the audio recordings and transcriptions will be destroyed. Minimal risk was anticipated for the participants in this study. An anticipated inconvenience to participants was time. It was also assumed that asking queer individuals about their Peace Corps experiences in relation to their queer identities might cause emotional distress. Therefore, before and after the interviews, interviewees were provided 
information surrounding various counseling and support options they could seek out if need be.

An ethical issue that may arise pertains to the Peace Corps' reaction to my study. The nature of my participants' responses surrounding how well the Peace Corps supported them throughout their volunteer experience varies. Some volunteers feel that they did not receive adequate support from the Peace Corps in regards to their queer identity negotiation and management. Therefore, Peace Corps might take exception to how the organization is portrayed in this study. The Peace Corps could react in one of three ways. They could take it as constructive criticism and improve their support services and systems for queer volunteers, they could completely ignore it, or they might react negatively and denounce the study. With that said, reactions to the organization varied. There were plenty of positive thoughts and feelings surrounding the Peace Corps as well, and, therefore, a negative response from Peace Corps itself may not even be an issue. 


\section{CHAPTER IV}

\section{RESULTS AND ANALYSIS}

On May 21, 2013, Peace Corps Deputy Director Carrie Hessler-Radelet announced that Peace Corps would begin accepting applications from same-sex couples who wanted to serve together abroad. "Service in the Peace Corps is a life-defining leadership experience for Americans who want to make a difference around the world. I am proud that the agency is taking this important step forward to allow same-sex domestic partners to serve" (Peace Corps 2013a). Furthermore, Peace Corps, as an agency, stated that this groundbreaking step would help to draw a more diverse pool of applicants to serve in the Peace Corps. The truth of the matter though is that gay and lesbian volunteers have been serving with the Peace Corps since its inception in 1961. Michael Learned, President of the Lesbian, Gay, Bisexual, Transgender Peace Corps Alumni group, was a volunteer in the very early days of Peace Corps (1963-1965). He states, "During these early years, Peace Corps would not select an applicant/nominee who was known to be gay or lesbian. So I was very closeted during my time in Malawi. Very much an experience of the times" (McCloud 2013:16). Back in those days, a gay or lesbian individual would have to go completely back in the closet if they wished to serve in the Peace Corps. Times have changed though...to some extent. 
Today, the Peace Corps recognizes the importance of diversity in the Peace Corps and is actively working to invite people with different perspectives and backgrounds:

The Peace Corps promotes world peace and friendship. Peace, tolerance, and improving lives are core values of our organization. Supporting a diverse and inclusive environment essential to achieving the Peace Corps mission. We value diversity - the individual attributes that together help us meet our goals. This includes, but is not limited to, sexual orientation and gender identity and expression. Our success and longevity are dependent on our ability to engage and include people of all backgrounds and perspectives. (Peace Corps 2014d: para. 1)

Currently, there are 6,818 Peace Corps volunteers. $63 \%$ of these individuals are female and $37 \%$ are male. Of those volunteers $94 \%$ are single and $6 \%$ are married. Minorities make up 25\% of volunteers. The average age of a Peace Corps volunteer is currently 28 , but $7 \%$ of volunteers are over the age of 50 , with 84 being the age of the oldest volunteer to ever serve in the Peace Corps (Peace Corps 2013b). As one can see from these statistics, the Peace Corps draws in a diverse group of people from all walks of life.

As the announcement in May of 2013 claims, Peace Corps has been working further to invite people of diverse experiences and backgrounds to serve. In the future, it will be fascinating to hear the experiences of same-sex couples who serve abroad together, but what about the experiences of previous queer volunteers? This study hopes to give voice to that population.

\section{THE NARRATIVE OF A PEACE CORPS VOLUNTEER}

Through the use of autoethnographic data from my own time as a queer, Peace Corps volunteer, as well as data from the interviews of ten other queer, Returned Peace Corps volunteers, I hope to shed light on the experiences of queer volunteers who serve in communities where compulsory heterosexuality still exists. Furthermore, I hope to provide an opportunity for queer volunteers to consider their relationships to the 
dilemmas they face in the field and to suggest further implications their sexuality and other facets of their identity may have on their service work. Finally, these narratives also perform a crucial function for future generations of queer volunteers by making clear the kind of self-awareness and introspection that is needed to successfully complete Peace Corps as a queer individual.

For various reasons, through various means, these ten individuals and myself became Peace Corps volunteers. Furthermore, not only did we all become Peace Corps volunteers, but we all served in the same country of service. Some of our services overlapped with one another's. Others did not. None of our experiences were exactly the same, but there were definite commonalities. Here is a window into our experiences:

\section{A Seed is Planted...}

The story of a queer, Peace Corps volunteer starts well before they step foot in their country of service. My journey to becoming a Peace Corps volunteer started in high school after attending an informational meeting about the organization. As someone who was interested in both community development and learning about other cultures, it seemed like the perfect fit for me. For others, the seed is planted at a much younger age though. Pam, a twenty-five year old, queer, white woman, who I interviewed was just eight years old when she decided that she wanted to volunteer:

I had a babysitter/nanny who had left and did Peace Corps in Namibia when I was like eight, so that was my first experience with it. And then, after that, it was kind of just like this really romantic concept to me. I was like, 'I'm going to help people, I'm going to go travel, and I'm going to be one of those people who just know things.'

For others, Peace Corps sounds like a good option during a transition period in their life. A few of my participants decided it was the right move to make after their current job had 
ended or after graduating from college. Mark, a twenty-five year old, gay, white male, who did Peace Corps right after college, explained:

I wanted basically to get out and about and actually do something before going straight into graduate school. I wanted a few years off, but I also wondered that if I went into the work world, I might not go back. I needed something with a deadline. I got to travel, got to do some work, and had a deadline to where I could get back into school.

Others join Peace Corps because as the agency states, "It's hardest job you'll ever love" (Peace Corps 1997). These individuals are looking for a challenge in their life, as well as some direction. Joanne, a thirty-one year old, gay, Latina woman, recalled, "In the first place, I think I was looking for a challenge. And where I was at that point in my life was NOT the person I wanted to be in the future, so I decided to do Peace Corps before my life went to crap." Maureen, a thirty-three year old, bisexual, African American woman added, "I was joining for something more... I joined Peace Corps in kind of an effort to find myself. Also, as a self-experiment on how well I adapt."

Previous volunteer work is also a factor that draws individuals to Peace Corps. After volunteering in South Africa for a short term, Collins, a twenty-seven year old, gay, multi-racial male had the desire to do more. He explained, "That experience pushed me toward something more long term or permanent where I could see I could have an impact, and you know, like grow with whatever projects I was doing and what not." Sue, a twenty-seven year old, white lesbian further elaborated, "I had always been interested in doing volunteer service work. I had always done just kinda more short term kind of things, and just kinda wanted to do something bigger." For many individuals, Peace Corps seems to be the ultimate service project. In reality, it is so much more. It is the 
ultimate service project, but it is also the ultimate journey towards more awareness of the world and one's self.

Applying for Service

In 2014, Peace Corps came out with a new, shorter application process. Prior to this revamp, "Peace Corps alumni described waiting on average more than a year before being accepted. Some had come to calling the anxiety they felt 'restless applicant syndrome.' Under new guidelines, these steps could be completed in six months" (Shapiro 2014: para. 5). Additionally, new applicants can now choose the program areas and countries in which they would like to serve.

Unfortunately for the participants of this study, who all served at different times between 2011-2015, they just missed this new application process. When they applied to Peace Corps, the average application process took approximately nine to twelve months and applicants did not have the option of choosing their program area or their country of service. At that time, applicants simply went wherever Peace Corps chose to send them, or they did not go at all. This application process was not for the faint of heart. It involved an online application/soft skills questionnaire, interview, and grueling medical clearance portion. For some, it took years to complete this process and get invited to serve.

For me, I applied shortly after I graduated college in December of 2010 and began my service in the Fall of 2012. I opted to take the Mater's International route, which allows individuals to combine graduate school with Peace Corps. There are over ninety institutions of higher education that are participants of The Peace Corps Mater's International Program (Peace Corps 2015a). Therefore, I completed courses prior to my 
time abroad and Peace Corps actually served as my professional practicum. It was not until the Spring of that year in graduate school that I received my invitation to serve, giving me just a few months to prepare for my departure. I considered myself lucky to have my classes to distract me from the long-winded and strenuous application process.

Others are not so lucky. They often feel like they are putting their lives on hold, waiting for an invitation that may never come. The new application process addresses this downfall of the old system as well. In the new application process, there are clearly identified "Apply By and Know By" deadlines. These deadlines give applicants an idea of when they should expect an invitation to serve. "If they apply on time, they'll know if they were selected on time- - just like applying to college or a job. These deadlines give applicants more certainty than ever and help them plan for the future" (Peace Corps 2014b: para. 6).

\section{To Come Out or to Not Come Out?}

One challenge queer volunteers face during the application process is whether or not they will come out to Peace Corps representatives during their application process. Many gay, foreign-aid workers face this dilemma, whether they are applying to Peace Corps or a different organization. Raquel Moreno (2015), a gay male, had the following to say in an article about gay aid workers working abroad:

Many LGBTQI NGO workers choose to remain invisible for fear of being discriminated against or hindering their employment prospects. Coming out during an interview (e.g. if applying for accompanied status, where you would like your partner to come with you) triggers too many questions about homosexuality in the country where you are planning to go and how you would cope with that. These questions often reveal hidden fears, misconceptions as well as a lack of research and understanding from the NGO side. (para. 7) 
Luckily, Peace Corps encourages applicants to feel comfortable coming out in the application process, but they do not force anyone to reveal their sexual orientation. In an interview back in 1999, Dan Barutta, an RPCV and Peace Corps Placement Officer, explained:

It's a safety issue. The worst thing that we could do is place someone overseas who wants to wave the rainbow flag down the streets of Manila and gets beaten up. So, it's our job to educate people. We really encourage Gay and Lesbian people to apply, and we love talking to them if they'll come out to us during the application process. But they've got to know that serving as a volunteer can seem sometimes as semi-in, semi-out of the closet. (Wright 1999: para. 2)

I decided early on in my application process that I would come out to Peace Corps. In my initial interview with Peace Corps, I told my recruiter that I was gay. In my mind, I not only felt like it would be best to not try and hide it, but I also naively hoped that by being honest, Peace Corps might work with me to place me somewhere where I could do work with an LGBT population.

Others mentioned their sexual orientation in their interview for other reasons. For example, some were concerned for their physical safety. Collins explained, "I did talk to my recruiter about it... and I think I noted it in my application. Just to say, like, don't send me to a place where, you know, I'm going to be in physical violence (Laughter) or, you know, at risk of violence because of it, if it so happens to come out." Some individuals bring it up more out of curiosity of learning more information about serving as an LGBT Peace Corps volunteer. Roger, a forty-five year old, gay, white male brought it up in his interview hoping to find some answers as to what life might be like for him as a gay volunteer. He explained that the recruiter told him that "It's really going to depend on the country that you are assigned to." Other volunteers come out during their interview to learn if Peace Corps, as an agency is supportive of LGBT volunteers. Pam explained, "I 
was fine identifying as bisexual in front of them cause I was kind of like, 'If that's going to be a problem, then I'd rather find out now."' As one can see, there are various reasons a queer applicant might disclose their sexual orientation during the application process.

Although some queer individuals who are applying to Peace Corps come out to Peace Corps representatives, not everyone chooses to disclose their sexual orientation during the application process. They choose to keep their sexual orientation to themselves for various reasons. Some choose to conceal it out of fear of stigma or pushback. Maureen explained:

I purposely did not mention (my sexual orientation) cause I was like, you know, I have so many other things, you know? Like, I have so many other things that will stand me out from the crowd or maybe even ostracize me. I didn't think that was something that needed to be brought up.

Other individuals are just not comfortable discussing their sexuality with others, especially strangers. Joanne elaborated on choosing not to disclose her sexual orientation:

I don't (disclose my sexual orientation). When I do that, I just don't. I don't know. Maybe I'm like insecure about it, and I feel weird about those things still, even though I'm like super gay. Like, cause I was just, like growing up religiously and those things are just, they're sometimes weird to me. You know. It's just the way I am...more private.

As previous research has shown, Joanne's and Maureen's feelings of discretion was very much warranted. Disclosing one's sexual orientation is one of the toughest issues that queer individuals face in the workplace. Coming out in an interview "involves considerable emotional turmoil and a fear of retaliation and rejection" (Griffith and Hebl 2002:1191).

Furthermore, the process of coming out can have drastic implications for the social and economic status of queer workers (Willis 2011:959). As Lewin and Leap (1996) explain: 
Although debates about the advisability of being open about homosexuality tend to focus on the sexual forces such revelations might unleash, the actual effect on lesbian and gay lives has to do most with questions of opportunity, personal emotional support, and the ability to undertake whatever activities - in this case professional ones - the individual wishes to pursue. (3)

Overall, it is up to the individual whether or not they disclose such information. Peace Corps does not force one to do so. There is no box an applicant must check as to whether they are gay or straight. As mentioned before though, Peace Corps does welcome this information, as it helps the organization in the process of placing volunteers and educating them about safety concerns.

For those individuals who do come out in the application process, Peace Corps discusses with them the possible reality of going back into the closet for two years. In the Spring 2013 issue of WorldView magazine, a publication put out by the National Peace Corps Association, a Paraguay RPCV touches upon such a discussion:

While applying to Peace Corps, I received a call from the Paraguay country desk in Washington, D.C. with some follow up questions regarding my interview and application. Near the end of the call, as we were wrapping up, the women on the line asked me, 'You are comfortable staying in the closet for two years, right? The country you are being invited to isn't that open to homosexuality. You'll have to keep it a secret.' (Colon and Martin 2013:18)

He explained the awkwardness of the conversation and his hesitancy to respond. Finally, he mustered up enough courage to say, "Well, I suppose. But I'm pretty gay. Like even if I didn't tell anyone, it wouldn't be too hard to guess." (18). The placement officer assured him that non-spoken cues are culturally specific and the place where he was going was not exposed to gay culture, so the cues would not be picked up on.

Other queer volunteers recall similar conversations with their placement officers. Sue recalled that when her recruiter asked her if she would be okay going back into the closet for two years, that she simply replied, "Yeah, I mean, I'm not joining Peace Corps 
to be like... be gay (Laughter)." I still remember the day my placement officer called to talk about my possible assignment. I was studying in my University's library when my phone started to vibrate. I knew Peace Corps was going to call that day, so I excitedly grabbed my phone and ran as fast as I could to the basement of the library where I could talk in private. My placement officer enthusiastically told me that he had found the perfect placement for me. I naively thought he had found an LGBT organization for me to work with as I had requested to be placed at one if at all possible. Instead, he told me that he had found an assignment in Sub-Saharan Africa where I would be able to work in both the health and education field. He then proceeded to say, "Homosexuality is illegal there though. Is that a deal breaker? It wouldn't be safe for you to be out." At the time, I was thrilled that Peace Corps had found a placement for me in my geographical region of

choice. After all, I had not joined the Peace Corps in hopes of finding someone to date, so I assured him that it definitely would not be a problem for me. With that said, I do remember hanging up the phone and sitting with my thoughts for a while. I remember thinking, "What have I just gotten myself into? What is it going to be like to go back into the closet for two-plus years?"

Being Invited to Serve and Researching the Social Climate

Regardless of whether or not queer individuals decided to come out during the application process, they were all eager to be placed. After volunteers are placed, they could begin researching the social climate surrounding homosexuality in their country of service. When I received my invitation to serve, it came with a twenty-four page booklet on my assignment and country of service. I flipped through the pages looking for 
anything on homosexuality. Under a section labeled, "Diversity Issues," I found the following:

Gay and lesbian Volunteers must know that (this country) is a very conservative society and that homosexual acts are a crime for men and women. Expatriates and (locals) have been prosecuted under this law. Homosexuality is not likely tolerated with the general public and many (locals) are in denial that homosexuality exists in their culture. Thus, any display of homosexuality will be severely frowned upon and it is important to the Volunteer's success to exercise discretion. It should be noted that the denial of one's sexuality has proven frustrating for gay volunteers. (Peace Corps 2012c:19)

I immediately wanted to know more, so I took to the Internet. It quickly became apparent that homosexuality was not only a taboo subject in my soon-to-be country of service but, as the welcome packet had stated, also illegal. I found that acts of homosexuality were punishable with up to seven years in prison. With this new-found information, I began to become a little nervous. Again I wondered, "What was I getting myself into?"

Luckily, I stumbled upon the Lesbian, Gay, Bisexual, Transgender Peace Corps Alumni website, which actually had stories from LGBT volunteers who were currently or had previously served in the country of service where I had been assigned. Although there were only three narratives at the time, the information found in these stories proved to be both invaluable and insightful, as they spoke of an underground movement and community that existed in the country in which I would be living. I would not have been able to find this information anywhere else, unless I had actually been in the country talking to someone face-to-face. This new information also attested to the fact that there were, in fact, differing opinions and attitudes surrounding homosexuality among the locals living there, which the booklet from Peace Corps had not mentioned. Much like other countries, it appeared that there was somewhat of a community and movement occurring in the bigger cities, especially the capital, whereas homosexuality continued to 
be frowned up and stigmatized in the rural areas of the country. In those months leading to my departure, my mind was racing. I wondered, "Where would I be placed? Would I be in a bigger city or a rural village? Would I have the opportunity to come out to anyone? Was I really going to be able to go back into the closet for over two years?" I was not the only one individual with these concerns. Mimi, a twenty-six year old, multi-racial, queer woman, who had actually come out to her friends a few weeks before departing for Peace Corps explained, "I was like actually terrified. I googled some things, but I was just like, I'm overwhelmed. I'm just going to go and see what happens...I'm just like I can't deal with this right now.” April, a twenty-five year old, white, bisexual woman, explained that she did not seek out any resources prior to leaving the U.S. because she was too nervous. She was very concerned about what lay ahead for her:

Before coming to Peace Corps, I worried about two things: First, that I would be the only queer volunteer serving in country, and second that I would not have any local support as a bisexual woman. At the time of my departure from the U.S., I was just starting to come out of the closet. Most of my family did not know about my sexuality, and several of my close friends were still in the dark. I wanted to come to a better understanding of my sexual orientation since I felt like I had started on that journey during my pre-departure months, but I was very scared that no one would be able to relate to me. I thought I was going to be all alone.

These concerns prevented her from doing much investigation prior to departure, as she was scared that what she found might deter her from going abroad.

As noted before, people who join Peace Corps come from all walks of life. They represent many different groups of people, and they also are all at very different places in their lives both professionally and personally. Some of the participants of this study had come out years prior to even applying to Peace Corps and had been living as out-andproud individuals. Others came out just mere weeks and even days before leaving for 
their service, resulting in a very unique and interesting coming out process. Furthermore, some individuals did not realize their queer identity until they were actually already abroad and serving in the Peace Corps. These varying life trajectories are important to keep in mind while considering the experiences of all these queer, volunteers. Desire to Serve Outweighs Concerns of Going Back into the Closet

Although we all had concerns going into Peace Corps as queer volunteers, the concerns or fears did not deter us from embarking on such an adventure. Collins explained, "I gave it (sexual orientation) thought, but it was something that wasn't going to prohibit me from going ...I guess I just sort of assumed that I wouldn't really be able to be out while I was in the Peace Corps. Um, which was a sacrifice I was willing to make." In regards to having to having to go back in the closet, Mark explained, "I wasn't thrilled about it. I can say that much. But it was a sacrifice that I was willing to make." Overall, the desire to serve as a Peace Corps volunteers far outweighed the fears and concerns of living abroad as a queer individual.

Some queer volunteers go into Peace Corps with a plan to manage their queer identities. As mentioned earlier, many volunteers figured they would have to stay in the closet. They did not plan on coming out while volunteering. This is not unique to queer, Peace Corps workers. Many gay aid workers face this decision. Each individual who enters the field must decide what level of discretion they will use when it comes to their personal life. In a recent article, “One step forward, two steps back? The gaps between LGBTI policy and practice in foreign aid," Chloe Schwenke, vice president of global programs for Freedom House and former Obama administration appointee as USAID's senior advisor for LGBTI global policy stated, "We have to trust them to be careful 
themselves. If they're closeted or being really discreet, it has to be their responsibility"

(Rogers 2014: para. 20).

I, myself, believed I would have to be completely in the closet, not disclosing my identity to locals or even other volunteers, but other queer volunteers decided they would just play it by ear. Maureen explained that her plan was to basically just wing it:

I was just kind of like, you know, why spoil the mystery? I'm just going to jump into it. Whatever happens, happens. I just went for it. I didn't talk to any queer volunteers. I did wonder, like, um, if there were any queer volunteers, but I think when I was preparing to go to Peace Corps, I was very self-aware that, or was under the impression that there would be no one like me. Like, I also thought there was going to be no black people, so I was like okay! (Laughter). Like I'm going to be that ONE. Like yeah, we have that black, lesbian girl...The token everything. So I was just kind of like preparing myself for, um, just being outgoing, trying to be myself, and hoping that would be perceived well. But as far as like my gender, my identity, you know, it was like in the same bucket as my race. I was like, ah. (Laughter)

Regardless of a Peace Corps volunteer's plan prior to departure, whether it is in terms of managing their queer identity or in regards to their professional work goals, much changes once that volunteer arrives in-country. Expectations are thrown out the window, and volunteers make new plans for how they will navigate both their personal and professional spheres of life.

Preparing for Departure: Saying Good-Bye to the Familiar

It needs to be noted that although queer volunteers are concerned about the impact of their sexual orientation prior to leaving for service, for some, it is the least of their worries. When an individual is invited to serve in the Peace Corps, he or she is sent a lengthy checklist to complete prior to their departure. This checklist can be overwhelming to say the least. In addition to completing this daunting list, future volunteers must also figure out how they will say goodbye to everything that is familiar 
to them, including their loved ones. This leaves volunteers feeling stressed and emotional prior to departure. Alexi, a twenty-five year old, white, pansexual woman was concerned most about missing her family and friends. She explained, "I felt like I'd get left behind."

For Roger, he was more concerned about leaving big city life behind than anything else:

Having lived in really BIG cities since I left college, the ideas of going to a country with two million people, where every city I had lived in since college is bigger than the country, that was more of an adjustment, and I'm sure, I, you know, had some concerns about the gay part, but they were part of the larger concerns which was like how am I going to make this work?

When I spoke to Mark, he expressed that in hindsight he had been concerned about the wrong things:

I was more concerned with like what I should pack, what the work environment was like, when really what I needed to know more about just like what do you do in your down time, what's the general day to day look like. I wish I would have asked more of just like the general day to day, instead of my preconceived expectations of the day to day.

Pam also spoke to the fact that sexual orientation is not always the biggest concern prior to departure:

There were so many other things I was stressed out about, that, you know, the issues when it came to my service and my identity happened really more in country. They weren't concerns that I necessarily had going into country, especially because it wasn't an LGBT organization. I think if I were doing human rights work in Ethiopia and purposely, you know, going into gain human rights for LGBT folks, it would be a much higher concern.

As one can see, some volunteers were concerned more about other factors than the impact their sexual orientation might have had during their service.

One major concern that participants expressed in regards to sexual orientation was their physical safety and rightfully so. A 2014 report by the CSIS Global Healthy Policy Center stated: 
Homophobia is widespread and ingrained in African society, providing an opportunity for governments to use prejudice in order to mobilize popular support. Even in South Africa, whose constitution outlaws discrimination on grounds of sexual orientation and guarantees the right to same-sex marriage, deep-seated homophobia has led to appalling violence against members of the LGBT community. Lesbians have been particularly vulnerable to attack, targets of so-called corrective rape. The police have often treated the victims of these assaults with indifference. Africa is also a deeply religious continent in which the fastest-growing denominations, both in Christianity and Islam, take an uncompromising stance on homosexuality. In Nigeria, a country of high sectarian tensions, opposition to homosexuality is one of the only issues that bridge the religious divide. It is an uncomfortable fact that the antigay laws passed by Nigeria and Uganda have been popular with the public. (Downie 2014:4)

Although this particular report came after many of the participants of this study served in Peace Corps, the harsh reality of intense homophobia on the continent was widespread, well-known, and well-documented before their departure. Alexi explained that prior to leaving for service, "I was kinda worried that I would die...or get raped.” She wasn't the only one with this concern. Joanne also expressed fear about the possibility of corrective rape and rape in general. Additionally, she said, "And just thinking like in the old times, like we were just going to get hanged up there or something if we get caught." Sue added:

I was a little nervous about like maintaining my safety. Cause I wasn't sure like, could I get stoned? I don't' know. (Laughter). Like what happens if I'm found out and how concrete of evidence do they have to have? Can it just be like I heard a rumor from this person...I didn't know if someone could just like start a rumor and if that would get me in trouble, but I think just that unknown made me a little nervous.

Overall, it was that unknown that Sue attested to that made us all a little apprehensive, not just in regards to our sexual orientation, but to all aspects of our service. What exactly awaited us in that country so far from where we called home?

And so it Begins: The Staging Process

Prior to departing for their country of service, volunteers must go through a short, two-day process called staging where Peace Corps prepares volunteers for what lays 
ahead for them. My staging took place in Philadelphia. Before I left for staging, I was very nervous. I still did not have a plan as to how I would deal with my sexuality in the Peace Corps. I had only decided that I would only come out if I deemed it safe to do so. There were a couple times during staging that I wanted to say something about being gay or ask questions about obstacles queer volunteers may face. However, not knowing the people in my training cohort for even twelve hours yet, I was hesitant to say anything. I remember thinking how these people may be my only form of support for the next two years, so I did not want to burn any bridges that early in the game. I waited eagerly through the entire staging to see if anything would be mentioned about LGBT volunteers. The woman who facilitated our staging, talked in depth about how race, gender, ethnicity, and religion affect Peace Corps Volunteers' experiences, but she did not go into depth at all about LGBT volunteers. In fact, I did not think she was going to even mention it. Then at the end of her presentation on diversity in the Peace Corps, she said something to the effect, "So as you can see African American volunteers, female volunteers, and even gay volunteers can face very unique obstacles while in the Peace Corps." The mere fact that she even mentioned the word gay gave me confidence to approach her after the staging had finished that afternoon. I did not want to ask her anything too elaborate while everyone was still nearby. Basically, I asked for her advice surrounding queer volunteers in the Peace Corps. She said she could not speak from personal experience, only from things she had heard from other volunteers. She explained that Peace Corps never wants queer volunteers to have to hide themselves, but for safety reasons, she suggested I should not come out to the people in my village. Instead, she said I should seek support 
among my fellow Peace Corps Volunteers and staff. She assured me I would find a support network amongst other volunteers in my cohort.

After staging that afternoon, a group of us volunteers had dinner together in the hotel. It was the first time we all had the opportunity to sit down and get to know each other. People were talking about where they hailed from and what they had done prior to Peace Corps. Naturally, the conversation evolved into a discussion about relationships. It was in that moment that I realized our facilitator was probably right in regards to finding support among my fellow volunteers. One girl, after talking about her boyfriend, had asked, "Who else has a boyfriend? Or a girlfriend cause that would absolutely be cool too." At that moment, I was really tempted to say something like, "No, but I used to have a girlfriend." Rarely, does someone give you such an easy way to come out, but the moment passed and I did not say anything. At the time, I regretted not speaking up, but the mere fact that she had made that comment put my mind at ease.

Other volunteers had positive experiences as well at staging in regards to their queer identity. In fact, the first experience Pam had with members of her cohort group, in regards to her queer identity, was at staging. She explained:

I'm sitting across from Mindy and we were kind of all taking about ourselves, you know, kind of like the talk you do with the people you know you're going to get close to but aren't close to yet, and I mentioned my ex girlfriend, and she kinda, she kinda paused, and we kept talking and kept eating. Then she kind of came back to it. She was like...' You know, how do you feel about being out to the training group?' You know, and I had not in mentioning an ex girlfriend, in my mind, been like, 'Oh, I'm outing myself!' Like, it was just kinda like, you know whatever, and so that was the first time I was like, Oh, well, I hadn't thought anything about it up until you just asked me right now. Oops (Laughter).' Um, so yeah, I identified myself as queer pretty quickly, and didn't really catch any flack for that. 
Pam felt supported from the very beginning. Other volunteers were even lucky enough to connect with another queer volunteer at staging. Roger recalled:

It was interesting 'cause Collins was my roommate during staging...We started talking and we both realized pretty quickly that we both were gay. Um, and we talked a little bit about it then, but I don't think either one of us had any idea of what it was really going to be like.

Roger discussed that even though they did not know what to expect in-country, it was still nice to have somebody to talk to about their concerns prior to leaving for service. Mark had the same sentiment. The night of staging, he was able to connect with a fellow queer volunteer as well. He said, "We talked about it the very first night. We just kind of clicked right away." They would continue to be a close support system to each other for their entire service. As one can see, staging helps volunteers to begin to form friendships and support groups that they utilized throughout the duration of their service.

Good-Bye Amercia: Hello to the Toughest Job You'll Ever Love...and/or Hate

After staging ends and after a sixteen-hour flight to their country of service in Sub-Saharan Africa, volunteers finally found themselves in the place that they would call home for the next two-plus years. Regardless of their country of service, all Peace Corps volunteers must go through pre-service training (PST) prior to being sent to their work sites. My PST was approximately 2.5 months long. This training focuses on developing language and cultural skills that will help volunteers in their communities and provide them with the knowledge and practice to successfully complete their primary assignment. Overall, PST is designed to produce volunteers who can operate sensitively and skillfully in their country of service. During this training, each volunteers stays with a separate host family. The host family experience provides a unique context for cross-cultural learning and is designed to ease volunteers' transition to life at site. Host families go through an 
orientation conducted by Peace Corps staff to explain the purpose of PST and to assist them in helping volunteers adapt to living in-country. Many Volunteers form strong and lasting friendships with their host families. It is also with these host families that volunteers can gain insight and understanding into topics that might not be broached or thoroughly discussed in a classroom setting at PST, including homosexuality.

In fact, my first conversation with a local about homosexuality was with my twenty-one year old host sister. This occurred about a month into my training. I was playing cards with her and her younger sister. The younger sister left for the room for a moment, so I was talking to the older sister about how I ran into a friend of hers earlier that day. Her friend was a moral education teacher and a soccer coach in town. I told her how he kept asking me to come play soccer with him and some friends. Just trying to make small talk, I asked her if she liked soccer. With a disgusted look on her face, she said, "No!" I laughed and asked why she had reacted in that manner. She replied, "Only silly girls play soccer." I laughed again. Not following, I asked, "What do you mean by silly girls?" She answered, "Lesbians." I wish I could have seen my face at the exact moment. I was in shock. I could not believe that she had even uttered that word. Before arriving in-country, everything I read said that the locals do not talk about homosexuality, and if they do, it is always in reference to men, not women. The mere fact that my host sister had used the word "lesbians" caught me completely off guard. She continued to say, "It's a big problem, especially in boarding schools. Girls trying to be like guys and doing guy things. It's not good." At this point, the younger sister had returned, and even though I wanted to ask more questions, she gave me a look and pointed at the cards, 
letting me know the conversation was over. I picked my jaw up from off the floor and continued playing cards.

The next day I was talking to a fellow volunteer about the conversation, and she explained to me that this stereotype of only lesbians playing sports is actually a huge problem in most of Southern Africa. She went on to explain how the stereotype prevents girls from playing any sports as they are scared of being mistaken as lesbians and being ostracized and discriminating against because of it. Jere Longman (2011), a journalist who examined the effect homophobia has on women playing soccer in Africa, wrote of this problem:

On a continent where homosexual behavior is widely considered immoral, lesbians (or girls perceived to be gay) are sometimes ostracized and subjected to beatings. In countries like South Africa and Zimbabwe, some women are raped in so-called corrective treatment for homosexual behavior. In one high-profile case in South Africa, a top female soccer player and lesbian activist, Eudy Simelane, 31, was murdered in 2008. (para. 9)

This is a prime example of how compulsory heterosexualty is enforced and perpetuated in different societies and how gender plays a role in the heterosexual assumption. As found in previous literature, Butler (1990) explains that certain actions and behaviors are assigned to specific genders and if you stray from these norms you are considered deviant and a "problem." Young girls in Southern Africa are not playing soccer because of fear of being mistaken as too masculine or as lesbians. This illusion of natural gender identities hides the role gender plays in the regulation and perpetuation of heterosexual dominance. Preventing girls from playing sports is just one example of how the gender binary can be used to ensure that heteronormativity prevails. 


\section{Learning How Intersectionality of Identity Impacts Service}

As one can see, it is during Pre-service Training that volunteers first gain insight into cultural attitudes surrounding homosexuality, whether it be during training or at home with their host families. With that said, when volunteers do receive insight surrounding LGBT issues at training, it is important to note that it does not typically come from pre-scheduled Peace Corps' training sessions. A lack of training surrounding LGBT issues is not uncommon among foreign-aid organizations that serve in environments that are less than accepting of homosexual behavior. Shaun Kirven, who is currently working in the Philippine province of Mindanao and has more than fifteen years of experience in human rights, conflict and post-conflict reconstruction around the world, explains:

A large gap still often exists between an organization's policies which are set at headquarters and their implementation around the world. The difficulty in creating an LGBTI-friendly work environment lies in that so much development work takes place in LGBTI-unfriendly environments. (Rogers 14: para. 33)

Therefore, in the case of Peace Corps volunteers, they usually cannot rely on Peace Corps itself for insight into issues surrounding homosexuality. Instead, trainees rely on current Peace Corps volunteers for information. These volunteers often come to training to help out with other sessions and are able to incorporate the homosexuality into their topics or bring it up during down time with trainees.

A strong bond is formed amongst volunteers quite quickly when they arrive incountry and start PST. A mutual respect and understanding develops and volunteers are aware that although they are all placed at different sites after training, none of them are in the experience of Peace Corps alone. The support volunteers give to one another occurs in both less formal and more formal ways. One of the more structured and more formal 
ways this support occurs is through various Peace Corps committees that are made up of current volunteers. One committee, in particular, called The Peer Support and Diversity Network (PSDN), provides much support surrounding diversity issues, and, therefore, is very helpful to queer volunteers throughout their service. This particular committee works to educate volunteers, as well as raise awareness, surrounding the impact that Peace Corps Volunteers' identities will have on their service. Furthermore, the committee also serves as a resource to fellow volunteers in regards to their emotional health and well-being. Alexi explained, “They're like volunteers who are there to talk to you if there are problems or if you are dealing with different feelings or just in a shitty place.” In fact, the first queer volunteer I met was on this PSDN committee. She came to our PST early on to sit in on our training sessions and answer any questions we might have. I had approached her after a session to inquire if she knew of any LGBT individuals currently serving and it turned out that she identified in that manner. She also informed me that there were others that would also be coming to our training, so I would have the chance to talk to them as well. In my journal I had this to say about the conversation and the realization of other LGBT volunteers already in country:

It's nice knowing that there are other LGBT volunteers in country right now!! They can not only offer me advice, but they know what I will be going through, so it will be really easy to find someone to talk to who understands/is going through the same situation as me. She also informed me that homosexual acts are illegal but being homosexual itself is not because they don't see homosexuality as an identity but rather as a behavior... Like others I have talked to, she recommended not coming out to my village, but she thought that fellow Peace Corps Volunteers and staff would be supportive.

As one can see, it is PSDN that provided the most insight in to what life at site might be like for LGBT volunteers. Mark explained the impact a PSDN session had on him: 
They did this like round table panel thing with all the volunteers, there they talked, they had like people who were representing married couples, older, younger, female, male, gay, bi, different races, just trying to get the whole perspective of different diversities and what it kind can be like to deal with in (country). I mean, based on the size of the panel, they couldn't handle every thing, but they hit what they could.

These representations gave volunteers insight into what their life might be like at site. It was especially helpful because it was not just focusing on how one mere facet of one's identity could impact your life. It looked at the intersectionality of your identity and how different facets could overlap and have a compounded effect as well.

Although I was not in Mark's cohort, PSDN facilitated a similar session for my training group. PSDN presented to us a panel of various volunteers who talked about their experience in Peace Corps in relation to their diverse identities. Therefore, people talked about how their race, sex, age, and sexual orientation affected their Peace Corps service. It was actually very interesting as it provided a window into how different identities interplay and impact the volunteering experience. The panel shed light on the fact that a single facet of one's identity does not occur in vacuum. Identities cannot be separated and experienced individually. A volunteer's reality is shaped by the compilation and interaction of each, and every single facet. As Hames-Garcia (2011) explains in his book, Identity Complex:

Social identities do not simply intersect now and then. They blend, constantly and differently, like the colors of a photograph. From within this multiplicity, over the course of a history of experiences colored by social interaction, emerge personal identities, or concrete, fleshy selves. No one in U.S. society (or anywhere in the modern world, for that matter) ever exists without class, ethnicity, gender, sexuality, and so forth...As a result, one's ethnicity or race is always shaped by class, by gender, by sexuality, and so on, and these other identities are shaped by one another as well. Social identities, within the context of the self, expand one another and mutually constitute each other's meanings. In other words, the subjective experience of any social identity always depends fundamentally on relations to other social identities. (6) 
This notion resonates with all volunteers, regardless of their identity make-up, as they are forced to experience their notion of "self" in a new cultural context.

Due to the nature of my study, I, of course, was most interested in what people had to say about serving as a queer individual, but discussions on race, age, and sex were insightful as well because, unlike sexual orientation, these identity markers could not be hidden or changed. All of these facets of one's identity are non-negotiable. Therefore, volunteers are left with little to no choice but to roll with the punches in terms of what is thrown their way because of their age, sex, or race. Therefore, the panel provided much insight into what identity management strategies volunteers utilize when identity negotiation is not an option.

It should be that noted that the LGBT population was represented on the PSDN panel. To be more specific, there was a gay male volunteer, as well as a bisexual female volunteer. I received much insight and advice from listening to both volunteers' experiences. Both queer volunteers represented on the panel agreed that they would never come out to anyone in their respective community. The girl said she might come out right before she ended her service, but until then, she did not want to jeopardize her safety or reputation while still working in the field. She did, however, mention that she had previously dated a fellow female Peace Corps volunteer for a while, so she was obviously out to some Peace Corps volunteers. At the time, I remember this really fascinated me. I wondered how queer volunteers could possibly date while in Peace Corps, not only in terms of how they managed to have a relationship in a culture where homosexuality is forbidden but also while living in two very separate communities. 
During the panel, an African American woman also spoke. During her presentation, she focused on her struggles as a black Peace Corps volunteer. She explained how most locals in-country do not respect black Americans as much as white Americans. Additionally, most have a hard time believing that black volunteers are actually Americans, as they believe all Americans are Caucasian. This can be very difficult for African American volunteers. As the woman explained, prior to her service, she believed that she would feel more at home in Africa because of her ancestral ties and be more accepted than she had felt back in America. However, she found the opposite to be true. This made her question her identity as an African American and soon began to identify as Black American instead. She also touched upon how being an older female has affected her experience in the Peace Corps. Most women her age in-country are retired. They are considered to have paid their dues to society and are not expected to work. Therefore, the people this particular woman worked with did not understand why she would want to volunteer, and, furthermore, they flat out told her that they wanted a younger volunteer. Overall, her presentation spoke to the fact that it is not one single identity marker that impacts one's experience.

Next, a young, gay male spoke about the perks of being male and the obstacles he faced being a queer volunteer. He too stated that he would never come out in his community, especially because, as he explained, there appeared to be a hatred of gay males more so than gay females in-country. Although he did not openly talk to anyone in his village about it, he did not completely hide his queer identity either. He stressed that he was very open with his fellow volunteers, and he even was quite active in the queer community in (the capital city). In fact, at the time of the panel, he was dating a local 
man from the capital. I recall being extremely interested in talking to him about this. I believed he could provide much insight into what it was like to be gay in this country. After this young man shared his story, a couple more volunteers talked about the impact of being multi-racial and young women in Peace Corps. Their stories resonated very much with what the other volunteers previously touched upon. This particular panel was very eye-opening to many volunteers, including myself, as it was our first in-depth look at how our identities would impact the type of service we had while in Peace Corps. Furthermore, it shed light on how no two volunteers' experiences are the same. As Hames-Garcia (2011) explains, no two people are alike, even if they do share certain identity markers, so why would we even expect two people to have the same experience?

Personal Identity involves so many complexities and so much variability from one individual to another that it might seem that any attempt to group people together under larger categories of social identity can only amount to a kind of deceit. No person, after all, is just a man, or just white, or just middle class. We all amount to much more than any other thing. One might justly ask, therefore, if it is falsehood to imply that all men are the same, that all whites are the same, that all middleclass people are the same. Do not categories of social identity (black, white, male, female, straight, gay, disabled, able-bodied) simply cover up individual differences and falsely imply sameness among all members of each group?

The experiences of Peace Corps volunteers resonate with Hames-Garcia's claim, as no two black volunteers, no two white volunteers, no two males, no two females, no two gay volunteers have the same experience. No two people, in general, ever have the same experience. Experience cannot be generalized to any specific demographic as it minimizes individuals' differences among that specific group and the impact those differences can make on volunteers' experiences. 


\section{Coming Out to Fellow Volunteers}

After PSDN presented their panel, our training cohort participated in a couple of follow-up activities. The first of these activities entailed us writing our name in the center of a piece of paper and then around it, we wrote all the different ways in which we identified. Some of my identifiers included: Sister, daughter, advocate/activist, gender queer, gay, volunteer, friend, and life-long learner. At the beginning of the activity, I was not aware that we would be sharing our work with the people sitting next to us, with the aim of discussing how these different identities would differently affect us during our service. At this point in training, I had only come out to a few individuals in my cohort, so I most likely would not have listed all of those identifiers previously mentioned. Luckily, the people sitting next to me were very receptive to what I had to say. I was sitting next to a Nurse Practioner, and when I shared my web, she seemed very accepting and actually talked about how she had worked with the LGBT population back home, specifically transgendered individuals infected with AIDS. We had a great discussion and I felt very supported. Furthermore, it provided much insight into how different identity markers may impact our service.

At the end of the session, PSDN had us do one more activity. We all stood in a circle and listened as the facilitator read statements to us. If the statement applied to us as an individual, we stepped into the middle of the circle. Some statements were very general and harmless in nature, while others were really personal and almost invasive. In fact, people cried at various points throughout the activity because there were some very sensitive topics that were touched upon (Death, HIV/AIDS, etc.). When the activity began, I immediately wondered if they would ask a question about belonging to the 
LGBT community, and indeed they did. My heart was racing as the facilitator read, "I belong to the GLBT community." I really did not even have time to think. I just automatically stepped forward, trying really hard not to make eye contact with anyone. Three people from the panel also stepped forward. In addition, another girl from my training cohort stepped forward as well. I had previously suspected this girl might be queer because I had noticed a Human Rights Campaign tag on her luggage at the JFK airport. I wrote these feelings about the activity afterwards:

Overall, I felt good coming out to everyone. It is a relief and it was such an easy way to do it. I really didn't have to say anything. This made it really simple. And the fact that I didn't step into the circle alone was quite a relief as well. It is nice knowing I have at last one fellow queer person in my group. In fact, I have talked to her a couple times about LGBT related things since that day. I probably never would have done that if we had not done that circle activity.

This Diversity Day that PSDN put on for us was not only insightful in many ways but it provided me with a network of support that I would utilize for my entire service. Even though only two of us stepped into the circle, others approached us that day and identified themselves as allies. They said they would have done so sooner if they had known either of us were gay.

All of the activities we completed that day were very enlightening, not only in regards to the study at hand, but for practical reasons as well. To put it simply, it opened our eyes to the many obstacles we may face in the field in regards to our identity markers. I also learned that it does not matter how one identifies; everyone's sense of self would be challenged in one way or another throughout our time in-country.

I am not the only one who was so deeply impacted by PSDN's diversity session.

As I mentioned earlier, all cohorts receive this particular training session during their PST. In fact, that session is where most queer volunteers come out to their peers. When I 
asked Maureen when she came out to fellow volunteers, she said, "Um, that game we

played. That circle game." She went on to explain:

We didn't play that circle game until waaaaay into our PST, like we had known each other for a month, six weeks or whatever, and it was interesting to see what parts of ourselves everybody put out there, and what parts were exposed during that game. Like it was still, like, 'oh wow! I didn't know that about you. I didn't know you were a veteran. I didn't know this. I didn't know that. And you know, I didn't know you were an only child?' You know? Like simple things. When we played that game, that's when I was like, well, I'm going to be honest. I didn't want to hide it. But I, you know, I didn't feel like I needed to be like, 'Hey I'm black. I'm from Oakland, and I'm gay.' (Laughter)

Although many queer volunteers came out in that setting, some chose not to step forward.

In fact, Joanne said, "I hated that circle...I mean, like a year later I would have done that, you know, but I didn't want to step forward within two weeks or one week of knowing everyone." Although she didn't step into the circle that day, that game did have an impact on Joannne:

What really surprised me was that I think we were like the majority (Laughter). We were like half, not the majority, but like it was a surprise to see other like lesbians, gay people, bi people there. You know? Whatever it is. So then I got more comfortable, and I'm all like, 'OK. There's more of you! (Laughter). Not everyone is straight.'

She eventually did come out to fellow volunteers after she became more settled and more comfortable with everyone. If nothing else, that infamous "circle game" left queer volunteers feeling supported, accepted, and, perhaps, most importantly, not alone. Leaving PST Behind and Heading to Site

After successfully completing Pre-service training, volunteers are assigned to villages where they work and live for two-plus years. It is the hope of Peace Corps that the Pre-service training provides volunteers with the necessary knowledge and skills to be successful at site. Peace Corps volunteers' sites vary from village to village. Some are 
more urban and industrialized in nature, while others are just small settlements of a few hundred residents. These smaller settlements have no running water or electricity, no grocery stores, hospitals, or police presence. Most villages simply have a primary school, health post, and a volunteer watch group — which usually consists of women - that walks around patrolling the village for crime. The more urban settings have better infrastructure: paved roads, running water, electricity, schools, hospitals, police, etc. As one can see, each Peace Corps volunteer's experience can vary drastically, based simply on where one is placed in-country.

Personally, I was placed in small, rural village in the southern region of the country. It spanned approximately three kilometers of land and was home to approximately 800 individuals. Located on the edge of a desert, it was a very sandy and arid place. As a result, there was minimal vegetation and the soil was somewhat infertile and barren. My initial needs assessment shed light on a myriad of problems within the impoverished community, including issues of food security, alcohol abuse, extremely low levels of education among community members, and a high prevalence of HIV/AIDS, as well as other health ailments. My primary assignment as a Peace Corps Volunteer was to be a School and Community Liaison for Life Skills. To put it simply, I was expected to teach community members the importance of life skills and how they could be used in the fight against the spread of HIV/AIDS.

\section{Discovering the Varying Attitudes Surrounding Homosexuality}

Participants in this study lived in communities of varying sizes, ranging from a small village of 500 people to a city of 82,000. All participants were either placed at schools, NGOs, District AIDS Coordinating offices, or worked with local government 
offices. Regardless of their placements, volunteers' work usually overlapped with all of these entities at one point or another throughout their service. Additionally, all work was related to HIV/AIDS prevention or education. Due to their different work environments, as well as living environments, volunteers experienced different attitudes and beliefs surrounding homosexuality. Pam touched upon the difference between urban and rural settings, "HUGE difference. Um, you know, in (the capital), there is a community. People have found each other. People are attempting to create safe spaces for themselves, even if it's not publicly." April spoke of the spectrum of attitudes surrounding homosexuality that can be found in-country:

There is a spectrum of attitudes toward homosexuality in (country), respective to urban/rural environments, level of education, age, and political/social views. In urban areas...you have a contingency of movers and shakers who are openminded allies; they provide that counter-balance to the virulent, religion-fueled homophobia that rages in the community. I also find that there are many people who are in the middle of the road: they don't feel comfortable with sexual minorities but they are not strongly homophobic.

Maureen reiterated:

I would say it definitely depends on where you are. You know, a lot of my friends that experienced, you know, the more negative, harsh critical social climate, you know, they are from the villages. The closer you are to (the capital), the more, I would say they are OPEN to the conversation. Or at least, they have HEARD of the conversation. I would say most of the social climate is ignorance, and they LOVE their ignorance

These findings aligned with what previous research has found in regards to how the level of urbanization of one's city affects attitudes surrounding homosexuality. To elaborate, past research shows that the size of a town in which people reside influences levels of tolerance in regards to social issues (Stephan and McMullin 1982; Herek and Capitanio 1996). Tolerance increases as town size increases. In addition, Eldridge, Mack, and Swank (2006) also found a positive relationship between level of urbanization and 
acceptance of homosexuality. Newman's study (2007) also found that the setting in which an individual is raised plays a significant role in how he or she will perceive homosexuality. Finally, in Andersen and Fetner's (2008) study, findings show that individuals from larger communities are more accepting of homosexuality than individuals from smaller communities. Therefore, where one hails from plays a major role in how they view homosexuality and treat homosexuals, and as a result, the size of the community in which a queer volunteer is placed deeply impacts their experience.

Living in a small village myself, I was surrounded by people who were less accepting and, in some cases, very homophobic. Therefore, it was not only insightful to hear the experiences of my participants who resided in more urban settings, but it also was somewhat of a relief to find out that my community's reality in regards to homosexuality was not, in fact, the reality for the entire country. For two years, my frame of reference was restricted to an 800 person village. Therefore, hearing about volunteers' experiences in larger settings prevented me from generalizing my interactions and experiences in a small village to the larger population of the country.

\section{Don't Ask, Don't Tell}

Volunteers observed an interesting phenomena surrounding homosexuality while serving abroad. They explained the locals' overall outlook and behavior towards homosexuality to be similar to the "Don't Ask, Don't Tell" policy that used to be in effect in the American military. Maureen explained it as, “Don’t ask. Don’t tell. Don't put it in my face. Like, I don't wanna see you kissing another man, like that's not okay." Pam elaborated:

I phrase it as it is a "Don't ask, Don't tell" country. Very much so. Um, you know, and most of the LGBT population that I worked with in (country) felt like 
that way as well. You know, they could bring their boyfriend home every single day for years and years and years, and it was fine, assuming they did not...sit down and talk about it.

Although this behavior towards homosexuality might seem odd to some, it has been found to occur in other cultures as well. For example, Connie Chan (1997) described a similar phenomenon in a piece on the formation of queer identity and sexual expression among Asian Americans:

A crucial distinction between traditional East Asian culture and Western culture is the concept of sexuality and sexual expression as a private matter. Any direct and open discussion of sexuality is unusual in East Asian cultures, as sexuality is considered to be a very sensitive subject. Even among one's closet friends, a discussion about sexuality is considered to be awkward and highly embarrassing at best, and at worst, strictly taboo. (244)

When it comes to looking at sexuality in a global perspective, it is important to note that there are fundamental differences in the social construction of sexuality, sexual expression, and sexual identity.

Therefore, it would be a grave assumption to believe that the local people of this country were ignorant about the homosexual behavior. People were well aware that homosexuality existed. They just did not want to witness same-sex couples together or discuss the topic of homosexuality in general. As Maureen explained, "Because (the locals) are such a non-confrontational type of people, they don't WANT a fight. They want to just be able to ignore it." Furthermore, it was described as an open secret. Mark testified to this sentiment:

So to borrow an American phrase, "Don't ask, don't tell." (Laughter). It happens. In fact, I met plenty of host nationals who were LGBT, but it's not something you talk about with your family or friends. You talked about it specifically with your group. Almost everyone knew that if you go to a certain bar in (the capital) at (the local) mall at certain nights, it was primarily LGBT folks there that night, but no one really talked about that, BUT everyone knew it, so it was just kinda like a very open secret. 
Again, this idea of an "open secret," is not unique to this specific culture. In an issue of WorldView” magazine, RPCVs Colon and Martin (2013) wrote about navigating gay identity in Paraguay. They explained how in the specific society that they served in LGBT individuals can safely live and work in Paraguay if they never broach the topic of their sexual identity with anyone else. Colon and Martin elaborated, "Open secrets allow us to retain our identity and behavior but with the understanding that we must remain silent and never demand public recognition and approval. There is an unspoken agreement; we won't say anything if you don't say anything" (20-21). Furthermore, they discussed how this "open secret" helps people to avoid confrontation that might prevent societal operations from running smoothly. Colon elaborated, "If they were to openly acknowledge the 'secret,' they would be expected to do something about it, at the very least shun me, and by doing so, potentially lose a valuable and productive member of the team" (20). Therefore, this 'open secret' is seen as a mechanism that allows the society to keep functioning without conflict.

In the country of service where the participants of this study lived, the society is extremely co-dependent in nature. Citizens rely heavily on each other for survival. Similar to the situation described in the Paraguay article, the locals cannot afford to be split and divided on issues such as homosexuality. The consequences would be too grave. Mimi shed light on how the "Open Secret' philosophy and "Don't Ask, Don't Tell” attitude of the country are used as survival mechanism:

Well, 'cause I think that's a way to kind of, not just deal with it, but I feel like a survival mechanism. You know what I mean? Like you can't ask, cause then your morals would be questioned, and then you can't then ask for a ride or ask for whatever cause then you have to face these kind of challenges, and then, you know, how are you going to deal with that? You're in this small space with all 
these people where you're going to have to rely on each other. There's no way to not interact with another person in such a small village. You can't avoid them like in a big city where it's like, oh whatever, I don't have to talk to that person, but if you see them EVERY day because there is only 500 people, then yeah, it's going to happen. You're going to have to deal with it.

Therefore, people do not bring the topic up for discussion. It is merely something that is swept under the rug. People know it is happening and that it exists in their communities and society as a whole, but they do not acknowledge it publicly. This insight explains the drastic difference in attitudes in rural versus urban settings. Those who live in places, such as the capital have the means and resources to be independent. Those who live in small villages are interconnected and rely on each other for daily survival. Therefore, social issues such as homosexuality are not addressed or discussed, as conflict must be avoided at all costs to ensure the symbiotic relationship of the community continues to operate smoothly.

It is important to note, however, that although open secrets allow certain communities to function in a peaceful and effective manner, they can be detrimental to the queer community. Colon and Martin (2013) touched upon the detrimental effects of these "open secrets" and having to serve in silence as a queer, Peace Corps Volunteer:

They contribute to the sequestering of positive imagery of gay citizens, a 'glass closet,' if you will. I am unable to counteract the pervasive, harmful rhetoric of gay men being pedophiles and sole carriers of HIV because despite being a successful working professional, I am not officially out. My sexual orientation cannot be publicly acknowledged. My passion for social justice and diversity advocacy is silenced and squelched where it should matter the most; my personal identity. Not only are we unable to serve as positive counterexamples to the pervasive and damaging stereotypes about gays, we are also unable to serve as positive role models to youth just now coming to terms with their sexuality. A culture of open secrets allows and encourages passiveness of the status quo, rather than challenging ignorant or bigoted ideology. (21) 
An “Open Secret” policy or a “Don’t Ask, Don’t Tell” policy may keep queer individuals safe from physical harm, but it definitely is detrimental to the betterment of the queer community as a whole.

\section{It's All Relative: Social Climate Surrounding Homosexuality}

It is important to note that queer volunteers expressed that their country of service seemed much more accepting than other parts of Africa. Mimi explained, "I think (our country) is kinda really chill compared to so many other places." Volunteers realized that although the social climate was less than ideal for gay and lesbian individuals, they still considered themselves lucky to be in that particular country as opposed to other places in Africa. For example, Pam explained the difference between serving as a Peace Corps volunteer in Ethiopia compared to her own country of service:

I know that Peace Corps Ethiopia is instructed upon when they land in the country that if any of them (the volunteers) identify as LGBT, they are not to speak to anyone but American staff and American volunteers. Yeah, so, Peace Corps Ethiopia, doesn't have a safe place staff, unless you're talking to an American staff.

This differed greatly from our experience as there were many local staff members working for Peace Corps who were open, accepting, and people volunteers felt comfortable talking to about such issues.

Pam went on to explain how the social climate in our country of service actually seemed better than that of other African countries where laws are on the books to protect the LGBT community:

Um, you know, it's a small country (our country of service), so, uh, you know, I don't think gay marriage is going to happen any time soon to be frank...There were very few gay people that I met (in our country of service) that would have preferred to live in South Africa. Even though they have laws protecting LGBT people, they DON'T use them. I one-hundred percent think the social climate is better (in our country of service) which I think is the difference between a country 
that is attempting to enact laws that kind of push its people forward versus a country that has enacted laws that its people did not support nor were they ready for...Um, so I absolutely think it's safer to be a gay person (here as opposed to South Africa).

Laws created to protect LGBT individuals and their rights are only effective if enforced. The fact that South Africa has laws on its books does not necessarily translate into a better life for its LGBT population. The discrimination and violence LGBT individuals face in South Africa is horrifying. Individuals are physically assaulted and sometimes even killed for being gay or lesbian. As mentioned earlier, corrective rape- - "an act of violence against women committed by men ostensibly to "cure" lesbians of their nonconforming sexual orientation—or 'correct' it"—is a terrifying reality in South Africa (Di Silvio 2011:1470). In her 2014 article, "Crisis in South Africa: The shocking practice of 'corrective rape' - aimed at 'curing' lesbians," Clare Carter touches upon the extent of this atrocious human rights violation:

Ever since a 1998-2000 report by the United Nations Office on Crime and Drugs ranked South Africa as highest for rapes per capita, it has repeatedly been described as the rape capital of the world: 500,000 rapes a year; one every 17 seconds; one in every two women will be raped in her lifetime. Twenty percent of men say the victim 'asked for it', according to a survey by the anti-violence NGO, CIET. A quarter of men in the Eastern Cape Provinces, when asked anonymously by the Medical Research Council, admitted to raping at least once - three quarters of whom said their victim was under 20, a tenth said under 10. A quarter of schoolboys in Soweto described "jackrolling" - the local term for gang rape - as 'fun.' Although statistics for corrective rape have not been compiled nationally, one support group in Cape Town told ActionAid researchers in 2009 they deal with 10 new cases every week. (para. 6)

These statistics come from a country were legal protections for LGBT individuals are on the books. In a country where little to no legal protections exist, our country's social climate was shockingly better in terms of physical safety for LGBT individuals. Roger explained what he learned from talking with queer locals, "The times that I met with 
people...I heard some of their stories. They had difficult times. No one's story I met had violence attached to it though. Most of it was sort of emotional violence, some way with family and friends shunning them if they came out." I, myself, never once feared for my physical safety in my entire two-plus years of service.

In fact, our country of service is actually known for its peaceful nature. There has never been a war, civil or otherwise. Gun violence is non-existent. The local people are very non-confrontational individuals, hence the "Don't Ask, Don't Tell" attitude of the country. Queer individuals face social stigma and ostracization when they come out, but they do not have to fear being attacked or killed for being gay. Collins confirmed, "I never encountered anyone like being outwardly, like physically or verbally homophobic. Um, but, but if it was ever brought up in conversation, it was always sort of just dismissed." With that said, it should not be assumed that violence does not exist in this country. Yes, it is true that there has never been a large scale, violent act, such as a war or genocide. It is also true that LGBT individuals do not have to fear for their physical safety. However, there are various forms of violence, of varying degrees, that manifest itself in different ways in both public and private spheres that I will touch upon later. Right now, I will continue my focus on the physical safety of LGBT individuals. In all of my interviews, the only story of physical violence surrounding homosexuality, was attached to, surprisingly enough, an exorcism of children. To fully understand this story, the reader must be aware of two cultural facts: 1) Satanism is thought to be alive and thriving in the participants' country of service, and 2) Corporal punishment is used often in the disciplining of children, even if they simply give the wrong answer to a question in class. Let me further explain these cultural practices. The 
locals use Satanism as an explanation for anything they consider to be wrong or abnormal in nature. Additionally, they use Satanism as an easy explanation for anything they find puzzling or cannot easily solve. Since homosexuality is seen as abnormal or deviant behavior, it is often tied to Satanism. In regards to the second cultural reality that I mentioned earlier — corporal punishment—locals of this country use it on a daily basis. It is common belief in this country that it is the only effective form of punishment or discipline.

Keeping those cultural practices in mind, this aforementioned demonstration of violence took place at a youth forum, where a handful of Peace Corps Volunteers were working. Mark and Maureen were two of these volunteers. Mark explained why the locals believed it necessary to have an exorcism, "The reason the demons got into the camp, where they had to do this mass two-hundred person exorcism, was because the day before one of the facilitators ran a session talking about homosexuality, so he invited the demons in because of that." Apparently during this session on homosexuality, some students had felt comfortable enough to come out as gay and lesbian to facilitators, and that is when the local facilitators decided an exorcism must occur. Mark went on to describe what unfolded next:

They basically brought everyone to the main hall of the school. All of a sudden teachers started pushing tables in front of the door. At that point, most of the Peace Corps volunteers just left 'cause we didn't want to be stuck in the room while that was happening. We waited outside mostly, and then we saw (through the windows) and heard what was going on. They were doing an exorcism. And then they took like four or five students out of the room, the ones who were identified to be possessed and brought them to other classrooms. One of the people with me, not myself, went and looked and saw that they were beating the children in the classrooms, at which point, most of just left 'cause there were four of us against a culture and multiple hundreds of (locals) who were on board with this. 
When asked who was in charge of this exorcism, Mark replied, "It was run by the Ministry of Education, the Ministry of Health. The chief official from the Ministry of Education is the one who ran the exorcism." As one can see, this only sheds light on the type of structural violence that fuels the compulsory heterosexuality that exists in this country. Maureen added her side of the story and touched upon the incident in her interview as well :

Basically, it was a youth forum. It was supposed to be uplifting for these kids. It was also for needy. A lot of them had physical, mental, emotional disabilities, so it was to give these kids the tools to be successful in life. The first three days were amazing. The last three days were a mass exorcism. Um, and they exorcized for kids having sex. That was the devil, and, uh, and there was that girl who was gay. There was a girl who was gay, and she was trying to be very open about her sexuality...She told some of her friends, and they had mixed views. Some of them thought she was going to hell. I think her friends ending up telling her teacher. Then the teacher decided she was possessed by the devil, and she needed to be exorcised from that devil.

Maureen went on to explain how witnessing this exorcism impacted her personally:

It was so hard to see, and that was the only time where I felt scared for myself 'cause if they're going to do this to this child, this like INNOCENT, like what would they do to me?? Like if they felt like I could be a threat. I can fight back. I had never felt so scared. Me and Mark both were like, 'We gotta get the hell out of here.' We called Peace Corps. We felt like Peace Corps was definitely not supportive.

She described why she felt a lack of support from Peace Corps:

We called... and we were like, 'Look we're out here. They're exorcising these kids.' And he (the Peace Corps staff member) said, 'Good. They probably need it.' And then we called (another Peace Corps staff member), and I think by this time, it had gone from locking the kids in a room and yelling at them to literally extracting kids one by one and dragging them across the sand to lock them in a room to beat the living crap out of them.

Uh, and so when we saw the kids being dragged out, we were like, okay, so we call, and he's like, 'What are you talking about?' 'Cause we were yelling and screaming, and he was like, 'Can you be a little more specific? Who's dragging the kids away?? Where are they dragging them away too? I'm going to have to call you back.' 
(He) didn't call us back.

And of course, we're getting more and more frantic. And we're like, oh, they're coming after this little girl for being gay, and what if they think me and Mark are gay 'cause (another Peace Corps Volunteer) had outed me and Mark to this girl, trying to help her. And, yeah, so we had had a conversation with her and were I involved. SO we called (The Country Director of Peace Corps). And I think (he) didn't pick up at first but he called us right back, and then he was like, if you feel uncomfortable, you are welcome to leave. And I was like, 'What the fuck does that mean???' (laughter) 'Where?? Are you coming to pick us up??' (Laughter) 'To America??' (Laughter) 'Like, 'cause right now that is the ONLY place I want to go to!' (Laughter)

Maureen continued:

By this time, it's night time. And we're at this school, and this school is like three miles away from (A Peace Corps Volunteer's) house- the Peace Corps Volunteer who lives in the village. There's no public transportation to this village, so like, if someone is not coming to pick us up, then we can't get out. And everyone in that village knows where (the Peace Corps Volunteer) lives. They all know, like, they didn't leave. They're just at the (white person's) house. So yeah, we definitely thought they were coming for us. We had a bat by the door, or a little branch of wood. We didn't have an actual bat. (Laughter). We're like, 'Look, if they're coming for us, like, I'm going to fuck 'em up first.' (Laughter)

No one ever came for Mark and Maureen, who eventually rejoined the camp the next day. Maureen explained what that following day entailed:

They made the kids stand up in front of everyone and confess their sins or recant how they got possessed. Now all of this was happening in (the local language), but one of the Peace Corps volunteers was dating one of the guys, so he was translating. The lesbian girl got infected through a monsta pop (a lollipop). She ate one of those lollipops and someone had put the devil in the lollipop, so when she ate it and digested it, she became possessed. And that's when she started being gay.

Maureen explained how the adults had forced the kids to make something up to explain their "deviant" or "undesirable" behavior, and to avoid another beating, they complied. Luckily, this story is the exception in terms of violence based on homophobia. Physical violence against gays and lesbians in this country is not common. Other forms of 
violence related to different social contexts, is, unfortunately, very common and will be touched upon later.

This story sheds light on how religion as an institution is used to perpetuate compulsory heterosexuality. The regulation of sexuality by the church or other religious institutions occurs in many cultures and its influence shapes the cultural and political spheres of society. As Jeffrey Weeks (2003), explained in his book, Sexuality:

Historically, we are heirs of absolutist tradition. This has been based on a fundamental belief that the disruptive powers of sex can only be controlled by clear-cut morality, intricately embedded in a particular set of social institutions: marriage, heterosexuality, family life...This absolutist morality is deeply rooted in the Christian West and in the Islamic East, but though its grounding may be in faith, it is today a much wider cultural and political phenomenon, embraced as readily by the atheist as by the Christian (or other religious) who is ready to worship at the food of strong, moral values. Moral absolutism has deeply influenced our general culture, and in particular the forms of legal regulation, many of which still survive. (106)

As one can see, it is not just one social institution that perpetuates compulsory heterosexuality. Various institutions impact other institutions' decisions and actions, and, therefore, they all have a compounded effect on societal behaviors and beliefs surrounding homosexuality.

Social sanctions for deviating from sexual norms vary from culture to culture. Luckily for locals who identify as LGBT in these Peace Corps Volunteers' country of service, local LGBT individuals do not typically face physical violence, but they usually do face emotional or mental forms of abuse, such as shunning or ostracism. Roger explained, "Most of the people I met in (the capital) that identified as lesbian or gay or even bi had some sort of trauma when they came out where a family member or family members shunned them." Maureen elaborated on how gay women are discriminated against differently than gay men: 
For the men, I think it was a little bit harsher though. 'Cause they're expected to be married or to at least have knocked up a girl, have children. I mean, women are too, but if women don't have children, they're just worthless. You know? So for like my male friends, I know they've had issues with being harassed, and being like, shunned and not talked to. I know my friend does not talk to his family.

Being shunned and ostracized by family and friends can have an extremely negative impact on one's mental health and well-being

In addition to the aforementioned emotional violence that LGBT individuals face, they are also exposed to verbal violence in the form of print, as well as economical violence as they are often at risk of losing their jobs if they are publicly out in their communities. National publications have been known to out gay and lesbian individuals living in-country in scathing articles that denounce homosexuals and homosexuality as a whole. Joanne explained, "They like to OUT people in public in newspapers, you know, and it happens (here). Obviously it's not okay." In fact, during their Peace Corps service, April and Pam were working with an underground LGBT youth group that was, unfortunately, discovered by some anti-gay individuals. Due to the fact that the knowledge of their group fell into the wrong hands, they were almost outed in a national magazine. Peace Corps had to call the publication on behalf of them and beg them not to run the story. Luckily, the magazine cooperated, and the volunteers were never outed. Nevertheless, it was still a stressful experience for the two young women, not to mention the youth in their group. In addition, the local leaders that these women worked with explained to them that it was typical for individuals to lose their jobs after being outed in national publications. In fact, one of these local leaders, had experienced it firsthand and that is why she was insisted on working only with underground groups and never being in 
the forefront of the movement. She did not want to risk losing another job and facing additional economic hardship.

This reality is not based solely on anecdotes. Studies have shown that "outing" an individual or using the knowledge of someone's homosexuality to blackmail an individual is common behavior. A 2009 survey of men who have sex with men found that $26.5 \%$ of men who sleep with men in this country reported incidents of blackmail (Baral et. al 2009) This is just another example of how the society maintains control over citizens' sexual behavior. As one can see, although LGBT individuals may not have to fear for their physical safety, they do have to worry about their emotional and economic well-being.

\section{An LGBT Movement: Thriving and Growing}

Despite the seemingly pervasive "Don't Ask, Don't Tell," attitude of the country, it would be grave mistake to generalize this attitude to the whole country. Although it is often easy for people to do so as the discourse surrounding homosexuality in this country would point in that direction. As Patton and Sanchez (2000) discussed in Queer

\section{Diasporas:}

Indeed, one of the major concerns of recent activist research has been to deconstruct regional and national rubrics, while trying to pay attention to the "real people" who might also inhabit the discursively fantasized space. A focus on the drift of discourse, especially in the form of national and international media, policy, and the academic writings that border on them, rather than on the bodies who may convey, relay, delay, or contest such flows, extends and problematizes (true understanding of queer living abroad). (10)

Therefore, I would like to note that an LBGT movement and community is alive in the capital, and I would like to shed light on the people who are a part of it. Mark explained,

“There IS a community in (the capital). I mean, you can probably, if you're willing to 
take the risk, find people in the smaller villages, but word gets around a lot faster there. But in (the capital), you can find a community if you know the places to go to." In fact, despite the laws and stigma surrounding homosexuality, there is, indeed, an LGBT movement happening in this small, Sub-Saharan African country.

In more rural and remote areas, the movement is underground, but in bigger cities, such as the capital, it is more visible. In fact, there are two well-known LGBT organizations in the country. One is geared towards the well-being of gay, lesbian, bisexual, transgender, and intersex individuals. This particular organization works towards the acceptance and legal protection of the queer community. The second organization focuses on transgender and intersex people. This organization aims at exploring ways of challenging transphobic laws and transphobia that exists in the country. This particular organization was legally registered with Registrar of Societies in December 2010. It succeeded in getting registered with the government in 2010 because it is not an organization that focuses on sexual orientation but, rather, gender identity. Prior to 2015, there had been multiple attempts to register the group that works with the LGBTI population with the Registrar of Societies, but the government continued to reject their application. The main objection by the registrar officials was that they saw registering such an organization as an act of aiding and encouraging an illegal act as defined under the Penal Code. Therefore, the work of this organization has been limited, including the ability to raise funds.

With that said, the organization was able to successfully register in 2015. Pam explained the legal battle the organization had to fight to make this a reality:

Basically, (this organization) attempted to get organizational status, which is basically the government recognizing them as a separate organization. They were 
denied by the government on the grounds that they supported illegal activities... They were denied one time, and then when they were denied the $2^{\text {nd }}$ time, they decided to sue the government for organizational status. Um, and (a judge), who is, um, an amazing female judge and advocate in (country) was the lawyer on the case. Um, and basically (they) went to court and how they phrased their argument was that the country...was denying people their right to organize. They also used the argument that organization wasn't going around and saying everyone should have sex... and because homosexuality is ONLY illegal in (country) in the context of sex, in order to get arrested for gay acts, you have to be caught in bed with someone. There has to be someone who has witnessed you having sex with a same sex-partner in order for you to get thrown into jail. Um, so (the organization) sued the government for organizational status and that lasted about a year and a half. That was going on pretty much the entire time I was there, and, um, recently, about a month ago (in early 2015), they won!

This was a big accomplishment for the queer community, as it is believed that it will only give the movement momentum.

Many volunteers think the future looks bright for local LGBT individuals. Mimi explained the shift in attitudes surrounding homosexuality that she witnessed while serving:

I feel like it's changing. Like, it's shifting certainly. It think, um, once it becomes more normalized in like the big cities, like (the capital), once it really establishes, like a really great community, it will kind of filter through to all the other places...They're mobilizing. They're really doing things, and trying to make it better for the LGBT community there, so once, you know, they get their footing and things change, I think it will definitely filter through to other places.

Collins added how a younger generation is making an impact:

I think that the young people in (country) are much more progressive than the older people, and I think that it's shifting much faster than it was, than it would have in any time in the past like decade or so, you know? I think that it landslides things where the young people are the educated, you know?

This aligns with what previous research has found in regards to age influencing attitudes towards homosexuality. In fact, research has found age to be a significant predictor of attitudes toward homosexuality. For example, in Ronald Inglehart's (1990) research on culture shift in advanced industrial societies, he discovered that in almost every society, 
younger individuals were significantly more tolerant of social issues, such as homosexuality, than older individuals. Hicks and Lee's (2006) study of trends and predictors of public attitudes toward gays and lesbians support this finding. They found that older individuals were much less tolerant of homosexuality than younger individuals. Furthermore, in Andersen and Fetner's (2008) study on cohort differences in tolerance of homosexuality, they found that "more conservative generations have been replaced by younger, more tolerant generations" (311). Therefore, younger generations are found to be much more accepting of homosexuality than older generations. However, Andersen and Fetner (2008) make sure to note that "widespread cultural and political change" throughout history have played an influential role in why age is a predictor of attitudes toward homosexuality (325).

Maureen reiterated the change in attitudes surrounding homosexuality that she witnessed in her few years living there:

As you see, (the capital) is like a fire that's just spreading, you know? You go to (the capital) and you start seeing rainbow flags places. Towards the beginning of my service, you still didn't see that in (the capital). Towards the end, I was seeing places and events that were very welcoming or at least they were like accepting. I saw boys kiss in public. Two boys kissing in public!

Pam speculated on what may happen next, "I think probably the next thing to happen, hopefully, is that they strike off those laws that are in the books. Um, you know, whether or not those laws will be actually stricken off or whether or not they'll just fade into oblivion." As one can see great strides were made for the LGBT community in this society over the span of just five short years. With the momentum of their LGBT organization gaining national and legal recognition, the future looks promising for the queer community in this small, Sub-Saharan country. 


\section{Volunteers' Identity and Negotiation Strategies}

As one can see, the social climate surrounding homosexuality can vary from city to city, depending on size and proximity to the capital. Peace Corps volunteers' sites vary drastically in regards to both of these factors. Therefore, the size of one's site and it's proximity to a larger city can have a substantial impact on a volunteer's service.

Regardless of these factors, however, all volunteers are still living in a country where homosexual behavior is not only less accepted than back in the States but also illegal. Therefore, when queer individuals become Peace Corps volunteers, they implement identity negotiation and management strategies while working and living abroad. Various strategies are used to survive. Identity negotiation and management is a constant and consistent effort. As Lewin and Leap (1996) explain:

This kind of constant, and conscious, identity management is something that needs to be organized in order to survive in a remote field... What personal narratives of gay men and lesbians reveal consistently is the urgency of identity management in the course of ordinary activities. We must consider on a daily basis how much of our personal lives to reveal, how to create a 'role' for ourselves that will lessen the likelihood of ostracism or other hostile treatment, and how to coordinate our homosexuality, however we perceive it, with other dimensions of our identities. (13)

As stated on the organization's website, "Peace Corps is a 24/7 job. Thus the work of a Peace Corps Volunteer does not end when they leave their work site for the day. As cultural ambassadors, Peace Corps Volunteers still carry the responsibility of their commitment to service during their off-hours and free time" (Peace Corps 2015b: I[2). Therefore, identity negotiation and management is also a $24 / 7$ job.

For me, I implemented multiple, identity negotiation and management strategies.

First of all, I changed my outward appearance. In the states, I dressed more masculine in nature, often wearing men's clothing as opposed to women's clothing. When I got 
accepted to the Peace Corps though, I went out and bought a whole new wardrobe of dresses and skirts. In my mind, I figured if I looked like a stereotypical, straight female outwardly, it would help conceal my true identity. It is important to note, however, that not all stereotypes are universal. I would later learn when I got to my site that some of the American stereotypes surrounding homosexuality, such as gay women dressing more masculine in nature or rainbows representing gay pride, are not necessarily stereotypes in other parts of the world. They ring somewhat true in places that are exposed to LGBT issues or have an LGBT community, such as the capital, but in the villages, such as the one where I was placed, they are not on anyone's radar.

In my village of 800 people, clothing was not abundant. People wore what they had and, more importantly, they wore practical clothes that they were comfortable in while doing daily activities, such as fetching water, gathering fire wood, and tending to their livestock. Therefore, the majority of women in my village actually wore men's clothing and no one gave this a second thought. When I first got to country, I was very worried about being outed and what the consequences of that might be. Therefore, I still dressed more feminine in nature because it put my mind at ease. Even after I realized that I could dress as masculine as I wanted and it would mean nothing, I still wore dresses and skirts nearly everyday of my service for two-plus years.

Two other negotiation strategies that I implemented almost daily were silence and avoidance. In the states, I am a very out and proud individual. At my site, however, I did not bring up issues surrounding homosexuality. I did not talk about my past relationships with women. When people asked me questions about dating, I avoided the question at hand and redirected the conversation. Additionally, when asked about past relationships, I 
would somewhat talk about them, but try not to use gender specific pronouns. It should be noted, however, that in my country of service, the local language uses gender-neutral pronouns. There is only one pronoun for men and women, not two separate ones. Therefore, when locals speak in English they often interchange "he" and "she" because they are not used to having two separate ones for each sex. Therefore, I could have used "she" and no one would have probably caught on, but, with that said, I did not want to take that risk. When I got to site, I planned on staying in the closet for the next two years and not come out to anyone in my village. That did not go exactly as planned, but I will get to that later.

Other volunteers implemented similar strategies while at site in regards to their queer identity. For example, others tried to change their outward appearance as well, and, like me, learned that it was not necessary. Maureen explained, "Bought skirts, dresses, and heels. Shoes that I brought to Peace Corps with me, and I never wore them. I brought them back. Still haven't worn them. (Laughter). So that idea was that...I couldn't be me." Similarly, Sue said:

I brought all my pretty dresses... I tried growing out my hair once. It didn't work out. (Laughter). Um, but luckily I think the social cues in that country are different enough that like it didn't necessarily mean anything. Um, like for me to have short hair or wear pants or anything like that.

Pam elaborated on how American stereotypes do not hold true in all parts of the world:

A shaved head...doesn't mean anyone will think you're a dyke, um, you know, and that wearing male clothing, again, NOT something. There were definitely women I saw in (country) that, I was like if you were in the US, EVERYONE would think you were a lesbian, but you're not.

Due to the fact that negotiating outward appearance was not an effective strategy, volunteers implemented other ones to manage their queer identities. 
Avoidance, silence, and lying-outright or by omission — are three main strategies that volunteers implemented while serving abroad. Sue explained, "I kind of just ignored that part of myself publicly for two years...I played the avoidance card. It was kind of stressful. Like is that person going to ask me something that I can't just brush off?" Joanne added, "I did not dress differently for sure. Definitely acted like I was straight, like pretended I had a boyfriend... changed (my girlfriend's) name to like Dan or something." This fits with the finding of previous research. Self-editing, or monitoring and modifying speech, is a concealment strategy that many queer workers have reported using (Rogers and Hebl 2001; Willis 2011). An example of this is when queer individuals use neutral pronouns ('they' rather than 'she' or 'he') when talking about a significant other. Pam elaborated on using this strategy:

Clothing I didn't really change. Occasionally, I posed with a boyfriend, but didn't for the most part. Um, you know, occasionally if I really felt like I wanted to talk about my partner, I'd just do it in gender neutral pronouns because, like, people didn't pick up on it. (Laughter) I'm crafty enough at not kind of getting stuck in sentences, having been in situations where gender neutral pronouns were the appropriate preferred terms. Um, so I just talked to people about (her partner) but never stated that her sex is female.

Mark also spoke about using silence and avoidance as a strategy:

I was probably more reserved than I would have been. I feel if I was a heterosexual volunteer, I would have been a bit more open about my personal life, but I was always on guard with it, just in any way, shape, or form in my village. I spent a lot of time like reading or just doing like solo, like I would hang out with my village now and then, but it was more out of social obligation than social desire.

This aligns with previous research that found silence to be popular strategy among queer workers in general. Employees use strategies of concealment, such as presenting oneself as asexual or simply avoiding questions about his or her personal life (Chrobot-Mason et al 2001; Woods and Lucas 1993). 
Not only did volunteers feel like they had to be silent about their personal lives, but they also felt like they had to be distant in regards to their personal interests that arise from being queer. Mimi touched upon this:

I didn't really have to change much of my appearance or anything like that. Um, I feel like I did have to change like, my media, sometimes, like around them. The things I was reading, I wouldn't necessarily tell them. Um, you know, LGBT based or anything like that. Or the TV shows. Like if I'm watching the L-word all over again, like I wouldn't be like, 'Oh, this is what I'm watching today.' (Laughter). I had to avoid those kind of things, but, yeah. Those were...things I felt like I had to hide.

Overall, volunteers tried to hide or conceal any part of them that might give away their sexual orientation, making it somewhat difficult to interact and connect with locals at times. Identity negotiation and management is not unique to queer, Peace Corps volunteers. Lewin and Leap (1996) described how these strategies have been used for decades among the queer population:

Most gay people, particularly those who came of age before the gay liberation movement of the 1970s, can testify to some period of secrecy about their sexuality, with passing as straight having been a valued strategy at some point in their lives. Accomplishing this involves careful use of language - no tell-tale, same-sex pronouns in speaking of one's recent dates - and other manipulations of impressions. It may not be enough to avoid dress or demeanor associated with gay or lesbian stereotypes, but it may be necessary (or felt to be necessary) to prevent a convincing image of heterosexuality in various social contexts. (12)

As one can see, strategies of concealment have been used for decades in the queer community.

To build upon that thought, many queer volunteers also relied on society's heteronormative assumption as an effective identity management strategy. They used this to their advantage, April explained, "When I'm in public, I pretend to be straight, and I rely on the fact that I'm a cisgender woman in a monogamous relationship with a man to cover up my sexuality. Even with close (local) friends, I hide the true nature of my sexual 
orientation." Lewin and Leap (1996) explain the negative impact that relying on the "heterosexual assumption" can have on an individual:

Of course, gay people are always aided by the 'heterosexual assumption,' the tendency of heterosexuals to regard heterosexuality as axiomatic, but the stakes are high, it may not feel safe to rely too much on this...That secrecy and passing tend to have a painful effect on the individual's self-esteem is by not a truism; the personal history that includes a period of concealing one's orientation from oneself makes clear how painful it can be to realize that one belongs to a despised category.

Due to this fact, many volunteers feel as though they are suppressing and hiding much of their true selves during service and this can lead to numerous problems for queer volunteers.

Impact of Suppressing One's Identity

The suppression or silencing of one's identity has negative implications on a volunteer's well-being. Throughout their service, many queer individuals feel as though they are not being true to themselves nor are they being true to the locals they interact with on a daily basis. As Espin (1997) explains in her chapter, "Crossing Borders and Boundaries: The Life Narratives of Immigrant Lesbians":

The transitions (in identity) often result in many different feelings: the loneliness that results from the absence of people with shared experiences; strain and fatigue from the effort to adapt to and cope with cognitive overload; feelings of rejection from the new society that affect self-esteem and may lead to alienation; confusion in terms of role expectations, values, and identity.

Throughout my service, there were many times when negotiating my queer identity caused me much inner turmoil. Just six months into my service I recorded this in my journal:

Not being able to show all aspects of our American identity can be detrimental to the improvement of the social climate in the places where we serve. If we could openly advocate against homophobia and in favor of equality and acceptability, then the lives of gays and lesbians in our communities would improve. Instead, 
we stay quiet, and the locals just assume Americans share the same attitudes and beliefs surrounding homosexuality as them. In a way, we are trading our own safety and security for that of those gay and lesbian locals living in silence for fear of being ridiculed, harassed, and maybe even killed. That's hard to grapple with. It's hard going from being such an activist back home to being someone who through my silence is actually promoting intolerance and discrimination against something I'm so proud to be.

These feelings aligned with Shallenberger's (1994) findings of queer workers' desire to come out and advocate for their community. I am not the only volunteer who felt this way at times.

Others volunteers wished to disclose their queer identity as well, with the hope of discussing issues relevant to the queer community. April said:

The most difficult challenge has been the attitudes of my (local) friends toward sexual minorities. Many times, I've been a passive participant in discussions that veer into the territory of gay bashing. People - colleagues, friends, acquaintances - will start saying how gay people are sinners/Satanists/devil worshippers, and inside, I will fall to pieces. Friends whom I once trusted become threats to my emotional well-being.

Collins reiterated this thought, "That was the hardest part for me personally. Like not coming out to them, I know that if you can put a face to a gay person, for people who don't know any, that that can be really powerful." As one can see, for many queer volunteers, they feel like their silence perpetuates and encourages homophobic attitudes and behaviors in the places they serve.

Additionally, they believe that their silence promotes the negative attitudes and beliefs they encounter surrounding homosexuality. It is one of the biggest obstacles for volunteers to overcome during their service as it causes much stress and inner turmoil.

Due to this suppression of queer identity, volunteers are at risk of falling pretty to internalized homophobia and minority stress. In previous studies, Frost and Meyer (2009) illuminated that internalized homophobia represents "the gay person's direction of 
negative social attitudes toward the self." In this study, volunteers' recollections and insights shed light on how they were forced to question their self-worth many times throughout their service. Additionally, previous research has found that minority stress results from "culturally sanctioned, categorically ascribed inferior status, social prejudice, and discrimination" (Otis, et al. 2006:83), which definitely occurred amongst these volunteers. Furthermore, findings of the study at hand align with previous research has been done to that showed a significant relationship between minority stress and adverse psychological health effects among gay and lesbian individuals (Bos et al. 2004).

\section{Coming Out to Locals}

One might wonder why queer volunteers chose not to come out to locals during their service. Well, the fact of the matter is that some actually do. For those who choose to stay closeted though, there are various reasons. Joanne, for example, was tempted to come out on many occasions. However, her fear of homophobic individuals finding out about her identity stopped her. She explained:

I think the anxiety, thinking someone might go inside my house and do corrective rape. It's, um, you know, that security that we don't have when we're in the village. You know some people would risk it and tell everyone cause they're proud and everything, but I'm not risking my health or harassment in that situation.

Queer volunteers, like Joanne, may have wanted to come out to just one or two people in their village, but the risk and possibility of being involuntarily "outed" to others by these individuals kept them in the closet. This is consistent with other research findings.

(Badgett 1996; Ward and Wistanley 2005).

Other volunteers did not deem coming out to be important in their Peace Corps journey. Collins explained his reasoning for not coming out to locals: 
Not to any locals. No. I didn't. Um, and I would say the reason for that was probably where my site was. Um, because I was in SUCH a rural place. I knew I wouldn't really have anyone to like share my identity with that would really understand. Um, I, of course, had friends when I was in Peace Corps, like local friends, but I think that, there were a couple of times that I thought of it. There were MANY times that I thought about coming out. But, um, in the end, I didn't really see the benefit, um, to our relationship. You know? Like, you know, of course, we would have like perhaps grown closer or whatever, and there's always some, you know, like, whole world benefit to like, $\mathrm{OH}$ this is the first gay person you've met, and that's great, but I didn't see the immediate benefit for us and our relationship. It was just kind of not an important part of my identity when I was there.

Although Collins did not come out to his community, he did not regret the decision:

I definitely thought about it towards the end of my service, like what if on my last day I was like, "I'M GAAAAY!" (Laughter). Like I think you all think I'm a pretty decent person and we were friends and we hung out and you know a gay person now...I don't regret it though. I think in a different situation I might have, if it wasn't illegal. (Laughter) So yeah, like I don't regret what I did or didn't do, but um, yeah, it definitely crossed my mind.

Most volunteers thought about coming out especially at the end of their service but in the end opted not to disclose their queer identity before leaving.

Some volunteers deeply regret the decision to not come out to any locals. Mark is one such volunteer. He explained, "I had debated for a long time about like telling people on my way out the door, like on my last two days in the village and see what happened, but I didn't, and I really wish I would have now." What stopped Mimi from coming out was the effect it might have on future volunteers at her site. She stated:

Uh, I almost, I really wanted to. I really did, but I was just like, uh, but what about the next volunteer? That was the thing, like I didn't want ruin that experience for them, like I didn't know what their experience was going to be. If they were LGBT, I didn't want to put them in that position. If I was the last volunteer there, definitely would have.

Pam also spoke of the issue of not coming out:

I never came out to anyone in my community, which was REALLY unfortunate, but I, and, you know, I kind of thought about doing a last day, "I'M GAY!!!” But, 
I feel like it would have severed a lot of ties and it also wouldn't have left any room for discussion for those who wanted discussion...I wouldn't have been there to kind of like defend, not defend myself, but I wouldn't have been there to explain to people that I've always been this way, and that it doesn't really change anything about me, and if you loved me before I told you this, then you should love me after. Um, you know, so I kind of, and I struggled with the idea of telling people, but it was just kind of like, I didn't want to run scared, like if I wasn't going to come out fine. I'll be the person who talks to people about gay issues as a straight person. I don't want to be the cowardly, queer woman who ran away.

As one can see, volunteers chose not to come out in their villages for various reasons but often times wish they could have been open and honest about their queer identities.

It is important to note, however, that not ALL volunteers chose to stay fully in the closest in the communities they serve. Some chose to come out to varying degrees. I, for example, came out to one of the teachers I was working with in my village. She was my best friend and confidant. We became very close as the months went by. We would talk about many topics that I usually would not discuss with locals, such as religion, eating disorders, sexual harassment, gender roles, child abuse, death, etc. Unlike my relationships with other locals, our friendship went deeper than a superficial level. I started to feel guilty that I was not being completely honest with her about my true identity, but at the same time, I was terrified to tell her the truth. I did not know how she would take it, and I did not want to risk losing the only true friend I had there. We continued to grow closer, and we would even joke about how one day we would get married and go live in America together. I used to call her my gorgeous wife, and she would call me her handsome husband. Then finally one day, a little over a year and a half into my service, she flat out asked me if I was gay. At the time, we were both coaches for our school's netball team, and we had taken the girls to a weekend tournament. She asked 
me this question right before we were going to bed. This is what I wrote in my journal

about the incident:

So we were all getting ready for bed. Everyone was just sleeping on the floor of this classroom they put us in, and (this teacher) and I were sharing blankets in one of the corners. Now I can't even remember how she asked me cause it seriously caught me so off guard, but she turned over, and said she needed to ask me something. Immediately, I thought she was going to ask me if something was going on between me and (her boyfriend). Then she was like, 'You probably know what it's about.'... Then she becomes really hesitant, and I start to get really nervous. I tell her, 'Say it. You can ask me anything.' And she says, 'Yeah, you said we can talk about anything, right?' And I said, 'Yeah, what's wrong? Talk to me.' Then she goes, 'Are you straight or not?'

(Silence.)

I just stared at her. Then I laughed and turned away. I think I may have put my head in my pillow. Then I said, 'Why? Would it matter if I was or not? Do you think I'm not?' She says, 'I don't know. Answer.' Again, I said, 'What do you think?' She said, 'I think you're bi.'

I said nothing.

She continued, 'Or maybe you're confused. People can be confused.' At this point my mind was racing. I had no clue how to handle this situation. I so desperately wanted her to know the truth and at the same time, I didn't.

So then I said, 'I can't believe you just asked me that'...I asked her why she suspected, and she explained that I always joke about it, and that sometimes she feels like I'm hitting on her. Then she said, 'Answer.....the fact that you aren't answering is an answer in itself.'

Finally, I asked her if this conversation would stay between the two of us. And she said, of course, and asked if I trusted her or not, and I said, I did, but that Peace Corps had told us not to tell anyone. Then she said, 'Then you are.' I said, 'Yes.' Then I explained that I had wanted to tell her 'cause I had felt like I was lying to her by not, but I just didn't think it was safe. She said she understood. Then I said, 'But I'm not bi.' And she seemed confused, and then it clicked. 'You're lesbian?' And I said yeah. And then she asked about my ex I always talk about, and I explained that she had just assumed it was a man, so I went with it 'cause it was easier than trying to use gender neutral language while talking about it. I just kept saying that I couldn't believe she had asked me that. And she kept saying that had been suspecting. She just couldn't decide. She kept saying, 'I would think about it, but then I would just decided, no, she is just funny. She 
likes to joke. But then there were times that I felt like you were hitting on me.' Which I said, 'I was!' And then she just laughed and said, 'C'mon now.'

Then I started explaining how I had wanted to tell her for a while, and I just didn't know what to do 'cause I didn't know how she really felt about homosexuality. She told me that she has a cousin who is gay, and her family doesn't care. I wasn't really convinced though. I don't how to explain it, but I just wasn't. She asked me some more questions like if I had ever dated guys, when I knew.....Then she said something about how she didn't understand what changes in someone to make them gay. I tried to explain that for a lot of people, nothing changes, people just finally decide to come out. I told her that I knew from a very early age, but being raised Catholic, I thought it was wrong, so I was trying to fight it....Finally I decided it wasn't fair to me or the guys I dated. Then I told her that people were too concerned with labels, and that sometimes people identify as straight, but they can find themselves attracted to someone of the same-sex in their lifetime. It happens. Then she asked me if it was hard to find someone to date, and I was beginning to say yes, but then I think the girls got rowdy, and she yelled at them to go to sleep. Then she told me that we would talk more tomorrow, and rolled over to go to sleep.

Before I let her sleep though, I made her promise we were okay. I told her that her friendship meant the world to me, and that I didn't want that to change. I also asked her not to tell anyone because it was a safety concern. She assured me that we were fine, and she promised not to tell anyone.

I'm pretty sure I did not sleep at all that night. My mind was racing. What had just happened?? It seemed so surreal. I could not believe she had actually asked me that, and I could not believe I was not prepared with an answer. Should I have denied it? It was definitely too late for that. I felt so uneasy. However, as the days and weeks and months passed, it turned out to be a blessing in disguise. I finally had a local friend with whom I could be my true authentic self. To this day, she is the one local I stay in touch with from my time in Peace Corps.

I am not the only volunteer who came out to people in their village. Maureen, too, was open about her sexuality with the locals. Maureen had been placed in a village of over 80,000 people. Due to the size of the village, multiple volunteers were serving there. One of Maureen's fellow volunteers happened to be queer as well. Maureen had met this 
volunteer during a training session she had come to facilitate during PST, and the two of them hit it off right away. They started dating soon after Maureen moved to the city where they both worked. However, Maureen's new girlfriend was at the end of her service, and with just four months left, she decided to come out. By coming out, she inadvertently outed Maureen as well. Maureen explained, "The interesting thing was, okay, basically she didn't tell anyone until four months before she was about to leave.

And then by outing herself, she outed me to everyone in the village. She was like, 'Yeah, I'm gay. I've been dating that girl."' Maureen had mixed feelings about this, and the two unfortunately broke up a week later. Nevertheless, Maureen does not regret what happened. She believes that this accidental outing allowed her to be more of her authentic self and she continued to be open about her sexuality throughout her service.

To elaborate, Maureen believed that being open and honest about her identity was key to her success as a volunteer. In fact, she encouraged other queer volunteers to do the same. She explained:

The thing is that is, you know, anything you try to do to cover up who you are, it's going to seem false, and I feel like most most (locals) are very intuitive about people...I kind of approached my service the way I did even coming out and going into Peace Corps, I'm just like I'm going to do the best job of being me, and hoping that my general personality and my heart and, you know, comes through... So you know, I never tried to hide anything from anyone, and I think, uh, the (locals) they kind of appreciated that authenticity, like, you know, and I think in return, they were always very honest with ME. I mean most of my friends (in-country) were very honest and open and sometimes too honest...You know! Um, in return, it was, it gave grounds for an actual mutual exchange, instead of false pretense of it.

This authenticity set Maureen up for much success in her work as she could truly connect and form deep relationships with the members of her community. 
Maureen's claims ring true with what past research has found. Some research has found that attempting to hide one's queer identity can be detrimental to the research at hand. Frank Proschan (1990) who conducted fieldwork in Cambodia explains, "As a result of my own evasiveness and their sensitive avoidance of potentially embarrassing questions, I remained a riddle to the people with whom I worked" (59). As a result, this made it hard for his informants to trust him, and many did not feel comfortable disclosing personal information to him. Proschan claims, "As long as I presented myself as a riddle, leaving any sexual identity undefined and unsaid, my Cambodian friends consistently left anything with explicitly sexual content unsaid in my presence—silence begetting silence" (62-62). Similarly, Hector Carrillo (2009), an openly gay ethnographer in AIDS research, attests to the positive impact authenticity can have when working overseas:

My assessment is that being open about my sexual orientation mostly had a positive impact on the research, and that it also facilitated my connections with the many people with whom I interacted on a regular basis, gay and non-gay. I often felt that being open about my sexual orientation also opened up spaces for discussion - that people could then reveal to me things that otherwise they might have felt inclined to keep a secret...Furthermore, I was pleased when, after realizing that I was gay, non-gay people who were previously unsuspecting had to confront their own biases and begin the process of knowing, perhaps for the first time, an openly gay man who did not necessarily conform to the stereotypes that they carried in their mind. (40)

This notion resonates greatly with what Maureen found when she was open about her sexuality during service.

Maureen does admit that the size of her village probably played a factor in her Peace Corps experience. With that said, she claimed that even if she would have been placed in a small village that she would have still been open about her identity. She explained: 
Um, I think even if I was in the small village, I would have just been me, and I think it would have hindered my access to, um, to being able to help (local LGBT organizations), like if I was in a smaller village, I probably wouldn't have met (local LGBT activists), and never would have had the access to (the capital) or something like that, but who would have known? Who would have known? Cause I think my experience would have been similar, regardless of a small or big village.

Overall, volunteers had varying experiences when it came to coming out of the closet. Some remained completely closeted for two years, some came out to a handful of people, and some, like Maureen, tried to live completely open and authentic lives while working abroad.

The Struggle to Remain Authentic to One's Self

Being authentic is an issue that many queer Peace Corps volunteers struggle with throughout their service. Being authentic was freeing to Maureen and really helped her to have a positive experience while in Peace Corps. For others, the lack of authenticity they can show surrounding their queer identity causes much stress and guilt. Volunteers must turn to other outlets to deal with these feelings. For many, that means finding ways they can connect with and support the LGBT community.

Therefore, although queer Peace Corps volunteers did not usually feel comfortable coming out in their communities, many still went of their way to incorporate work surrounding LGBT issues into their service. Incorporating LGBT issues into a Peace Corp Volunteer's work can happen on multiple levels. Some volunteers attempted it on a more macro-level and others took a simpler approach. Like gay and lesbian anthropologists who do research surrounding homosexuality, queer Peace Corps volunteers must be cautious when attempting to incorporate LGBT issues into their work. As Lewin and Leap (1996) said: 
Whether the inspiration for this work stems from involvement in the gay rights movement, or whether gay researchers undertake such studies because they feel more able to address the subtleties of the topic, they must confront the issue of being 'insiders' and how this will affect their professional status. (11)

Regardless of the scale of the project, volunteers must be careful when addressing issues that surround homosexuality as they cannot be seen as "promoting a gay agenda" on behalf of Peace Corps or America as a whole. Personally, I tried to incorporate LGBT work as a member of my cohort's Peace Corps Gender Equality Committee. A year and a half into my service I started working on a conversational guide that would help Peace Corps Volunteers talk to locals about issues surrounding homosexuality. As I was close to finishing up the manual, I wrote the following article in our Peace Corps newsletter to explain the guide and my reasoning for creating it:

'Breaking the Silence'

As someone who is a proud member of the lesbian, gay, bisexual, and transgender (LGBT) community back in America, it was a bit unnerving when I was invited to serve in a place where "homosexual acts" are not only frowned upon but are actually illegal. Prior to Peace Corps, I had spent the majority of my adult life living an openly queer existence in a society that when compared to the rest of the world is not a terrible place to be if you identify as LGBT. Now I live in a society where compulsory heterosexuality is a stark reality, as opposed to academic jargon one might stumble across while reading the work of a 1960s' American, feminist scholar.

Going back into the closet was not as hard as one might imagine. After all, I did not come to Peace Corps in hopes of finding a life partner. I came to volunteer. There is, however, something that has caused me a great amount of inner turmoil in regards to living in this hetero-rigid society. Surprisingly, it is not the lack of gay sub-culture here. Yes, I miss the queer enclaves that exist all over America. I miss the pride parades and the drag shows, as well as the colorful and unapologetic people who frequent them. I miss the LGBT youth I had the privilege to mentor while working at an LGBT community center back home. And it goes without saying that I miss seeing LGBT individuals representing our community in all walks of life. However, all of this is the result of a long-standing and organized LGBT movement in the United States. What I miss here is much simpler: Dialogue. I miss having conversations surrounding homosexuality and gender identity. You see, it is the silence that really gets to me. More specifically 
though, it is my own silence that bothers me the most. It is my lack of confidence in addressing LGBT issues in a society where the topic is still so taboo.

It is not like the topic never arises. Since I have arrived in (country), I have had many encounters with people talking about the subject. For example, during PST, my host sister told me, 'Only silly girls play soccer.' Not understanding what she meant, I laughed and asked her to explain. She leaned in and whispered, 'Lesbians.' I wish I could have seen my face at the exact moment. I was so in shock that a (local) had even uttered the word that I am sure my jaw had dropped all the way to ground. I said nothing. She continued to say, 'It's a big problem, especially in boarding schools. Girls trying to be like guys and doing guy things...It's not good.' Although it killed me not to say anything, I continued to sit there in silence. During my community assessment, I shadowed my Community Development Officer for a week. One day we were in a nearby city, and we saw a flamboyant young gentleman. My village's Community Development Officer began speaking with a "gay lisp" and making fun of him in a derogatory manner. Again, I sat there in shock and, yes, silence. My teachers periodically make homophobic remarks at school, and the topic gets brought up a surprising amount at workshops. Each time I am in these situations, I find myself paralyzed, not knowing what to say... and each time, I am left feeling like I am perpetuating homophobia through silence.

I know I am not the only one dealing with this dilemma. I have heard similar stories from multiple volunteers. In addition, according to data collected by the Gender Committee, $65 \%$ of volunteers have had conversations with locals about homosexuality. However, due to the illegal nature and stigma attached to homosexuality in this society, volunteers report that they do not feel comfortable having such conversations. As a result, volunteers have requested more information regarding culturally appropriate ways to discuss such issues.

In response to these requests, the Gender Committee has developed a conversational guide for volunteers. The guide aims to assist volunteers in approaching conversations surrounding homosexuality and gender identity in a culturally sensitive manner. The guide includes the following information:

- The Legal Status of local LGBT individuals

- How to Address LGBT Issues In-Country

- Conversational Tips

- Myths and Misconceptions

- Frequently Asked Questions

- LGBT Organizations in-country

- A Glossary: Understanding the LGBT Lingo

It should be noted that this guide was NOT created in the hopes of promoting a "gay agenda." We are not encouraging volunteers to advocate for LGBT rights in-country. Instead, the guide is intended to be a tool for those looking to 
participate in dialogues surrounding homosexuality and gender identity. It is simply here to assist volunteers who wish to break the silence."

As one can see, I took a micro-level approach to combating homophobia and creating a more accepting environment in our country of service. I focused simply on sparking dialogue and creating conversations that would, otherwise, never occur.

Other volunteers took different approaches to incorporating LGBT work into their service. Pam was fortunate enough to create and work with three underground LGBT support groups during her service. This work was very rewarding to her and also helped with her mental well-being. She explained:

I think it was helpful that I was involved in LGBT communities that weren't in my community...I was lucky enough to be involved with really three different support groups throughout my service, so that helped me get over emotional stress...I think it would have been harder if there had not been groups I could have (expressed myself in).

April worked with Pam on these endeavors. This is what she had to say about how the experience impacted her own well-being:

Thankfully, working with (the local) LGBT community has helped me feel more at home and more accepted. I have been inspired by the struggles and triumphs of the queer youth in the (local support group). They make me feel like I'm not alone. Also, my best local friend is the former coordinator at (another local organization) and is an out-of-the-closet lesbian. Becoming close with her has helped me reconcile my feelings and struggles with her own experiences. It has humbled me and made me more compassionate toward myself.

Working with these groups was a win-win for these ladies because they not only were helping the LGBT community in-country, but the work also allowed them to connect with their queer identities in a way that was otherwise impossible. This work helped them stay true to themselves, which had a positive effect on their mental and emotional wellbeing. April shed light on how being able to do this type of work impacted her service: 
My passion for working with LGBT (locals) has pervaded my service. From 2012 to 2013, I helped found and run the first LGBT support group in the "Bottom Four" districts (of the country). However, a break in confidentiality in the support group exposed it to the national media, fueling a libelous story that alleged child abuse by "(local) gays." Even though my name was ultimately left out of the story, several community members connected me to the story and were quite cold to me thereafter. However, I'm proud of my work with queer locals. (Her village) did not have an organized LGBT community before 2012. Now, we have an identified structure and focal people who represent our region at workshops and interactions with the Ministry of Health, the US Embassy, and other key stakeholders. We have held film festivals and sensitization workshops, and we have built a network of allies.

As on can see, April dedicated much of her time to aiding the LGBT population in her community. Due to her hard work, she was able to leave her village with a strong, organized LGBT community.

The work that Pam and April were able to do occurred outside the capital. Other volunteers worked with LGBT organizations in the capital. Roger was one of these volunteers. He explained:

I honestly can't remember how I found out about (the local organization), but I did, and then I contacted them. Mostly what I would do was looking at grant proposals. Looking at different grant proposals, sort of helping them with editing and making it persuasive, and making sure the English was good.

When asked why he sought out the organization, he said:

I sought them out one because I was curious, curious about, you know, were there any organizations (in-country), and then, you know, when you are doing the kind of work that I was doing-HIV prevention program and HIV education programs - I knew anecdotally and from some statistics online and from my office that having sex with men was a component of HIV ... It certainly wasn't the main component but it WAS a component, and it was very underreported. Um, and so, part of it was to try to somewhat fill gaps. You know, finding ways to make that part of the official government report, and some of it was sort of my own wanting to reach out to people and work with them because I, you know, I knew it was something I was passionate about.

Being able to work on something Roger was so passionate about while in Peace Corps helped his emotional well-being and made a positive impact overall on his service. 
Maureen was another volunteer who was able to help out with the community in the capital. Due to her connections with the community, event planners and organizers would reach out to her for help. Here she touches upon how her friend got her involved in the movement and how she had to carefully navigate her involvement due to her status as a Peace Corps volunteer:

He was also helping the movement, so he would tell us (Peace Corps Volunteers), oh, they're having a...rally, and we need someone to help plan it and get people to come. You know, (Maureen) can you help do something? Sure! No problem! Like, I was more responding to their requests, like I wish I would have took more action myself...But also, I felt like Peace Corps was a little bit binding of what you could do as a Peace Corps volunteer, like they were very clear that if someone asked me for my help, I was allowed to help. But I wasn't necessarily allowed to plan or necessarily give ideas. I think they got a little more flexible on that towards the end of my service.

Maureen went on to discuss some of the events she was a part of with the LGBT

community and how it grew over just a few years:

There were people having gay nights. We threw a couple of gay parties ourselves. Um, which, seeing the amount of people as the parties grew. We throw about five of them. The first one, it was like twenty or thirty people. Second one it was like forty people. Like the third one, it was like one hundred-some people all came, and we still couldn't get the place right. Like we couldn't get the speakers to work right, and there's still people standing there. Still people doing performances. The fourth one was a going away party, which we had a drag show... This was in (the capital). You know. Stuff like that was NEVER happening before. And then after a while, there were so many people who were like I'm going to be comfortable in being myself. You could see it start to move upward, you could start to see a couple of things happening in (another city), a couple things happening in (somewhere else). You know, a couple of things here and there and just spreading out, (Up North in the country). Spreading out from there. I know of couple of events in (even farther north).

The movement was spreading, and it was spreading quickly!

With that said, many volunteers commented on the social nature of the movement.

They expressed that the movement seemed to be more social in nature than anything else. Mark explained, "It's definitely more of a social community. There are political elements 
to it for small amounts of members, but MOST of them are really just looking for like-

minded individuals to have a safe environment." Roger confirmed this sentiment, "It was more social. They occasionally would have planned activities, usually at the University. Um, it seemed more social in nature when they got together. You know, cook dinner or something like that. Pam further broke it down:

The community kind of functions at a social level. There are people who are involved with (the organization), and there will probably be more now that it has organizational status, but, you know, the community leaders that I knew that were really like out and loud LGBT activists ended up leaving, not leaving, but like, you know, (one woman) does stuff with the UN. She does stuff kind of on an international basis. She's living in South Africa doing LGBT stuff there now, and (another woman) ended up going on sabbatical to Thailand, so you know it kind of suffered...The strong leadership comes and changes. It's such a hard line to balance cause it's kind of like, if no one comes out, then who's gonna be heard, but no one wants to be the first person to come out, 'cause in countries like that, it's a really lonely ship to be on. So, and you know, people are afraid of losing their jobs. The woman who runs (a LGBT) group, part of the reason she's not so great at running it is because she lost a job. Like, you know, because she's had horrible backlash when she comes out to people.

Although the community and the organizations that exist in country are currently trying to find their footing, they still serve as invaluable resources and support to not only the LGBT locals living in country but also to the LGBT Peace Corps Volunteers serving there.

\section{Taking Part in the Local LGBT Social Scene}

Taking part in the local LGBT social scene was one of the major coping strategies for queer volunteers while serving in-country. Maureen explained how the local LGBT community welcomed her and other queer volunteers into their group:

Okay, so when I was dating (my first girlfriend in-country). She had a couple of gay friends and she knew a couple people in the community. She introduced me to this volunteer who was a lesbian from Japan, and she was like REALLY out. She introduced me to Benny. When I told her I was gay, 'She's like, oh yeah, I'm 
gay too. I have a wife at home. You need to come to our movie nights. We watch like lesbian and queer movies from around the world.'

On some occasions, these local activists even put on events for queer, Peace Corps

volunteers. Maureen described once such party:

Benny threw us an Australian themed lesbian pool party. (Laughter) In (country)! He like decorated his apartment with wombats, and he let us have his whole entire apartment. It was a NICE apartment....He's one of my best friends. He shaped my experience in that way. I was so fortunate and blessed to meet him.

Mimi was also fortunate enough to participate in the social aspect of this community, and she touches upon how it was such a good escape when she needed to just unwind and be herself:

It was strange, only because in my village, I had to be careful, but then I went to (the capital), and like all my friends there were like super chill, and I was out with my friends there, and (my girlfriend) was really active while she was here. She actually created like, um, like a gay night in (the capital) and she put an event together, and it was like during International Women's Day, and like it was this whole big thing, and it was like a drag queen show, and like it was so much fun. (Laughter) But, um, yeah, so I'd go to (the capital) A LOT during that period and just like hang out, and be like Yeah!!! Everything's fun. I'm in the capital! (Laughter) It was really great. Yeah, there's such an amazing gay community in (the capital) especially.

As one can see, being able to be involved in both social and activist aspects of an LGBT community while serving abroad proved to be invaluable experiences for many queer volunteers. It provided a healthy outlet for them, as well as a safe space for validation and affirmation surrounding their queer identities. Past resource supports these findings as it has been shown that increased ability to reveal one's sexual identity, opportunity for in-group identification, and greater access to social networks is strongly linked to positive mental well-being (Jordan \& Deluty 1998; Meyer 2003; Halpin \& Allen 2004; Kertzner et al. 2009). 
Coming from a country where homosexuality is much more understood and accepted than that of the country they served in, these queer volunteers were given the rare opportunity to learn what an LGBT movement and community looks like in a culture very different from their own. Pam explained how being involved in that community shaped her global perspective in regards to the international, queer community:

I definitely think it impacted my view of the global queer community. I don't think it necessarily affected my view on LGBT people necessarily. Um, you know, I assumed there are gay people everywhere, but it kind of gave me a better idea of how we are all together and we are all separate. Um, gave me a better idea the types of resources that people in countries like that, that are queer, need. Or you know what they want.

Collins added:

I was always cognizant of the fact that if this wasn't a permanent situation (for me), then of course, it would be a problem that would wear on me. You know? I guess to some extent, I came to appreciate the plight of the closeted person in rural (Africa). You know what I mean? I get that there's like no community there, and it was hard.

After their time abroad, these volunteers could no longer think of their queer community as simply American-based. They came to see it as internationally-based instead. They had become global, queer citizens.

\section{Coping Strategies for Going Back in the Closet}

Besides incorporating LGBT work into their service and partaking in the social aspect of the local queer community, LGBT volunteers utilized other coping strategies as well while serving abroad. One of the major coping strategies was leaning on other LGBT volunteers for support. This was one of the major coping strategies I utilized myself. Before leaving for Peace Corps, I figured I would be in the closet for the next two years. I had no idea how hard it would be to stay in the closet. I had come out when I was eighteen years old, so I figured that if I had survived being in the closet prior to coming 
out, I could do it again. However, I had never experienced going back into the closet and the impact that can have on one's well-being. I struggled early on with not being out in Peace Corps, especially with my host family and with my fellow Peace Corps volunteers during our training. It was such a relief when I finally came out to my fellow volunteers, and it was an even bigger relief to learn that I was not the only queer volunteer incountry. I quickly learned that the queer volunteers were a great support system for each other.

Throughout my service, I leaned on these individuals greatly. We may have been spread out across the country, but we made a point to keep in touch through phone calls and texts. Occasionally, we even found time in our busy schedules to get together for what we called "queer weekends." It was an opportunity for us to relax and socialize with a group of like-minded individuals. Joanne explained why she enjoyed these weekends where she could talk to fellow queer volunteers, “They'd listen. We'd vent. We'd drink...I guess partying and getting away helped a lot to get out and to think about things besides Peace Corps." It was also a safe place for us to express our concerns and be able to talk them out with people who were experiencing similar problems. Sue explained, "We would talk about being gay in Peace Corps and kinda of troubleshoot different people's issues." Additionally, those queer weekends provided us volunteers with the rare chance to show our true selves in a country where we felt our identities were compromised. As Sue explained, queer weekends were all about "letting that part of you that's been suppressed for so long and just letting it go, and just being your wonderful queer self." Having this support network made a world of difference for all of us. Mimi, 
who came out to her family and friends just weeks before leaving for Peace Corps,

touched upon how belonging to this queer network impacted her:

I didn't expect for there to be a strong LGBT (community). I didn't expect them to be so open and caring. Since I really didn't identify with that community at the time, I didn't know how I would be received. So it was kind of nice to be like okay, I'm in this whole completely different country, but I have a community that's like here for me, that I didn't have back home, and now I can kind of feel like I belonged somewhere that I didn't belong at home, and it was kind of nice. It was, um, a different community and experience that I have never had before, so it was really great. I never expected to belong somewhere so quickly and kinda feel so comfortable with myself somewhere, so it was nice.

Past research shows that being connected to the queer community has a positive impact on both sexual identity and social well-being (Kertzner et al. 2009).

Having a group of queer friends is an amazing support, but the opportunities to meet as a collective were few and far between. Therefore, most of the support between queer volunteers occurred on a smaller level. These one-one-one interactions proved to be just as meaningful though as when the entire group gathered together. Participants tended to gravitate towards queer volunteers who were near them. I, for example, was lucky enough to have another queer volunteer just thirty kilometers from me. She and I were an invaluable support system and resource for one another. Alexi added, "I had like a volunteer the same age who was nine kilometers away who identified as a lesbian. Um and she was great through it all." Mimi too was lucky enough to be close in proximity to another queer volunteer. She explained:

I think it helped having other volunteers that were near me to like discuss these things and not being in my head ALL the time. 'Cause, yes, you could talk to some of the people in your village that you trusted about some things, but certainly not, you know, my identity. And so, it was nice having my friend. She was kind of near me, and we'd hang out and just talk about things, so that was helpful. Just knowing you're not alone was pretty great. 
April also touched upon the impact just one fellow volunteer can have on an individual's service and well-being:

My best Peace Corps friend Pam was BY FAR the biggest factor in my ability to cope with my queer identity while serving abroad. We hit it off immediately during PST, and we journeyed together through the realization and acceptance of our sexual orientations. Pam's no-nonsense, queer pride inspired me to celebrate my sexuality, not to suppress it. Her love and unconditional support transformed my service from one of potential depression and isolation into an experience that shattered my personal trials in the face of greater self-realization.

It is remarkable how just one person can be the difference between a good or bad Peace Corps experience. Sometimes all it takes to improve a volunteer's well-being and mental health is just one person he or she can rely on for friendship and support.

I personally consider myself very lucky to have had such a wonderful queer support network while I served in the Peace Corps. Talking to other queer volunteers, they too are grateful. Although we all did not all serve at the same time, some of our services did overlap and collectively we did serve continuously for a duration of five years. For those five years, there was always a group of queer Peace Corps volunteers serving in-country. It should be noted that this is not the case in every country where Peace Corps exists. Some queer volunteers end up being the only LGBT volunteer in their cohort. One of the reasons that so many queer volunteers may be sent to the country where we served is that the laws surrounding homosexuality are less severe than other African countries where Peace Corps is present. With that said, not all of the participants came out to Peace Corps during their application process, so, in all reality, part of it was a miraculous coincidence. Mark theorized the possible explanation of why our country of service tended to have a higher amount of queer volunteers than usual:

There was...an abnormally high number. I don't know exactly why that was cause I mean isn't the statistic like one in ten? Or something ridiculous like that? 
But, I mean out of my group, there was I think one of seven or six that was either bi, lesbian, or gay, so. We had, we had an abnormally large number, which I think helped a lot. I mean, part of it might be Peace Corps phenomena, just because as stereotypical as it sounds, you're not going to get a lot of conservative people in Peace Corps, and, therefore, the more liberal your base is, the more likely you're going to have these different identities. And also (in-country), I mean, you're mostly in education and healthcare, which tend to have, even in those field in the U.S., tend to have more people of LGBT representation.

Maureen agreed with this theory as well, "I would say that sometimes Peace Corps draws queer people, but you know, I think it's also our program: Education. Maybe education draws more queer people. Just like it draws more women, like our program draws more women than men.”

I know that, without a doubt, my Peace Corps experience would have been drastically different without a queer support network. I can confidently say it would have been drastically worse. I would have felt so alone and isolated as the only queer volunteer because I would not have had any one to talk to who fully understood what it was like to suppress that part of myself for so long. I probably would have started to believe something was wrong with me and, perhaps, I would have even started to suffer from internalized homophobia. Other volunteers shared similar sentiments when asked what their service would have been like if they were the only queer volunteer in-country. Joanne was almost in disbelief and shock at the mere thought of being the only queer volunteer in country. She said, "Like in the whole country??? The only one?? That would be AWFUL! (Laughter)." Mark also said, "It would have been a lot harder." Some expressed that they would probably not have been able to stay the full-length of their service. Mimi explained:

I think it would have been so lonely. I don't know. I think it would have been really hard. I think I probably wouldn't have made it the two years. I probably would have gone home to be honest. I think that's already such a tough thing to 
go through, and then to go at it like completely alone on top of being isolated from everyone in your own village, it just would have been too much I think.

Sue shared, “That would have been horrible. I kind of can't imagine that. Like from other groups and stuff, but, no, it would have been so much harder if I hadn't had other queer volunteers." Pam elaborated and touched upon how it was vital to her service to be have other queer volunteers serving with her as she had just recently come out prior to leaving for Peace Corps:

Oh, I would have been so screwed up. (Laughter). If I had not had any outlet?? I think it's dangerous, and especially for me it would have been dangerous, 'cause I had JUST come out to my family, like the cat was out of the bag, and I didn't have this chance to kind of like, you know, 'I'm out! I'm going to go to all the gay bars! I'm going to sleep with ALL the women.' Like, I feel like a lot of queer people, and not ALL, but I feel like a lot of queer people kind of are able to have this kind of celebration of their identity...I think it would have driven me nuts, especially as a very expressive and very social person, it was important for me to be able to identify that way, and that's why, you know, I ended up reading a lot of queer literature and I got into queer blogs...I tried to do what I could to kind of release that valve occasionally, but had there really not been an outlet, I think it would have been very detrimental to my being.

Prior to leaving for Peace Corps, queer volunteers are willing to make the sacrifice of going back into the closet and suppressing their identity. However, they do not realize the full impact of that sacrifice until they arrive in their country of service. Therefore, having other queer volunteers there, going through the same experience, can be the difference between queer volunteers successfully completing their service and queer volunteers packing up their belongings early to head back home. For those of us serving in this particular society, we were lucky to have other queer volunteers to rely on. Others are not so lucky. 
In a recent Peace Corps Times' issue, Julia Schulkers, touched upon the effects of having no support system or outlet as a queer volunteer in Thailand. She wrote of the negative impact this reality had on her emotional well-being:

In America, my sexual orientation elicited little challenge or adversity. When I came home at age 20 with a crush on a girl, no one batted an eyelash, not even Grandpa who has seen it all by now. A closet never existed in my world so when people spoke about coming out, I had no closet to come out of. I dove right into a supportive LGBTQ community at home and didn't look back. But that all changed when I arrived at my site in rural Thailand. After trying to integrate into my village for over a year...I started to crumble. I lied through my teeth for over a year, making excuses that I was a single woman too busy with work to find a husband. All the while, the relationship with my (then) long-term girlfriend back in America began to cave under the weight, as did I. Some days, I couldn't tell the truth from the lie anymore, and all I knew was that something was very wrong inside. Sometimes I thought it was me: I thought I was doing something wrong and I was failing to be a good, Thai woman, and, therefore, a successful volunteer. (2013:5)

As one can see, the participants of this particular study had obstacles and challenges to overcome as queer volunteers. With that said, they were extremely lucky to have found support systems and outlets to help them cope with their identity negotiation and management processes. In other Peace Corps posts, queer volunteers are not so fortunate.

Julia's story is a testament to this fact.

Queer Volunteers Dating in the Peace Corps

An additional coping strategy that is very relevant to the narrative of a Peace

Corps volunteer is that of dating. It is important to note that:

Despite the differing social contexts for same-sex and heterosexual relationships, there are many commonalities in the close romantic relationships of lesbian, gay, bisexual, and heterosexual individuals. Human needs for intimacy and the capacity to form strong emotional attachments affect all of us... most individuals seek similar qualities in a romantic partner, including affection, dependability, and shared interests. (Peplau and Ghavami 2009: para. 4) 
Therefore, it should be no surprise that although queer Peace Corps volunteers may be serving in societies that are not accepting of homosexuality, they still seek companionship and meaningful relationships. With that said, dating is not on the radar of many queer volunteers prior to leaving for service. Most individuals believed that they would not even be able to be out while abroad, so dating was never in the forefront of their minds. That is, until they arrived in-country and were slowly exposed to a community of LGBT Peace Corps volunteers, as well as a thriving local community in the capital. As a result, one of the main coping strategies that queer Peace Corps volunteers utilize is dating. This leads to significant others being one of the main sources of support while serving abroad.

Before I left for Peace Corps, the thought of dating while abroad had not crossed my mind. Believing I would be in the closet for two years, I had not even entertained the possibility of being in a relationship. However, I was in a relationship... twice. It still hard for me to comprehend the fact that I somehow managed to have two relationships while living in a country where homosexual behavior is punishable with up to seven years in prison. The first girl I dated was from my training cohort and was assigned to a village just thirty kilometers away from mine. We dated for just a couple months after leaving PST, and then we decided that our relationship was distracting us from the work we came so far to do. Due to our close proximity, we would spend a lot of time together, meaning one of us would always be away from our village. We decided we should focus more on our work and less on each other. It was a hard decision, but we remained close through our entire service, serving as a great support for one another even when we were not dating anymore. 
I stayed single for quite a while after that, focusing on integrating into my community and on my work. By the time I had been in-country for a year, I had developed some pretty close bonds and friendships with my fellow Peace Corps volunteers. There was one girl in particular that I had formed an exceptionally close bond with, and after much discussion and back-and-forth, we decided to date, even though we knew that we were far from being in an ideal situation. As opposed to my first attempt at a relationship in Peace Corps, this girl and I lived nowhere near each other. In fact, she lived about six hours away by public transport. The distance helped us to stay focused on our work but did not bode well for our relationship. There were many ups and downs, but throughout it all, we served as each other's biggest source of support.

Maureen was another volunteer who dated fellow volunteers during her Peace Corps service. Prior to her service, she too figured that she would be single her entire time abroad. Before leaving, she remembered thinking, “I'm going to Africa. I'm not going to have sex for two years. (Laughter). SO I definitely thought that my identity would definitely be locked (in that regard)," Ironically enough, she was in a relationship more often than not while in the Peace Corps. She explained, "I was single ALL of six months of my entire Peace Corps service, including extending. That was a surprise!.” Maureen relied greatly on her significant other throughout her service. She explained, "My girlfriend was always my biggest support."

Other volunteers dated individuals who lived in-country but were not fellow volunteers. Mimi, who came out just weeks before her service, had her first same-sex relationship in Peace Corps. She explained:

Yeah, it was very strange. I only dated one woman while I was in the Peace Corps. Um, she was British...She was a bit older than me. We met at a pool party 
in (the capital). Um, she was great. It completely was an amazing experience for me. She even visited me in my village, which was crazy. So, um, that was strange. I never really came out to anyone in my village, but she was a presence there. Some people that I was close with, like the nurse in my village, she had like two daughters my age who studied in (a neighboring country) and they knew. Like, they never specifically told me that they knew, but they knew.

Mimi and her girlfriend dated for six months, spending most of their time together in the capital where Mimi's girlfriend was a major activist in the LGBT community. Dating her and being involved in this community proved to be a great outlet and source of support for Mimi.

Some Peace Corps volunteers even date locals while they serve abroad. It is more common for straight volunteers to do this, but sometimes when queer volunteers are involved in the local LGBT community, relationships evolve. Mark experienced this during his time in Peace Corps. Through his involvement with the LGBT community in the capital, he met a young man that he dated for a while. Throughout this relationship, he learned much about what it was like to grow up gay in such a hetero-rigid culture. $\mathrm{He}$ explained how his significant other shed light on how people know homosexuality exists but they do not wish to ever talk about it, let alone embrace it:

He was dead set against EVER telling his family, and that was where I kind of got the information about it being like an open secret. He would tell me people know that it happens. They don't want to talk about it or don't want to think about it or don't want to admit that it happens in their families.

The two only dated for a couple months due to cultural barriers and the distance. Mark explained:

The biggest problem was that there was just a cultural difference on timeliness, and the communication was a bit weaker than I would have preferred myself, and part of that was on my end cause I lived so far out that I couldn't do anything about it, so I mean, 5 hours in the U.S. versus 5 hours (in-country) are completely different things, so yeah. It was fun while it lasted, but it just was not meant to work out. 
Nevertheless, Mark was happy the experience happened. It may have been a short relationship, but Mark gained much insight from his boyfriend in regards to growing up gay in a society where compulsory heterosexuality is still enforced.

Additionally, some volunteers are in long-distance relationships with people from back home. Pam was once such volunteer. She kept in touch with her significant other through e-mails, text, phone calls, and skype. Although her significant other could not fully understand what Pam was experiencing abroad because she was not experiencing it herself, she still served as a prime source of support for Pam during her service. She even came out to visit her in-country for a short time.

It should be noted that although significant others were great sources of support for queer volunteers, the relationships themselves were also sources of immense stress. The context in which volunteers serve is not exactly conducive to dating. First of all, volunteers are serving in societies that are very different from their own, and in this case, they were serving in a society where homosexual behavior was actually illegal.

Therefore, volunteers are already struggling to navigate successfully through this foreign culture on a day-to-day basis. Throw in trying to make a relationship work there, and, well, it can create some complicated situations. As hard as volunteers try to make it work, the relationships rarely last. In fact, out of all the participants of this study, Pam's longdistance relationship was the only one to survive Peace Corps. Mimi explained that her relationship just got to be too much. She eventually had to tell her girlfriend, "I'm a little overwhelmed, and I can't deal with this, so we stopped talking."

Joanne stated, that although her girlfriend was the source of much support and happiness, it also was a constant source of fear for her: 
I was always fearing something was going to happen. That fear that's in the back of your head, and me, since I'm still like private about being lesbian and everything, I think I tend to over think things, and if I was holding hands with a girl and they knew we were gay, I was afraid that somebody was going to try and come hurt us or harass us, and I'm not confrontational, like I don't like confrontation at all. And I know once you push my buttons, and somebody's trying to hurt my partner, it's not going to end well... Yeah, so I mean, yeah, there was always this fear, just being back in the closet, and it just sucks. It just fucking sucks. I mean, that's like ten times worse, being with my partner and not showing how I feel or how affectionate I am because I think somebody is watching us or somebody might do something to us. I don't want to feel like that ever again. EVER.

For me, it was stressful as well. Trying to balance the life of a Peace Corps volunteer AND make a relationship work led to some very tumultuous times. It was also stressful to be in a relationship and have to hide it. Every time a community member would ask me if I had a boyfriend or if I was dating anyone, I had to lie and say no. This slowly ate away at me, as I am not one to normally hide my identity or relationships.

When Pam's significant other came to visit from the States, she was beyond delighted, but it was also a bit of a stressful time for her. She described the experience as such:

She brought a lot more of that baggage as someone who for the majority of her life has identified as a lesbian, and who definitely, by US standards, gets read as a lesbian, pretty much all the time, likes gets read as either a lesbian or a man ALWAYS. I had to explain to her that like a shaved head (in-country) doesn't mean anyone will think you're a dyke, but she was still nervous...Um, you know, there was a few times I slipped up and called her babe in public, and, you now, it wasn't a big deal, but it was something that we were so concerned about that it was like, oh my gosh. So her coming to see me was awesome. I was excited to show her around. It was a little stressful in public. Um, you know, I think you're always a little bit more paranoid than you need to be. It's always like, 'Oh no, people will see! People will see that we want to be together!'(Laughter).

Pam went on to explain how hard it was for her girlfriend to go back to America,

"Having to deal with kind of like the emotional reaction to her leaving and not being able to be authentic in telling people why. You know, it was just like, 'Oh. I'm sad my 
FRIEND left." This attests to the inner turmoil it causes when queer volunteers have to suppress such important parts of their life. Even for those of us who dated people incountry, it was hard to say good-bye to significant others. We never really knew when we would see our significant other again, and then it just caused additional stress when we would have to put a smile on for our communities and pretend everything was just fine.

It is important to note that some queer volunteers do not date while serving abroad. Roger, for example, explained, "I was single when I went in. Single while I was there, and single when I left. I had never had a romantic experience while I was there.” When I asked if that was challenging for him, he said, "Yeah, I probably underestimated it going in, but there also wasn't an opportunity. The only time the opportunity presented itself was when I happened to be in South Africa (on vacation)." He told me that not dating was challenging but not devastating because he knew it was just a temporary reality. Additionally, it was not extremely challenging because he did not have to struggle with deciding whether or not to date someone because the opportunity did not arise in his country of service. He explained, "I just sort of settled into a routine. It wasn't even something where the opportunity ever presented itself, and I had this sort of difficult choice to make about, 'Oh, should I pursue this or not?' It just NEVER happened.”

In contrast to Roger, where the opportunity of dating never presented itself, Collins actively chose not to engage in dating or relationships while in the Peace Corps. He stated,

Being in a country that was so hit by the epidemic of HIV, anyone would be hesitant to have sex. Um, you know, straight people included, but, um, I guess for me, I just completely didn't engage in that way. I was basically abstinent my entire Peace Corps experience, so THAT was the biggest challenge. (Laughter) THAT I will say was the biggest challenge, BUT I don't think that's unique to me. I think there are other straight volunteers who had that same experience. 
As one can see, Peace Corps Volunteers have a wide range of experiences when it comes to dating during service. Some find companionship among fellow volunteers and some date locals or individuals who hail from other countries. In comparison, other volunteers actively chose to refrain from dating while serving abroad, while some never have the opportunity to date present itself.

\section{Additional Coping Strategies}

It is important to note that queer volunteers utilize other coping strategies — aside from those related to their sexual identity - to successfully navigate their Peace Corps experience. Collins described the strategies he implemented as a volunteer:

I would lock myself in my house (Laughter) for days on end, you know, like any (Laughter) any upstanding volunteer. Um, I liked to do things for myself. I think that, um, one of the things that I sort of pointed out as a big problem among all my friends who were ETing (ending their service early) was that they didn't layout things they wanted to do for themselves. Like I just wanted to do this project, and it's just going to be about me, and, you know, it doesn't have to involve anyone else. It's just a thing I want to do. SO like, you know, if your goal is to like read like twenty books in six months or something, that's a goal you can accomplish by yourself. I had little things like that. I really liked to cook, I read a bunch just like everyone does, watched a ton of movies and TV. Those were good coping strategies. I worked out. Um, in terms of like socially, I traveled a lot. Um, I left my site every two or three weeks. If I was at my site for more than three weeks, it was a problem. Yeah, I was out of there a lot. First of all, to shop because I lived in a place where I wasn't able to buy groceries, but, also, because I needed to be social. I needed to be around my friends, so I did that. I traveled in the country a lot, but also internationally. I would pick up and go every few months. Those were my coping strategies.

Other volunteers utilized many of these strategies as well. Mark, for example, said, "Reading was a big coping strategy. I did a lot for like personal self-improvement. I read a lot. I did the national novel writing month one year in November, and then I also decided to run a marathon when the longest race I've ever done was a 5K. (Laughter)" Some volunteers turned to more drastic forms of coping. Joanne explained, "Yeah, I 
would just drink a lot, and I never smoked so much weed in my life.” Others also used an arguably healthier coping strategy: Humor. Maureen explained, "I can make a joke out of anything, even if, if I bust my ass, I'd be the first one laughing. I'd be like, 'That was funny. I wish I could have seen that.' So every time I would trip or get frustrated, I would ALWAYS, like find something funny about it." Humor is a big coping strategy among volunteers. I remember as volunteers we used to say that sometimes you just have laugh to keep from crying.

The Role of Intersectionality of Identity on One's Peace Corps Service

Up to this point, this paper has focused on how queer identity can impact the experience of queer Peace Corps volunteers. However, it would be a grave mistake to reduce these queer individuals to one facet of their identity. It would also be a grave mistake to assume that their queer identity was the only facet that impacted their service. Therefore, this paper, like Hames-Garcia's (2011) book, Identity Complex: Making the Case for Multiplicity, uses a theoretical lens of multiplicity, which "understands social identities as mutually constitutive," rather than as discrete and separable (xi).

With that said, I would now like to move on to a discussion surrounding the intersectionality of identity and how different facets of volunteers' identities played a role in their experiences as Peace Corps Volunteers. As Cronin and King (2010) explained, "applying intersectionality theory can be problematic because decisions about which categories should be included are reflexive, selective tasks" (884). In this study, the main facets that affected these Peace Corps volunteers' experiences, other than sexual orientation, included race, sex, age, and nationality. Therefore, these are the social categories that will be discussed. Furthermore, readers may or may not be surprised to 
learn that these additional facets impacted volunteers' experiences more than their queer identities.

It is important to note that the influence one's identity markers have on their life do not occur in a vacuum. More often than not, these facets overlap and intersect to have a compounded effect or impact on an individual. Two facets that play a major role in the culture where these volunteers serve is both age and sex. The society in which these volunteers served can be described as a very ageist one. The older an individual is, the more respect he or she receives. As a child or young adult, an individual has almost no respect and is expected to do anything and everything that an older individual tells one to do. In addition, this particular society considers individuals children until they reach the age of thirty-five. As a result of this cultural belief, older volunteers have the respect of locals almost immediately upon arrival, while younger volunteers have difficulty gaining that respect, as they are initially perceived as incapable and unqualified. This cultural attitude surrounding age is very different than America culture, and, therefore, is a huge obstacle for younger volunteers to overcome throughout their service. Prior to their time in Peace Corps, most individuals actually left their childhood homes at the age of eighteen to embark on a life of their own. By the time they do Peace Corps, they have been living on their own for years. This fact makes it very difficult for individuals when they come to serve in a country that all of sudden views and treats them as a child again.

In regards to how men and women are viewed and treated, the country of service has made great strides in gender equity in the modern sector, but in most rural villages where volunteers serve, gender equality is far from being reached. This can impact a volunteer's service greatly. Local women who live in rural areas have low economic 
status and tend to have less authority and responsibility than men do. Although this is slowly changing, many rural communities have not had much experience with women taking on professional roles, remaining unmarried, and living away from their families. Therefore, many female Volunteers are viewed as unconventional and almost deviant in nature. As a result, they experience a great deal of unwanted attention. Female volunteers also tend to discover that it takes longer to establish credibility with co-workers than their male counterparts. Alexi provided much insight into how being a young female affected her service:

In this culture, age is definitely revered. Being young, even though I'm college educated, was hard. I'm like a very intelligent person. It sounds like I'm bragging (Laughter), but I have good ideas. Like I know how to help them. I have training in ways to help them, but it almost doesn't matter. I have a male counterpart at my school, and I just have him run my ideas by people 'cause they listen to him more. Um, so that's hard. I'm my own person. I have these ideas. But I'm not a guy, and I'm young, so I'm not considered to know as much as someone older than me, even if I do. It's like almost disrespectful if I know more than someone older than me. Um, like trying to teach an older population, a lot of my older teachers are just like embarrassed that I know more than them, so they just refuse to even learn. They don't want me to see them not doing well at something. Um, so that makes it difficult.

Alexi described in detail how being female is difficult far beyond just not being taken seriously in a professional setting:

Being a woman, like women are constantly sexually harassed...Men are always like, 'I want to have your babies. I want to marry you. Be my woman.' And it's like you're an object. And it sucks, 'cause I feel like I could never have a legitimate male friend (in-country) 'cause the experience always gets creepy eventually. Like some male teachers and I would always joke around and be friends, and then eventually it was like, 'Are you going to sleep with me?' And I'm like hahaha (thinking they were joking). And then it's like no, they're serious. It seems like it's always in the back of their minds. 'Can I get with her? She's white. She's a woman. She'll obviously sleep with me.' It's very common in the culture, and it's common for men to like call women baby, mine, and creepy things like that. And just like, touch women. It's a very touch friendly culture. But just like touching women, like that's inappropriate, like don't touch me. 
Finally, she went on to discuss how this negatively affected her relationships with the men in her community:

The longer I was there, the more I was like, 'Get away from me.' Or I just didn't want to engage with them (men). Like, 'No. I'm fine. Go away. I'm done.' Which is bad, 'cause sometimes people were so nice, so it made me feel guilty because normally I would just tell them to go away, even if they weren't actually being creepy. Also, there are certain people in the village that I just avoided being around, which sucked, cause one was my nurse, one worked at the police post, so that was like two major areas of the village that I just didn't go to anymore 'cause it was so annoying. Cause it's like I wasn't going to keep going and fight them about it. I just stopped and focused on something else. But it definitely affected my service.

As one can see, the sexist behavior that exists in this society can prevent female volunteers from a successful service, as it deters them from interacting with key stakeholders in the community.

Alexi was definitely not the only female volunteer to face obstacles due to her gender identity. Joanne elaborated on how being a woman was the most challenging part of her service:

Being a woman. THAT was hard. Oh man, I just wanted to like punch some guys in the face sometimes. You know? 'Cause I'm a woman, you don't think I'm strong enough to hit you? (Laughter). That equality. Ahh, cause I'm a woman, I can't change a tire? I had a friend (in-country) who was an engineer, and they told her at an interview, 'Hey, you're a woman. You know you can't be an engineer. It's all for men. It's a man's job.' God, I think that was the most challenging part...Like I just felt not represented as being smart. I felt like really downplayed... Yeah, it affected my self-esteem A LOT, and I already have like low self-esteem from it, but then it's just like (Laughter), like I'm glad I was brought up playing soccer because I'm like, 'No, I'm persistent. I don't quit. I'm going to keep doing it, and I don't care what you say anymore.' After one year of knowing the ropes and everything and knowing what to say, like you just push on.

Furthermore, it not only affected her self-esteem during her service but also long after she returned home. At the time of her interview, which was months after her return to America, she was still struggling to get that self-esteem back. She touched upon 
readjusting to being gay back home compared to being a woman back home, "Um, being gay is easy here (in America). It's just who I am. Being a woman, just trying to get back that confidence, just saying, 'I can do this again' Um, adjustment is hard here."

Joanne and Alexi were not the only volunteers who struggled as young women in the Peace Corps. Pam touched upon how patriarchal she deemed the society to be:

As a woman and as a someone who grew up in a liberal community, and as someone who was never told that I couldn't or I can't, I think what is most frustrating about (this country) is that it is a patriarchal society that is MOSTLY from what I saw in the small communities I visited, and it seemed to be every community I came across was these small, local economies is almost entirely on the back of women. That, you know, most of the nurses, we had a few male nurses, and the only doctor we had was male, but most of the nurses and midwives were females. Almost all of the teachers I met were females. All of the tuck shops and general stores in my community were run by females. Um, you know, all the librarians were females. SO what was frustrating most to me was that you have this community that kind of gives men all the power but doesn't expect them to do any of the work. You see these patriarchal societies (in other parts of the world) where it's like the men are in charge of working and protection and, you know, the women are in charge of family and kind of cultural activities, and at least then, the men are like contributing. (Laughter). But (in this country), it's like this patriarchal society where not only are the men not really expected to protect anyone, but they're not really expected to work either. It's like here. Just have this power. Don't worry about giving us anything in return. Um, you know, and it's kind of why, I said it multiple times while I was over there that it's is like a country of man-babies. It's just it is!! It's an entire country of manbabies who will never get kicked out of their mother's house, who will ultimately inherit all the wealth...It's a country full of man-babies!

Pam discussed how sexism affected her and her service,

Being a woman...that was frustrating. You know, explaining that I didn't want the attention of men was frustrating. Explaining to young women why I didn't seek out a boyfriend, and then hearing back, you know, that well, women who don't seek out boyfriends just want to sleep with everyone... So being a woman in that culture was really frustrating and agitating and just people thinking they had rights over my body and over, you know, my actions in ways that they didn't have rights to. Um, so that sucked. 
Due to the reasons fleshed out above, it is not hard for one to see why many female volunteers stated their gender as the most difficult part of their identity to grapple with while serving abroad.

Serving a society where gender equality is far from being reached proved to be a daily struggle for many female volunteers. They faced sexual harassment and sexist attitudes towards them on a daily basis. Like many volunteers, Mimi faced many challenges due to the make-up of her identity. She explained:

I'm pretty petite. I'm like 4'11.' So, um, just looking young and small, people taking advantage of you. Like I'd go to shop, and I'd literally be grabbed by men in grocery stores, like, 'Oh, come here!' And I'm just like, 'I'm not some (object), you can't, no!' So that was hard, just being objectified by men in that way. I've never really had that kind of male attention to that level. It was really kind of scary, I'd have to say.

These testimonies shed light on how hard it can be for female volunteers to serve in societies where gender equality is not valued, especially coming from a frame of reference where gender equality is more widely accepted and more of a reality.

Due to the societal attitudes surrounding gender, it is not surprising that the male volunteers reported a much different experience than the female volunteers. Whereas gender was a detriment to the women, it played a positive role for the men in my study. Collins touched upon his experience as a male:

Being a male (in-country) is incredibly easy. (Laughter). Uh, you know, like you deal with some added responsibility, especially in terms of Peace Corps situations. Like I always felt like I had to watch out for my female friends. Um, I always felt like I had a responsibility to take the lead on certain things where like it wouldn't be safe for females to do the same thing or, you know, whatever, do the talking if someone was being a dick or something, you know? (Laughter). Like, there was added responsibilities I guess. Um, but in terms of like harassment and what not, like, no I didn't really have that. I didn't really have that experience, beyond what like a normal white person would have. Yeah, It was easy I think. (Laughter)... I guess I don't know how being female would be, but, of course, in comparing myself to my friends who were there, I know that my 
experience was much easier. I could get things done easier. I would immediately have respect from people, whereas they might not.

Mark's experience of being a male volunteer resonated with that of Collin's:

Being male helped. Um, it gave me a bit more credibility than the female volunteers got. So that helped. It let me kind of pick what I wanted to do. In my first year, I actually coached the women's soccer team instead of the boys, which I thought kind of surprised them (the locals) to see a male doing that 'cause it was usually the female teachers who would do that. I tried to use it to my advantage to give them pause to think.

As one can see the experiences of male and female volunteers differed drastically. With that said, gender identity was just one factor that affected a Peace Corps Volunteer's service.

As Alexi spoke to earlier, age also played an influential role in volunteers' experiences. I would like to further discuss the impact of age in this section. For example, even though Mark had the advantage of being male, his young age was a detriment to him. He explained, "Um, the other thing that hindered my service was my age. The older you are, the more respected you are. I was only twenty-three when I started. I was much younger than most of the staff at the school." Maureen attested to what it was like to be on the border of what the locals considered youth and the age of adulthood:

You're a child in (country) until you're like twenty-nine, thirty-two. And you know, I was like thirty-one, so they're like, 'We'll she's not a child, I can take her seriously.' You know? 'And she's also knows how to have fun.' So I was in that age where people would listen to me, but I was allowed to act a fool the same time, and they're like, 'You're just young enough to do that!' (Laughter)

Unfortunately for Mimi, she was in her early twenties during her service. Therefore, her age caused her co-workers to view her as unqualified. She explained how she had to overcome this:

It was really hard. I pride myself on being really accomplished, like I put myself through school. I graduated Suma Cum Laude. I'm freakin' smart. I was like, 'No, 
this is not cool. I'm educated,' and so we had a life skills retreat somewhere, and all the principals and head teachers came and we had like a talk, and I broke down crying to my principal. I was like, 'You don't take me seriously.' I was like, 'Before the Peace Corps, I was a teaching fellow. I've taught English. I taught Art History. I've done this before. I'm not a certified teacher, but I've done this, and you're treating me like shit, and you don't take me seriously,' and I just like bawled. And he was like, 'Okay, I had no idea, like these are your credentials.' I was so upset. I was like this is so frustrating. But finally I was like, okay, that's where the disconnect is, like Peace Corps did NOT inform them of any of our shit, so let me talk you through why I'm qualified (Laughter) to be here. After that, things went smoothly. He was actually one of my biggest advocates. $\mathrm{He}$ was actually really great, and any project I had, he was behind me $100 \%$.

This experience was not unique to Mimi. Due to age, many of the younger volunteers have to prove to their communities that they were capable and qualified.

On the flip side, Roger, who was forty-one at the time of his service, had the advantage of being both older and a male. His experience was very unique compared to all of the other participants in this study, as the facets of his identity seemed to be a compounded advantage as opposed to a detriment:

I think there was a lot of difference shown to me because I was male and in my 40s. I think it gave me a bit of a different experience than other volunteers, especially other female volunteers. I seemed to be given a lot of latitude, and I think it was partly because of age and experience and partly because I was a man. You know, either because of age, gender, or both. No one really questioned me. They seemed to assume I knew all the answers when I got there. I felt and saw the difference based on other people's experience, but for me, it ended up being kind of a net-positive.

Due to Roger's age and gender, as well as the fact that he was a white man, local people did not harass him or ask incessant questions about his personal life. This caused his Peace Corps experience to be vastly different than most of the participants of this study, as they were asked questions of this nature almost daily.

Also making his experience vastly different than other participants was the fact that Roger faced little to no identity negotiation, especially in terms of his queer identity. 
It was just a non-issue for him. It never came up. When asked how he managed his queer identity at site, he explained:

You know, it's surprised me how little it ever came up. The people in my community, they didn't ask a lot of personal questions. Period. So I was surprised. I thought more people would inquire are you married? Do you have a girlfriend? They knew I didn't have kids. You know, it really just never came up. I mean, I had people over one night. They were looking at some of my photos on my computer. They asked who certain people were, and I would say, 'Oh, that's my friend Mary. Oh, that's my friend Jenny.' They just sort of nodded. And I was ready for them to ask like, 'Well, is this your girlfriend? Is this your ex-wife?' No one ever did...The previous three volunteers in (his village) were all female volunteers who ended up marrying local men, so I would have thought with that precedent set that the flip side would have been expected of me. You know? But it never really came up.

Due to the fact that he did not have to face much identity negotiation, Roger experienced minimal stress in regards to his queer identity. He explained:

I thought it might be a little more stressful to live in the closet after being out for so long. But then, my day to day to life, like I said, it just didn't come up, so whatever stress I felt about it, it really just sorta dissipated. You know? There were a couple of other volunteers, um, in different places who ended up becoming friends with gay (locals), um, and they had different experiences because they were concerned about their well-being and concerned about how people, um, perceived their friend, not themselves. Because they were friends with people who were openly or suspected to be gay, um, they got, um, questions from their, um, people at their site or from their work place. But I never met anyone in (country) who ever told me they were gay or that they had romantic interest towards me, nor did I have any romantic interest towards anyone... So it ended up being very unstressful. It didn't really create that much stress.

Roger's experience is quite an anomaly in the regard that the facets of his identity turned out to be a net-positive for him. There was not any single facet that he had to learn to negotiate or manage. This is definitely not the case for most volunteers.

It should also be noted that race played a role in how volunteers were viewed and treated. Outside of the capital of this country, local residents have little exposure to other cultures, races, and lifestyles. It is important to note that in these volunteers' country of 
service, there are very few Americans living there. The only representations of

Americans they see are through the media. Therefore, the locals have some pretty

incorrect perceptions of America and American life. For example, many locals believed

that all Americans are white and all Americans are rich. This can cause a lot of distress

for Peace Corps volunteers. Mimi, who is Hispanic, explained the struggled it caused for

her during her service:

So I'm Hispanic, right? My mother is Black Cuban. My dad is White Cuban. So I'm mixed race Hispanic, and so, the (locals calling me white) drove me crazy. 'Cause I'm like, 'I am not white! I have never identified as white! I refuse to identify as white! Stop calling me white!' And it took me a good like 4-6 months to convince people that I'm colored. (Laughter) And they were finally like, 'Okay, we'll call you colored. That's fine.'

She went on to explain how this was a daily struggle for her:

But everyday was a fight, and I'd get so upset. It's just like 'I'M NOT WHITE! I HAVE NEVER BEEN WHITE.' Like I grew up in Little Havana, in Miami, right? So it's a very Cuban populated area, and, you know, I grew up on food stamps and, you know, single working mom, and, you know, I grew up poor, so I was coming here, and they're like, 'Oh, you're white, and you had all these advantages and all these privileges,' and I was like, 'I'm going to tell you something, that was not the case. That was not what happened. I had to work two jobs to put myself through college, like F you, I have so much money in debt,' like, 'No, no. You cannot treat me like a privileged white person!' (Laughter)

Overall, this struggle was harder for her than any LGBT issues she faced during service:

So, yeah, that was probably even harder I think than LGBT issues for me....Growing up in Miami, like I never had to defend my like culture or like kind of explain to people. They (Americans back home) were like 'Oh, your name is Mimi Gonzalez, of course, you're Hispanic.' (Laughter). You know what I mean? It's just expected. And so it (being Peace Corps) was the first time for me to have to kind of really delve in and be like what does Hispanic mean to me? Is it because I speak Spanish? Is it my food? What is it that makes me Hispanic? And how do I identify? And how do I, um, kind of make that come across to people? That this is what it is important to me, you know? So, I don't know. It was new I guess. 
Mimi was not the only volunteer whose race played a more influential role than his or her sexuality.

Many other volunteers attested to the importance race plays on one's Peace Corps service. Collins, who is multi-racial, also said that race impacted his service more than his sexuality. He explained, "I think that the color of my skin impacted my service way more than my sexuality, which I'm sure that most people in (country), especially most white people, um, experienced that as well. Um, but I think that being an outsider is typical of the Peace Corps experience.” Maureen, a black volunteer, told me, "You know, I think, uh, being black affected my service probably even more than even being gay." In fact, she claimed that serving in Africa changed the way she identified in regards to her face:

The biggest realization I had there was that I'm American. Before this, I was all like, 'Black Panthers, Marcus Garvy, let's go back to Africa.' Then I went to Africa, and I'm like, 'I'm American. I'm sorry. No, I could not. I've been there, and I'm okay.' It changed my perspective like that I wasn't African the way I would like to think of myself. Like I'm black. I'm not African American. I don't know shit about Africa. (Laughter). Even after going there, I don't know shit about Africa.

As a black volunteer, Maureen was forced to examine and reflect on her race and what it meant to her personally.

Maureen also had to deal with many misconceptions from locals in terms of the

reality black Americans face back in the United States. She explained:

I would get different misconceptions. It wasn't all like, you know, daisies and tulips. It was horrible. I remember I was at a bar one time, and I was ordering us some drinks for everyone else. This guy comes up next to me. He's like, 'Hey, you're American.' I'm like, 'Yeah, yeah, I'm American, but before you even ask, I don't got no money.' He was like, 'Oh no, I wasn't going to ask you for money.' And I was like, 'Okay, then what do you want?' And he was like, 'Well, you're black, so, of course, I wouldn't ask you for money.' I'm like, 'So whatcha going to ask me for?' He points at the TV, and there just happens to be some 
BET, American booty shaking on, and he said, 'I just assumed you were a whore.' Said that straight out. 'Cause he's like, 'All American black women are slutty, right?' And I'm like, 'Noooo! (Laughter). I'm sorry have you seen me in a Juvenile video? Like no!' And he's like, 'Oh, well, why are you so weird?' And I'm like, 'I swear to God I'm not.' (Laughter). And because of my locks (dreads), all the guys on my corner would also, uh, every time I would walk by the car wash, they'd all be like, 'Hello Rastapastafara!!' And they would just yell random Jamaican things at me. It's always like a pain in the ass that people would assume who I was or they'd come up to me and say I was from the ghetto.

Another misconception that Maureen faced quite frequently from locals was that black individuals could not possibly be American. Furthermore, she was made to feel guilty that she did not know more about her African background:

All the time, I got that I wasn't or I wasn't good enough American. I got more though that I didn't know my African roots, like how dare I? Like, 'Do you hate yourself so much that you don't know where your family comes from?' And I'm like, 'I would LOVE to know the answers to those things.' (Laughter). I also got that I had to be whatever tribe they wanted me to be and talk shit about the other tribes. You know? Uh, or I had to be someone's token, like, you know I did have some friends invite me places, just to have me speak for no reason. Like I went to a wedding, sat up front, and I gave a speech, and I barely even knew the people getting married. Had to sing a song too. (Laughter) Like, c'mon, I'm not your dancing monkey.

It is for reasons like these that Maureen found her race to be much more of an obstacle during her service than her sexual orientation.

With that said, Maureen did find some advantages to being a black volunteer. She speculated that her Peace Corps experience may actually have been harder as a young, white volunteer:

I also felt like if I was a white volunteer, trying to be me, and especially if I was younger, it would have been enormously hard. I think being black and being older, you know, they (the locals) were less intimidated. You know? 'Cause a lot of times if I stood very still and didn't talk, they would think I might be (a local) or, they're like, 'You're not from here, but from somewhere near by.' You know? Or like, 'Oh ok, we get you're American, but where's your daddy from? America. Okay, okay. Where's your granddad from?' 'STOP! They're from America. As far back as I can go, they're ALL from America!' 
This experience was by no means unique to Maureen. In fact, many other volunteers faced challenges with their American identity as well.

This brings us to another point of discussion: the role of nationality on one's Peace Corps service. Adam explained, "Being American, eh, it was a hit and miss. In certain ways, it helped. In other ways, it was just always people begging me for money."

Alexi touched upon some of the misconceptions locals had about Americans:

Just that Americans are rich. Americans don't have problems. Like, the average (local) you meet will say, 'Oh, but you are rich. But you have money. You don't have problems. You don't have debt. There are no Americans without homes.' The average (local) doesn't want to hear that that's not true.

Sue had similar experiences with locals, "I think people probably thought I had money, even though I would always tell them I don't.” Joanne encountered this problem as well:

That stereotype of being rich and all that stuff. Uh, I don't know, they just question being American sometimes and the stuff we do. So sometimes that's when I'd be like, 'Hey I'm Mexican, not American.' So I wouldn't get that stereotype of, 'Hey, take me to America.' And they don't even know where Mexico is.

It was interesting for volunteers to see how the locals viewed Americans, but, as insightful as it was, it did become old quickly and volunteers were more annoyed by the stereotypes than anything else.

With that said, volunteers did learn important lessons about being an outsider or standing out in such a homogenous society. Pam touched upon how being white in a predominately black community gave her much insight and perspective on how it must be for racial minorities in other places of the world:

Being white, I do think that having the experience of being an extreme minority in a country as a white person was really educational to me. Um, you know, and knowing what it feels like to walk down a road and have people stare at you JUST because of the color of your skin. I don't think that by any stretch means I have a 
minority perspective on life, but I certainly it gave me a wider perspective as a white person.

Collins added what it was like to be an outsider in his community and how community integration, although greatly emphasized by Peace Corps, is nearly an impossible feat for volunteers:

I guess, uh, I always sort of had qualms with the idea of community integration. Um, like, you're supposed to be one with your community. You know? There are always going to be inherent barriers though. Like every single person who comes in as a Peace Corps volunteer is NEVER going to be (a local), like that is a fact. Like you will NEVER be (a local). You may after like years and years of gaining citizenship or something, but you will never have grown up in that experience, that culture. So, there's going to be inherent barriers no matter what. Um, so I think like that is the number one obstacle that everyone faces in Peace Corps, which, of course, is really vague and broad and what not, but being an outsider in general has a bigger impact on people's, or at least on mine, it had a bigger impact on my experience as a Peace Corps volunteer than, than any other part did.

It is clear to see from all of these stories that an individual's facets can impact their service in different ways and, as a result, Peace Corps volunteers have a wide array of experiences when they serve abroad. No two volunteers have the same story. Therefore, how identity affects experience cannot be generalized. The only fair conclusion to draw is that the impact of each of these facets does not occur in a vacuum. They often overlap and intersect, causing a compounding effect on an individual's experience.

As for me personally, many of what my participants discussed with me in regards to how different facets of their identities impacted their service, resonated with me greatly. Throughout my service I would often reflect on how my identity was playing a role in my work. For example, I wrote the following in my autoethnographic journal on how my American identity was impacting my experience abroad:

My identity as American has definitely played a huge role during my experience here thus far. And it's not just how others view me and treat me. I'm always going 
to be treated different here because of my status as a (white person). I can't change that as my race and skin color are ascribed statuses. I have found that my attitudes and beliefs have changed surrounding America and Americans... I know that growing up in America has molded me into a certain person. I was socialized to believe and behave in certain ways. Success is equated with being the best. Individualism is very much valued in American society. All the factors that make for successful capitalistic endeavors, such as competition, efficiency, innovation, motivation, dedication, ambition determination, structure, organization, etc. are what is instilled as values in Americans. Therefore, coming here, where there is a much slower pace of life, and an incredible lack of organization, motivation, and ambition, as well as no value surrounding efficiency, it's been very hard to adjust.

I find myself thinking how things could work so much "better" here if they would only do this or do that.... and then I remind myself that I only think this way because I'm an American and I come from a culture that puts profits before people. And then I find myself thinking, 'Maybe it's not about who is wrong or right. It's just a different way of life here. I can put my two cents in, but I should not force my values or beliefs onto people.' This is a constant internal struggle though. When is it my place to step in? And when do I need to respect cultural boundaries?

Furthermore, it's no secret that I'm very critical of America. Being a minority in America, it's hard to see it as the ideal nation that so many people view it as. I see it as hypocritical, exploitative, and ridden with stratification and disparity beyond belief. For a country founded on equality and freedom, the institutionalized discrimination and structural violence that exists in America makes me sick. In a country that claims to be a level playing field and a place where everyone has equal opportunity, the breakdown of demographics surrounding class, education, and employment screams anything BUT that. In a country that claims to have separation of church and state, every four years our president is still sworn in with this hand over the Bible, our currency still says, 'In God we Trust,' and our legislation is driven by a Christian belief system. For all these reasons, I'm critical of those who believe that America is an equal, just, and fair nation.

Since coming here though, I have to admit, I have learned that no nation is perfect. There is corruption, disparity, and injustice everywhere. I guess it's just that America claims to be different, so I'm going to continue to hold it accountable. I will continue to be critical until what is written in our nation's constitution actually becomes a reality.

I'm tempted to say that after seeing what people have to deal with on a daily basis here, I'm lucky that I grew up in America, but that's a generalization that I won't make. So let me be more specific. I'm lucky I grew up in America in a family and place that had the means and resources to provide me with everything I needed and then some to become an educated, productive member of society. I've 
met so many people here who think all Americans are rich, happy people with endless opportunities. I have to tell them, that not all Americans are rich and not all who are rich are happy. Working in a school here, I often find myself thinking how lucky Americans are to have the education system we have, but the truth is that only some Americans have access to good education. A lot of Americans face the same obstacles that African children here face: lack of materials, lack of funds, lack of trained and motivated teachers, lack of extracurricular activities, lack of values surrounding education in their communities, etc.

Overall, being an American is one part of my identity that plays the biggest role in how I experience life here. Not just because of my beliefs and values that I grew up with there, but also because of the attitudes and beliefs of (locals) surrounding Americans. There are a lot of stereotypes, as I mentioned above. For example, that we are all rich. Many also believe Americans know everything. It's disheartening to hear how some believe (Americans) are superior to Africans...I've heard stories from my teachers of their children wanting to be white because they want to be beautiful and smart. My host sister would always tell me how beautiful I was, and how she wanted skin and hair like mine. When I would tell her that I wanted skin and hair like hers because she was so beautiful, she would not believe me. It sickens me that this mindset exists here. I know issues surrounding the beauty ideal are a universal concern. It just boggles my mind how its not just about shape and size but also race. It's about ethnicity. It's about factors beyond one's control.

And it sickens me even more that this is used to keep the current power structure in place in our world. If you drill an idea into people's head enough, they come to think of it as fact. If they think they need to look a certain way to be powerful and successful, and they don't look that way, then they'll believe it's not their place to hold certain positions in society. I wish I knew how to address this issue, but how do you successfully cause a paradigm shift to occur surrounding an issue that has become so engrained in a culture that it has become seen as fact?

Being an American is not something that you constantly think about back home, as you are constantly surrounded by other Americans. It's not until you find yourself in a culture very different than your own that you are forced to think about how it really affects your life. Using the only frame of reference you have, you compare everything you experience to that. For me, it's an American frame of reference, and as a result, I look at the world here through an American lens. I'm glad that I know the value of cultural relativism and reflexivity, or I think my experience here would be a much different one.

Being an American was one facet of my identity that greatly impacted my service, but it was not the only one. 
Like my participants, age and gender are two other facets that deeply impacted

my service. Therefore, I would often ponder the effects of being young and female in the

Peace Corps. I would often write about it in my journal. Here is one such entry:

Let me touch upon age first. In this country, age is closely tied to status and respect. The older you are, the more you are respected and valued in this society. The locals really take the notion of respecting your elders to a whole new level. Furthermore, individuals in this country are considered youth until they are thirtyfive, so people aren't seen as adults until they are almost forty years old. This cultural difference has proved to be a huge obstacle for me in many respects. First of all, in America, you are considered an adult when you turn eighteen, and, in my opinion, you actually receive a lot of flack from people if you don't act like an adult by this time. At this age, you are expected to start caring and providing for yourself. You're expected to move out of your parents' house, further your education, get a job, and start being a productive citizen of society. If you don't do this, you're almost looked down upon as someone who is a "loser" or someone who can't make it on their own. Therefore, for the seven years prior to Peace Corps, I was doing exactly that. I have been living on my own. Taking care of myself. I obviously still rely on my parents for some support, but not to the extent at which I did before I moved out and left for college.

I was seen and treated as an adult in America for the past seven years, so it has been quite the adjustment coming here and being viewed as a child. The majority of the staff at my school are older individuals. There is one girl who is twentyseven, a couple people in their 30s, but the rest are 40 or older. A few of the older teachers call me their 'daughter,' 'my girl,' 'my child,' etc. It's not just the staff at school either. Whenever people find out how old I am, they are so shocked and surprised, saying that I'm just a (child). Coming from a society, where asking someone their age is actually a cultural misstep and a society that values young individuals instead of older, this has been quite the culture shock for me. Back home people lie about their age, so they can appear younger to people. Here, people lie about their age, so they can appear older. Furthermore, I have learned $t$ hat if someone tells you how old they are, you should NOT tell them that they look younger. They actually get insulted. People here WANT to appear older. They want the respect and status that comes with it. I have come to hate when people ask me how old I am because I know that when they find out that I automatically lose respect. I don't think people take me as seriously when they find out that I'm twenty-five years old. I almost feel like they look down upon me when they find out my age. It's almost like they are asking themselves, 'Who does this child think she is, coming in here, and trying to do the work of elders?' All of this has been really frustrating. I feel like I have worked too hard to be where I am today to not be respected or taken seriously. 
Over time though, I have come to realize that thinking in this manner is an arrogant, selfish, and ethnocentric way to view the situation. Here, age carries much weight. Most people who are my age here have not accomplished what I have accomplished in my life. They are not expected to, so why should anyone here believe I am any different? They don't know my past. They don't know how life works in America. Therefore, I just have accepted that I have to show them through my actions that I deserve to be respected and taken seriously. I think I am slowly accomplishing that. Every time I come up with a new idea or complete a project, I can see that I'm earning their respect.

It's been interesting to hear the perspective of the twenty-seven year old female teacher that I work with, in regards to how age affects one's life here. Pretty much if any one older than you asks you to do anything, you have to follow the orders. I have seen this happen so many times between children and adults. Even the teachers at school have the children running around all over the village for them. Teachers seriously do not do anything for themselves. They are not expected to do things for themselves. This was somewhat surprising when I first witnessed it, but that's how the culture works here.

Children are just expected to do more here, even at home. They do the majority of the chores, starting at a very young age. With that said, the teacher who is twentyseven is also seen as a child in the other teachers' eyes. Therefore, she is expected to follow their orders as well, and, as a result, is very much taken advantage of in my eyes. Seriously, whenever a task comes up that no one wants to do, she is told to do it, and because of her age, she cannot fight with them. They treat me the same way, but to a lesser extent because being an American brings a certain status with it. This young teacher is made to go to workshops and meetings that no one wants to attend. She has to fill out result analyses when other teachers don't feel like doing it. She also has to go from classroom to classroom gathering information for other teachers. For my after school club, my counterpart makes her translate my lesson plans and present them when he doesn't feel like helping. One time, she even found me in the staff room and asked me to help her make fat cakes for the athletic competition because they had asked her to do so, and this was during the school day mind you. They just expected her to leave her class and cook. She has even made comments about how the students don't see her as a real teacher because of her age, and even some people in the village have treated her like she is a child. She told me a story once of going to one of the tuck shops (outdoor sale stand) and the woman wouldn't help her because she said she was a child. It's just a very ageist society but in the opposite manner of America.

On top of age being an issue for me, gender has also played a role in my experience here as well. With that said, it hasn't played as large of a role as I thought it would. During PST, it was drilled in our heads that this is a very patriarchal society with rigid gender roles and divisions. I definitely agree that this is the case, but I haven't really encountered any issues with not being respected because I am a woman. Also, it seems like in my village, the women 
outnumber the men, so that also plays a factor I believe. It should be noted though, that even though women outnumber men, most community committees have a male chairperson. For example, our PTA consists of all women and one male. The male is the chairperson. The last PTA committee consisted of the same demographics, and the one man on the committee was the chairperson. In our recent election of committees for the planning of the local chief's celebration, only a handful of men showed up for the meeting. Personally though, I believe women in my community have proved they can be effective and competent leaders. There are many women on the Village Development Committee, our social worker is a female who is one of the most respected individuals in our community. Our head nurse and welfare officer are female, and the majority of teachers are females. Women are expected to do most of the household chores and childrearing, but even here, in a settlement of just nearly 800 people, I have witnessed my landlady's boyfriend doing laundry, cooking, dishes, etc. I think it just depends on the household. Honestly, my host family during training lived in what is considered a large city in this country, and they seemed to have stricter gender roles and divisions than I have witnessed here in my rural village.

With that said, people have expected me to participate in specific gender roles because I am a woman. For example, at school events, I have been expected to cook because I am a woman. Men are not expected to cook. The men were put in charge of slaughtering the goat. Therefore, there are still certain gender roles that are quite evident, but I don't see it as an issue of respect. I was talking to one of my teachers the other day, and I asked her if she believed men were more respected and valued in her culture. She said that it used to be that way, but now she believed that they were viewed as equal. This was after we were looking at a pamphlet on gender-based violence. The statistics were quite disturbing. I think it's like any society, where gender equality depends on where you are in that particular society. It's going to vary from place to place.

I know that gender based violence is a problem here in my village from talking to the head nurse. She told me many stories of domestic violence, even some stabbings. Boyfriends will beat their girlfriends if they expect cheating or refuse sex. Very few times are these incidents ever reported to the police.

I think how I have been most affected in regards to gender is in terms of verbal harassment from men. It doesn't happen in my village, but when I'm in larger villages or cities, men will hit on me relentlessly. They will yell things, whistle, sit down and start up conversations about how they love me, want to get married, have a family, go back to America, etc. Their behavior would be considered sexual harassment in the States, but here, it's just how men act. Some volunteers even experience this behavior at their place of work. I'm lucky that I don't have to deal with it in my village. With all that said, gender definitely affects life here, especially for (locals). For me, it has affected my life, but not to the extent I 
expected it to, at least not yet because I spend most of my time in my village where it is less of a problem than in bigger cities.

In addition to my sexual orientation, all of these facets--my nationality, age, and gender-affected my experience as a Peace Corps volunteer. They were all challenging in different ways. My sexual orientation was probably the least difficult to deal with, only because it was one I could suppress and hide. The others were non-negotiable. I could not change my nationality, age, or gender to better my situation. I just had to learn to cope with the consequences of being young, female, and American in a foreign country.

\section{Taking on a Peace Corps Persona}

Many volunteers, regardless of the varying facets of their identity, develop somewhat of a "Peace Corps Persona" that they come to embody throughout their service. This is one the main identity negotiation strategies that volunteers, gay or straight, implement while serving abroad. Sue explained, “Any time you are living abroad, you kind of have to take on a different like identity for yourself." Alexi further described this phenomena:

No matter what country you are in, there are things that you have to hide about yourself or things that you don't feel comfortable sharing or things that don't fit into the culture. Peace Corps doesn't put you in countries that are just like the cultures you grew up in, so there are going to be these cultural differences that you have to negotiate. And sometimes they are things that are so close to how you identify, and it's a hard thing to negotiate: Your identity versus what's acceptable and what you feel comfortable portraying.

Every volunteer does this to one extent or another. Roger elaborated:

Every volunteer does that (takes on a new persona) for one reason or another. I mean, for certain reasons, you almost have to. Like, if you are an LGBT volunteer, I think you definitely have a private face and a public face, but I think almost every volunteer does that to some degree. I know one person that didn't want a lot of people to know they had very good friends back in the states who would send them A LOT of stuff, so they purposely displayed an image of having less than what they actually had just for that purpose. I think there are multiple 
reasons, but I think that almost every Peace Corps volunteer does (portray different personas). I'd be surprised to find a Peace Corps Volunteer who some degree didn't. Even the ones who were like the most integrated in their communities, who were the best at (the local language), they were a bunch of potheads in my group, so those people would hide that from their community. So, I mean, everyone has something.

These sentiments resonate closely with Woods and Lucas (1993) findings of "counterfeiting." This strategy occurs when individual create and embodies a fake, heterosexual identity. Due to these factors, many volunteers have two identities while in the Peace Corps. One of their identities is more true to their American self that they were back home. This identity is often suppressed and hidden from the locals they are working with, but it comes out again around their fellow Peace Corps volunteers. Their second identity, or "Peace Corps Persona" is the person they become the minute they step out of their homes and into their community. It is a more "culturally appropriate" version of themselves. Queer anthropologists implement a similar strategy. Hector Carillo (2009) explained his own experience in the field where at times he would portray himself as a straight man and at other times, a gay man:

Because of this constant strategic shifting between these two presentations, which I chose depending on the leads offered by my interlocutors and my particular goals on any given occasion, I often found myself feeling like a chameleon that changed colors according to the setting and the moment. (41)

I believe this notion of feeling like an ever-changing chameleon would resonate deeply with Peace Corps Volunteers. It definitely resonates deeply with me at least.

This phenomenon is often supported and perpetuated through a Peace Corps ritual where villagers give volunteers a local name. Volunteers are addressed as such name throughout their service, and, therefore, it is easy to see how this phenomena occurs. When addressed by their American names, volunteers feel like they can be their true 
selves. When addressed by their local name, they feel obligated to live out that identity.

Mimi explained, "It feels so weird. Like, for me, like my (local) name, was a whole different person. You know what I mean? It's so strange. Like, I was like living two separate lives!" This aligns with what past research has found. Ramirez (2005) explained that these difficult hybrid negotiations lead to inner turmoil for immigrants because they are faced with "competing systems of desire in a transnational frame" (150).

Furthermore, Alexi went into more depth about this phenomenon:

My local name was (T), so like (T) was helpful and happy and sunny, but when my grandmother died, (T) wasn't so happy. When I first got there, I didn't show them I was a human, like I was a character: This perfect person who was helpful. My teachers would say, 'You need a man. You need a man.' And I was just like, 'No I don't.' But I didn't like ever correct them or like say, 'Well, I could just need a woman.' Like once I said to one of my female teachers, 'No, I just need you.' And she was like, 'No, but I can't give you what a man can give you.' I just let it go cause (T) doesn't get that deep...(T) is not a gay activist. (Alexi) is, but (T) is not.

Previous research findings align with this notion of acting out different personas abroad. For example, Shohat and Stam (1994) argued that immigrants are "confronted with the 'theatrical' challenge of moving, as it were, among diverse performative modes of sharply contrasting and ideological worlds" (42). This constant battle between the ideals of their homeland and the ideals of their new homeland make it very difficult for individuals to fully acclimate to their new culture. Early on in my service, I wrote in my journal, "Basically, right now I feel like I'm not being authentic/genuine. I feel like I'm putting on this performance of the person I think that they want me to be. However, I don't think that is unique to me or queer volunteers." This suppressing of one's true identity and enactment of a culturally appropriate one leads to more dilemmas: inauthenticity and superficiality. 


\section{An Unauthentic and Superficial State of Being}

The inability to be authentic and connect on a deeper level left my participants feeling that the locals were not getting true representations of who they were, regardless of what their true identities may be. Collins explained "I don't think that they got the $100 \%$ accurate snapshot of what I am. Which, you know, that's hard to say for anyone. Again, I don't think that was completely because of me and my identity as gay person." Alexi added, "I feel like it's hard for me because I communicate best by sharing about myself, but I don't feel comfortable and I don't feel the need to do that here. So I feel like they know me on a surface level. Some people know me deeper, but not really." Sue elaborated:

I didn't feel like I had very many close relationships with people. I felt like most of my relationships were very topical, and sometimes I wondered if that was because I had to hide this pretty significant part of who I am, and like avoiding certain conversations with people, so I think it probably did play a role. I don't know if straight volunteers had similar experiences where they felt like they didn't have deep relationships with people. It might have just been the country, or it might have been me. But I mean I still had friendships. Um, you know, but not as significant as I thought I might.

Mark described how interactions between locals and volunteers usually were very superficial in nature:

It's mostly the volunteer will learn a lot about the host country, and you might get lucky and a few people in the host country will learn some things about the United States. 'Cause if I went to (the country of service) right now after being gone a year, the first thing I would be asked is, 'How are you? How do you find (the country) now? Where do you go to church? Do you have a girlfriend? Will you give me money? Those five questions, in some order, not necessarily in that order, but that's what I'd be asked. I always felt like it was very superficial, my conversations with people...It stayed on the superficial level but, I mean, I'd say there were probably about 20 people or so throughout my time in Peace Corps that I actually got to know better and actually had more than superficial conversations with but definitely not the majority. 
As Mark touched upon, forming deep relationships is somewhat of an anomaly for Peace Corps volunteers. It is one of the biggest challenges volunteers face during their service, as it leads to a pretty lonely existence.

This inability to be authentic in one's community and with one's community members leads to many problems for volunteers. Sue explained the difficulty it caused when trying to connect with locals, "Sometimes I would get done hanging out a group of people and be like, 'UH, why don't I feel right.' I just always felt like something was missing." When volunteers cannot reach that higher level of connectedness with the people in their communities, they find something lacking in those interactions and relationships. Alexi explained the frustration it caused her:

I don't think they'll ever really know me here. Like maybe a couple teachers I could open up to. But Peace Corps pushes integration, which I think is stupid. One of the goals in Peace Corps is cross-cultural like communications and understanding and learning, but then when they ask you to integrate, they ask you to lose parts of yourself to become part of this community. And that makes sense because when (locals) go to America, they lose parts of (themselves) to acclimate to America. So if you need to integrate that makes sense, but we're only here two years, and we're supposed to be sharing who we are as Americans, but at the same time, Peace Corps says, not too much. Like you need to kind of appease them. You need to integrate to be this, like be understanding of their cultural differences, but Peace Corps never says it's okay to be who you are though. They never really get that through or get that across. You just need to accept these differences, and not push back with who you are.

As a result, volunteers try to embody that "Peace Corps Persona" that was touched upon earlier. However, balancing two different identities is not an easy feat. Mimi touched upon her frustration and inability to balance these two identities:

It was too much. I like could not balance the two, and (my real name) is kind of a (local) sounding name, so it's like, 'Fuck it, just call me this. It's fine.' (Laughter) Um, yeah, it was just a bit too much. The two separate names. I always felt like I was walking on eggshells a little bit. It was a little hard...It was so strange trying to balance those two. Like, 'Oh, I can't really bring up this,' like, 'I can't, uh, would (my local persona) say that?' Like I'd have to think to myself, 'Would I as 
(my local personal) say that?' Like it was really strange, but by the end of the service, a lot of people were calling me (Mimi), so my (local) name in my village was not used all the time, so I felt more comfortable being there 'cause I was like, ok, I only have to deal with (Mimi) now. I don't have to deal with (my local name). She doesn't exist anymore. This is cool.

Luckily for Mimi, she found a way to merge the two identities. Others struggle with finding a balance between these two identities.

\section{Heading Home}

Volunteers spend their two-plus years of service trying to balance their American self and their Peace Corps self. At the end of their service, they are both excited and nervous to return back home. They have, undoubtedly, missed parts of America, but they also know that readjusting to American life will be tough. One important lesson that volunteers learn quickly upon returning home is that their Peace Corps persona was not just a temporary character that they came to embody, but, actually, a new part of their true self. As they once struggled to negotiate their American identity in a culture so very different from their own, they find themselves doing the same when they come back home, but vice versa. They now find themselves trying to negotiate their Peace Corps identity in America, and although it is often tough to come to terms with, they realize that being a returned Peace Corps volunteer is now a new facet of their identity that will now and forever be a lens through which they see the world. Everything comes full circle. Just as their age, gender, sexual orientation, and other facets influenced their life abroad, they now have a new facet of their identity that impacts their lives back home. They are forever changed. 


\section{Readjusting to Life Outside the Closet}

A unique experience for queer, Returned Peace Corps Volunteers compared to their heterosexual counterparts is readjusting into American gay culture and a society that is more accepting of homosexuality than the one they left behind in Africa. For some individuals, serving as a queer Peace Corps Volunteer who had to suppress that part of their identity for so long encourages them to be more open back home. Regarding his sexual orientation, Mark explained:

I'm definitely much more open about it than I was beforehand, like it was never something that I hid, but it wasn't something that I went out of my way to express, and now I'm a lot more open about people knowing that about myself 'cause since I've had to hide it. Going back into the closet after being out for seven years is AWFUL, and I don't want to have to do that again.

As one can see, having to suppress one's identity for so long can cause individuals to be much more open about their queer identity than prior to their Peace Corps service.

In contrast, other volunteers expressed that having to suppress their queer identity in the Peace Corps actually caused them to be more discreet about it when they returned back to America. Alexi said that she often forgets she can be open about her sexuality in America, "I've just gotten so used to hiding it, well, not hiding it, but not making a big deal about it, not like showing it that I'm just like, it's very natural now." She went on to speculate about the future. After discovering her true sexual identity in the Peace Corps,

Alexi was not exactly sure what the future would hold for her in America:

I think that I'll probably be a lot more out and proud, but it's still so complicated 'cause it's like who do I tell? When do I tell them? And if I don't ever end up with a woman, is it necessary to tell people? Like it's one of those complicated things where even though I don't identify as straight, if we're not having this conversation, then do I need to talk about it? I feel like it's something I'm going to have to figure out. I feel like it's going to probably be hard just because I'm so used to not making it a thing...But I don't think I'll be walking around being like, 
'I'm Pan (Pansexual)!' (Laughter) They would think I was talking about Peter Pan or something.

Joanne is also struggling with how open to be about her sexuality. She shared how the readjustment process is affecting her relationship with her girlfriend:

Not coming out to people, it's hurting me and like my girlfriend's relationship right now, not being so expressive about being gay, and uh, and I don't mean to do it, like she'll just kiss me out in public and I'll just kind of hesitate, but I do it 'cause I'm still in that mindset. And I know I'm here, but I still feel...it still feels like, now I'm just waking up out of it, and I'm like, 'NO, I'm in a country that, you know, accepts this now.' She (Joanne's girlfriend) doesn't understand.

As one can see, learning to navigating life outside of the closet causes much distress for recently Returned Peace Corps Volunteers.

Sue, who had been out for years prior to Peace Corps, also struggled with how to deal with her queer identity back home. She felt like it was more important to her now, but she also struggled with how to share that part of herself with others:

I feel like in some ways it's more important in my life and other ways it's less important in my life...Yeah, just like living two years like not identifying as LGBT. Um, I mean I think that kind of sticks with you for a while. And so kind of getting back into the hang of like, 'Oh yeah, I can be openly gay. It's okay. I can tell people.' And so, yeah, I had gotten so used to ignoring that whole part of my life. And so I'm just kind of getting back into the swing of BEING OUT AND OPEN! (Laughter)...Yeah, I think just cause there's not much of a gay culture where I'm living right now. Like I see someone who looks gay, and I'm like, '(GASP) GAY PERSON!' And I get really excited, and then I get really awkward, so. I think I need to spend some time in a place with an actual gay culture.

Sue is not the only one searching for that community.

Many queer volunteers struggle with finding a queer community to belong to when they return home. Mimi, for example, is in the process of finding a community. She explained, “I feel like I need to find my scene within the gay culture. 'Cause I don't really go to the gay clubs 'cause that's not really my thing, so that's a new challenge for 
me. Just to find where I fit in." Like Mimi, Pam is searching for a community as well.

She had come out right before leaving for Peace Corps. Therefore, the only gay

community she ever knew was back in her country of service. She explained the impact

this had on her coming back home:

It was difficult coming home because dealing with adjustment is a shit-show, especially for me.... I had finally created an LGBT community, but my LGBT community was back in (our country of service (Laughter). Which was really weird! I mean, I have yet to meet someone in the U.S. who was like, 'Oh yeah, like the first gay community I was apart of was NOT in America.' Um, so that was really WEIRD. That was really strange. And I kind of went on a gay binge, but it was hard cause it was kind of a lot of (sigh). There aren't a whole lot of places for gay women in my community. It's mostly bars for gay men. Um, the gay community here that encompasses women is mostly like a, 'Can we all hook up? Or can we all date?' And it's like I have someone with that I'm monogamously partnered with.

Finding a supportive, queer community is one of the biggest obstacles for queer volunteers when they return home from the Peace Corps.

What has also been interesting for Pam upon returning home is that she is experiencing somewhat of a culture shock when it comes to the gay community in the United States. The only gay community she ever knew was back in her country of service, so learning that the dynamics of a gay community can differ around the world was somewhat of a shock to her coming home:

So what's been interesting actually is that I didn't know about the queer community in the U.S. You know, so we went to this women's tent at Folsom, and I'm like, 'It's not even people are being strangers. It's just that, I don't know, people aren't being very nice, and they're not sending very nice vibes.' And (my partner) was like, 'Of course, they're not. They're a bunch of lesbians.' Um, so kind of having to learn, relearn some of the norms and expectations in the queer community here, just because I didn't feel very plugged into it before I left. That was just very weird. It was VERY strange. It is. It's different here. It's WAY different here...Um, so it's just difficult kind of having to learn about the community here and having to come to terms with some of its shortcomings. And some, like the exclusionary nature of certain things, which was NOT an issue in (her country of service) 
These shortcomings leave Pam missing the queer community back in her country of service, so it has been a struggle for her to not play such an important role here in the United States. She explained, "Going from playing kind of a key player, like a key role... to 'OH! You're intern. We're going to have you do grunt work.' I'm like, 'Well, fuck.' You know? Not as meaningful. And then having to do all that in course of also kind of just having to adjust as a human being back to America was difficult." I, too, have felt a little lost without a core group of queer individuals in my life. It is still hard to believe that I had more of a queer support system living in Sub-Saharan Africa than I do now, but that's due to the city I am currently living in. Like others mentioned, I am going to need to relocate if I want to find a strong, queer community to be a part of.

As one can see, an overall theme among queer volunteers returning home is finding an LGBT community to belong to and a gay culture to indulge in. After having to suppress one's queer identity for so long, it can be frustrating to be in a society where gay individuals can be open but have yet to find an outlet to do so. In addition, it should be noted that many volunteers missed their queer communities back in their country of service. This is important to note as it attests to the impact these communities had on the lives of queer volunteers. These queer communities and groups served as invaluable outlets for these volunteers, so much so that they actually long for them after returning to America.

In contrast to other participants, Maureen found a strong queer community to belong to when she returned to America. This allowed her to reconnect with the gay community quite quickly. She described her re-entry into the American gay scene in great length: 
You always want to see the lights and the glitter. I had a week where I went to all the gay bars, and I was going by myself. And there was like a week where I went to a lot of strip clubs because I could. Like, that's something that I didn't know that I even missed or even thought about that I was giving up when I went to (Peace Corps), but I came home, and I'm like, I live in Vegas. Like, you know what? I'm buying 200 dollars in ones and I'm going to a strip club...so yeah, there are certain things that as soon as you step foot in America, it's just like, 'Oh, I'm going to do that because I CAN.' Like, I'd go to this gay club here and go to drag performances, and I was the first one, like, tipping the girls.

Having outlets such as these has made Maureen's readjustment process a little easier compared to other volunteers who are still searching for a queer community.

\section{CONCLUSION}

As one can see, the narrative of a queer, Peace Corps Volunteer is tumultuous one, beginning with the anticipation and anxiety surrounding the application process all the way to their difficult readjustment process back in America after returning home. However, the narrative of a queer, Peace Corps Volunteer is also one of personal growth and eye-opening discoveries. It includes a lifetime's worth of lessons packed into twoshort years. As the RPCV Handbook explains;

Many RPCVs have said that reentry from their Peace Corps service was one of the most significant transitions of their lives. Many have recalled the challenges and difficulties of returning home. They searched for meaningful employment. They struggled to identify with their own culture - one that does not always share their global attitudes and cultural tolerance. They sought to understand why they sometimes felt disconnected from society, including from family and friends who had not experienced what they had. They tried to understand the abundance of food, technology, and choices for just about anything. They realized they were different, but were not sure who they were or how they had changed. Most RPCVs would agree that they did finally readjust well, but, they did not put their Peace Corps experience behind them. Instead, they took it with them and threaded it through their lives. (Peace Corps 2014c:10)

Nothing is the same after Peace Corps. Volunteers close their service and that chapter of their lives, but they are forever changed and shaped by the experience. That is why the 
narrative of a Peace Corps volunteer never truly ends. The story of their lives continues to unfold through the frame of reference and lens of a Peace Corps Volunteer.

\section{SUMMARY}

In conclusion, I would like to revisit each of the previously stated research questions and summarize the findings for each one:

\section{RQ1: How do queer, foreign-aid workers negotiate and manage their queer identities while serving abroad?}

This study sheds light on the fact that no two queer individuals negotiate and manage their identities in the same way. With that said, all participants had to negotiate their identity to some extent. A few volunteers had to work harder at negotiating and managing their identities, while some were able to rely on heteronormativity and the heterosexual assumption to simply pass as straight. Strategies of silence, counterfeiting, and lying by omission were popular strategies among participants. Some volunteers, like Maureen, lived an open and out existence while in Peace Corps. She believed that being her authentic self led to a more rewarding and successful service than if she would have remained closeted. Others would probably attest to this claim as staying in the closet caused many of them distress and led to varying degrees of internalized homophobia. Many of these negative impacts lingered well after returning home to the States. With that said, a cautious strategy of staying in the closet in regards to locals but coming out to fellow volunteers helped to ease the distress and inner turmoil of remaining in the closet in other spheres of life.

It should be noted that the context of each volunteer's reality while serving abroad

played a major role in volunteers' choices of negotiation and management strategies. For 
example, those living in more urban areas had more opportunity to meet like-minded people and even take part in the LGBT community there. Those volunteers in more rural areas had little to no exposure to such community and faced a harsher social climate surrounding homosexuality. Therefore, volunteers located in these more rural areas had to practice more caution when it came presentation of self. Overall, volunteers' negotiating and management strategies evolved and changed over time, depending on the situations in which they found themselves. In addition to negotiating and managing their queer identities, they also found themselves negotiating and managing other facets of their identity as well, hence the discovery of how impactful the intersectionality of identity can be on an individual's service. In fact, in most cases, most volunteers reported that their queer identity impacted their service less so than other facets of their identity, such as gender, age, and race.

\section{RQ2: What role, if any, does compulsory heterosexuality play in the social} construction of sexuality in societies where queer, foreign-aid workers serve, and how does this affect their queer identity negotiation and management processes?

Compulsory heterosexuality played a vital role in the social construction of sexuality where these participants served as Peace Corps volunteers. From laws banning homosexual acts to the way gender roles are taught, reinforced, and perpetuated in this particular society, heterosexuality is embedded in the culture as the "normal" or "natural" way of living. Homosexuality is seen as "abnormal" or "unnatural." Religion is one major social institution that is used to literally demonize such behavior, as those found to be homosexual are often called "Satanists" or are accused of being possessed by demons. Furthermore, when discussed in school or the workplace, if discussed at all, topics 
surrounding homosexuality are portrayed in a negative light. There are no safe spaces publicized for queer youth in schools and very limited outlets outside of school, mainly in the capital and other larger cities. There are more opportunities for queer adults to organize and socialize as they have more free agency than the children living in this society and are able to relocate themselves to the areas where a movement is actually taking place. Additionally, the few homosexual characters that can be found in the media portray negative representations of queer life. Finally, tabloids and newspapers provide only negative press coverage on issues surrounding homosexuality. Some publications even out queer citizens in their stories. As one can see, through the use of laws, religion, social norms, education, and the media, compulsory heterosexuality creates a social construction of sexuality where heterosexuality is the only acceptable way of life.

\section{RQ3: What role, if any, does the organization (i.e. Peace Corps) itself play in the} negotiation and management processes of its queer, foreign-aid workers?

As expressed by participants, the organization itself played a passive role in the negotiating and management processes of its queer volunteers, providing them little to no training or support. Therefore, participants expressed a desire for improvement in the way Peace Corps works with its queer volunteers - before service, during service, and even after service. Suggestions as to what could be done to alleviate this problem will be discussed more in depth in the next chapter, as it requires a more lengthy discussion.

\section{DISCUSSION}

The study at hand adds to an almost nonexistent body of research examining queer, foreign-aid workers' experiences negotiating and managing their identities while working abroad. It provides an in-depth look into what it is like to not only work in these 
societies but to live in them as well. This study shows that queer individuals cannot be reduced to one facet of their identity, and that, in fact, a variety of identity markers impact the experiences of foreign-aid workers more so than any one particular facet of their being. Thus, it suggests that the experiences of an individual cannot be fully understood unless an entire person's being is taken into consideration and examined in relation to the social, economical, historical, and geo-political context of that situation.

Furthermore, the findings of this study align with previous research, as well as build upon it. First of all, the findings of this study support previous findings of critical, social theorists who view sexuality as a social construction (Weeks 1986; Binnie 2004; Rand 2005; Weeks 2007; Seidman 2009; Jackson and Scott 2010; Seidman 2010). To elaborate, through autoethnography, as well as through interviews with participants, I was able to gather much data that showed that the way sexuality is categorized and viewed is not a natural phenomenon but actually fundamentally social. The stories that queer volunteers shared provided invaluable data that showed how the meaning, the organization, and the social acceptability surrounding sexual behaviors and desires are products of social factors. As Steven Seidman once proposed:

Not very long ago, conventional wisdom held that race and gender differences were creations of nature. Today, however, many of us recognize that such beliefs are mistaken. We suspect that such beliefs may be ideological and contribute to creating racial and gender differences and inequalities. At a minimum, the new conventional wisdom views race and gender as shaped as much by social factors as by nature. Is it possible that the same is true for sexuality?" (Seidman 2010:ix).

My answer is, "Yes." I believe this study provides evidence to back that argument up.

To elaborate, this study shows how a society uses these factors to regulate sexuality to enforce compulsory heterosexuality and to keep current power structures in 
place. In this particular society, the regulation of sexuality is used to keep the patriarchy intact. As a way to reassert gender difference and the normality of dichotomous gender roles, this society emphasizes the "naturalness" and "rightness" of heterosexuality. To put it simply, this particular society uses a very complex network of social norms and rules to regulate sexuality and make people believe that that heterosexuality is the only "normal" and natural way of living. It can be argued that this society hypes up the differences between men and women to ensure that the current gender roles stay in place. In other words, heterosexuality is viewed as "natural" and essential for survival and a stable social order. Therefore, it is thought that the fate of society depends on men and women occupying different roles. Asserting a clear heterosexual identity is a way to reinforce and normalize a dichotomous gender identity. This particular society does so through the use of various social institutions: Government, Education, Religion, and Media to name a few.

This normalization of heterosexuality leads to a culture of homophobia. As heterosexuality becomes viewed as the "normal" sexual and gender identity, homosexuality is thought of and represented as a deviant and abnormal identity. Not only does it become stigmatized to be attracted to someone of the same-sex, but gender deviance also became attached to the notion of homosexuality. This deters men and women from exhibiting any gender traits that deviate from the norms of masculine men and feminine women out of fear of being labeled homosexual. This results in a sexual system that aggressively enforces heterosexuality.

In regards to coming out in the workplace, the results of this study are congruent with previous research as well. Although the participants in this study were working 
overseas, the struggles they faced in the workplace were similar to those found in studies conducted on gay Americans in the workplace. For example, disclosing one's sexual orientation has been found to be one of the toughest issues that queer individuals face in the workplace (Griffith and Hebl 2002, Willis 2011) and this was definitely true among my participants as well. Furthermore, studies have shown that queer individuals who choose not to disclose their sexual orientation at work report increased health risks (Cole et al. 1996), lower levels of psychological well-being and life satisfaction (Garnets and Kimmel 1993; Lane and Wegner 1995; Savin-Williams and Rodriquez 1993), less positive attitudes toward work and careers (Colgan et al. 2006; Ragins, Singh, and Miller 2007), and they also exert a substantial amount of time and energy on identity negotiation and management strategies (Ellis and Riggle 1996). These results resonate greatly with the findings of this study, as many of my participants chose to stay closeted in their professional lives and faced much emotional turmoil because of that decision.

Furthermore, specific identity and negotiation strategies utilized by my participants have also been found in previous research: Strategies of concealment (Chrobot-Mason et al 2001;), self-editing or modifying speech (Rogers and Hebl 2001), and counterfeiting (Woods and Lucas 1993) were all utilized by participants of this study. In fact, volunteers went as far as creating a whole new Peace Corps persona that they came to embody while living and working abroad. Volunteers felt as if they were leading double lives during their Peace Corps service. Volunteers also relied heavily on the heterosexual assumption for passing as straight, which previous research (Lewin and Leap 1996; Willis 2011) has shown to be a very popular identity negotiation strategy among queer individuals. No two volunteers followed the same queer identity negotiation 
and management plan. Results ran the gamut. On the spectrum of coming out, some volunteers were completely closeted throughout their service while some were completely out in both their professional and personal lives.

This study also resonated with research done on queer migrants (Shohat and Stam 1994; Luibheid and Cantu 2005; Manalansan 2005; Ramirez 2005; Randazzo 2005). These previous studies have shown that the constant battle between the ideals of immigrants' homelands and the ideals of their new homeland make it very difficult to fully acclimate to their new culture, which was definitely apparent among participants of this study. Participants were torn between behaving in a way they were accustomed to back home and behaving in a way that upheld he norms and ideals of the country in which they were working and living. It is important to note though, in contrast to previous studies, this study looked at the experiences of individuals who leave countries that are more accepting of homosexuality to go live in countries that are less accepting. Therefore, this study provides unique insight into how individuals negotiate going back into the closet after living a somewhat open existence in their nation of origin.

Going back into the closet caused many of the participants of this study much distress. This too aligns with past research. Previous research on the role minority stress plays in lives of gay and lesbian individuals indicated a significant relationship between minority stress and adverse psychological health effects (Bos et al. 2004). This was definitely the case in this study as participants battled much inner turmoil when it came to negotiating and managing their queer identities. This led to a decrease in mental wellbeing among most participants. In this study on the identity negotiation of queer, foreign- 
aid workers, it was interesting to see how adjusting to everyday life, as well as minority stress, affected the identity management processes.

This study especially clarifies Lewin and Leap's (1996) work on queer anthropologists' experiences in the field. The findings of this current study are consistent with Lewin and Leap's research to the extent that similar negotiation and management strategies were found among queer anthropologists and queer, foreign aid workers. In addition, this study's findings resonate with the dilemmas and obstacles that queer anthropologists face living and working in a completely new culture. Furthermore, both studies shed light on the importance of intersectionality on the experience of a queer individual abroad. However, findings of this study also expand on Lewin and Leap's work in the sense that it does not focus on the experiences of anthropologists but rather development workers. Although the experiences of the queer anthropologists provide valuable insight into the dilemmas queer, foreign-aid workers may face and what identity management strategies they may implement, the study at hand may prove to be a more resourceful tool to queer, development workers.

Furthermore, this study provided much insight into how Peace Corps as an organization trains and supports their queer, Peace Corps volunteers. Findings shed light on a need for improvement in these areas. Participants expressed an extreme lack of support from Peace Corps throughout their service when it came to issues surrounding their queer identity. Volunteers had to form their own support groups and rely heavily on each other for resources. However, they emphasized that these self-made support groups should be supplemental to an already existing support structure from Peace Corps itself. Therefore, implications surrounding the training and support of queer volunteers will be 
the focus of the next chapter, as the findings of this study call for a much deeper examination and discussion of this topic.

Overall, this study not only contributes greatly to previous gaps in the literature, but it also contributes immensely to sociological research. More specifically, it expands upon existing research pertaining to the social construction of sexuality and the social construction of identity. It also provides cross-national research pertaining to compulsory heterosexuality, which is lacking in the research surrounding the sociology of sexuality. Finally, it sheds light on how queer individuals construct and manage their identities while working in societies where homosexuality is not tolerated or tolerated to a lesser extent than in the United States.

\section{LIMITATIONS}

One major limitation surrounding this research project is the majority of data is based on past events. Therefore, I relied on my participants' memories for accurate data. Some individuals see studying past behavior as a disadvantage, but I actually see it as an advantage. By interviewing former Peace Corps volunteers, as opposed to current volunteers, I was able to investigate the long-term effects that serving as queer Peace Corps Volunteer had on their identity. A second limitation of my study is that it is not generalizable. My sample size is relatively small, so I cannot generalize my results to all queer Peace Corps Volunteers. Nevertheless, it provides insight into the experiences of queer volunteers as well as foreign-aid workers in general, and it addresses gaps in the literature surrounding queer identity negotiation and management. Finally, the third limitation of my study is that I, myself, was both a researcher and participant of this study, putting me in quite a unique position. I will admit that at times it was difficult to 
approach this project objectively when I, myself, had experienced all the ups and downs of being a young, white, queer woman in Sub-Saharan Africa. Sometimes it was very hard emotionally to have to sort through the data and re-live the stories over and over. With that said, one may argue that being both a researcher and participant is actually a strength of this study. The autoethnographic portion of my study helped me to keep biases in check. Furthermore, serving in the Peace Corps myself gave me the ability to not only build rapport with my participants, but it also provided me with a rare opportunity as a researcher to empathize and fully understand the meaning behind the messages that my participants were communicating to me. Their stories become more than just simple narrative. Their stories came to life because they resonated so deeply within me.

\section{FUTURE RESEARCH SUGGESTIONS}

Future research could and should be conducted to expand on the findings of this study. There are three main areas of research that could be further studied. First of all, additional research could be done on how queer, foreign aid workers negotiate and manage their identities while abroad in other parts of the world. Second of all, compulsory heterosexuality outside of the United States should continue to be examined in various parts of the world. Finally, further research should be done surrounding Peace Corps' role in the training and support of queer Peace Corps volunteers. Let us break down each of these areas of research in more detail.

This study examined how queer, foreign-aid workers negotiate and manage their identities abroad. However, due to the limited scope of the study, the only foreign-aid workers included were Peace Corps volunteers. Therefore, additional studies could be 
conducted that draw participants from various organizations in the foreign-aid sector. This would help to expand upon the already existing research and make results more generalizable. Furthermore, although this study did include Peace Corps volunteers, they were all participants from the same country of service. As social climates surrounding homosexuality vary from country to country, additional studies should be conducted that look at the experiences of Peace Corps volunteers in various countries and various regions of the world. A cross-national comparison of queer, Peace Corps volunteers experiences would prove very insightful to both sociologists and queer-foreign aid workers alike.

Next, as mentioned before, this study included participants from the same country of service, giving insight into how compulsory heterosexuality operates in just one society. To gain a better understanding of the role compulsory heterosexuality plays worldwide, additional studies must be conducted that examine and include more societies around the globe. Again, a cross-national comparison of queer, Peace Corps volunteers' experiences would provide much insight into the social construction of sexuality in the societies where these volunteers serve and how this impacts their identity negotiation and management strategies while living abroad.

Finally, I suggest that certain research be done that creates tangible change in the life of queer, foreign-aid workers. Up to this point, I have suggested further research that would contribute to sociological literature. The present results have implications for the development and implementation of improved training materials for queer, Peace Corps volunteers. Therefore, I suggest that certain applied research be conducted to ensure improvement of such materials, and, thus ensure the overall betterment of training and 
support for queer, Peace Corps volunteers. The next chapter examines this concept more closely. 


\section{CHAPTER V}

\section{IMPLICATIONS AND PRACTICAL SOLUTIONS}

In this chapter, I would like to outline practical steps that could be taken by Peace Corps to better improve the experiences of their queer volunteers. It should be noted that I am not suggesting that Peace Corps attempt to change the social structures of the societies that they operate in currently. I am, however, suggesting that certain steps could and should be taken to better train and support their volunteers who identify as queer.

Furthermore, being queer and working overseas is far from a unique experience to queer, Peace Corps volunteers:

LGBTI development professionals around the world - no matter their sector of work - are faced with challenges and safety concerns above and beyond those faced by their peers. And although many donors and aid groups are pushing LGBTI rights and trainings internally, there is often a gap between headquarters policy and implementation in the field, especially in countries like Mauritania and Sudan, where being gay is still punishable by death. Even in the case of inclusive policies and safety measures, every LGBTI aid worker or ally must still judge for themselves how open they want to be in order to function in potentially lifethreatening environments. (Rogers 2014: para. 10)

Therefore, the practical solutions suggested in this chapter could prove to be insightful for not only Peace Corps but also other development organizations and LGBTI development professionals in general. 


\section{NEED FOR IMPROVEMENT: QUEER VOLUNTEERS VOICE CONCERNS}

Before I delve into what improvements could be made, I would like to address why there is a need for such changes. Throughout my interviews, participants had much to say about Peace Corps' training of LGBT volunteers and LGBT issues in general. Participants expressed an overall lack of training surrounding these issues. In fact, due to the ever-changing nature of the Pre-service training schedule, some cohorts received little to no structured training surrounding LGBT issues in-country. As a result, volunteers had to rely heavily on other queer volunteers already serving in-country for advice and information. Collins explained:

When I went through PST, it (LGBT education/awareness) wasn't an institutionalized part of the training program... It wasn't like, you know, structurally addressed. It wasn't a competency they had to check off. It was not built in...but, you know, we came across volunteers who came to do sessions and to present who identified that way and were able to like, you know, organically make those conversations happen.

Mimi added, "Peace Corps never warned us. They never talked about it (issues surrounding homosexuality and LGBT volunteers)." Mark said, "The majority of it (training on LGBT issues) wasn’t necessarily Peace Corps themselves. It was more the other volunteers that came along to PST." Pam further explained, "I think in part it might have been touched on vaguely by staff because they didn't want to scare us and because they knew we'd probably have negative feelings about legislation like that." Overall, volunteers expressed an extreme lack of training surrounding homosexuality and issues queer volunteers may face at their sites.

Due to the rigorous training schedule and limited time for sessions, some topics, such as LGBT issues, are often overlooked and not included in the schedule. Sometimes these topics are included in the training schedule and then later cancelled to make room 
for a topic that Peace Corps feels to be more important. Personally, my cohort had an

LGBT session on the schedule in the second month of training. I remember being very

excited about it. In my journal I wrote, "It's a huge weight off my shoulders to know that

there will be some information provided to us at training about LGBT volunteers."

Unfortunately, when that day rolled around, we learned that the session had been

cancelled to make room for a different topic. I was very disappointed, as were many other volunteers in my cohort.

April, who was in a different cohort than me, touched upon her experience in

regards to how Peace Corps prepares, trains, and interacts with their queer volunteers:

Prior to my departure, I perceived Peace Corps to have a "Don't Ask, Don't Tell" mindset about volunteer sexuality. I thought that when it came to countries that had homophobic laws or cultures, Peace Corps wanted us to be in the closet. Peace Corps didn't do much to change that perspective. There was no outreach prior to departure, no information spread to Invitees to let them know that there are support services for LGBT volunteers. I felt this to be irresponsible because LGBT Trainees and Volunteers face unique challenges and anxieties before and during their service... In-country, I feel like LGBT issues have been a hot potato in some ways. Several staff members at Peace Corps are quite open and supportive of LGBT Volunteers. These usually tend to be expat/American staff members. On the other hand, the subject of being an LGBT Volunteer becomes a bit of a taboo subject with host country staff. I feel paranoid about my sexuality with host country staff members. Despite the openness of some Peace Corps employees, I still feel like I'm not in a safe space when I'm in Peace Corps trainings or Peace Corps headquarters as a bisexual woman. In general, I feel like Peace Corps' attitude toward LGBT Volunteers is: 'We know you're here, but stay in the corner and stay in the closet.'

As one can see, queer volunteers do not feel fully supported by Peace Corps staff or at the organization as a whole. The taboo laws and attitudes surrounding homosexuality incountry make it difficult for Peace Corps to properly support queer volunteers. Volunteers understand that a cultural barrier exists regarding this topic. However, they 
hope that Peace Corps would work to bridge the gap between the two societies' attitudes surrounding homosexuality, rather than simply ignore the issue altogether.

Many volunteers expressed a desire for change regarding how Peace Corps treats their queer volunteers. Like April, Maureen felt that Peace Corps chose to ignore the obstacles and challenges of queer volunteers in training because it was easier for Peace Corps to do this than to have to address such controversial issues with host country staff members. When questions were asked by queer volunteers during training sessions, they were usually dismissed or answered with extremity, as you will see in the example below. Additionally, there was never any dialogue surrounding the issues, unless it was between volunteers themselves. The only time Peace Corps seemed to recognize that queer volunteers even existed was when they were boasting about the organization's diversity.

This left many queer volunteers feeling tokenized and used. Maureen explained:

You know, I would think Peace Corps should treat LGBT volunteers like they treat any other minority group of volunteers. I felt like Peace Corps puts us in a box, and only when we were beneficial to them did they ever take us out of that box or acknowledge us in any aspect. Only when we were doing something good, or, you know, when we had that meeting with the ambassador. THAT was the only time I got ANY acknowledgment that there are LGBT volunteers at all, and the fact that their sexuality can be of any asset to Peace Corps...And the fact that our sexuality has to be an asset or else it's automatically a detriment. You know, I remember some American Peace Corps staff member told us that if people in our communities knew that we were gay, we would be killed. Annnnd, you know, when I was in that mass exorcist, I actually, my mind goes back to that. And it's like, 'Oh my gosh, I'm going to be killed.' It's possible. I can get killed 'cause I can trip on a rock and die, but that's a very SLIM possibility, and that's a very slim possibility that I probably had of being killed that night, but the fact that it was said to me, it came into my head and added more anxiety to the already stressful situation.

It is for reasons like April and Maureen mentioned that Peace Corps volunteers are grateful to have each other. As much as the organization itself might dismiss the topics or issues surrounding queer volunteers, Peace Corps volunteers themselves could always 
find support in each other. With that said, support from one another is only so helpful. Support between volunteers should be supplemental to structured training and support from the organization itself.

\section{IMPROVING SOCIAL CLIMATES WHERE VOLUNTEERS SERVE}

In addition to improving the overall service of queer volunteers, an improvement in training and support of queer volunteers would also have a positive effect on host country nationals and the host-country as a whole. Volunteers emphasized the impact that an organization like Peace Corps could have on the social climates surrounding homosexuality in the countries where volunteers serve. Roger stated, "I think they could have a greater impact than they either realize they could or they want to...It seems like their stance, at least in (my country of service) was, um, this is culturally offensive to the host country, so just deal with it." Volunteers emphasized that ignoring this issue hurts both volunteers and the host-country alike.

Although homosexuality is offensive to many cultures around the world, it can be argued that homophobia is actually detrimental to the overall well-being of a country. One must realize that social, political, economic, environmental, geopolitical, and health issues are all connected and interrelated. Therefore, addressing issues surrounding attitudes towards homosexuality is actually essential to the various sectors outside the social realm. For example, in the country where I served and where the participants of this study served, the main focus of our work was HIV/AIDS prevention and education. The country itself had a goal of no new infections by a certain year. One can argue that to make that goal a reality, the country must include all people, especially at-risk populations, in their prevention strategy. 
It is a well-known fact, that gay men are one of the at-risk populations when it comes to contracting HIV. However, when there are laws and sanctions in a country surrounding homosexuality, there are obstacles for gay men to seek and obtain services and resources surrounding HIV/AIDS. Additionally, there are barriers to health care providers as well who wish to serve the gay community. Although gay men make up a small portion of the country's population, not being able to help these individuals results in the country not reaching its goal of no new infections. Therefore, improving the social climate surrounding homosexuality would actually help improve the overall health of the country. It would help to alleviate those barriers that exist when it comes to serving such a population. If Peace Corps took the steps necessary to improve the social climate surrounding homosexuality in this society, they would NOT be promoting a "gay agenda." Instead, they would actually be promoting the betterment of this nation's health by focusing on an at-risk population that is often neglected and ignored in the dialogue surrounding the HIV/AIDS epidemic in this country. WHAT CHANGES ARE NECESSARY?

With all that said, one may wonder what steps could be taken to better improve the training of queer volunteers, and, as a result, improve the social climate surrounding homosexuality in this society. Volunteers had a lot of insight into what changes could be made. Some volunteers simply yearn for an open and honest discussion from Peace Corps staff. April explained, "I would like to see host country staff go through extensive sensitivity training regarding LGBT issues. I would also like to see sexuality discussed openly in training and that Peace Corps publicize services for queer Volunteers. She was not the only volunteer with these suggestions. Alexi had similar views: 
It'd be nice if they were just open about it. Like I don't feel like they ever, and maybe they have and I've just never heard it, but I don't feel like I ever heard them be like, 'Let's have a discussion about it.' Like Peace Corps, not like a committee through Peace Corps or volunteers, but PEACE CORPS. 'Cause sexuality is spectrum, but people don't look at it that way, so it's like maybe like in some way it affects everyone, but we don't talk about it. Like even if you're like the straightest person ever, you know people who are gay. You know people who are, and it's like how do you support them? Peace Corps knows these countries and these cultures they are putting us in, but they're not vocal about it at all. They'll talk to you about it if you bring it up with them and you like make them, but they're not going to go out of their way to have this conversation with volunteers.

Acknowledgment of such issues would go a long way with many volunteers. Becoming a Peace Corps volunteer is a long and strenuous process. Volunteers are nervous and scared about many things prior to departure. The more informed they are about all issues they may face while overseas or at site, the better equipped they will be during service, and, therefore, the more successful they will be throughout their time there.

One can see just how lacking the training and support surrounding queer volunteers is when one of their biggest desires for change is such a simple one: opportunity for dialogue and discussion. Pam elaborated:

I wish they would have talked to us more. I think it's hard for them as programming to want to program in a whole session, you know, for ultimately a topic that most people don't need to worry about. Um, but it would have been nice to even have an optional session to sit down and be like, here are the laws. Um, here are the resources we can provide you. It would have been nice if it had been addressed. It would have been nice to kind of go over that, even if it had been an optional session. I can understand especially just knowing how intense the programming is for Peace Corps and how you are training for something every minute that wanting to put in a whole deal for essentially, you know, in my group, I think five out of forty-five. Yeah. Or six out of forty-five. Um, you know, it's hard. I can understand why they wouldn't want to be like, 'We're going to put everyone through a session on LGBT issues when only six of you really need that.' Not to say Allies wouldn't gain something from that, but yeah.

As one can see, volunteers just want the issues to be addressed, even if it is an optional session for those who are interested. As of now, volunteers are receiving such little 
training surrounding these issues that even just an open dialogue between staff and volunteers would be a step in the right direction.

With that said, it should be noted that how these issues are addressed in training cannot be generalized, not even across cohorts in the same country of service. In fact, some cohorts are already lucky enough to get an optional session revolving LGBT issues. Again, it is important to note that this training is put on by fellow volunteers and not by Peace Corps staff themselves. This can be viewed as a step in the right direction, but some queer volunteers argue that ALL volunteers, regardless how their sexual orientation, would benefit from being educated and informed on such matters. It should not be an optional session. It should be mandatory like the other sessions held during training. Joanne explained:

I feel like everybody should be educated, even straight Peace Corps volunteers, all together. It shouldn't be like, 'Hey, we're going to single you out, and everybody has a counseling session.' (Laughter). You know what I mean? Like I feel like everybody should be in the same classroom, and they talk about facts and what's happening in the country, and how they feel about being gay, lesbian, bi, transgender, or whatever! You know? Um, more education is needed. And maybe like recent news about what's been happening and stuff like that (in-country). I feel like that should be a class in every training, and that should involve everybody, not just us (queer volunteers). Something like that should be mandatory. It shouldn't be an optional thing. I feel like all the LCFs (Language and Cultural Facilitators) should be there too. Like I feel like everyone should be there! More knowledge, more power? 'Cause if you go to a training like this and it's optional, you will feel outed. If we're going to spend two years with each other, this is who we are. And I mean, it can just be a half an hour.

At this point, volunteers are not asking for an extensive, multi-session training on issues surrounding homosexuality and queer volunteers. As mentioned above, even a thirtyminute conversation about these issues would be a step in the right direction and would mean so much to queer volunteers. They would feel better supported and better prepared for what lay ahead of them at their villages and work sites. 
Before going any further, it should be noted that volunteers realize issues surrounding homosexuality are culturally-sensitive. Pam explained, "Peace Corps has the difficult task of functioning in a lot of countries that either have anti-sodomy laws or have very strict social confines on LGBT communities, so I understand that attempting to navigate within those international confines, especially with gay rights being such a hot topic in the U.S., is difficult." She further elaborated:

It would be (sigh). It would be impossible to do this, but it would be great if there was one host country national staff that was comfortable. But considering how dangerous that information can be to leak out, I would never want Peace Corps to FORCE a staff person to be like an LGBT contact point cause it can be just so dangerous, especially in certain countries.

As one can see, volunteers are not under any false illusions as to how complicated it would be to develop and incorporate LGBT issues into their Peace Corps trainings. Therefore, volunteers are not suggesting a universal, standardized training session for every country where Peace Corps serves. Trainings should be culturally-specific and tailored in a way that takes into consideration the local views and attitudes surrounding homosexuality.

Additionally, it should be noted that volunteers are well-aware of the controversy surrounding homosexuality in certain countries they serve. They are also well-aware of the possible backlash Peace Corps may face from host-country nationals if they publicly promote the rights and well-being of queer individuals, volunteers or otherwise. With that said, volunteers are not arguing that Peace Corps should promote a gay agenda. Roger explained:

You know, it's a tricky thing. I can appreciate it because in many cases, especially from what I've read, um, being open about being gay and being gay means something Western. Um, and, you know, it sort of falls in that tricky bounds of, you know, if we're openly advocating for gay rights or equality, are we pushing 
some sort of, you know, Western or U.S. belief system down the throats of the local culture? I think it was Hilary Clinton who made a speech the other day and said, 'Gay Rights are Human Rights,' and I think if the Peace Corps approached it from that perspective more, it wouldn't come off as some weird cultural colonialism. It's more, this is a basic human right, and we need to work with the home countries more to realize that. I think they (Peace Corps) could do more of that. I think they are just afraid of pushback from host countries.

A human rights approach is less controversial than presenting it as a gay rights issue and would be better received. As previously mentioned, approaching homosexuality from a health perspective, as it is related to the fight against HIV/AIDS, makes perfect sense in this setting. It also helps Peace Corps to avoid being seen as pushing a "gay agenda" or as explicitly promoting gay rights.

Volunteers know that Peace Corps can only do so much to address issues surrounding homosexuality in the countries they serve. They cannot change the cultural context of a place. However, they can better train and support their own staff and volunteers working there. As Collins explained:

You know there's only so much Peace Corps can do I guess. Peace Corps doesn't really have the power to change the context of the culture. So in that regard, they can't make places more accepting of LGBT people. Um, I think they can do a better job of providing resources for people, you know, if they want to engage in projects like that. Um, I remember on my way out actually, as I was closing my service, the staff was having a training on LGBT people in America. It was like the local staff, like this is what it means to identify as these certain things. It was like the way that Peace Corps would train volunteers, but they were training staff. Um, to say like, oh these are things that LGBT people might experience here. These are the ways they live in the U.S. Um, and I think that it is an incredibly important part of training for staff. I think that at the very least, staff should be understanding. And volunteers should be able to be out to their local staff if they want to be. Um, and I think that should continue. That should improve. I think that would improve relations between volunteers and staff. Um, you know, it's why I'm able to share something about my culture, the way that people are different in the U.S.

Allowing queer volunteers to be more open about their sexual orientation, at least among host-country staff, would help the organization achieve the cultural exchange portion of 
service that Peace Corps so passionately promotes. As of now, volunteers feel like they must censor certain parts of themselves while interacting with locals. Therefore, locals only see snapshots of what it means to be American. If volunteers were able to be more true to themselves, locals would receive more diverse and more accurate representations of Americans. This would result in a more authentic and genuine exchange of cultures.

\section{TAKING ACTION: PRACTICAL STEPS TO BETTER SERVE QUEER}

\section{VOLUNTEERS}

Thus far, I have outlined why there is a need for change surrounding how Peace Corps trains and supports its queer volunteers. I have also touched upon the benefits that change may bring to both volunteers and the host-country nationals alike. Finally, I laid out suggestions from Peace Corps volunteers themselves in regards to what areas they would like to see improved. Now I would like to flesh out some practical steps that Peace Corps could take to make turn these ideas into reality. April summed it up well when she said, "I would like to see host country staff go through extensive sensitivity training regarding LGBT issues. I would also like to see sexuality discussed openly in training and that PC publicize services for queer Volunteers.

Therefore, I will focus on three main areas of improvement: 1) Sensitivity training for Peace Corps staff, 2) Infusion of LGBT issues into volunteers' training sessions, and 2) Creation and distribution of resources for queer volunteers.

\section{Sensitivity Training for Peace Corps Staff}

Throughout their service, Peace Corps Volunteers rely heavily on Peace Corps staff for guidance and support. In most countries where Peace Corps works, the majority of staff is made up of host-country nationals, as opposed to American staff. Therefore, 
Peace Corps Volunteers turn to these host-country nationals when trying to figure out how to navigate the new culture in which they find themselves. Host-country nationals are able to provide invaluable advice to the volunteers as they are natives of the country and have lived there the majority of their lives. However, it is sometimes difficult to turn to these individuals for help when it comes to sensitive and somewhat controversial topics, such as homosexuality. This is why sensitivity training for Peace Corps staff would prove to be invaluable. Queer volunteers would be less hesitant to approach Peace Corps staff with concerns surrounding their queer identity if they knew they would be well-received.

It should be noted that the idea of sensitivity training for Peace Corps staff is not an innovative idea. In fact, in some countries where Peace Corps serves, these trainings have been conducted for years. In 2011, Michael Learned, President of the Lesbian, Gay, Bisexual, Transgender Peace Corps Alumni group, wrote an article entitled, "The History of Safe Zone Training in Peace Corps.” In this article he explains how these sensitivity trainings have been around since the early 2000s. Furthermore, Michael fleshes out the importance of these trainings:

'Safe Zone' is a LGBT sensitivity, acceptance and awareness training exercise designed to promote understanding and promote ally development among our straight peers. Subsequently, the mission is simple. By facilitating a better understanding of LGBT issues among Peace Corps staff, LGBT trainees and volunteers will feel more supported, comfortable and accepted in their individual interactions with staff members and thus in their service as a whole. Since that time LGBT PCVs and their Volunteer supporters have hosted or are planning Safe Zone training or versions of it in several countries: The Gambia, Jordan, Ecuador, Costa Rica, and El Salvador. What I find incredibly amazing about this is that this has all been spear-headed, developed, adapted and trained by LGBT PCVs and straight PCV allies. These are not training packages developed by PC HQ in Washington. Our Peace Corps volunteer compatriots have seen a need for this and done it. (para. 2-3) 
This article was posted on the Lesbian, Gay, Bisexual, Transgender Returned Peace Corps Volunteers' website and includes links to updated training resources used by Guatemalan RPCV Martin Picarillo during 2010. In his Safe Zone training kit, he includes a Safe Zone Workshop Final Script (2010a), an appendix to the safe zone workshop (2010b), and safe zone PowerPoint slides (2010c).

Picarillo, having implemented the trainings himself while serving in the Peace Corps, can attest to the importance of such programming. In a 2010 article entitled, "Safe Zone: Making Peace Corps Havens for LGBT PCV/Ts Worldwide," Picarillo emphasizes why these trainings are necessary:

An inclusive and accepting environment of mutual support and acceptance is vital to relationship building between PCV/Trainees and PC administration and staff. This fact can be particularly true when it comes to LGBT issues such as 'coming out,' personal sharing, feelings of safety and security, self-esteem, and mental health. Dealing with a LGBT identity can be hard in the United States, let alone in a different and often more 'conservative' culture...All this is going on while dealing with the other adjustments that being a PCV entails.

Speaking from personal experience, I found dealing with my sexual orientation identity in this new environment to be one of the hardest adjustments in my transition from American to Guatemalan living. One of the mediating factors to this challenge has been my interaction with Peace Corps staff. While I can't say I have ever felt discriminated against or unsupported there have been moments of uncertainty and doubt. For example, questions such as 'Is it OK if my APCD knows that I'm gay?' 'Can I openly talk about my boyfriend with a teacher when we share stories in language class?' 'What if I have to ask the nurse a question that 'outs' me?' While some of these questions are applicable to my own case and others not, I can promise that all of these and more have been concerns to countless volunteers.

The negative ramifications of these feelings and hesitations can be harmful to the volunteer and to her or his ability to thrive in their community. Compounding this situation is the sad reality that we non-straight identifying volunteers (for the most part) must live a lie in site for two years; acting as heterosexual for the sake of our safety and integration. To have few obvious outlets to be open and honest, neither on site nor in our interactions with staff could be extremely damaging to one's Peace Corps experience. 
As one can see, there are many commonalities between Martin's experience as a queer volunteer and the participants of this study. This sheds light on how the obstacles and struggles that queer volunteers face abroad are not unique to the society where the participants of this study served. This attests to the importance of Peace Corps providing ALL of their staff with LGBT sensitivity trainings, regardless of the country of service.

Martin further explained the need for such trainings in not only Guatemala but in all Peace Corps posts worldwide:

Therefore, it is my strong belief that should the general knowledge of LGBT issue be raised and should any number of staff members sport the "acceptance symbol" on their door or in their office as a symbol to say 'I'm a safe person to talk to about LGBT issues,' the PC community in Guatemala would be healthier, safer, and more inclusive. Note: as is also outlined in our safe zone script (See Appendix), PC-Washington also states that all PC-Centers must be supportive and accepting places for volunteers. So from the PCV community up and the Washington headquarters down PC Posts worldwide have little excuse not to engage their LGBT volunteer community. (2010d: para. 2-3).

As Martin points out, there really is no excuse for Peace Corps not to utilize these resources worldwide. They are versatile. As Michael explains, "All of these pieces can be adapted for any Peace Corps country. No one has to start from scratch" (Learned 2011:

para. 5). In fact, in addition to the Guatemalan resources (See Appendix B), the Lesbian, Gay, Bisexual, Transgender Peace Corps Alumni Group’s website also provides links to adaptations that volunteers serving in other countries have made with the help of these already existing resources. Additional resources include a Gambian adaptation and an Ecuadorian adaptation. Therefore, no one has to re-invent the wheel. The trainings already exist. Peace Corps does not have to develop an universal training. They just have to provide each country with these resources which can serve as a template to create and develop their own, culturally-specific trainings. Once Peace Corps staff members are 
trained on such a sensitive topic, it will make it that much easier to infuse issues surrounding homosexuality in volunteers' training sessions.

\section{Infusion of LGBT Issues into Volunteers' Training Sessions}

Ideally, Peace Corps Washington would mandate that each Peace Corps post conducts a session for trainees that examines LGBT issues in-country and concerns facing queer volunteers. If this seems like an insurmountable task though, there are simpler steps that can be taken to ensure such topics are covered. This can be accomplished by simply infusing these issues surrounding homosexuality and queer volunteers into already existing training sessions. Every training cohort receives sessions pertaining to diversity in the Peace Corps. In these sessions, age, race, and gender are usually topics of conversations. Volunteers are told how these different facets of their identity may impact their service. Sexual orientation should be included in these dialogues as well. Additionally, during language and cultural training, different topics are discussed daily. Homosexuality could be one of the daily topics. This would provide much insight for volunteers as host-country nationals conduct these lessons. Finally, Peace Corps could develop a session that consists of a panel of current, queer volunteers who could share their experiences with the new training cohort. This may be tough if there are no current volunteers who identity in this manner, but, in this case, certain resources could be created and distributed with the same information that the panel would have dispensed, which leads to our next topic of discussion: creation and distribution of resources for queer volunteers. 


\section{Creation and Distribution of Resources for Queer Volunteers}

Training staff and talking openly about LGBT issues in training are great steps in better supporting queer volunteers. However, volunteers also expressed a need for concrete resources that they could utilize throughout their service. These resources could take many forms, ranging from simple handouts, videos, manuals, to a possible mentorship program between new and already serving queer volunteers.

One of the most valuable resources to future and current Peace Corps Volunteers are, in fact, other Peace Corps Volunteers or Returned Peace Corps Volunteers. An extremely helpful resource that Peace Corps could work to compile would be a book of experiences and advice from queer RPCVs. This booklet could be sent out to Invitees prior to departing for service. Although each volunteer's experience is different, depending on a myriad of factors, this book would help to prepare individuals for the obstacles they may face as a queer volunteer abroad. This book could also include information on resources and organizations that volunteers may want to look into before leaving for service, such as the Lesbian, Gay, Bisexual, Transgender Peace Corps Alumni organization. I have mentioned this organization a few times prior to this. The problem is that not many people know this organization exists. Peace Corps should promote and support this group as it would prove to be an invaluable resource to volunteers prior to departure, during service, and afterwards. Additionally, this group's website includes stories from queer volunteers who have served all over the world. It also includes challenges that queer volunteers face in the Peace Corps. Furthermore, as mentioned earlier, it provides resources for safe space trainings. Finally, it provides a mentorship program for queer individuals departing for service. It would be better for volunteers to 
know about such resources prior to leaving because the accessibility to such resources and organization may be limited once volunteers reach their country of service. Volunteers' adjustment to their host-country can be very overwhelming, so any preparation they can do beforehand, only helps them in an already daunting process. Furthermore, the book should take intersectionality into consideration. Peace Corps promotes diversity among volunteers and provides some resources on what experiences of minority volunteers are like. However, there is much improvement that could be done when addressing the intersectionality of identity and how that impacts a volunteer's service. The impact of a certain facet of a volunteer's identity does not occur in a vacuum. Peace Corps addresses each facet individually, but I think it would be more beneficial to take all facets into account and provide different narratives focusing on the intersectionality of each identity marker.

Additionally, a simple resource that Peace Corps could create is a handout of quotes from previous queer volunteers. Throughout my interviews, my participants shared many words of wisdom that would be beneficial for future volunteers to hear. Here are ten sound bytes of wisdom that my participants provided:

1) Alexi, who realized she was pansexual while serving in the Peace Corps, shared what she would say to new, queer volunteers and the tough questions they should contemplate before agreeing to be a Peace Corps Volunteer:

I would tell them to talk to someone who knew they were gay before (laughter) they came here. No, I mean, I would tell them that they really have to think about what the culture feels (about homosexuality) before they come, and think about how they are going to deal with it. Like how they are going to try to prepare themselves? You can never prepare yourself fully but you can try, and I think I would tell them that about anything 'cause it's not like I came here being like, 'How will they look at me?' 'Cause I didn't even know I was like this! But this was who I was, so it's like ANYTHING can change... Be prepared for it to 
change. Like I wasn't prepared for my identity to change, and I was kinda like, 'Really??' 'Cause Peace Corps is already really hard, and now I'm like dealing with a new part of me, and now it's like, 'Okay!" I gotta fit this in here too.' Um, so I think that just looking at being prepared for things to change about you or for maybe the way you identify, you don't anymore. Because of the culture, it changes how you feel about that identity. 'Cause it's not something I thought of. I mean, I don't really prepare for things, so I didn't really prepare for Peace Corps in that way. But I think that it would be a good way to do it, especially if you come here knowing (you are gay). Like how does the culture feel about it? How are you going to respond to it? Be honest with yourself. Can you go somewhere and for two years completely hide who you are? Know that if they find out, you might have to leave a place where you thought you were safe but you're not. I mean, it's not that these things are necessary but it, I think it can help. It's hard to hide so much of yourself...It's exhausting.

2) Sue had some general words of wisdom to share. This advice would be invaluable to any volunteer, regardless of how they identify:

Um, let's see. I mean, I would probably give this advice to just about anyone. Just be flexible and have an open mind and have a sense of humor about things, like don't take things personally. Yeah, just have them go with the flow and keep expectations low.

3) Joanne emphasized the importance of letting incoming, queer volunteers know that they will not be alone. They will have a support system in-country:

They're not going to be the only one out there. There are other people who are queer in other countries. (New volunteers) will find their niche somewhere. I thought I wouldn't. I thought there wasn't anything up there. But times are changing now. And it might be a third world country, and it may seem like they're not updated, but they are. Um, I'd just tell them there is always going to be somebody. We're always connected somehow.

4) Pam had a lot of advice to give as well. She emphasized the importance of reflecting on how going back into the closet affects a person. She stressed the importance of finding safe, healthy outlets, as well as the importance of being kind to oneself while navigating this difficult journey:

I would say that it is critical to find outlets. Um, if that means with the people you are working with, if that means finding an LGBT community in the country you're in, if that even just means having like a web community because it's not 
safe otherwise. Um, you know, safety is the number one concern, but if you are able and if you are safe, if you feel safe doing so, like talk about shit. Definitely talk about it. Like try to talk it out. Try to see if, um, you know there are instances where you can try bringing that subject up if it's something you're comfortable with. Um, yeah, I (sigh) you know, be aware of how much the closet kills someone. Be like thoroughly aware of that. Be thoroughly aware if you go in and you're like, 'I'm just going to stay in the closet the whole time. I'm not going to bring this up with anyone. I'm not going to do anything. That's my strategy is going to be to shield this.' Be aware of the toll that takes. It might be easier for a foreign-aid worker who's in the closet domestically to do that. But if you have been out in the country that you're living in and then you go and you have to go back into the closet, like, the closet may kill you. Going BACK into the closet is more dangerous in my opinion. In my experience, yeah, it's kind of like knowing what freedom tastes like. It's hard to not want it. Um, yeah, make outlets. Find outlets. Figure out how you can negotiate that process. Figure out where you can get resources. If you can't get resources physically, get them over the web. What's great is we've got a very large, vibrant online community. Be in touch with how you're doing. Be gentle with yourself. Um, don't assume you have to shut off that identity completely whatever dangerous situation you're in. Like expressions of self might need to be more closely guarded, but there should also be an expression of self in one way or another.

5) Collins, like others, stressed the importance of finding support and preparing oneself

for a life back in the closet:

Everyone's going to have a different experience. I guess my advice would be to find support when you're there. I guess for me the source of my support was other Peace Corps Volunteers. Um, but I know other people who served who lived in more urban settings that made gay friends and had like a gay community, you know, around them. Um that wasn't my experience, but I think that's based on where I lived. I guess my advice is not profound or anything (Laughing) But just to find support, um, in whichever way you can, and maybe to prepare yourself for the fact that you won't be able to be out.

6) Mark further elaborated on the importance of finding a support system that volunteers can access in-country, as trying to access one back home can be somewhat difficult at times, In addition, he touched upon his regret for not coming out to anyone during his service:

Definitely find similar people for support systems where you are at 'cause as great as friends and family back home are, it's not the easiest to get a hold of them all the time. So you definitely need something more immediate and much closer and 
more personal in that regard. Besides that, looking back now, part of me really wishes I would have just said, 'Fuck it,' and let people know.

7) Maureen emphasized the importance of staying true to oneself during his or her service and how being open with locals can be advantageous to the success of a volunteer's service.

Don't forget who you are and stay true to that. I would say worry a lot less. When I first got there, (others) had me actually worried. Like, I can't do this and I can't let anyone know. As long as you represent yourself, like, there's so many aspects about you, other than being gay, so be YOU, and just know that's just one of your many facets, and, you know, your many dimensions. Uh, don't be wrapped up in it. Like, don't be like all I can be is gay or I'm nothing. Just be open. Like, that was my biggest benefit, not thinking that if this person was too close to me and they found out, or if I was too, you know, too truthful and accidentally let out my secret that this person was automatically going to shun me or hate me or not let me come over for dinner anymore. 'Cause I barely met ANYONE that truly felt that way. You know? And make sure you keep respecting them. Like I'm not going to make out with someone in the middle of a (Local) wedding, like, you know, that's in bad taste. They're not big on public display affections between HETEROSEXUAL people, so, you know, I think that as long as you stay within their boundaries, there should be no worries whatsoever. I think my openness has allowed people in without worry.

8) Roger built on the importance of preparing oneself prior to departure. He stressed the importance of doing research beforehand and mentally preparing for having to negotiate one's identity to some extent:

Do research. Try to find out information about the country you've been assigned to. Uh, Peace Corps itself seems to be supportive of everyone who serves in terms of their identity, gay, straight, or, uh, even when it's not in the question of sexual orientation or sexual identity, racial or religious. I think for the most part, you'll get support from the Peace Corps, but you need to know that there is a good chance that when you sign up for Peace Corps that you're going to be going into a situation where you'll have to NOT be open about that part of yourself, at least to the people in your host country. I would THINK being open about it with other PCVs would not be an issue. Um, I have never heard that it was. I hope in 2015 that THAT is not the issue. It's more, um, host country nationals. 
9) Like so many other participants, April's main point of advice revolved around finding support in-country. However, in contrast to what others have said, she stressed the importance of finding support among BOTH locals and expats:

Find LGBT communities with both locals and expats. Expats will help you adapt to new attitudes regarding homosexuality, especially when you come from ultraaccepting urban centers like NYC or San Francisco. Local queer friends will make you feel at home in your new country as a sexual minority without feeling like you're at war with all locals.

10) Finally, Mimi, too, explained the importance of finding a queer support system. She also emphasized that people may try to convince you that gay people do not exist in these conservative societies, but they, in fact, do. One just has to know where to look:

Find your like clique. Find your people. Like there's going to be like that one gay person in your village or that like one friend that you're going to make and just like own it. It's going to be fine, like people (gay people) exist. You know what I mean? They're going to be pretend there's no gay people, but there are always gay people. Just find them.

These words of wisdom may just seem like ten random sound bytes to some people, but to a queer individual who is about to live in a country where homosexuality is not accepted, these words provide them with a lifeline. These words provide them with proof that queer people like them served and were okay. It provides them with advice but, more importantly, it provides them with confidence that they can serve and not only be okay but also successful.

A handout of advice would be helpful, but a more effective resource that could be created is a video. Maureen explained the effectiveness of videos during Peace Corps trainings:

Uh, I think the Peace Corps should definitely talk to current, active volunteers about how they cope, and maybe put that into some kind of video, strategy, or something. Like we had a video that was made by Peace Corps on if you have sex 
with a local and contract HIV what happens? That was a very helpful tool for us volunteers.

A similar video could be made surrounding LGBT issues in-country and the possible obstacles that queer volunteers may face during service. If an in-person panel is not possible, this movie could be shown instead to new trainees. To further reiterate the importance of taking intersectionality into consideration, this movie could also focus on more than just sexual orientation. Participants could touch upon how all their facets impact their service. This would prove to be a valuable resource to all volunteers, not just queer volunteers. Again, this movie could be made available prior to volunteers departing for service, allowing them more time to prepare for service. Additionally, making this resource available prior to service, ensures that the session will not be cancelled due to time restrictions. Therefore, it eliminates the possibility of trainees never receiving this information.

It should also be noted that these stories would serve as archetypal figures.

Obviously they would not be representative of everyone's experiences. As Collins explained:

Peace Corps' idea for preparing someone for like whatever experience they may face are like to put a panel together and say like, 'This might be something that happens to you.' (Laughter). You know? Like they bring these archetypal figures, like here's a Black volunteer. Here's an Asian volunteer. Here's a female volunteer. He's an older volunteer. And their method of addressing it is just to like infuse the room with anecdotes and while that's like fine, it does NOT represent everyone's experience. Even if they had brought in someone to say like, 'Here's a gay volunteer.' Like, 'Tell us your story.' It would span. You know? There'd be a huge spectrum of experiences. I know that my experience was NOT typical of all people, so even if it was me preparing someone else, I wouldn't be able to do an adequate job...I'm of the belief that as a volunteer that you need to like make your own path and figure shit out on your own. Um, and that was my experience too. 
Collins definitely has a point. It would be impossible to create a resource that was representative of everyone and could prepare everyone $100 \%$. Nevertheless, I wholeheartedly believe that a resource of this nature would still prove to be invaluable as it would prepare volunteers to some extent, which is better than simply not addressing the issue at all and leaving them to figure it out for themselves.

Creating and distributing resources for queer volunteers prior to departure and during training is essential for their success as Peace Corps Volunteers. In addition to these resources, Peace Corps should also provide tools that can be used in the field as well. For example, the conversational guide that I created during my service could prove to be a valuable resource for volunteers who wish to have dialogues surrounding homosexuality during their service. My guide could be used as a template for others. Each guide would obviously have to be tailored to be culturally-specific but some of the advice in there is universal (See Appendix C). Again this resource is helpful because no one has to start from scratch. There are already so many resources out there that could be utilized. Peace Corps just needs to work on compiling these resources and promoting them.

\section{IN SUMMARY}

Overall, queer volunteers, like all volunteers, just want to be as prepared as they can be for service. Furthermore, they want to feel fully supported and comfortable going to Peace Corps staff if they need guidance or direction. I fully believe that if Peace Corps takes these three easy steps-Sensitivity training for Peace Corps staff, infusion of LGBT issues into volunteers' training sessions, and creation and distribution of resources for 
queer volunteers - that it would benefit both the volunteers and the organization as a whole. It will be a step in the right direction for everyone involved. 


\section{REFERENCES}

Adamczyk, Amy, and Cassidy Pitt. 2009. "Shaping Attitudes About Homosexuality: The Role of Religion and Cultural Context." Social Science Research 38(2):338-351.

Andersen, Robert, and Tina Fetner. 2008. "Economic Inequality and Intolerance: Attitudes Toward Homosexuality in 35 Democracies." American Journal of Political Science 52(4):942-958.

Austin, J.L. 1962. How to do Thing with Words. Cambridge, MA: Harvard University Press.

Badgett, Mary Virginia Lee. 1996. "Employment and Sexual Orientation: Disclosure and Discrimination in the Workplace.” Journal of Gay and Lesbian Social Services $4(4): 29-52$.

Baral, Stefan, Gift Trapence, Felistus Motimedi, Eric Umar, Scholastika Iipinge, Friedel Dausab, and Chris Beyrer. 2009. "HIV Prevalence, Risks for HIV Infection, and Human Rights Among Men Who Have Sex With Men (MSM) in Malawi, Namibia, and Botswana," PLOS ONE 4(3):1-8.

Bhavnani Kum-Kum, and Donna Haraway. 1994. "Shifting the Subject: A Conversation between Kum-Kum Bhavnani and Donna Haraway.” Feminism \& Psychology 4(1):19-39.

Binnie, Jon. 2004. The Globalization of Sexuality. London: SAGE Publications. 
Blumer, Herbert. 1969. Symbolic Interactionism: Perspective Method. Englewood Cliffs, NJ: Prentice-Hall.

Bolton, Ralph. 1996. "Coming Here: The Journety of a Gay Ethnographer in the Years of the Plague." Pp. 147-168 in Out in the Field: Reflections of Lesbian and Gay Anthropologists. Champaign, IL: University of Illinois Press.

BONELA, LeGaBiBo, and IGLHRC. 2008. The Violation of Lesbian, Gay, Bisexual, and Transgender Persons in Botswana. (Shadow Report). Gaborone: The Botswana Network on Ethics, Law, and HIV/AIDS.

Bos, H. M. W., F. Van Balen, D. C. Van Den Boom, and T. G. M. Sandfort. 2004. "Minority Stress, Experience of Parenthood and Child Adjustment in Lesbian Families." Journal of Reproductive and Infant Psychology 22:291-304.

Burke, Peter J. 1991. "Identity Processes and Social Stress." Annual Sociological Review $56: 836-849$.

Burke, Peter J. and Donald C. Reitzes. 1991. “An Identity Theory Approach to Commitment.” Social Psychological Quarterly 54;239-251.

Butler, Judith. 1990. Gender Trouble: Feminism and the Subversion of Identity. New York: Routledge.

Carrillo, Hector. 2009. "Changes and Challenges: Ethnography, Homosexuality, and HIV Prevention Work in Guadalajara." Pp. 33-53 in Out in Public: Reinventing Lesbian/Gay Anthropology in a Globalizing World, edited by Ellen Lewin and William L. Leap. Blackwell Publishing Ltd.

Cass, Vivienne C. 1979. "Homosexual Identity Formation: A Theoretical Model." Journal of Homosexuality 4(3):219-235. 
Chan, Connie S. 1997. “Don’t Ask, Don't Tell. Don’t know: The Formation of a Homosexual Identity and Sexual Expression Among Asian American Lesbians.” Pp. 240-248 in Ethnic and Cultural Diversity Among Lesbian and Gay Men, edited by Beverly Greene. Thousand Oaks, CA: SAGE Publications.

Chrobot-Mason, Donna, Scott B. Button, and Jeannie D. DiClementi. 2001. "Sexual Identity Management Strategies: An Exploration of Antecedents and Consequences. Sex Roles 45:321-336.

Clinton, Hillary. 2011. “Secretary Clinton's Speech to the United Nation's on LGBT Human Rights.” Retrieved August 10, 2012 from (http://www.bilerico.com/2011/12/hillary_clintons_lgbt_rights_speech_to_the_un .php).

Cole, Steve, W., Margaret E. Kemeny, Shelley E. Taylor, and Barbara R. Visscher. 1996. "Elevated Physical Health Risk Among Gay Men who Conceal Their Homosexual Identity.” Health Psychology 15:243-151.

Coleman, Eli. 1982. "Developmental Stages of the Coming Out Process.” American Behavioral Scientists 25:1-43.

Colgan, Fiona, Chris Creegan, Aidan McKearney, and Tessa Wright. 2006. "Equality and Diversity Policies and Practices at Work: Lesbian, Gay, and Bisexual Workers.” Equal Opportunities International 26(6):590-609 .

Colon, Manuel and Fiona Martin. 2013. "Open Secrets: Navigating gay identity in Paraguay,” WorldView, Spring 2013, Vol 26, No. 1, pp. 18-21. 
Confessore, Nicholas and Michael Barbaro. 2011. "New York Allows Same-Sex Marriage, Becoming Largest State to Pass Law." nytimes.com Retrieved October 19, 2015 (http://www.nytimes.com/2011/06/25/nyregion/gay-marriage-approvedby-new-york-senate.html?_r=0).

Cooley, Charles H. 1902. Human Nature and Social Order. New York: Schocken Books. Cottrell, Randy and James F. McKenzie. 2005. Health Promotion \& Education Research Methods: Using the 5 Chapter Thesis/Dissertation Model. Boston, MA: Jones \& Bartlett.

Cox, Stephen and Cynthia Gallois. 1996. "Gay and Lesbian Identity Development: A Social Identity Perspective. Journal of Homosexuality 30:1-30.

Cronin Ann and Andrew King. 2010. "Power, Inequality, and Identification: Exploring Diversity and Intersectionality amongst Older LGB Adults.” Sociology 44:876892.

Demino, Kathleen. A., George Appleby, and Deborah Fisk D. 2007. "Lesbian Mothers with Planned Families: A Comparative Study of Internalized Homophobia and Social Support.” American Journal of Orthopsychiatry 77:165-173.

Diamond, Lisa M. 2007. “A Dynamic Systems Approach to Female Same Sex Sexuality.” Perspectives in Psychological Science 2:141-161.

Di Silvio. 2011. “Correcting Corrective Rape: Carmichele and Developing South Africa's Affirmative Obligations To Prevent Violence Against Women.” The Georgetown Law Journal 99:1469-1515.

Dovidio, John F. and Samuel L. Gaertner. 2000. “Averise Racism and Selection Decisions: 1989 and 1999. Psychological Science 11:315-319. 
Downie, Richard. 2014. Revitalizing the Fight Against Homophobia in Africa. (A report of the CSIS Global Health Policy Center). Washington, D.C.: Center for Strategic \& International Studies.

Drucker, Peter. 1996. "In the Tropics There is No Sin: Sexuality and Gay-Lesbian Movements in the Third World." New Left Review I(218):75-101.

Eldridge, Vicki Lea, Lisa Mack, and Erick Swank. 2006. "Explaining Comfort with Homosexuality in Rural America." Journal of Homosexuality 51(2):39-56.

Ellis, Carolyn. 1999. "Keynote Addresses From the First Annual Advances in Qualitative Methods Conference: Heartful Autoethnography" Qualitative Health Research 9(5):669-683.

Ellis, Carolyn and Arthur P. Bochner. 2000. "Autoethnography, Personal Narrative, Reflexivity: Researcher as Subject.” Pp. 733-768 in Handbook of Qualitative Research, edited by Norman K. Denzin and Yvonna S. Lincoln. Thousand Oaks, CA: SAGE Publications.

Ellis, Alan L., and Ellen D. Riggle. 1996. Sexual Identity on the Job. Issues and Services. New York: Haworth Press.

Espin, Olivia M. 1997. "Crossing Borders and Boundaries: The Life Narratives of Immigrant Lesbians.” Pp. 191-215 in Ethnic and Cultural Diversity Among Lesbian and Gay Men, edited by Beverly Greene. Thousand Oaks, CA: SAGE Publications.

Espin, Oliva M. 1999. Women Crossing Boundaries: A Psychology of Immigration and Transformations of Sexuality. New York: Routledge. 
Floyd, Frank J. and Terry S. Stein. 2002. "Sexual Orientation Identity Formation Among Gay, Lesbian, Bisexual Youths: Multiple Patterns of Milestone Experiences.” Journal of Research on Adolescence 12:167-191.

Frost, David. M., and Illan H. Meyer. 2009. "Internalized Homophobia and Relationship Quality Among Lesbians, Gay Men, and Bisexuals.” Journal of Counseling Psychology 1:97-109.

Garnets, Linda, and Douglas Kimmel. 1993. Psychological Perspectives on Lesbian and Gay Male Experiences. New York: Columbia University Press.

Goffman, Erving. 1959. The Presentation of Self in Everyday Life. Garden City, NJ: Doubleday.

Goodman, Liz. 1996. "Rites of Passing." Pp. 49-57 in Out in the Field: Reflections of Lesbian and Gay Anthropologists. Champaign, IL: University of Illinois Press.

Griffith, Kristin H. and Michelle R. Hebl. 2002. "The Disclosure Dilemma for Gay Men and Lesbians: “'Coming Out' at Work.” Journal of Applied Psychology 87:11911199.

Gupta, Alok. 2008. “The Alien Legacy: The Origins of 'Sodomy': Laws in British Colonialism." Humans Rights Watch Report 1-66.

Halpin, S.A. and M.W. Allen. 2004. "Changes in psychosocial well-being during stages of gay identity development." Journal of Homosexuality 47:109-26.

Hames-Garcia, Michael. (2011). Identity Complex: Making the Case for Multiplicity.” Minneapolis, MN: University of Minnesota Press.

Hansen Charles E. and Anne Evans. 1985. "Bisexuality Reconsidered: An Idea in Pursuit of a Definition.” Journal of Homosexuality 11:1-6. 
Hebl, Michelle R., Jessica B. Foster, Laura B. Mannix, and John. F. Dovidio. 2002.

"Formal and Interpersonal Discrimination: A Field Study Bias Toward

Homosexual Applicants.” Personality and Social Psychology Bulletin 28:815-

825.

Hennessey, Rosemary. 2000. Profit and Pleasure: Sexual Identities in Late Capitalism.

New York: Routledge.

Herek, Gregory M., and John P. Capitanio. 1996. "Some of My Best Friends: Intergroup

Contact, Concealable Stigma, and Heterosexuals' Attitudes toward Gay Men and Lesbians." Personality and Social Psychology Bulletin 13(1):34-44.

Hicks, Gary R., and Tien-tsung Lee. 2006. "Public Attitudes Toward Gays and Lesbians:

Trends and Predictors.” Journal of Homosexuality 51(2):57-77.

Hollander, Judith and Linda Haber. 1992. "Ecological Transitions: Using Bronfenbrenner's Model to Study Sexual Identity Change.” Health Care for Women International 13:121-129.

Horowitz, Janna. L., \& Michael D. Newcomb. 2001. “A Multidimensional Approach to Homosexual Identity.” Journal of Homosexuality 42(2):1-19.

Human Rights Campaign. 2012. "Issue: Federal Advocacy.” Washington, D.C: Human Rights Campaign. Retrieved August 5, 2012 (http://www.hrc.org/laws-andlegislation/federal-legislation/employment-non-discrimination-act).

Human Rights Campaign 2015a. “The Need for Full LGBT Equality.” Washington, D.C: Human Rights Campaign. Retrieved October 19, 2015 (http://www.hrc.org/ campaigns/ support-the-equality-act). 
Human Rights Campaign 2015b. "What is the Equality Act?" Washington, D.C: Human Rights Campaign. Retrieved October 19, 2015 (http://www.hrc.org/ campaigns/support-the-equality-act).

Inglehart, Ronald. 1990. Cultural Shift in Advanced Industrial Society. Princeton, NJ: Princeton University Press.

Jackson, Stevi and Sue Scott. 2010. Theorising Sexuality. Maidenhead: Open University Press.

Jordan, K. M. and R. H. Deluty. 1998. "Coming out for lesbian women: Its relation to anxiety, positive affectivity, self-esteem, and social support." Journal of Homosexuality 35:41-63.

Kaufman, Joanne M. and Cathryn Johnson. 2004. "Stigmatized Individuals and the Process of Identity.” The Sociological Quarterly 45(4):807-833.

Kennedy, Elizabeth Lapovsky and Madeline Davis. 1996. "Constructing an Ethnography of the Buffalo Lesbian Community: Reflexivity, Dialogue, and Politics." Pp. 171199 in Out in the Field: Reflections of Lesbian and Gay Anthropologists. Champaign, IL: University of Illinois Press.

Kertzner, Robert M., Illan H. Meyer, David M. Frost, and Michael J. Stirratt. 2009. "Social and Pyschological Well-being in Lesbians, Gay Men, and Bisexuals: The Effects of Race, Gender, Age, and Sexual Identity.” Am J Orthopsychiatry 79(4):500-510.

Killian, Caitlin and Cathryn Johnson. 2006. “'I'm Not an Immigrant!': Resistance, Redefinition, and the Role of Resources in Identity Work.” Social Psychology Quarterly 69(1): 60-80. 
Kvale, Steinar. 1996. InterViews: An Introduction to Qualitative Research Interviewing. Thousand Oaks, CA: SAGE Publications.

Lane, Julie D. and Daniel M. Wegner. 1995. "The Cognitive Consequences of Secrecy." Journal of Personality and Social Psychology 69:237-253.

Leap, William L. 1996. “Studying Gay English: How I Got Here from There.” Pp. 128146 in Out in the Field: Reflections of Lesbian and Gay Anthropologists. Champaign, IL: University of Illinois Press.

Learned, Michael. 2011. "The History of Safe Zone Training in Peace Corps. Retrieved from the Lesbian, Gay, Bisexual, Transgender Returned Peace Corps Volunteers website: (http://lgbrpcv.org/2011/04/03/the-history-of-safe-zone-training-inpeace-corps/)

Lee, John Alan. 1977. "Going Public: A Study in the Sociology of Homosexual Liberation." Journal of Homosexuality 3:49-78.

Lewin, Ellen and William L. Leap. 1996. Out in the Field: Reflections of Lesbian and Gay Anthropologists. Champaign, IL: University of Illinois Press.

Liptak, Adam. 2015. "Supreme Court Ruling Makes Same-Sex Marriage a Right Nationwide." Retrieved from NY times website: (http://www.nytimes.com /2015/06/27/us/supreme-court-same-sex-marriage.html?mabReward=A1\&_r=0).

Longhurst, Robyn. 2010. "Semi-Structured Interviews and Focus Groups.” Pp. 103-115 in Key Methods in Geography, edited by N. Clifford and G. Valentine. London: Sage Publications Ltd. 
Longman, Jere. 2011. "In African Women's Soccer, Homophobia Remains an Obstacle.” Retrieved from the NY times website: (http://www.nytimes.com /2011/06/23/ sports/soccer/in-african-womens-soccer-homophobia-remains-an-obstacle.html? $\left.\_r=2\right)$.

Luibheid, Eithne. 2005. “Introduction: Queering Migration and Citizenship.” Pp. ix-xlvi in Queer Migrations: Sexuality, U.S. Citizenship, and Border Crossings, edited by Eithne Luibheid and Lionel Cantu Jr. Minneapolis, MN: University of Minnesota Press.

Luibheid, Eithne and Lionel Cantu Jr. 2005. Queer Migrations: Sexuality, U.S. Citizenship, and Border Crossings. Minneapolis, MN: University of Minnesota Press.

Manalansan, Martin F. 2005. "Migrancy, Modernity, Mobility: Quotidian Struggles and Queer Diasporic Intimacy.” Pp. 146-160 in Queer Migrations: Sexuality, U.S. Citizenship, and Border Crossings, edited by Eithne Luibheid and Lionel Cantu Jr. Minneapolis, MN: University of Minnesota Press.

Martin, Harold P. 1991. "The Coming-Out Process for Homosexuals." Hospital \& Community Psychiatry 42:158-162.

McCloud, Adrienne. 2013. "Q\&A with Michael Learned: President of the Lesbian, Gay, Bisexual, Transgender Peace Corps Alumni Group," WorldView, Vol. 26, No. 1, p. 16. 
McFarlane, Colleen A. 2004. "Risks Associated with the Psychological Adjustment of Humanitarian Aid Workers.” The Australasian Journal of Disaster and Trauma Studies 2004-1. Retrieved August 5, 2012 (http://www.massey.ac.nz / trauma /issues/2004- 1/mcfarlane.htm).

Mead, George Herbert. 1934. Mind, Self, and Society. Chicago: The University of Chicago Press.

Meyer, I.H. 2003. "Prejudice, social stress, and mental health in lesbian, gay, and bisexual populations: Conceptual issues and research evidence." Psychological Bulletin 129:674-697.

Minton, Henry L. and Gary J. McDonald. 1984. Homosexual Identity Formation as a Developmental Process. Journal of Homosexuality 9:91-104.

Mizzi, Robert. 2010. "Unraveling Researcher Subjectivity Through Multivocality in Autoethnography.” Journal of Research Practice 6(1):1-14.

Moreno, Raquel. 2015. "I'm an aid worker... and I'm gay.” Global Development Professionals Network. Retrieved from The Guardian website: http://www.the guardian.com/global-development-professionals-network/2015/mar/12/im-an-aidworker-and-im-gay-lgbt-ngos).

Morris, Jessica F. 1997. "Lesbian Coming Out as a Multidimensional Process. Journal of Homosexuality 33:1-22.

Newman, Bernie Sue. 2007. “College Students' Attitudes About Lesbians.” Journal of Homosexuality 52(3):249-265. 
Newton, Esther. 1996. "My Best Informant's Dress: The Erotic Equation in Fieldwork." Pp. 212-235 in Out in the Field: Reflections of Lesbian and Gay Anthropologists. Champaign, IL: University of Illinois Press.

Ngunjiri, Faith Wambura, Kathy-Ann C. Hernandez, and Heewon Chang. 2010. “Living Autoethnography: Connecting Life and Research.” Journal of Research Practice 6(1):1- 17 .

Ochberg, Richard L. 1992. “Social Insight and Psychological Liberation.” Pp 214-230. Storied Lives: The Cultural Politics of Self-Understanding, edited by G.C. Rosenwald and R.L. Ochberg. New Haven, CT: Yale University Press.

Otis, Melanie. D., Sharson S. Rostosky, Ellen D. B. Riggle, and Rebecca Hamrin. 2006. "Stress and Relationship Quality in Same-Sex Couples." Journal of Science and Personal Relationships 23:81-99.

Owens, Timothy J., Dawn T. Robinson, and Lynn Smith-Lovin. 2010. “Three Faces of Identity." Annual Review of Sociology 36:477-499.

Oxford University. (2012). "International Development.” Retrieved August 5, 2012 (http://www.careers.ox.ac.uk/wpcontent/uploads/2012/02/International_ Development_20111.pdf).

Patton Cindy and Benigno Sanchez-Eppler. (2000). Queer Diasporas. Durham, NC: Duke University Press.

Peace Corps. 1997. 'Peace Corps: 'Toughest Job You'll Ever Love' More Popular Than Ever; Top 10 Peace Corps States Named. Retrieved October 1, 2015 (http://www. peacecorps.gov/media/forpress/press/67/). 
Peace Corps. 2012a. "Fast Facts." Washington, D.C.: Peace Corps. Retrieved March 25, 2012 (http://www.peacecorps.gov/index.cfm?shell=about.fastfacts).

Peace Corps. 2012b. "The LGBT Community and the Peace Corps: Gay and Lesbian Returned Peace Corps Volunteer Panel.” Washington, D.C.: Peace Corps. Retrieved March 25, 2012 (http://www.peacecorps.gov/index.cfm?shell $=$ meet.regrec. event\&eventid=97529).

Peace Corps. 2012c. Your Assignment. Peace Corps, Washington D.C.

Peace Corps. 2013a. "Peace Corps Announces New Service Opportunity for Same-Sex Couples." Washington, D.C.: Peace Corps. Retrieved August 1, 2015 (http://www.peacecorps.gov/media/forpress/press/2238/).

Peace Corps. 2013b. "Fast Facts." Washington, D.C.: Peace Corps. Retrieved August 1, 2015 (http://www.peacecorps.gov/about/fastfacts/).

Peace Corps. 2014a. "The Peace Corps Welcomes you to Botswana." Washington, D.C.: Peace Corps. Retrieved August 14, 2015 (files.peacecorps.gov/manuals/ welcomebooks/ bwwb637.pdf).

Peace Corps. 2014b. "Peace Corps Announces Historic Changes to Application and Selection Process.” Washington, D.C.: Peace Corps. Retrieved August 14, 2015 (http://www.peacecorps.gov/media/forpress/press/2418/).

Peace Corps. 2014c. "RPCV Handbook: You're on you way back home." Washington, D.C. Peace Corps. Retrieved August 14, 2015 (http://files.peacecorps.gov/ resources/returned/staycon/rpcv_handbook.pdf). 
Peace Corps. 2014d. "Peace Corps: LGBTQ Volunteers.” Washington, D.C.: Peace Corps. Retrieved August 14, 2015 (files.peacecorps.gov/multimedia/pdf/learn /howvol/faq/LGBTQ_FAQs.pdf

Peace Corps. 2015a. "Master's International.” Washington, D.C.: Peace Corps. Retrieved September 15, 2015(http://www.peacecorps.gov/volunteer/university/mastersint/). Peace Corps. 2015b. "Secondary and Upper Primary Education Science Teacher." Washington D.C.: Peace Corps. Retrieved September 15, 2015 (http://www. peacecorps.gov/openings/3741br/).

Peplau, Letitia Anne, and Negin Ghavami. 2009. “Gay, Lesbian, and Bisexual Relationships." Encyclopedia of Human Relationships. 2009. SAGE Publications. Retrieved from: (http://www.sage-ereference.com/humarelationships/Article _n238.html).

Picarillo, Grant Martin. 2010a. "Safe Zone Workshop Final Script.” Lesbian, Gay, Bisexual, Transgender Returned Peace Corps Volunteers' website. Retrieved September $14^{\text {th }}, 2015$ (http://lgbrpcv.org/2010/02/03/safe-zone-making-peacecorps-havens-for-lgbt-pcvts-worldwide/).

Picarillo, Grant Martin. 2010b. “Appendix to Safe Zone Workshop.” Lesbian, Gay, Bisexual, Transgender Returned Peace Corps Volunteers' website. Retrieved September 14 $4^{\text {th }}, 2015$ (http://lgbrpcv.org/2010/02/03/safe-zone-making-peacecorps-havens-for-lgbt-pcvts-worldwide/).

Picarillo, Grant Martin. 2010c. "Safe Zone Slides." Lesbian, Gay, Bisexual, Transgender Returned Peace Corps Volunteers' website. Retrieved September $14^{\text {th }}, 2015$ (http://lgbrpcv.org/2010/02/03/safe-zone-making-peace-corps-havens-for-lgbt- 
pcvts- worldwide/).

Picarillo, Grant Martin. 2010d. "Safe Zone: Making Peace Corps Havens for LGBT PCV/Ts Worldwide. Retrieved from The Lesbian, Gay, Bisexual, Transgender Returned Peace Corps Volunteers website: (http://lgbrpcv.org/2010/02/03/safezone-making-peace-corps-havens-for-lgbt-pcvts-worldwide/).

Plummer, Ken. 1975. Sexual Stigma: An Interactionist Account. London: Routledge.

Powers, William T. 1973. Behavior: The Control of Perception. Chicago: Aldine.

Proschan, Frank. 1990. "How is a Folklorist Like a Riddle?" Southern Folklore 47(1):5766.

Radazzo, Timothy J. 2005.“Social and Legal Barriers: Sexual Orientation and Asylum in the United States.” Pp. 30-60. Queer Migrations: Sexuality, U.S. Citizenship, and Border Crossings, edited by Eithne Luibheid and Lionel Cantu Jr. Minneapolis, MN: University of Minnesota Press.

Ragins, Belle Rose, Romila Singh, and John M. Cornwell. 2007. "Making the Invisible Visible: Fear and Disclosure of Sexual Orientation at Work.” Journal of Applied Psychology 92:1103-1118.

Ramirez, Horacio N. Roque. 2005. “Claiming Queer Cultural Citizenship: Gay Latino (Im)Migrant Acts in San Francisco. Pp 161-188 in Queer Migrations: Sexuality, U.S. Citizenship, and Border Crossings, edited by Eithne Luibheid and Lionel Cantu Jr. Minneapolis, MN: University of Minnesota Press.

Rand, Erica. 2005. "The Traffic in My Fantasy Butch: Sex, Money, Race, and the Statue of Liberty.” Pp 92-122. Queer Migrations: Sexuality U.S. Citizenship, and Border 
Crossing, edited by Eithne Luibheid and Lionel Cantu Jr. Minneapolis, MN: University of Minnesota Press.

Reinard, John C. 2001. Introduction to Communication Research. New York, NY: McGraw-Hill Companies, Inc.

Rich, Adrienne. 1986. "Compulsory Heterosexuality and Lesbian Existence.” Pp. 310328 in Feminism in Our Time: The Essential Writings, World War II to the Present, edited by Miriam Schneir. New York: Vintage Books.

Robertson, Roland. 1992. Globalization: Social Theory and Global Culture. London: Sage.

Rogers, A. and Michelle R. Hebl. 2001. "To Disclose or Not to Disclose: A Micronarrative Account." Presented at the Annual Meeting of the American Psychological Society. Toronto, Ontario, Canada.

Rogers, Kelli. (2014). “One step forward, two steps back? The gaps between LGBTI policy and practice in foreign aid.” Retreived from the Devex website: https://www.devex.com/news/one-step-forward-two-steps-back-the-gapsbetween-lgbti- policy-and-practice-in-foreign-aid-82832).

Roseneil, Sasha. 2000. "Queer Frameworks and Queer Tendencies: Towards an Understanding of Postmodern Transformation of Sexuality." Sociological Research Online. 5(3):1-21.

Rosenwald, George C, and Richard L. Ochberg. 1992. Storied Lives: The Cultural Politics of Self-Understanding. New Haven, CT: Yale University Press.

Rupar, Terri. 2014. "Here are the 10 Countries Where Homosexuality may be Punished by Death.” The Washington Post. Retrieved August 14, 2015 from 
(https://www.washingtonpost.com/news/worldviews/wp/2014/02/24/here-are-the10-countries-where-homosexuality-may-be-punished-by-death/).

Savin-Williams, Ritch C. and Richard G. Rodriquez. 1993. "Advances in Adolescent Development." Pp. 77-101 in A Developmental, Clinical Perspective on Lesbian, Gay Male, and Bisexual Youths, edited by T.P Gullotta, G.R. Adams, and R. Montemayer. Newbury Park, CA: Sage.

Schulkers, Julia. 2013. "Volunteer Life: Gender and Development of Self." Peace Corps Times 4:5.

Seidman, Steven. 2009. "Critique of Compulsory Heterosexuality." Sexuality Research \& Social Policy 6(1):18-28.

Seidman, Steven. 2010. The Social Construction of Sexuality. New York: W. W. \& Norton Company, Inc.

Shallenberger, David. 1994. "Professional and Openly Gay: A Narrative Sudy of the Experience.” Journal of Management Inquiry 3:119-142.

Shapiro, Danielle N., Desdamona Rios, and Abigail J. Stewart. 2010. “Conceptualizing Lesbian Sexual Identity Development: Narrative Accounts of Socializing Structures and Individual Decisions and Actions." Feminism \& Psychology 20(4):491-510.

Shapiro, T. Rees. 2014. "Peace Corps announces major changes to application process." Retrieved from The Washington Post website: (https://www.washingtonpost.com /local/education/peace-corps-announces-major-changes-to-application-process /2014/07/14/f1cff488-0931-11e4-bbf1-cc51275e7f8f_story.html). 
Shohat, Ella and Robert Stam. 1994. Unthinking Eurocentrism: Multiculturalism and the Media. London: Routledge.

Sophie, Joan. 1986. “A Critical Examination of Stage Theories of Lesbian Identity Development.” Journal of Homosexuality 12:39-51.

Steinberg, S. H. 2009. "Queer Theory is for Everyone." Retrieved from the AHSASHA website: (http://ahsasha.com/theory/my-lectures/4448780).

Stephan, G. Edward, and Douglas R. McMullin. 1982. "Tolerance of Sexual Nonconformity: City Size as a Situational and Early Learning Determinant." American Sociological Review 47(3):411-15.

Strudwick, Patrick. 2014. "Crisis in South Africa: The shocking practice of 'corrective rape'-aimed at 'curing' lesbians." Retrieved from The Independent website: (http://www.independent.co.uk/news/world/africa/crisis-in-south-africa-theshocking-practice-of-corrective-rape-aimed-at-curing-lesbians-9033224.html).

Tajfel, Henri and John Turner. 1979. The Psychology of Intergroup Relations. Monterey, CA: Brooks/Cole.

Thomas, Edwin. 2012. “About Foreign Aid Workers. Retrieved August 5, 2012 (http://www.ehow.com/about_4881752_foreign-aid-workers.html).

Troiden, Richard R. 1979. "Becoming Homosexual: A Model of Gay Identity Acquisition." Psychiatry 42:362-373.

Turner, John and Henri Tajfel. 1982. Social Identity and Intergroup Relations. Cambridge, UK: Cambridge University Press. 
UUA. 2001. "Queer 102." Boston, MA: Unitarian Universalist Association: Office of Bisexual, Gay, Lesbian and Transgender Concerns. Retrieved March 15, 2012 (http://www.uua.org/obgltc/resource/queer102.html).

Vogue, Ariane and Jeremey Diamond. 2015. "Supreme Court rules in favor of same-sex marriage nationwide.” cnn.com Retrieved October 19, 2015 (http://www.cnn.com/2015/06/26/politics/supreme-court-same-sex-marriageruling/).

Wafer, James. 1996. "Out of the Closet and into Print: Sexual Identity in the Textual Field." Pp. 261-273 in Out in the Field: Reflections of Lesbian and Gay Anthropologists. Champaign, IL: University of Illinois Press.

Ward, James and Diana Winstanley. 2005. "Coming out at Work: Performativity and the Recognition and Renegotiation of Identity.” Sociological Review 53:447-475.

Weeks, Jeffrey. 1986. Sexuality. London: Tavistock Publications.

Weeks, Jeffrey. 2003. Sexuality: Second Edition. London: Routledge.

Weeks, Jeffrey. 2007. The World We Have Won: The Remaking of Erotic and Intimate Life. London: Routledge.

Weston, Kate. 1996. “Requiem for a Street Fighter." Pp. 275-285 in Out in the Field: Reflections of Lesbian and Gay Anthropologists. Champaign, IL: University of Illinois Press.

Whitaker, Brian. 2006. Unspeakable Love. Berkeley, CA: University of California Press. Williams, Walter L. 1996. "Being Gay and Doing Fieldwork." Pp. 70-85 in Out in the Field: Reflections of Lesbian and Gay Anthropologists. Champaign, IL: University of Illinois Press. 
Willis, Paul. 2011. "Laboring in Silence: Young, Lesbian, Gay, Bisexual, and Queer Identifying Workers' Negotiations of the Workplace Closet in Australian Organizations." Youth and Society 43(3): 957-981.

Woods, James D. and Jay H. Lucas. 1993. The Corporate Closet: The Professional Lives of Gay Men in America. New York: Free Press 


\section{APPENDIX A}

\section{INTERVIEW PROTOCOL}

1. Tell me about yourself (Icebreaker question)

-Age

-What do you do for a living?

-What do you enjoy doing in your free time

-How do you identify in regards to your queer identity?

2. Please tell me how you came to identify in this manner?

-Coming out story?

3. First of all, please give me a little background of your Peace Corps service -Where did you end up getting placed?

-What was your primary assignment?

4. What drove you to apply to the Peace Corps?

-What got you interested in the Peace Corps in the first place?

5. Before the application process, did you have any questions or concerns about serving in the Peace Corps as a gay, lesbian, or bisexual volunteer?

-What resources did you seek out to answer these questions or diminish these concerns?

-Did the Peace Corps itself provide any helpful material to you throughout this process in regards to serving as a queer volunteer? And if so, what?

6. During the application process, did you have any questions or concerns about serving in the Peace Corps as a gay, lesbian, or bisexual volunteer?

-What resources did you seek out to answer these questions or diminish these concerns?

-Did the Peace Corps itself provide any helpful material to you throughout this process in regards to serving as a queer volunteer? And if so, what? 
7. After you were placed, what were your expectations/fears of volunteering as a queer individual in your country of service?

-Why did you have these expectations?

-Again, what steps did you take to overcome these fears?

8. In your opinion, did the Peace Corps do a good job of preparing you for any obstacles you may face as a queer volunteer? Why or why not?

-What specific steps, if any, where taken during through out your application/placement process to address any challenges queer volunteers may face while serving?

-What specific steps, if any, where taken during your in-country training to address these challenges?

9. What were the general attitudes surrounding homosexuality in the society where you served?

-Were most people accepting or unaccepting of homosexuality?

-Did people discuss the topic of homosexuality a lot, or was it not spoken of?

-What were most peoples' beliefs surrounding homosexuality?

-Did people believe it was a choice?

10. What laws, if any, were in place surrounding homosexuality in the society you served?

-What were the sanctions surrounding these laws?

-Were these laws highly enforced?

-Did the local people agree or disagree with these laws?

11. Were there any LGBT organizations in the community in which you served? If so, can you tell me more about them?

-Were there support groups in general for LGBT individuals?

-What kind of LGBT movements were taken place in your community?

-Were they public or underground?

12. What challenges did you face as a queer volunteer in your community?

-Did you ever face any problems because of your queer identity?

-Was there any time you every felt uncomfortable during your time of service because of your queer identity? 
13. While serving in your respective community, how did you present yourself to others, not only in terms of your queer identity, but in general as well.

-Why did you feel you had to present yourself this way?

-Was the way you presented yourself different than how you would normally present yourself to others in your home country?

-Why or why not?

14. Now more specifically, what identity negotiation and management strategies did you implement in terms of your queer identity while serving abroad?

-Did you "come out" to anyone while serving abroad?

-Did you attempt to "pass" as straight?

-Did you try to hide your sexual identity in any way? Why or why not?

-What strategies did you find most useful and why?

15. What support systems did you utilize during this time in regards to your queer identity?

-Were there other queer volunteers you were in touch with there or back at home while you served?

-Were there other queer individuals in general that you were in touch with there or back home while you served?

-What role, if any, did the Peace Corps organization play as a support for you while serving?

-What support systems did you find most useful and why?

16. Did your experience as a Peace Corps volunteer change the way you view homosexuality? Why or why not?

17. Did your experience as a Peace Corps volunteer have any lasting effects on how you present your queer identity to others back in the states? If so, how?

-How is your queer identity affected still today because of your experience abroad?

18. What advice, if any, would you give to future queer Peace Corps volunteers or queer, foreign-aid workers in general?

19. Personally, is there anything you would like to see the Peace Corps change in regards to how they work with gay, lesbian, and bisexual volunteers for service?

-Throughout the application/placement process?

-Throughout your in-country training?

-Throughout your actual service?

-After your service? 
20. Is there anything else you would like to tell me about serving in the Peace Corps as a queer volunteer that we haven't had a chance to talk about yet? 


\begin{abstract}
APPENDIX B
LGBT SENSITVITY TRAINING EXAMPLE

**Created and first implemented by Guatemalan PCV Martin Picarillo in 2010**
\end{abstract}

\title{
SAFE ZONE WORKSHOP SCRIPT
}

\section{Agenda}

\section{Section 1 - General Information}

- Part A - Distribution Heterosexual questionnaire. - 0 minutes

- Part B - Introduction of session and Goals - 10 minutes

- Part C - Guidelines of session and statement of inclusion - 5 minutes

\section{Section 2 - LGBT Development}

- Part A - Word Association poster - 0 minutes

- Part B - LGBT vocabulary game - 15 minutes

- Part C - What is "coming out?"

- Part D - Discussion of risk and benefits of coming out (part $\mathrm{c}+\mathrm{d}$ ) -15 minutes

- Part E - Coming out Role plays

- Part F - Processing role plays

- Part G - Revisiting and concluding Role Plays - (part E + F + G) - 15 minutes

\section{Section 3 - Ally Development}

- Part A- What is homophobia - 5 minutes

- Part B - what is Heterosexual Privilege - 10 minutes

- Part C - Definition of an Ally - 10 minutes

- Part D - Ally scenario game show - 10 minutes

\section{Section 4 - Conclusion}

- Part A - conclusion and safe zone sticker

- Part B - Thank you from GAD and hand out of GAD resources 


\section{Section 1 - General Information|Introduction}

\section{Part A - Handout of bilingual "Heterosexual questionnaire" to participants as they walk in to session. Ask participants to hold on to and think about as topic will be revisited later in the session. See appendix $A$}

\section{Part B - Introduction/why are we doing this/Goals for session}

Introduction of why he organized event - personal struggle and difficulties felt by other LGBT PCVS and hang agenda, made before event, on wall.

Problems faced by LGBT volunteers:

1. Isolation

2. Depression, angst

3. Fear of being "found out."

4. Fear of physical harm

5. Sexual loneliness ... risk taking.

6. Loneliness from larger LGBT community

7. Family problems

8. Lack of trust with others. (i.e. APCD)

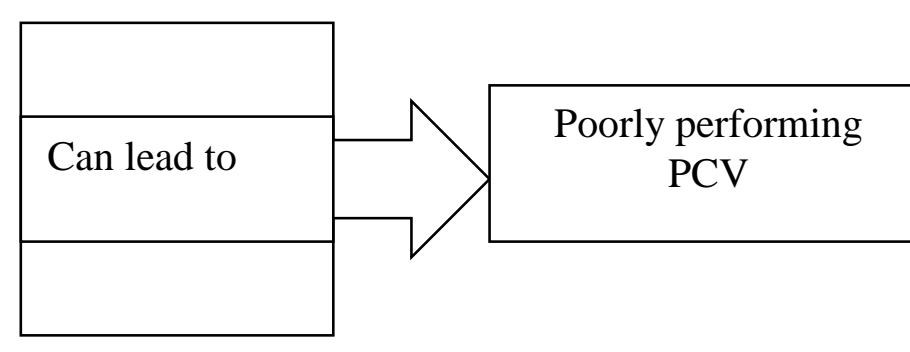

Hand out of bilingual PC-Washington paper on need for LGBT sensitivity at PC posts. See appendix B.

Review 5 main goals of the Safe Zone training (make poster to hang during entire presentation):

1. To increase the overall PC community's understanding and awareness of LGBT issues

2. To provide a greater sense of safety for the LGBT PCV community

3. To spread the belief that PC Guatemala is enriched and enlivened by the diversity of gay, lesbian, bisexual, and transgender people

4. To show that we are willing to discuss issues impacting LGBT peoples' lives in a nonjudgmental manner.

5. To teach staff how to support PCVs who come to them with LGBT related issues

\section{Part C - Guidelines of session}

\section{Medium: PowerPoint}

- P.R.O.C.E.S.S. = Participate, Respect, Open communication, Confidentiality, Experiment with new Ideas, Step forward/step back, Seek to understand.

- Read bilingual statement of inclusion: "I won't assume to know what your sexual orientation or gender identity is during this session and will never specifically ask you. Some of you may be LGBT and others will be heterosexual. If you are LGBT you can get something out of this session by thinking about your own identity development. Most importantly, we will all begin to learn about the ally development of your heterosexual peers. This Safe Zone session is for everybody. 


\section{Section 2 - LGBT Development}

\section{Part A -Word Association.}

Have hanging poster with Words Lesbian/Gay/Bisexual/Transgender bolded at the top. Below write many derogatory words in English and Spanish that you have heard (i.e. queen, fairy, mary, hueco, faggot, mariposa, mora, dyke, butch, lipstick lesbian, confused, pansy, "one of those").

To be referenced during Ally development section but OK to put up at the beginning before session to pique participants' interest and get their minds working.

\section{Part B - LGBT Terminology - Vocabulary game. Match definition to term.}

We are now going to process and learn about a wide range of words relating to LGBT issues though a game involving matching terms with their respective definitions.

Separate and shuffle the definitions and terms (See appendix C for cards.) Before session starts tape terms under the random chairs that will be used by the participants and place the corresponding definition on a side table. When the moment arrives, ask participants to feel under their chair to see if they have a word. Have people who DO NOT have words go up to the table to select a definition card. Have people find their pair. (I.e. if somebody has the world "bisexual," they would have to find the person who had the definition "a person who is emotionally, romantically, sexually, affectionately, and relationally attracted to both men and women though not necessarily simultaneously.")

Once participants have found their pair they can sit down. Ask each pair to read each their word and definition to the group.

\section{Part C - What is "coming out"?}

Coming Out: Grant to discuss definition and stages of coming out with participants Coming out is the term used to describe the process of and the extent to which one identifies oneself as lesbian, gay or bisexual. There are two parts to this process: coming out to oneself and coming out to others. This includes the realization that one is not straight and accepting that fact and deciding what to do about it. Coming out to others is an experience unique to LGBT people. Remember, Coming out is not a single event, but a life-long process, which may begin at any age. 
Stages of coming out (make poster)

Closeted = "I don't want you to know"

Passing = "I assume you don't know"

Covering = "I don't know what you know"

Implicitly Out = "I'm gay. See it if you can."

Explicitly Out = "I'm telling you I am gay."

Publicly Out = "See me as gay."

(Note that regardless of where a PCV is with his American peers or PC staff, they often have to go back to stage 1 "closeted" when they return to site. This frequent transitioning can be difficult, cumbersome, and painful.)

\section{Part D: Discussion of risks and benefits of coming out:}

Tape up two posters one that states "Why come out? Benefits." The other which reads "Risks of coming out:". Asks audience what they think are some benefits and risks, if they don't come up all of these ideas below, share them with the group.

\section{Some Risks of Coming Out (make poster via brainstorming session)}

- Not everyone will be understanding or accepting.

- Family, friends, or coworkers may be shocked or confused, or even hostile.

- Some relationships may be permanently changed.

- Rejection from religious community

- An individual may experience harassment or discrimination. (It is important to know that discrimination based on sexual orientation is still legal in the vast majority of the United States (Although much progress has been made since this resource was created in 2010) and Guatemala. In most cases, there is no legal protection for people who are lesbian, gay, or bisexual - they may be fired from their jobs, denied housing, or denied insurance.)

- People under the age of 18 may be thrown out of their homes or lose financial support from their parents.

Why Come Out? Benefits (list on paper without brainstorm - have poster prepared)

- Ability to live one's life honestly.

- Building self-esteem by being honest about oneself.

- Developing closer, more genuine relationships with friends and family.

- Alleviating the stress of hiding one's identity.

- Connecting with other people who are LGBT.

- Being part of a community with others with whom you have something in common.

- Helping to dispel myths and stereotypes by speaking about one's own experience and educating others.

- Being a role model for others. 


\section{Part E: Coming out Role Play}

Scenario 1: Kathy (PCMO) and Aliyya (PCT) sit down for their first medical interview in training. Kathy begins asking Aliyya questions regarding her medical background when Aliyya tells Kathy she needs to tell her something. Aliyya comes out to Kathy, as a lesbian because she thinks her medical professional should know. She also has a serious girlfriend back at home and misses her a lot, which causes some emotional strain. Kathy responds by telling Aliyya some WRONG responses such as "Ay pobrecito.... You're too pretty to be a lesbian. Just wait till you start meeting Guatemalan men. That Latin flavor will fix you right up." Aliyya looks confused and upset by this comment...looks to the audience with her hands up like.... "What do I do now!"?

Scenario 2: David (APCD) and Grant (PCV) sit down in David's office. Grant tells David that things in site are OK but he has been having problems feeling really lonely in site. Looking uncomfortable, Grant explains how he feels uncomfortable when everybody in town asks if he has a girlfriend and when the girls in town whistle at him. David doesn't quite understand, "what do you mean, Grant?" Grant responds by sheepishly telling him that he does not like women because he is gay and has found it hard lying to everybody at site. David responds in the WRONG way and whispers "ohhhh you're a h*eco.... I get it." "what does that word mean, Grant asks? (not understanding the

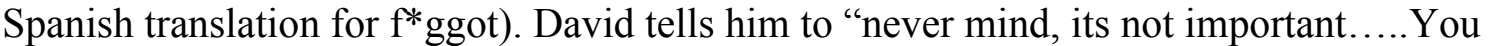
are probably just confused and that he thinks the PCMO's can set you up with some therapy sessions to help cure/fix you." Grant looks to the audience with his hands up like....."what do I do now!"

\section{Part F: Processing role plays:}

Ask audience the following questions based on their own ideas or the role-plays they just saw. Have PowerPoint slides ready also.

How Might People who are LGBT feel About Coming Out to Someone?

- Scared $\bullet$ Vulnerable $\bullet$ Unsure - wondering how the person will react

- Relieved • Proud

What Might People Who are LGBT Want from the People They Come Out to?

- Acceptance $\bullet$ Support $\bullet$ Understanding $\bullet$ Comfort $\bullet$ Reassurance that their relationship won't be negatively affected

What persons who are lesbian, gay, or bisexual have been told about their sexual orientation ... and what you should not say?

- You're just going through a phase.

- It's just because you've never had a relationship with someone of the opposite sex.

-You can't be gay - you've had relationships with people of the opposite sex.

-You can't be a lesbian - you're too pretty!

-You're just depressed. 
- You're just confused.

- Maybe you can find a therapist who can help you get over anything.

\section{Some good things to say/ask are:}

- How long have you known you are lesbian, gay, bisexual, or transgender?

- Are you seeing anyone special?

- Has it been hard for you carrying this secret?

- Is there some way I can help you?

- Have I ever offended you unknowingly?

\section{Role-play revisited:}

Replay scenario 1 except this time Kathy responds to Aliyya's revealing her sexual orientation with a CORRECT response such as "how long have you known you were a lesbian?" and "That's nice, do you think your girlfriend will come visit you here in Guatemala? If I can help in any way regarding this issue, please let me know. I will also hold this information confidential." Aliyya responds, obviously happy with the accepting response of her PCMO and answers that yes she would like this to be confidential and that she hopes her girlfriend comes and visits next Christmas.

Replay scenario 2 except this time David responds to Grant's revealing his sexual orientation with a CORRECT response such "That must be very hard for you, especially coming from a culture where maybe you had more flexibility to be open in public. I hope I have never offended you and if I have I apologize. If you would like to talk more about how it has been hard for you, I would be happy to and will hold that information confidential. I also know that Adam on staff is really comfortable talking about this information, so maybe you want to talk to him too." Grant responds happily that he has been offended a few times but that he appreciates the apology and that yes he would like to talk to Adam.

\section{Role-play conclusion:}

Tell audience that it is very probable and in fact maybe you have already had the experience of a PCV (or anybody else) coming out to you.

\section{Why might they do that? What are some situations in which someone might come out to you in Peace Corps Guatemala?}

- They want to have an honest and genuine relationship with you.

- They may feel you are a person who will be understanding and accepting.

- They prefer to be honest and are tired of putting time and energy into hiding their identity.

- They may come out to you because some aspect of your professional relationship makes it difficult to continue to hide their sexual orientation.

- They may come out to you because you are in a position to assist them with a concern or address policies which impact their life. 


\section{Section 3 - Ally Development}

\section{Part A - What is HomophobialLiving in a Heterosexual world?}

Offer brief definition of what Homophobia is. Then ask audience to create a list of examples of Homophobia.

Homophobia takes many different forms. Sometimes it takes the form of physical acts of hate, violence, verbal assault, vandalism or blatant discrimination, such as firing an employee, evicting someone from their housing, or denying them access to civil rights awarded to heterosexual persons and public accommodations based solely on their sexual orientation or their perceived/assumed sexual orientation. In the clinical sense, homophobia is defined as an intense, irrational fear of same sex relationships that become overwhelming to the person. In common usage, homophobia is the fear of intimate relationships with person of the same sex.

There are many other kinds of homophobia that happen every day. We often overlook these more subtle actions and exclusions because they seem so insignificant by comparison but they are not. It is important for supportive allies of the LGBT community to recognize certain homophobic levels of attitude so that they may take steps towards changing that attitude.

\section{Examples of Homophobia (make list/ poster with audiences help and have index card cheat sheet ready for facilitator)}

- Changing your seat in a meeting because a lesbian sat in the chair next to yours.

- "Gaydar" - Thinking you can spot a not straight person.

- Using derogatory names for not straight people.

- Thinking that a lesbian (if you are female) or gay man (if you are male) is making sexual advances if she/he touches you or is friendly to you.

- Feeling repulsed by public displays of affection between lesbians and gay men but accepting the same displays of affection between heterosexuals.

- Not asking about a woman's female partner or a man's male partner although you regularly ask "How is your husband/wife/girlfriend/boyfriend?" when you run into a heterosexual friend.

- Assuming that everyone you meet is heterosexual.

- Feeling that a lesbian is just a woman who couldn't find a man or that a lesbian is a woman who wants to be a man.

- Feeling that a gay man is just a man who couldn't find a woman or that a gay man is a man who wants to be a woman. 


\section{Part B - What is Heterosexual Privilege?}

Remind people of that first handout they received - the heterosexual questionnaire. And how it relates to heterosexual privilege.

Define Heterosexual Privilege as the many things we are privy to as heterosexuals, things we often never think about, that people who are not straight are denied access to. Then ask participants to break into groups of 5 and write their own lists of heterosexual privileges. Reconvene after 5 minutes and have each group share their answers (have cheat sheet created for facilitator).

Heterosexual privilege is living without ever having to think twice, face, confront, engage, or cope with anything on this list.

- The right to marry the one you love in the majority of countries in the world. US (federally and most states) and Guatemala included.

- Public recognition and support for an intimate relationship.

- Paid leave from employment and condolences when grieving the death of your partner.

- Inheriting from your partner/lover/companion automatically under probate laws.

- Sharing health, auto, and homeowners' insurance policies at reduced rates.

- Immediate access to your loved ones in cases of accident or emergency.

- Family-of-origin support for a life partner/lover/companion.

- Increased possibilities for getting a job, receiving on the job training, and promotion.

- Being affectionate in public with your partner without threat or punishment.

- Talking about your relationship or what projects, vacations, family planning you and your partner/lover are creating.

- Not questioning your normalcy, sexually and culturally.

- Adopting children and foster-parenting children.

- Living with your partner and doing so openly to all.

- Receiving validation from your religious community.

- Receiving social acceptance by neighbors, colleagues, and new friends

- Not being fired or risking being fired from your job because of your sexual orientation.

Conclusion: There are many things that are easier in life for heterosexual people than there are for not heterosexual people. We must recognize these injustices and work against them and create a more equal environment for all.

\section{Part C - Definition of an "Ally" [Get suggestions from the audience.]}

An ally is somebody who will confront instances of derogatory language, confront stereotypes, use inclusive language, work to educate themselves, treat LGBT people like they do everybody else and support policies and laws that promote equality. 
An ally is a "safe person" for someone who is gay, lesbian or bisexual to speak with. This means that one is committed to providing support and to maintaining confidentiality. This commitment extends to people with a gay, lesbian or bisexual roommate, friend or family member who may wish to speak with someone.

\section{Ten Concrete Ways to Be an Ally While working at PC and with PCV. (Create} poster ahead of time)

1. Don't assume everyone is heterosexual.

2. Do not ever out someone. Just because you might know, don't assume that others do.

3. Don't use, avoid and challenge anti-gay jokes, words and conversations. (Reference sheet with derogatory words listed on it hanging up since the beginning)

4. Use all-inclusive language until you know an individual's preference. Use "partner" instead of "boyfriend" or "girlfriend," or "boyfriend AND girlfriend."

5. Educate others. One-on-one, group programming, teachable moments.

6. Interrupt prejudice and take action against oppression of LGBT people.

7. Don't be surprised when someone comes out to you.

8. Respect confidentiality. It is imperative that you can be trusted.

9. Know when and where to seek help. Know all available resources.

10. Don't try to guess who's gay.

\section{Part D: Ally Scenario Prize Questions}

Below are some example situations and reactions you could have as an ally to the LGBT community. Take these reactions as suggestions for things you might say. Use your own style and stick to what you feel comfortable saying. Remember, if you don't feel comfortable speaking up with a lot of people around, you almost never have to confront someone in a group. You could pull someone aside and tell him or her one-on-one how you feel.

Read scenario and then read the multiple choices that are up on a PowerPoint screen. When people know answer, they raise their hands. If they answer correctly they get a "congratulations for being an ally, here is a safe zone sticker" reward.

You're sitting with a group of friends, and a couple of them make an obnoxiousbigoted comment about gays. Do you...

A) Ignore it.

B) Casually leave.

C) Ask them not to make such comments around you.

A friend comes up to you and tells a rumor that a floor member or classmate is supposedly a lesbian. Do you....

A) Tell them it doesn't matter what sexual orientation she is.

B) Ignore them.

C) Say that if she is a lesbian, let her come out on her own terms

D) $\mathrm{A}$ and $\mathrm{C}$. 
Some of your colleagues make fun of a new trainee because he uses stereotypically feminine body language. Do you....
A) Ignore it.
B) Tell them it is not funny and possibly offensive to talk about somebody like that.
C) Join in and start making fun of the trainee too.

You hear some friends discussing the marriage equality debate happening in the United States when some of them state that they think LGBT deserve equal rights under the law. Do you...
A) Tell them your supportive feelings about LGBT people
B) Tell them you think gay people are gross.
C) Ignore it.

Discuss difficulties and trade offs of being an ally to process this exercise. (Make cheat sheet index card for facilitators)

What's difficult about these responses?

- You could be ridiculed.

- They might think or accuse you of being gay.

- Friends might get mad at you.

- It might create an awkward situation.

What are the tradeoffs? What do you gain?

- Self-respect.

- Respect from friends.

- You could possibly support a person in the group who is a closeted GLBT person or has friends or family who are GLBT.

- Model acceptance of differences for friends.

- Build a sense of personal integrity. 


\section{Part A - Conclusion}

\section{Section 4 - Conclusion}

Thank participants for coming, their involvement and that you will now re-iterate how a goal of this training was to make the PC-Guatemala community a more obviously friendly place for LGBT staff and volunteers. Remind participants that it is also $\mathrm{OK}$ to still be uncomfortable with these issues but what's important is that we are open to more understanding, learning and acceptance.

So, we have designed a logo sticker to be placed in a visible location so people walking know you are an ally to LGBT people. Show people sticker handout. If they feel they want to be a more visible ally tell them take a sticker to put up where they feel is appropriate. Pile stickers up so people can take on the way out.

\section{Explanation of sticker design:}

The rainbow flag became a visible symbol in the LGBT equal rights movement in the United States in the 1980's. The rainbow theme has therefore been adopted for "Safe Zone in Peace Corps" logo. It will be easily identifiable by LGBT people meaning you are supportive and trustworthy. PCVs will know they can come to you for help, advice, or just to talk with someone who is affirmative of their sexual orientation or gender identity.

The symbol also means that homophobic and heterosexist comments and actions will not be tolerated and will be addressed in an educational and informative manner. Colleagues and PCVs have a right to their opinion; however, if someone is stating myths or misinformation about LBGT individuals you will inform them of more accurate information in a respectful manner.

Part B - Hand out of other resources to take away (have gender blender copied, and LGBT GAD articles) 


\section{HANDOUTS TO SAFE ZONE WORKSHOP}

\section{The Heterosexual Questionnaire - Consciousness raising.}

The following are examples of the types of questions the GLBT community has been asked in the past and is still being asked today. We have reversed the audience of the questions to put the heterosexual community in question.

Your Favorite Questions about the World of Practicing Heterosexuals

1. What do you think caused your heterosexuality?

2. When and how did you first decide you were a heterosexual?

3. Is it possible your heterosexuality is just a phase you may grow out of?

4. Is it possible your heterosexuality stems from a neurotic fear of others of the same sex?

5. Isn't it possible that all you need is a good Gay lover?

9. To whom have you disclosed your heterosexual tendencies? How did they react?

10. Your heterosexuality doesn't offend me as long as you don't try to force it on me. Why do you people feel compelled to seduce others into your sexual orientation?

11. If you choose to nurture children, would you want them to be heterosexual, knowing the problems they would face?

13. Why do you insist on being so obvious, and making a public spectacle of your heterosexuality? Can't you just be what you are and keep it quiet?

14. How can you ever hope to become a whole person if you limit yourself to a compulsive, exclusive heterosexual object choice and remain unwilling to explore and develop your normal, natural, healthy, God-given homosexual potential?

16. Why do heterosexuals place so much emphasis on sex?

17. With all the societal support marriage receives, the divorce rate is spiraling. Why are there so few stable relationships among heterosexuals?

18. How could the human race survive if everyone were heterosexual, considering the menace of overpopulation?

19. There seem to be very few happy heterosexuals. Techniques have been developed with which you might be able to change if you really want to. Have you considered aversion therapy?

20. Do heterosexuals hate and/or distrust others of their own sex? Is that what makes them heterosexual? 


\section{Strategies for Supporting Gay and Lesbian Trainees and Volunteers: A Message from P.C. Washington}

Trainees and Volunteers must understand there are limitations to support and they are expected to adjust to conditions outside of the office. However, they will need knowledge and tools to do so and the following point will help orient staff about how to support GLB Volunteers.

Staff should also understand that all Trainees arrive with expectations for support, including GLB Volunteers. It is likely they have already been in contact with current or ex-volunteers who may or may not provide a positive view of staff support measures. Staff credibility will be undermined if they are not prepared.

- $\quad$ The Peace Corps Office and the Training Center should be safe havens where all gay Volunteers can be out and feel safe and accepted. Staff may feel uncomfortable about this for a while but will get used to it and some may even decide to "come out of the closet." Stranger things have happened.

- It is OK for staff to feel uncomfortable. It is not OK to ignore a situation or Volunteer support needs. It is better to admit you are uncomfortable and then offer to connect the Trainee or Volunteer to a staff member who is comfortable talking about gay issues, concerns, culture or contributions. With time, it becomes easier once you have confronted your fears and feel less threatened.

- Peace Corps Staff and Trainees should receive diversity training and specifically they should receive some training on gay culture. It is very important for staff to understand why they are homophobic or why they are uncomfortable (understand your own culture in order to be able to understand another). Gay people and gay cultures exist in every part of the world, though it may not be recognized as a distinct culture from the heterosexual norm, and it may not be overtly accepted or approved of. People may also interpret what is actually gay behavior differently from one culture to another. It is common, for instance in Latin America, for two men to be engaged in a sexual act but only one of them is considered gay. This is a widely accepted norm though not interpreted the same way from U.S. standards. A Traditional Culture is not necessarily a conservative culture. American staff should not assume HCN staff cannot address, would not address or don't know how to address gay culture from their own cultural perspective or that they couldn't understand and empathize with gay Trainees and Volunteers.

- Inclusive Language should be used in Training and in Language classes. For example, the terms "gay" and "lesbian" should be clearly mentioned when discussing diversity, when welcoming all Volunteers to Training during intro sections, and in Language classes, facilitators can be coached/trained to ask, "do you have a boyfriend, girlfriend or partner?" when discussing family in language classes.

- Cross Culture, Safety and Security and Health sessions should clearly address gay/lesbian information about local customs, dating, beliefs, etc. This will help 
them to be safe, healthy and productive. This information should come from a variety of sources including gay people in the host country, gay organizations in the host country and gay volunteers.

- Confidentiality outside of the Peace Corps office and Training Center should be addressed.

- GLB Volunteers may want contact information for the local gay organization in the capital so they can talk with gay people. This will help them to get unbiased information about gay culture in the host country. That way they will know how to behave and thus be able to keep safe.

- GLB Volunteers may or may not want to form a formal gay/lesbian support group. A Staff member should be liaison to this group.

- GLB Support does not belong in the Medical Office any more than other kinds of support. Just because a Volunteer is gay or lesbian doesn't mean they need counseling. All staff should be prepared to address support needs of GLB Volunteers.

- They may want to write articles in the Volunteer Newsletter to encourage other gay/lesbian volunteers to come to a meeting or to further educate Volunteers and Staff about GLB issues.

- PRACTICE MAKES PERFECT - it is OK to make mistakes! Be honest and brave. 


\section{LGBT Vocabulary Game}

Ally - a person who supports and honors sexual diversity, acts accordingly to challenge homophobic and heterosexist remarks and behaviors, and is willing to explore and understand these forms of bias within him or herself.

Bisexual - a person who is emotionally, romantically, sexually, affectionately, and relationally attracted to both men and women though not necessarily simultaneously.

Closet - being "in the closet" means keeping your sexual orientation a secret. Many LBGT people remain in the closet because of fear of rejection, harassment, and anti-gay violence, but like an actual physical closet, many LBGT people find that this mental closet is an isolated, confining place.

Coming Out - the developmental process in which a person acknowledges, accepts, and appreciates his/her sexual orientation. Coming out is a lifelong process, starting with coming out to oneself and then to others.

Gay Male - a man who is emotionally, romantically, sexually, affectionately, and relationally attracted to other men.

Gender - a sociological construct defining the collection of characteristics that are culturally associated with maleness or femaleness; gender is to "masculine" and "feminine" as sex is to "male" and "female."

Gender Identity - has to do with whether a person perceives him/herself to be a man or a woman; research indicates that gender identity is typically established by 3 years of age.

Gender Role - the norms of expected behavior for men and women assigned primarily on the basis of biological sex; a sociological construct which varies from culture to culture.

Heterocentrism - the assumption that everyone is heterosexual unless otherwise indicated.

Heterosexism - the individual, group, or institutional norms and behaviors that result from the assumption that all people are heterosexual. This system of oppression, which assumes that heterosexuality is inherently normal and superior, negates LBGT peoples' lives and relation-ships.

Lesbian - a woman who is emotionally, romantically, sexually, affectionately, and relationally attracted to other women.

LGBT - acronym standing for: lesbian, gay, bisexual and transgender. 
Outing - exposing someone's sexual orientation to others, usually without their permission.

Queer - term that is inclusive of people who are not heterosexual-includes lesbians, gay men, bisexual people, and transgendered people. For many LBGT people, the word "queer" has a negative connotation and provokes discomfort; however, many younger gay people are comfort- able using the term and have "reclaimed" it.

Homosexual \& Gay - a person who is primarily or exclusively attracted to people of the same sex.

Sexuality - the complex range of components that make us sexual beings; includes emotional, physical, and sexual aspects, as well as self-identification (including sexual orientation and gender), behavioral preferences and practices, fantasies, and feelings of affection and emotional affinity.

Sexual Orientation - an enduring emotional, romantic, sexual, affectional, and relational attraction to another person. Can involve fantasy, behavior, and self-identification; a person's general makeup or alignment in terms of partner attraction. May be same a same-sex orientation, male-female orientation, or a bisexual orientation.

Sexual Preference - what a person likes or prefers to do sexually; a conscious recognition or choice not to be confused with sexual orientation.

Homophobia - the fear and hatred of or discomfort with people who love and sexually desire members of the same sex. Homophobic reactions often lead to intolerance, bigotry, and violence against anyone not acting within heterosexual norms. Because most LBGT people are raised in the same society as heterosexuals, they learn the same beliefs and stereotypes prevalent in the dominant society, leading to a phenomenon known as "internalized homophobia."

Transvestite - an individual who dresses in the "opposite" gender clothing for a variety of reasons.

Transgendered - the old understanding of the word meant a person whose gender identity differs from what is culturally associated with their biological sex at birth. However, as information has evolved, it is now an umbrella term that includes a wide range of identities and includes pre-operative, post-operative, and non-operative transsexual people. In its general sense, it refers to anyone whose behavior or identity falls outside of stereotypical expectations for their gender.

Transsexual - a medical term referring to a person whose gender identity differs from what is culturally associated with their biological sex at birth and who chose to undergo sex reassignment surgery. This term is considered outdated. Most transsexual people refer to themselves as transgendered. 


\section{D) Statement of Ally-dom}

The rainbow flag became a visible symbol in the LGBT equal rights movement in the United States in the 1980's. The rainbow and pink triangle has been adopted for "Safe Zone in Peace Corps" and will be easily identifiable by LGBT people. Heterosexual allies also need visual representation to distinguish themselves thus the inclusion of the word "ally." The Safe at Peace Corps symbol is a message to lesbian, bisexual, gay, and transgendered students and colleagues that you are knowledgeable, supportive and trustworthy. PCVs will know they can come to you for help, advice, or just to talk with someone who is affirmative of their sexual orientation or gender identity. The symbol also means that homophobic and heterosexist comments and actions will not be tolerated, but will be addressed in an educational and informative manner. Colleagues and PCVs have a right to their opinion; however, if someone is stating myths or misinformation about LBGT individuals you will inform them of more accurate information in a respectful manner. 
APPENDIX C

CONVERSATIONAL GUIDE EXAMPLE

\section{Addressing LGBT Issues and Concerns in Country: A Conversational Guide for PCVs}

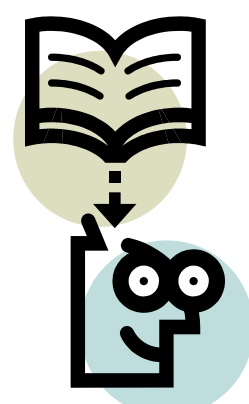

\section{Created by: Kate Slisz}

\section{Member of the Peace Corps Gender Equality Committee}

IMPORTANT NOTE: Information gathered from various sources were used to create this conversational guide. It should be noted that SAfAIDS's "Toolkit for Integrating LGBTI Issues Into HIV \& GBV Prevention" proved to be most useful, providing the basis for this guide. The FAQ, myths \& misconceptions, as well as the glossary were taken from this source and only slightly adapted. Information found on the BONELA, Global Gayz, LeGaBiBo, Rainbow Identity Association, and the National Lesbian, Gay, Bisexual Peace Corps Alumni Association websites also helped to shape the content of this guide. Lastly, volunteers' personal experiences in the field, regarding LGBT issues were also taken into consideration in the creation of this document. 


\section{Purpose:}

This guide is to serve as a resource for Peace Corps Volunteers who are encountering issues of homosexuality and gender identity within their communities. This guide is NOT intended to be used to advocate for LGBT rights. Instead, it is intended to simply assist volunteers in facilitating discussions surrounding homosexuality and gender identity, when deemed safe to do so.

\section{Rationale:}

According to surveys distributed by the Gender Committee at various training sessions, a high number of volunteers have reported having discussions pertaining to homosexuality and gender identity in their communities. However, due to the illegal nature and stigma attached to homosexuality in this particular society, volunteers report they feel illequipped to address these issues when speaking with locals. Therefore, this guide will serve as a resource to volunteers as to how to approach these issues and questions in a culturally sensitive manner.

\section{Legal Status of Local LGBT Individuals:}

Lesbian, gay, bisexual, and transgender (LGBT) individuals in-country are considered second-class citizens, meaning they are not entitled to the same rights and protections as heterosexual and cisgender citizens.

\section{Laws Regarding Same-sex Sexual Acts:}

According to the country's Penal Code:

Section 164. Unnatural offences. Any person who-

(a) has carnal knowledge of any person against the order of nature; [or]

(c) permits any other person to have carnal knowledge of him or her against the order of nature,

is guilty of an offence and is liable to imprisonment for a term not exceeding seven years.

Section 165. Attempts to commit unnatural offences. Any person who attempts to commit any of the offences specified in section 164 is guilty of an offence and is liable to imprisonment for a term not exceeding five years.

Section 167. Indecent practices between persons. Any person who, whether in public or private, commits any act of gross indecency with another person, or procures another person to commit any act of gross indecency with him or her, or attempts to procure the commission of 
any such act by any person with himself or herself or with another person, whether in public or private, is guilty of an offence.

Section 33. General punishment for offences. When in this Code no punishment is specially provided for any offence, it shall be punishable with imprisonment for a term not exceeding two years or with a fine, or with both.

To clarify, the general belief in-country is that homosexuality is NOT an identity but, rather, a behavior. Therefore, homosexual acts are illegal and punishable by up to 7 years in prison (this law pertains to both women and men), but simply identifying as homosexual is not illegal. Someone who identifies as lesbian, gay, or bisexual may face social stigma and discrimination, but to be arrested, they must be caught in a sexual act with someone of the same-sex.

\section{Recognition of Same-sex Relationships:}

Same-sex couples have no legal recognition and same-sex marriage is not allowed.

\section{Discrimination Protections:}

The Employment Act has prohibited employment discrimination on the basis of sexual orientation since 2010

\section{Laws and Protections Regarding Transgender Individuals:}

Gender identity and sexual orientation, although related and connected, are two different aspects of a person's self. In this particular society, it is illegal to commit homosexual acts, but there are no laws that outlaw being transgendered or the act of transitioning. With that said, there are also no laws in place to protect such individuals either. Additionally, like gay, lesbian, and bisexuals, transgendered people are at risk of encountering social stigma, prejudice, and discrimination.

\section{LGBT Organizations in-country:}

Despite the laws and stigma surrounding homosexuality and gender identity in-country, an LGBT movement does exist. In more rural and remote areas, the movement is underground, but in bigger cities, such as the capital, it is more visible.

The two most well-known LGBT organizations in are LeGaBiBo and Rainbow Identity:

\section{LeGaBiBo}

LeGaBiBo is the primary LGBT organization in-country. It was founded by the Center for Human Rights in 1998. However, due to lack of resources, the project could not be implemented properly and was, therefore, inactive until 2001 when it resurfaced under an organization that focuses on ethics, laws and HIV/AIDS.

\section{LeGaBiBo's Mission:}

To build an independent non-partisan organization that promotes the recognition, acceptance and equal protection of all human rights of the LGBTI community. 


\section{LeGaBiBo's Objectives:}

- To promote a non-discriminatory legal framework for LGBTI community

- To create a community that is educated and sensitized on LGBTI issues

- To recognize same-sex relationships for the purpose of:

○ Accessing social benefits

- Same-sex marriage and its benefits

- Children adoption

- create a safe space where the LGBTI community can interact

- To empower the LGBTI community so as to advocate for their rights

- To promote sexual health amongst the LGBTIs

There have been multiple attempts to register LeGaBiBo with the Registrar of Societies, Ministry of Labour and Home affairs, but the government continues to reject their application. The main objection by the registrar officials is that they see registering such an organization as an act of aiding and encouraging an illegal act as defined under the section 164 Penal Code. Therefore, the work LeGaBiBo is able to do is limited, including the ability to raise funds. $\mathrm{LeGaBiBo}$ is currently taking steps to sue the government to force it to register the organization.

\section{Rainbow Identity}

Rainbow Identity Association (RIA) is an organization of transgender and intersex people (trans women, trans men, gender questioning, gender queer, transsexual, and gender nonconforming) based in the country's capital.

Rainbow Identity aims at exploring ways of challenging transphobic laws and transphobia. Their vision is to create a democratic society that recognizes, respects, protects, and values the rights of transgender and intersex community. Rainbow Identity Association strives to provide transgender and intersex individuals with safe space to debrief and share necessary information with one another. Ultimately, Rainbow Identity hopes to breakdown the stereotypical concept of gender in this society, as it has a large influence on discrimination and ignorance in the transgender and intersex lives.

The organization was legally registered with Registrar of Societies in December 2010. It succeeded in getting registered with the government in 2010 because it was not a gay 'sexual orientation' group, but rather a support group for 'alternative gender identity' people. 


\section{Addressing LGBT Issues In-Country:}

\section{Be Culturally Sensitive}

This is arguably the toughest part of addressing questions and concerns pertaining to homosexuality and gender identity in our communities. A lot of PCVs feel very strongly about these subjects. Some volunteers have family members or friends that are LGBT, some identify as LGBT themselves, and some simply believe in equal rights for all. Therefore, our biases can sometimes impair our ability to understand the current beliefs surrounding homosexuality and gender identity in-country and our ability to address these issues in an objective and culturally sensitive manner.

As Peace Corps Volunteers, we are subject to the laws and social norms of the countries where we serve. As much as we may or may not disagree with the laws and beliefs surrounding homosexuality and/or gender identity in this country, we have to face the fact that it greatly impacts how we can approach these issues in-country. When we came to serve, we agreed to integrate and assimilate as much as possible and to work in a nonpolitical manner. Therefore, as Peace Corps volunteers, we cannot be perceived as advocating for LGBT rights. As a result, we must take a different approach. One way of accomplishing this is to view these issues through a human rights perspective and approach it as as fighting for Human Rights rather than LGBT rights.

\section{Use a Human Rights Approach}

Some people believe that the LGBT community is fighting for "special" rights. In reality, they are seeking the same rights as those of other human beings: rights that are basic, universal, and preserved in international human rights documents.

Sexual rights embrace human rights that are already recognized in national laws and international human rights documents. These include the right of all persons, free of coercion, discrimination and violence, to:

- Seek, receive and impart information in relation to sexuality;

- Receive sexuality education;

- Have their bodily integrity respected;

- Choose their own partner;

- Decide to be sexually active or not;

- Have consensual sexual relations (not be forced to have sex through the use of violence or non-physical force);

- Consent to marriage;

- The highest attainable standard of health in relation to sexuality, including access to sexual and reproductive health care services;

- Be protected from the risk of disease such as HIV and other STI's

- Decide whether, and when, to have children;

- Pursue a satisfying, safe and pleasurable sexual life.

By approaching LGBT issues through a human rights perspective, volunteers can mitigate the possibility of a moral debate unfolding. Using the aforementioned points above, the focus of the conversation can be on health or education as opposed to religion 
or personal values. Therefore, it reduces the risk of the conversation spiraling out of control and turning into a moral debate of sorts.

In addition to sexual rights, LGBT individuals are denied- either by law or practices basic civil, political, economic, health, social, and cultural rights. The following table provides examples of how these human rights are denied to the LGBT population:

\begin{tabular}{|c|c|}
\hline Human Right & How These Rights are Violated \\
\hline $\begin{array}{l}\text { The right to } \\
\text { equality in rights } \\
\text { and before the law }\end{array}$ & $\begin{array}{l}\text { Denied the right to equality before the law through } \\
\text { special criminal provisions or practices on the basis } \\
\text { of sexual orientation. }\end{array}$ \\
\hline $\begin{array}{l}\text { The right to } \\
\text { nondiscrimination }\end{array}$ & $\begin{array}{l}\text { Denied by omitting sexual orientation or sex/gender } \\
\text { identity in anti-discrimination laws, constitutional } \\
\text { provisions or their enforcement. }\end{array}$ \\
\hline $\begin{array}{l}\text { The right to } \\
\text { freedom from } \\
\text { violence and } \\
\text { harassment }\end{array}$ & $\begin{array}{l}\text { Denied by omitting sexual orientation and sex/gender } \\
\text { identity and gender expression in anti-discrimination } \\
\text { laws, constitutional provisions or their enforcement. }\end{array}$ \\
\hline $\begin{array}{l}\text { The right to free } \\
\text { development of } \\
\text { one's personality }\end{array}$ & $\begin{array}{l}\text { Violated by the failure to recognize human diversity } \\
\text { in all its forms and to develop legal protections for } \\
\text { that diversity. }\end{array}$ \\
\hline The right to life & $\begin{array}{l}\text { Denied by states which do nothing to curb a fear of } \\
\text { difference that results in violence and death. }\end{array}$ \\
\hline $\begin{array}{l}\text { The right to be } \\
\text { free from torture } \\
\text { or cruel, inhuman } \\
\text { or degrading } \\
\text { treatment }\end{array}$ & $\begin{array}{l}\text { Infringed upon by police practices in investigations or } \\
\text { in the case of LGBT persons in detention. Forced } \\
\text { stripping of transgender people in detention is } \\
\text { unfortunately all too common a form of torture. }\end{array}$ \\
\hline $\begin{array}{l}\text { The right to } \\
\text { protection from } \\
\text { arbitrary arrest } \\
\text { and illegal } \\
\text { detention }\end{array}$ & $\begin{array}{l}\text { Occurs when individuals are suspected of having a } \\
\text { homo/bisexual identity. Detentions of dubious legal } \\
\text { character are commonly carried out against } \\
\text { transgender persons. Even where the law criminalizes } \\
\text { same-sex activity it can only be enforced if "caught in } \\
\text { the act". Arresting someone on the presumption of } \\
\text { their sexuality is to all intents and purposes illegal. }\end{array}$ \\
\hline $\begin{array}{l}\text { The right to } \\
\text { freedom of } \\
\text { movement }\end{array}$ & $\begin{array}{l}\text { Denied to bi-national couples by not recognizing their } \\
\text { same-sex relationship and by states' failure to issue } \\
\text { identity cards according to "chosen" sex/gender } \\
\text { identity. }\end{array}$ \\
\hline
\end{tabular}




\begin{tabular}{|c|c|}
\hline $\begin{array}{l}\text { The right to a fair } \\
\text { trial }\end{array}$ & $\begin{array}{l}\text { Often affected by the prejudices of judges and other } \\
\text { law enforcement officials. }\end{array}$ \\
\hline $\begin{array}{l}\text { The right to } \\
\text { privacy }\end{array}$ & $\begin{array}{l}\text { Denied to transgender and intersex people by the } \\
\text { continued "overmedicalization" of their "condition." }\end{array}$ \\
\hline $\begin{array}{l}\text { The right to } \\
\text { freedom of } \\
\text { expression } \\
\text { and freedom of } \\
\text { association }\end{array}$ & $\begin{array}{l}\text { Either denied explicitly by law, or LGBT community } \\
\text { may not enjoy them because of the homo/transphobic } \\
\text { climate in which they live. }\end{array}$ \\
\hline $\begin{array}{l}\text { The right to } \\
\text { freedom of } \\
\text { practice of } \\
\text { religion }\end{array}$ & $\begin{array}{l}\text { Usually restricted in the case of LGBT persons, } \\
\text { especially in the case of the clergy advocating against } \\
\text { them. }\end{array}$ \\
\hline The right to work & $\begin{array}{l}\text { Many LGBT persons are fired because of their sexual } \\
\text { orientation and sex/gender identity or discriminated } \\
\text { against in employment policies and practices. }\end{array}$ \\
\hline $\begin{array}{l}\text { The right to } \\
\text { physical and } \\
\text { mental health }\end{array}$ & $\begin{array}{l}\text { Found to be in conflict with discriminatory } \\
\text { policies and practices by homophobic/transphobic } \\
\text { physicians. The lack of adequate training for health } \\
\text { care personnel regarding sexual orientation, } \\
\text { transgender or intersex issues can negatively impact } \\
\text { on this right. Denied to intersex persons whose } \\
\text { physiology/ bodily make-up is altered without their } \\
\text { consent at birth. A "simple" issue like the lack of } \\
\text { sex/gender neutral public toilet facilities can often } \\
\text { deny people the right to physical and mental health. }\end{array}$ \\
\hline $\begin{array}{l}\text { The right to form a } \\
\text { family }\end{array}$ & $\begin{array}{l}\text { This is denied by governments by not } \\
\text { recognizing same-sex families and by } \\
\text { denying the rights otherwise granted by } \\
\text { the state to heterosexual families who have } \\
\text { not sought legal recognition, but still enjoy } \\
\text { several rights. LGBT couples and individuals are not } \\
\text { allowed to adopt a child, despite that child being of } \\
\text { their same or opposite sex partner. Surgeries imposed } \\
\text { at birth in order for the child to conform to the sex } \\
\text { binary can leave people sterile,violating their right to } \\
\text { form a family. }\end{array}$ \\
\hline
\end{tabular}




\begin{tabular}{|l|l|}
\hline $\begin{array}{l}\text { The right of } \\
\text { protection against } \\
\text { separation from } \\
\text { parents }\end{array}$ & $\begin{array}{l}\text { Children can also be denied this right based on a } \\
\text { parent's sexual orientationand/or sex/gender identity } \\
\text { or gender expression. In a sense this right can be } \\
\text { violated when intersex children are rejected by their } \\
\text { parents because of ignorance and fear. }\end{array}$ \\
\hline $\begin{array}{l}\text { The right to } \\
\text { education }\end{array}$ & $\begin{array}{l}\text { LGBT students may not enjoy this right because of } \\
\text { prejudices and violence created by peers or teachers } \\
\text { in schools. The high rate of school drop-out amongst } \\
\text { LGBT youth is a direct consequence of bullying and } \\
\text { discrimination. "Sexed" or "gendered" toilets in } \\
\text { educational establishments again can contribute to } \\
\text { denying LGBT youth their rights to education. }\end{array}$ \\
\hline $\begin{array}{l}\text { The right to } \\
\text { defend these } \\
\text { rights }\end{array}$ & $\begin{array}{l}\text { Violated by states' failure to protect LGBT } \\
\text { defenders, laws that are used to discriminate against } \\
\text { LGBTI organizations and which prevent } \\
\text { organizational activities from being carried out. }\end{array}$ \\
\hline
\end{tabular}

As one can see, there are a myriad of ways that LGBT issues can be addressed through a human rights perspective. Volunteers should tailor how they approach a certain question or concern related to homosexuality or gender identity based on the specific situation at hand and the social climate of where they are.

\section{Conversational Tips:}

It is important to keep debate and confrontation to a minimum. Some suggestions for accomplishing such a feat, include:

- Be aware of the social climate. Before you even engage in a conversation surrounding these issues, get a good sense of your community's attitudes and beliefs on the issue or at least the people engaging you on the issues. Make sure it is acceptable and, more importantly, safe to do so. Gauging the social climate will also help you tailor your approach to the conversation or discussion, which will help to reduce negative consequences. If plausible, get a local you trust to help facilitate the discussion.

- Set up ground rules. Even if it's just a one-on-one conversation, don't be afraid to lay down some ground rules before beginning. Ground rules can help to avoid confrontation or conflict from occurring and help ensure the possibility of future discussions.

- Treat the matter objectively. The easiest way to discuss any topic is to approach it objectively. It will start to spiral out of control if you attempt to integrate values or principles into the conversation or when you expect the listener to share the same values or opinions you have on the matter. 
- Be open-minded. It is usually difficult to talk objectively about a topic when you have a strong bias for or against it. This is one problem that Peace Corps Volunteers often have. Since they have their own opinions on homosexuality, they cannot help but discuss it with people subjectively. This results in more difficult questions. Why is it bad to be gay? Why do you not want us to be gay? And so on and so forth. Save yourself the trouble of answering these questions by being open minded about homosexuality. This will make the discussion easier and more free-flowing because you can look at it from more than just one angle.

- Have an exit strategy. Be prepared for anything. If the conversation or discussion takes a turn for the worse, have a plan to get it back on track or to change the subject all together.

- Research the matter beforehand. Arm yourself with as much information about sexuality and gender identity as possible, especially culturally-relevant and culturally sensitive in nature. This will make answering questions easier. This guide is meant to aid in that regard, but there are also a plethora of resources online if you have access to a computer and internet. Additionally, volunteers who have discussed matters surrounding sexual orientation and gender identity in their communities can provide much advice and insight as well.

\section{Myths and Misconceptions:}

Sexual orientation and gender identity are concepts that are often misunderstood by people, especially in societies where sexuality and certain gender issues are taboo to discuss. Lack of awareness and education surrounding LGBT issues can lead to many false beliefs.

The following section will explore some of the common myths and misconceptions you may face in your community in regards to LGBT individuals. Additionally, suggestions have been provided as to how you can debunk these myths and misconceptions if you so choose.

\section{Myth 1: Homosexuality is contagious. Being with gay people and sharing spaces or even cups and cutlery with them will make others gay too.}

Reality: For many years, people thought that homosexuality was contagious. However, homosexuality is not an illness or a disease. This myth stems from and is perpetuated by homophobia. If people are properly informed on homosexuality, they will no longer view it as a sickness but, simply, as a way people identify. Sexuality is a spectrum. People can identify as heterosexual, homosexual, bisexual, pansexual, asexual, or even simply as queer if they chose not to use one of the more rigid labels. Although heterosexuality is viewed as the "normal" and "natural" way of identifying, the truth is that ALL societies have people that fall along various points of the sexuality spectrum. It is just that due to the legal status of homosexuality or the social stigma surrounding it, most people chose to "stay in the closet" and lead heterosexual lives. 


\section{Myth 2. People choose to be gay. Homosexuality is a choice.}

Reality: Sexual orientation, whether it is heterosexuality, homosexuality, or anything in between, is NOT a choice. The same way we cannot choose the color of our eyes, we cannot choose our sexual orientation. Who would choose something that if discovered could result in social ostracism and possible prison time? People cannot choose who they are attracted to. The only thing they can choose is whether to act on those feelings or not.

\section{Myth 3. Gay and lesbian relationships are short lived.}

Reality: Longstanding gay and lesbian relationships are common. However, due to the social stigma expressed against LGBT people, these partnerships are often invisible.

\section{Myth 4. Bisexuality is just a phase.}

Reality: People assume that bisexuality is just a phase people go through and not a legitimate sexual identity. Humans are diverse, and individual sexual feelings and behaviors develop over a person's lifetime. The creation and consolidation of a sexual identity is an ongoing process. Since we are generally socialized as heterosexuals, bisexuality could be a stage that many people may experience as part of the process of acknowledging their homosexuality. However, many others come to identify as bisexual after a considerable period of identification as gay men or lesbians. Bisexuality, like homosexuality and heterosexuality, may be either a transitional step in the process of sexual discovery, or a long-term identity.

\section{Myth 5. Bisexuals are promiscuous.}

Reality: Promiscuity, or having multiple concurrent partners, is something that is prevalent in all societies. Bisexuals, like people of all sexual orientations, have a wide variety of relationship styles. Contrary to common myth, a bisexual person does not need to be sexually involved with both a man and a woman. As is the case for heterosexuals and homosexuals, attraction does not involve acting on every desire. Like heterosexuals and homosexuals, many bisexuals choose to be sexually active with one partner only and have long term, monogamous relationships. Some bisexuals may have open relationships, just as some heterosexuals and homosexuals are sexually active with more than one partner.

\section{Myth 6. Lesbians don't have sex. Therefore, they are not at risk for HIV.}

Reality: The fact that there is no penis involved does not mean that a woman having sex with another woman cannot transmit HIV. Although for many years it has been believed that lesbian women are not at risk at all, risk is risk, even if it is low risk. There is a possibility for HIV transmission when vaginal fluids are exchanged and because of possible chaffing (when genitals rub against each other and result in broken skin), an entry point for the virus could be created. 


\section{Myth 7. MSM are gay men who are the receiving partner during anal sex and, therefore, are at high risk for HIV transmission.}

Reality: Men who have sex with men (MSM) could be of any sexual orientation. MSM are not a homogenous group. An MSM, although married to a woman, could be both the receptive or penetrative partner when it comes to same sex practices. His risk could be increased if he is uninformed about the HIV risks in anal sex. Some MSM still perceive anal sex as not risky, since there is no "pregnancy" involved. Although this may sound a bit absurd, remember that for many years, condoms were used to prevent pregnancy and the HIV prevention messaging was only directed at those practicing penile-vaginal sex. Many ill-informed men do not see anal sex as sex, but rather as something like "playing around with the boys." Thus when asked about having sex with men, they will answer no. There is a strong 'Anal Taboo' (The general avoidance of referring to the anus because of years of very complex social constructs which associate the anus with shame, guilt and dirt). Some gay identified MSM do not practice receiving anal sex at all.

\section{Myth 8. Masculine MSM, gay and bisexual men are always the 'top.' In other words, they are the anal penetrative partner and, therefore, are not at risk of HIV infection.}

Reality: Being a top or bottom is not related to a masculine (butch) or feminine (femme) gender expression, but again, the heteronormative model influences this thought process negatively. Most men experience sexual pleasure in different ways, with various forms of physical and mental stimulation. Although being the penetrative partner is less risky than being the receptive partner, risk is risk, and even tops should be encouraged to always use condoms and water-based lubrication as protection.

\section{Myth 9. Transgender and intersex people cannot have sex and, therefore, are not at risk of HIV transmission.}

Reality: Although talking about genitals and sexual practices is a very difficult area for many trans and intersex people (and this should be respected), they might have certain sexual practices that could increase their vulnerability and risk. Both trans men and trans women can have sex, including penile-vaginal as well

as penile-anal penetrative and receptive sex, depending on their level of acceptance of their own genitals and levels of physical and emotional comfort. Trans men can have any sexual orientation, as well as can trans women. Some are more vulnerable to sexual violence and HIV transmission, because of their gender expression and the perpetrator's ignorance. Because health care providers are generally uninformed, they lack the knowledge to give appropriate safer sex information to transgender individuals. 


\section{Myth 10. Two gay men who are both HIV positive can have unprotected anal sex, since they are both positive anyway.}

Reality: This is a risky practice. Re-infection can occur with a different strain of HIV and could end up complicating the treatment for both later when it becomes necessary to start antiretroviral therapy. Furthermore, continuous re-infection speeds up the progression of HIV to AIDS.

\section{Myth 11. It really is not violence when a lesbian or gay couple fights. It is just a lover's quarrel, a fair fight between equals.}

Reality: This is based on the false assumption that two people of the same sex have no power differences. It also ignores the fact that in domestic violence, it is the choice of one partner to take advantage of his or her power in abusive ways. There is nothing 'fair' about being knocked against a wall, being threatened, or enduring endless criticism from an angry lover. Dismissing domestic violence as 'just a lover's quarrel' trivializes and excuses violence that is just as real, and dangerous, as any in a heterosexual relationship.

\section{Myth 12. The abuser is always bigger, stronger, and more 'butch.' Survivors will always be smaller, weaker, and more feminine.}

Reality: Experience with heterosexual battering and attitudes about traditional sex roles lead many people to fall into accepting stereotypes of how abusers and victims, respectively, should look and act. A person who is small, but prone to violence and rage can do a lot of damage to someone who may be taller, heavier, stronger, and non-violent. Size, weight, 'masculinity,' 'femininity' or any other physical attribute or role is not a good indicator of whether a person will be a victim or an abuser. An abuser does not need to be tall and broad shouldered to use a weapon, or to smash belongings, to cut up clothing, or tell everyone at work about (to "out") their partner.

\section{Myth 13. It is easier for lesbian survivors of domestic violence to leave the abusive relationship than it is for straight abused women who are married.}

Reality: Same-sex couples are just as involved in each other's lives as straight couples and intimate violence has the same effect on anyone irrespective of sexual orientation. There is no evidence that the absence of children makes leaving a violent partner easier, and, many same-sex couples do have children. The invisibility and relatively limited support available to survivors of same-sex domestic violence may compound barriers to leaving. Many lesbian women lack support from their families and communities, and may not be able to rely on them for help. Survivors may also be convinced by the abuser that potential helpers will be homophobic and unhelpful. 


\section{Myth 14. A person with a disability cannot be lesbian, gay, bisexual, transgender or intersex.}

Reality: A person's sexual identity and orientation is not linked to any form of physical or mental disability. All human beings deserve to love whom they feel attracted to. Often, people living with disabilities are wrongly assumed to be in need of 'assistance' or seen as a child in 'need of help,' and it is challenging to see that person as an adult with sexual needs.

\section{Frequently Asked Questions:}

With the lack of awareness and education surrounding sexual orientation and gender identity in this country, it is important to realize that locals may have a lot of questions pertaining to these topics. It is also important to remember that you may be the first person a local has discussed these topics with. Therefore, try not to be offended by the nature of the questions because he or she is probably not trying to cause a fight but are, rather, genuinely curious.

The following is a list of questions you may encounter. Some are more controversial than others, but it is good to familiarize with a broad range of questions and answers to prepare yourself for anything that may come your way.

Furthermore, the answers provided are merely one suggestion as to how to handle the question. Remember to tailor your approach and responses to the audience at hand and always keep your safety and the safety of those you are talking with in mind.

\section{Q1. What causes homosexuality?}

This is perhaps the first and most common question about homosexuality. In order to understand the phenomenon of same-sex sexual relations, perhaps a better question is "What determines sexual orientation (e.g. heterosexuality, bisexuality, and homosexuality)?" One debate is whether a homosexual person is born that way or if it is learned behavior. It is also called the 'Nature versus Nurture' debate. In reality, what determines sexual orientation is complex. According to research, sexual orientation is determined by a mixture of genes and social influences, which is a theory that has become the more acceptable one.

There is a growing understanding that human beings have a basic sexuality that can be expressed in a variety of relationships (e.g. homosexual, bisexual, and heterosexual). The distinctions between these categories are fluid and may overlap. Although the origins are not known, some researchers believe that one's basic sexual orientation is predisposed at birth. With that said, someone's sexual orientation may not be recognized or acknowledged until much later in life.

For many years, even up to today, heterosexuality has been seen as the only socially accepted sexual orientation. Any other orientation, like homosexuality, was not understood and has been seen as foreign and, therefore, not accepted. It is quite understandable that when something is experienced as foreign, it needs to be explained 
and then the question of 'where does it come from?' or 'what causes it?' will inevitably be asked.

\section{Q2. Is being lesbian or gay against religion?}

Most religions, especially the Christian faith, started a long time ago, when having as many children as possible was important for people to survive, as quoted in the Old Testament of the Bible. The Qur'an contains the command to "procreate and abound in number." These holy books mention sex only to have children (for procreation). Interestingly, sex between men is often strongly condemned in religious teachings, while sex between women is rarely, if ever, mentioned. At the same time, the holy books mention compassion as a state that should be strived for. It is important to read any religious writing with this in mind. Not so long ago Bible texts were used to justify apartheid. Some people read and interpret the holy books literally, and are, therefore, against lesbian and gay people. Others use the texts as a source of inspiration, but in daily life they accept lesbian and gay people as human beings. There are many lesbian or gay and bisexual people who find ways to keep their faith and be who they are. It usually takes time to get to that point, but it is possible.

\section{Q3. Is there something wrong with being gay, lesbian, bisexual or transgender?}

No. There have been people in all cultures and times throughout human history who have identified themselves as gay, lesbian, bisexual or transgender. Homosexuality is not an illness or a disorder, a fact that is agreed upon by both the American Psychological Association (APA) and the American Psychiatric Association. Homosexuality was removed from the Diagnostic and Statistical Manual (DSM) of the American Psychiatric Association in 1973. Being transgender or gender variant is not a disorder either, although Gender Identity Dysphoria (GID) is included in the DSM of the American Psychiatric Association.

With that said, there can still be legal and social sanctions for gay, lesbian, bisexual, and transgender. This is important to keep in mind when talking with locals. Do not encourage a local to be "out and proud" without properly informing him or her of the possible consequences of such behavior.

\section{Q4. Can lesbian and gay people be cured?}

Again, let's have a look at why the question is even asked. It suggests that lesbian and gay people are pathologized, which is untrue. Since 1973, being lesbian, gay or bisexual is no longer described as an "illness" by the medical profession. Unfortunately, some uninformed parents still send their gay sons or lesbian daughters to professionals to be "cured." If being lesbian or gay was accepted by everyone, no one would feel the need to "cure" it.

\section{Q5. Is being LGBT normal?}

Each culture defines what is "natural" or "normal" to fit its own context. Definitions differ. Historians have determined that homosexuality has existed since the beginning of humanity. Anthropologists report that LGBT people have been part of every culture. LGBT people are represented in every socio-economic class, educational level, and race. 
Homosexual behavior is often criticized because it does not result in procreation. In reality, most heterosexual encounters don't result in births either, and relationships of all sexual orientations may have children.

\section{Q6. When do LGBT people first know?}

There is no set age at which a person becomes aware that they are LGBT. Some gay, lesbian, transgender, and bisexual people become aware of their identity during adolescence or earlier. Some transgender people become aware of being trapped in the wrong body from a very early age. People can realize their sexual orientation and gender identity at any point during their lives. Due to the strong pressures from a heternormative society to be heterosexual and fit into established gender norms, some people do not identify as gay, lesbian, transgender or bisexual until much later in life.

\section{Q7. How do people know they are LGBT?}

Some people say that they have "felt different" or knew they were attracted to people of the same sex from the time they were very young. Some transgender people express feeling that their gender identity did not match parental and social expectations. They report that they are aware of these feelings from an early age. Others do not figure out their sexual orientation or gender identity until they are adolescents or adults. Often it can take a while for people to understand their feelings, or people's feelings may change over time. What can make the coming out process more complicated is the level of homophobia experienced in families, communities and society. Understanding our own sexuality and gender can be a life-long process, and people should not worry about labeling themselves right away or ever for that matter. People do not have to be sexually active to know their sexual orientation - feelings and emotions are as much a part of one's identity.The short answer is that you will know when you know.

\section{Q8. Can LGBT people change their sexual orientation or gender identity?}

There are religious organizations that sponsor campaigns and studies that say LGBT people can change their sexual orientation or gender identity. For instance a well-known Dutch Reformed Church based in Pretoria, South Africa, has started an outreach to homosexuals, called "Homosexuality to Overcome (H2O)" (Christians for Truth). Their assertions assume that there is something wrong with being LGBT. It is however, the anti-LGBT attitudes, laws and policies that need to change, not LGBTs. Many of the studies and campaigns are based on ideological bias rather than solid science. Claims of conversion from gay to straight tend to be poorly documented, full of flawed research with a lack of follow-up.

Additionally, no studies show proven long-term changes in LGBT people, and many reported changes are based solely on behavior and not a person's actual self-identity. The American Psychological Association has stated that scientific evidence does not show that conversion therapy works and that it can actually do more harm than good. 
Q9.Can you tell if people are lesbian, gay and bisexual by their appearance? Lesbian, gay, and bisexual people are as varied in their dress, mannerisms, and lifestyles as are heterosexuals. Despite this diversity, many stereotypes persist about the effeminate man or masculine woman. Although some gay people reflect these characteristics, the overwhelming majority of lesbians and gay men do not conform to these stereotypes, and their sexual orientation is invisible to the general public. The notion of heteronormativity is can be internalized by gays and lesbians, thus the apparent 'butch' and 'femme' appearance and behavior but this cannot and should not be generalized to the entire gay and lesbian population.

\section{Q10. Why are LGBT people so blatant or 'exhibitionistic'?}

LGBT people are often accused of being blatant (wearing t-shirts, marching in gay rights marches, talking and writing about homosexuality, holding hands in public, etc.). This culture teaches that the only acceptable way to be gay is to be silent or invisible ("in the closet"). Any openness about LGBT identity is labeled "blatant" or as "flaunting it." "Blatant" heterosexuality is rarely questioned (media, entertainment, and other institutional practices such as asking for spousal benefits and hospital visiting rights, something as simple as wearing a wedding ring). In society, the assumption of heterosexuality is so strong that unless one proclaims lesbianism, gayness, or bisexuality, heterosexuality is assumed. To avoid being perceived as heterosexual, "coming out" is often a necessity.

\section{Q11. Is homosexuality healthy?}

Various studies have shown that people's sexual orientation has no bearing on their mental health and emotional stability. However, because of the high levels of homophobia and its accompanied prejudice and discrimination, many lesbians and gays are predisposed to mental health challenges.

\section{Q12. What is it like to be gay or lesbian?}

There's no right way or wrong way to be gay or lesbian. Because of society's stereotypes, some gays and lesbians think that they have to be a certain way to identify as gay and lesbian. But lesbian, gay, bisexual and transgender people come in all shapes and sizes, and are from all occupations, with all levels of education, and from all cultures.

\section{Q13. Is being lesbian or gay only about who you have sex with?}

For many years, people believed that only heterosexuals have relationships and homosexuals just have sex. However, in reality being lesbian or gay is about being attracted to a person of the same sex on various levels. It includes sexual, emotional, physical, and intellectual attraction and building a life and family together. Like heterosexual couples, lesbian and gay couples can live happy, loving, and fulfilled lives.

\section{Q14. Is being lesbian or gay un-African?}

Many years of research have shown that up to $10 \%$ of people in every community are lesbian or gay. Yet, sometimes people think that in Africa lesbian and gay people do not exist and that it is the negative influences from Europe or America which cause people to identify as gay or lesbian. This is not true. It is believed that it is colonialism that brought 
homophobia and other negative social constructs to the continent. LGBT individuals can be found in societies all over the world. All throughout Africa today, lesbian, gay, bisexual, transgender and intersex people live in every community and are from different cultures and religions. The South African Constitution is currently the only one on the African continent which does not allow discrimination against anyone based on their sexual orientation. However, religious intolerance and negative attitudes from others still force people to hide their sexuality, even more so in countries where homosexuality is criminalized. As a result, some lesbian or gay people, including those living in African communities, do not disclose or openly show who they really are in public, perpetuating the myth that being lesbian or gay is un-African.

\section{Q15. Do gay men want to be women and do lesbian women want to be men?}

The heteronormative notion suggests that a man must be or should be a "woman" to love another man. If one thinks like this then it seems logical that a man who loves another man must wish to change his sex, but this is not true. There is a big difference between being a gay man and wanting to be a woman. A man can love another man and still look like a man, dress like a man, and talk like a man. For lesbian women and gay men, traditional male and female roles often need to be abandoned to survive/live. Some lesbians enjoy gardening and taking care of their cars themselves, but others have to learn these skills as there is no husband around to perform these tasks on their behalf.

Similarly, gay men need to learn how to cook and clean, as there is no wife to depend on to get these things done. The heteronormative outlook on life, yes even by gay and lesbians, forces people to do certain tasks traditionally seen as those of the "wife" or "husband", but societal perceptions of gender roles are changing, and more and more individuals are doing what they like in life, no matter 'what other people say' or 'what's in their pants?'

\section{Q16. What is the difference between the terms "transsexual" and "transgendered"? \\ "Transsexual" refers to people who are undergoing or have undergone a "sex change"). \\ "Transgendered" is an umbrella term, generally used to include any person who feels their assigned gender does not completely or adequately reflect their internal gender. Transgendered people may or may not take steps to live as a different gender/sex.}

\section{Q17. What is the difference between "sex" and "gender"?}

Social scientists make careful distinctions between these two terms. "Sex" generally refers to biology, to the actual form of the human body (what's in the pants), including such factors as chromosomes and genital configuration, while "gender" refers to the social constructions, meanings, and characteristics associated with expectations of men and women.

\section{Q18. Is transsexual the same as homosexual?}

No. Transsexualism is about a person's core sense of their gender. This is a separate issue from the sex or gender of the people they are attracted to. Just like any other individual, a transsexual person may identify as heterosexual, gay, lesbian, or bisexual. For example, a person raised as a man who transitions to living as a woman may identify as heterosexual, 
in which case she would seek or continue relationships with men, or as lesbian, in which case she would seek or continue relationships with other women. Or she may not feel that it is necessary or meaningful to label herself with regard to sexual orientation at all.

\section{Q19. Do gay men sexually abuse children?}

Child abuse is deviant, criminal behavior and is not restricted to any specific group of people. Studies have shown that the 'average' child sex offender is a heterosexual male who is known to the child. The adult male who does sexually abuse boys is often a man who is attracted to children regardless of their sex. Child sexual abuse has nothing to do with being gay. Being gay involves two same-sex individuals having sex with consent.

\section{Q20. How do lesbians have sex?}

Sexual intercourse is often described as a process where a penis penetrates a vagina, based on the heteronormative model. However it is known that most people engage in various sexual practices for various reasons, using and sharing various body parts in order to experience sexual pleasure and climax. There are wide variations of sex, pleasure and desire, and the ways in which lesbians engage in sexual activities are no different from anyone else.

\section{Q21.What is bisexuality?}

Bisexuality is the potential of an individual to feel sexually attracted to and to engage in loving, caring relationships with people who are either male or female. A bisexual person may not be equally attracted to both sexes, and degrees of attraction may vary over time. Self-perception is the key to a bisexual identity. Many people engage in sexual activity with people of both sexes, yet do not identify as bisexual, because there is a difference between sexual identity and sexual practices. There is no behavioral "test" to determine whether or not one is bisexual.

\section{Q22. How common is bisexuality?}

It is not easy to say how common bisexuality is, since little research has been done on this subject. Most studies on sexuality have focused on heterosexuality or homosexuality. Bisexuals are in many ways a 'hidden' population. In most cultures, it is generally assumed that a person is either heterosexual (most frequently) or homosexual (based on appearance or behavioral clues). Because bisexuality does not fit into these standard categories, it tends to be denied or ignored. When it is recognized, bisexuality is often viewed as being "part heterosexual and part homosexual", rather than being a unique identity. Bisexuality threatens the accepted way of looking at the world by calling into question the validity of rigid sexual categorization, and encourages acknowledgment of the existence of a diverse range of sexuality. Since there is not a stereotypical bisexual appearance or way of acting, bisexuals are usually assumed to be either heterosexual or homosexual.

\section{Q23. What is intersex?}

Intersex people are born with external genitalia, internal reproductive organs, and/or endocrine system that are different from most other people. There is no single "intersex body"; it encompasses a wide variety of conditions that do not have anything in common 
except that they are deemed "abnormal" by the society. What makes intersex people similar is their experiences of medicalization, not biology. Generally speaking, intersex is not an identity category. While some intersex people do reclaim "intersex" as part of their identity, most regard it as a medical condition, or just a unique physical state. Most intersex people identify and live as ordinary men and women, and are gay, lesbian, bisexual, or straight.

\section{Q24. Are intersex conditions harmful?}

In general, intersex conditions do not cause the person to feel sick or in pain. However, some Intersex conditions are associated with serious health issues, which need to be treated medically. However, surgically "correcting" the appearance of intersex genitals will not change these underlying medical needs.

\section{Q25. Are intersex people "third sex"?}

Many people with intersex conditions identify solidly as a man or as a woman, like many non-intersex people. There are some who identify as a member of an alternative gender, like some non-intersex people do. People with intersex conditions should not be expected to be gender-transgressive just because of their physical condition.

\section{Q26. Are intersex people part of the transgender community?}

While some people with intersex conditions also identify as transgender, intersex people as a group have a unique set of needs and priorities beyond those shared with trans people. Too often, these unique needs are made invisible or secondary when "intersex" becomes a subcategory of "transgender." For example, people who talk about intersex in the context of transgender often stress the risk of assigning a "wrong" gender as an argument against intersex genital surgeries. While this is a valid concern, it overlooks the fact that intersex medical treatment is painful and traumatic whether or not one's gender identity happens to match her or his assigned gender. It is for this reason that some people prefer to have "intersex" spelled out explicitly rather than have it "included" in "transgender" umbrella.

\section{Q27. Intersex or hermaphrodite?}

In biology, "hermaphrodite" means an organism that has both "male" and "female" sets of reproductive organs (like snails and earthworms). In humans, there are no actual "hermaphrodites" in this sense, although doctors have called people with intersex conditions "hermaphrodites" because intersex bodies do not neatly conform to what doctors define as the "normal" male or female bodies. However, the word "hermaphrodite" is misleading, mythologizing, and stigmatizing. Although some intersex activists do reclaim and use this term to describe themselves, it is an inappropriate term to refer to intersex people in general. In short, snails are hermaphrodites; humans are not.

\section{Q28. What do I do if someone comes out to me? How can I support my LGBT loved one?}

Learning that a loved one is gay, lesbian, bisexual, transgender or intersex is a journey of self-discovery for you. It can send you on an emotional roller coaster ride. You may feel like you have lost a loved one. Remember that this person is the same one that you loved 
before they came out to you - they have just shared another part of themselves with you. Feelings of grief, guilt and denial are common. Whatever your reaction, try to reassure your loved one that they still have your love. Make contact with a local support group to help with your process of acceptance.

Q29. Is it the parent's fault if his or her child is gay?

It is never anyone's "fault" if they or their loved one grows up to be gay, lesbian, bisexual or transgender. If you are asking yourself why you or your loved one is LGBT, consider asking yourself another question: Why ask why? Does your response to a LGBT person depend on knowing why they are LGBT? Regardless of cause, LGBT people deserve equal rights and to be treated fairly.

\section{Q30. How can I reconcile my own or my loved one's sexual orientation with my faith?}

This is a difficult question for many people. Learning that a loved one is gay, lesbian, bisexual or transgender can be a challenge if you feel it is at odds with your faith tradition. However, being LGBT does not impact a person's ability to be moral and spiritual any more than being heterosexual does. Many LGBT people are religious and active in their own faith communities, where they are accepted. It is up to you to explore, question, and make choices in order to reconcile religion with homosexuality and gender variance.

\section{Q31. Can LGBT people have families?}

Lesbian, gay, bisexual, transgender, and intersex people can have families. Same-sex couples do form committed and loving relationships. More and more LGBTI couples are also raising children together, although different African countries' national laws on adoption and foster parenting vary. Also, of course many LGBT people have the support of the loving families they were born into, or the families that they have created with their other friends and loved ones.

\section{Q32. Won't homosexual and bisexual parents make their kids gay?}

Research has shown that children of lesbian or gay parents are no more likely to become gay or lesbian than children of heterosexual parents. Gays, lesbians and bisexuals are just as likely to be good parents as heterosexuals. Of course, children growing up in nontraditional families may face a certain amount of social prejudice. Fewer and fewer children in the world are growing up in two-parent, heterosexual, nuclear families and lesbian and gay families are one of the many forms of diverse families that exist.

\section{Q33. Why should people be informed about LGBTI issues?}

Becoming informed about LGBTI issues helps reduce heterosexism, homophobia, and transphobia. This makes it easier for one to live a more open and productive life in their work and home communities. The culture as a whole is therefore enriched. For LGBT youth, who are more likely to experience depression and rejection by friends and/or family, acceptance and understanding could be a matter of life or death. The risk of suicide in LGBT adolescents is two to three times greater than that of their straight counterparts. 


\section{Q34. Why do LGBT people need gay rights laws? Isn't that asking for special privileges?}

Currently, except for South Africa, in African countries there are no federal protections for LGBT people who are subject to discrimination. Gay rights laws do not give LGBT people special privileges. They are civil/human rights laws consistent with the beliefs that all people are entitled to such necessities as employment, housing, health care, and business services without fear of discrimination. Unfortunately, in African countries, LGBT people can be (and are) fired from their jobs, denied housing, health care, or insurance solely because of their sexual orientation and gender identity. These beliefs, like those used to discriminate against people on the basis of race, ethnicity, religion, age, physical ability, or gender, are based on prejudice and ignorance, rather than accurate information.

\section{Q35. Why should people support LGBT issues?}

As a collective, supporting LGBT initiatives and LGBT people encourages positive changes towards the acknowledgement, acceptance, and protection of the civil and human rights, as well as sexual and reproductive health and rights, of all people, and their advancement.

\section{Glossary: Understanding the LGBT Lingo}

The following is a list of terms you may have run across in this guide, as well as additional terminology you may find useful when discussing LGBT issues in your community:

\section{Androgyny}

Not having clear masculine or feminine physical characteristics or appearance.

\section{Asexual \\ Lack of sexual attraction (Not being sexually attracted to others). Lack of interest in or lack of desire for sex.}

\section{Bisexual}

A sexual orientation and identity. Bisexual people have an attraction to people of the same and opposite sex on various levels (emotionally, physically, intellectually, spiritually, and sexually). Not necessarily at the same time and not necessarily an equal amount of attraction.

\section{Cisgender}

Cisgender people are those whose gender identity matches their sex at birth (e.g. a cisman would be a person who is born male and presents himself as masculine and a ciswoman is a person who is born female and presents herself as feminine). The Latin prefix cis stands for 'on the same side,' while the prefix trans stands for 'on the opposite side.' Using this term has a more positive connotation than 'normal' or 'non-transgender.' 


\section{Coming Out}

A term describing the complex process where an individual realizes they are not heterosexual and the process of resolving related conflicts due to heteronormativity. Coming out is a process of understanding and revealing one's sexual orientation and identity.

\section{Conversion Therapy}

Also known as reparative therapy. To change the sexual orientation of an individual from homosexual or bisexual to heterosexual through a specific form of therapy. It is considered by many to be a homophobic act and has been proven to be ineffective.

\section{Discrimination}

The unjust or prejudicial treatment of different categories of people on the grounds of race, age, sex, gender, sexual orientation, or gender identity/gender expression.

\section{FTM/Trans Man}

A trans man, or female-to-male, is an individual who is born with a female body but identifies as male and presents oneself as such. Always use male pronouns in reference to these individuals, unless they request otherwise (.e.g. gender neutral pronouns).

\section{Gay}

This term is usually used in reference to males who are attracted on various levels (emotionally, physically, intellectually, spiritually, and sexually) to other males. However, it can also be used as an umbrella term for the LGBT community (e.g. gay community).

\section{Gender}

Socially constructed characteristics assigned that may vary according to the times and the society or group one belongs to, and which are learned or assigned to women and men. It is a broader concept than the mere biological differences between men and women, and includes masculine and feminine traits. Gender norms/roles are often used to ensure certain power structures are kept in place in societies, and gender norms/roles also greatly influence a society's overall attitudes and beliefs surrounding sexuality.

\section{Gender-based Violence}

GBV encompasses various forms of violence directed at women, because they are women, and men, because they are men (depending on the expectations of each in a given community). For LGBT people the violence is directed towards them because of their challenging notions of sexuality and gender identity and presentation.

\section{Gender Dysphoria}

The medical diagnosis for someone who experiences a disconnection between their assigned and preferred gender. Some transgender people disagree with the categorization of gender dysphoria as a medical condition because it relies on an understanding of what "normal" gender is and implies that a transgender identity is abnormal. 


\section{Gender Identity}

Refers to a person's persistent and consistent sense of being male, female, or genderqueer. This is different than gender expression but the two are usually related. However, one can be born female, present oneself as female, but internally identify as male or vice versa. It's just that social stigma may prevent individuals from expressing their true gender identities.

\section{Genderqueer}

An umbrella term for gender identities that are outside of the gender binary (male and female). Genderqueer people may think of themselves as both man and woman (bigender), neither man nor woman (agender), moving between genders (genderfluid), and/or third gendered.

\section{Gender Role}

Socially constructed or learned behaviors that condition activities, tasks, and responsibilities. Usually viewed within a given society as "masculine" or "feminine."

\section{Hegemonic Masculinity}

This is the 'normative' ideal of masculinity to which men are supposed to aim. It is not necessarily the most prevalent, but rather the most socially endorsed. It is supported by the heteronormative model.

\section{Heteronormative}

A social construct that views all human beings as either male or female with the associated behavior and gender roles assigned, both in sex and gender. Perpetuates the belief that sexual and romantic thoughts and relations are normal only between people of opposite sexes and all other behavior is viewed as "abnormal" or "unhealthy."

\section{Heteronormative Model}

The typical heteronormative family consisting of a father (male bodied person), mother (female bodied person, and their offspring.

\section{Heterosexual/Straight}

Attraction between two people of the opposite sex on various levels (emotionally, physically, intellectually, spiritually, and sexually).

\section{Homophobia}

Irrational fear of homosexual feelings, thoughts, behaviors, or people and an undervaluing of homosexual identities resulting in prejudice, discrimination, and bias against homosexual individuals.

\section{Homo-prejudice}

Prejudice against people of diverse sexual identities. 


\section{Homosexual}

Attraction between two people of the same sex on various levels (emotionally, physically, intellectually, spiritually, and sexually).

\section{Human Rights}

The basic rights and freedoms that all people are entitled to regardless of nationality, sex, age, nationality or ethnic origin, race, religion, language, or other status (e.g. a person's HIV status). Sexual orientation and gender identity are also basic human rights.

\section{Internalized Homophobia}

When a homosexual individual internalizes (make it their own) the shame and hatred projected onto gays and lesbians by a homophobic society.

\section{Intersex}

Born with ambiguous genitalia, or sex organs that are not clearly distinguished as female or male.

\section{MTF/Trans Woman}

A transwoman, or male-to-female, is an individual who is born with a male body but identifies as female and presents oneself as such. Always use female pronouns in reference to these individuals, unless they request otherwise (.e.g. gender neutral pronouns).

\section{MSM}

Men who have sex with men. A sexual practice irrespective of sexual orientation or gender identity. An MSM can be hetero-, bi-,homosexual, or trans. This term is more technical and is not necessarily an identity.

\section{Patriarchy}

A system of society or government in which the father or eldest male is head of the family and descent is traced through the male line. The wives / females are viewed as dependent. Roles assigned to men are considered superior and valued above females' roles. Patriarchy forms the basis of discrimination against minorities like LGBT people, as their relationships challenge the patriarchal power structure.

\section{Queer}

This word comes from the Germanic root quer, which means 'to cut across' or 'at an angle to,' so it has the connotation of being off the straight (or normal) path. In the beginning of the $20^{\text {th }}$ Century, "queer" began to be used as a derogatory term against the lesbian, gay, bisexual, and transgender (LGBT) community. More recently though, members of the LGBT community have been working to reclaim the word and eradicate the negative connotations society has attached to it. Many people who choose to identify as queer do so because they feel it allows for a broader identity as opposed to the more perceived rigid labels of bisexual, gay, lesbian, and transgender. These individuals view the term "queer" to be more open, fluid, and all-encompassing. 


\section{Sex}

A biological construct of a human being. "What's in the pants?" Male genitals - penis, testes, testosterone and genetic make-up and females - breasts, vagina, estrogen, progesterone and genetic make-up.

\section{Sexuality}

How people experience and express themselves as sexual beings, within the concepts of biological sex, gender identity and presentation, attractions, and practices. Culture and religion have a huge impact on how individuals see themselves as sexual beings, especially within relations of power.

\section{Sexual Fluidity}

Sexuality varying across time and situation. Fluidity offers a more inclusive definition than the more limiting conventional labels we have become accustomed to using to define sexual identity. Sexual fluidity, quite simply, means situation-dependent flexibility in people's sexual responsiveness. This flexibility makes it possible for people to experience desires for either men or women under certain circumstances, regardless of their overall sexual orientation. In other words, though individuals appear to be born with distinct sexual orientations, these orientations do not provide the last word on their sexual attractions and experiences throughout their lives.

\section{Sexual Identity}

The overall sexual self-identity which is influenced by how the person identifies as male, female, masculine, feminine, or some combination, and the person's sexual orientation.

\section{Sexual Minority}

A group whose sexual identity, orientation, or practices differ from the majority of the surrounding society.

\section{Sexual Orientation}

Attraction between any two people on various levels (emotionally, physically, intellectually, spiritually, and sexually). Attraction to the other person's sex and or gender presentation is the point of departure.

\section{Sexual Practices}

All behavior that creates sexual pleasure, practiced by one or more than one person, individually, or together.

\section{Stigma}

This is when a certain individual, with certain characteristics (e.g. HIV positive individual or trans woman), is rejected by their community or society because of that characteristic which might be considered as "abnormal." These individuals' lives might be at risk and may possibly be threatened and abused. 


\section{Transgender}

An individual who is born a man but identifies as a woman ( $\mathrm{M}$ to $\mathrm{F}$ ), or an individual who is born a woman but identifies as a man F to M). It can also be used as an umbrella term to describe a wide range of identities and experiences, including transsexuals, FTMs, MTFs, transvestites, cross-dressers, drag queens and kings, two-spirits, genderqueers, and many more.

\section{Transphobia}

The irrational fear of, and/or hostility towards people who are transgender or who otherwise transgress traditional gender norms. Because cultures are often very transphobic, transgender people can often have internalized transphobia and experience feelings of insignificance and self-prejudice.

\section{Transsexual}

A transgender person in the process of seeking or undergoing some form of medical treatment to bring their body and gender identity into closer alignment. Not all transgender people undergo reassignment surgery.

\section{Transitioning}

The process of changing one's gender presentation to align with one's internal sense of one's gender. For transgender people this may sometimes include sexual reassignment surgery but not always. It could also include hormonal therapy. However, sometimes is simply entails changing one's gender expression (e.g. clothing).

\section{Transvestite}

An individual who dresses in the clothing of the opposite sex for a variety of reasons and who has no desire to change or modify one's body.

\section{WSW}

Women who have sex with women. A sexual practice irrespective of sexual orientation or gender identity. A WSW can be hetero-, bi- or homosexual. This term is more technical and is not necessarily an identity. 